Final Report

FHWA/IN/JTRP-2003/17

\title{
Development of Indiana's SPS9-A Site
}

\author{
Ayesha Shah \\ Graduate Research Assistant \\ and \\ Jan Olek \\ Principal Investigator \\ Associate Professor of Civil Engineering \\ School of Civil Engineering \\ Purdue University \\ Joint Transportation Research Program \\ Project Number: C-36-56F \\ File Number: 2-13-6 \\ SPR-2148 \\ Prepared in Cooperation with the \\ Indiana Department of Transportation and the \\ U. S. Department of Transportation \\ Federal Highway Administration
}

The contents of this report reflect the views of the authors, who are responsible for the facts and the accuracy of the data presented herein. The contents do not necessarily reflect the official views and policies pf the Indiana Department of Transportation or Federal Highway Administration at the time of publication. The report does not constitute a standard, specification or regulation.

Purdue University

West Lafayette, IN 47907

April 2004 


\begin{tabular}{|c|c|c|}
\hline $\begin{array}{l}\text { 1. Report No. } \\
\text { FHWA/IN/JTRP-2003/17 }\end{array}$ & 2. Government Accession No. & 3. Recipient's Catalog No. \\
\hline \multirow{2}{*}{\multicolumn{2}{|c|}{$\begin{array}{l}\text { 4. Title and Subtitle } \\
\text { Development of Indiana's SPS9-A Site }\end{array}$}} & $\begin{array}{l}\text { 5. Report Date } \\
\text { April } 2004\end{array}$ \\
\hline & & 6. Performing Organization Code \\
\hline \multicolumn{2}{|l|}{$\begin{array}{l}\text { 7. Author(s) } \\
\text { Ayesha Shah and Jan Olek }\end{array}$} & $\begin{array}{l}\text { 8. Performing Organization Report No. } \\
\text { FHWA/IN/JTRP-2003/17 }\end{array}$ \\
\hline \multirow{2}{*}{\multicolumn{2}{|c|}{$\begin{array}{l}\text { 9. Performing Organization Name and Address } \\
\text { Joint Transportation Research Program } \\
1284 \text { Civil Engineering Building } \\
\text { Purdue University } \\
\text { West Lafayette, IN 47907-1284 }\end{array}$}} & 10. Work Unit No. \\
\hline & & $\begin{array}{l}\text { 11. Contract or Grant No. } \\
\text { SPR-2148 }\end{array}$ \\
\hline \multirow{2}{*}{\multicolumn{2}{|c|}{$\begin{array}{l}\text { 12. Sponsoring Agency Name and Address } \\
\text { Indiana Department of Transportation } \\
\text { State Office Building } \\
100 \text { North Senate Avenue } \\
\text { Indianapolis, IN } 46204\end{array}$}} & $\begin{array}{l}\text { 13. Type of Report and Period Covered } \\
\text { Final Report }\end{array}$ \\
\hline & & 14. Sponsoring Agency Code \\
\hline
\end{tabular}

\section{Supplementary Notes}

Prepared in cooperation with the Indiana Department of Transportation and Federal Highway Administration.

\section{Abstract}

The Superpave system for hot mix asphalt (HMA) design was introduced in 1995 and adopted throughout most of the USA by 2000. This system uses performance-oriented approach to materials selection and mix design, and takes into account the local environmental and traffic conditions. It recognizes that the behavior of HMA depends on the temperature, loading and aging conditions and provides tools (in the form of materials selection and performance-related tests) that should help to protect pavements against low-temperature cracking, rutting and fatigue cracking.

This report summarizes the field and laboratory studies conducted to investigate the influence of asphalt binder grade on the field performance of HMA pavements. In particular, the effect of binder grade on low temperature cracking and on permanent deformation (rutting) of pavement was investigated. In addition, the validity of some of the existing low-temperature models for assessing the susceptibility of a given binder to low temperature cracking is also analyzed.

The study involved construction and field evaluation of six test sections on the interstate I-70, east of Indianapolis, Indiana. Four of the six sections contained various SUPERPAVE binder grades, one of the sections was constructed using traditional Marshal mix design, and one of the sections contained $15 \%$ of recycled asphalt concrete (RAP). The monitoring of performance of the test sections involved periodical distress surveys and collection of field cores for laboratory testing of volumetric, binder and aggregate properties. In addition, the original binders and plant mix samples were also evaluated.

The results of this test program indicate that, in general, the binder grade does influence the field performance of HMA and that susceptibility to failure of a given material can (in many cases) be predicted from the laboratory test results. Particularly good correlation between the laboratory-based data and field performance was observed for low-temperature binder tests, indicating that these tests can reliably predict the critical cracking temperature of the pavement. On the other hand, the test results also confirmed that low-temperature prediction algorithms proposed in the original Superpave specifications were too conservative, for the environmental conditions present at the test site.

\section{Key Words}

low temperature cracking, rutting, recovered binders, critical cracking temperature, distress survey, weather station, Superpave performance tests, binder and mixture properties

\section{Distribution Statement}

No restrictions. This document is available to the public through the National Technical Information Service, Springfield, VA 22161

19. Security Classif. (of this report)

Unclassified

\author{
20. Security Classif. (of this page)
}

Unclassified

\begin{tabular}{|c|c|}
\hline 21. No. of Pages & 22. Price \\
198 & \\
\hline
\end{tabular}


Technology Transfer and Project Implementation Information
INDOT Research
TRB Subject Code: 31-6 Modified Binders
Publication No.: FHWA/IN/JTRP-2003/17, SPR-2148

\section{Development of Indiana's SPS9-A Site}

\section{Introduction}

The SUPERPAVE system introduced the concept of performance-based binder selection process, in which the binder is required to satisfy certain performance-based criteria within a temperature range of interest and traffic conditions that are specific to the pavement location. The temperature range of interest depends on the yearly maximum and minimum air and pavement temperatures occurring at the location.

To validate the SUPERPAVE Binder Selection Program and to provide data for long term field validation of the SUPERPAVE methodology, SPS9-A sites were constructed in different parts of the country. Indiana's SPS9-A site was one such study, in which six different test sections were constructed at a $2.5-\mathrm{km}$ long study site. Four of test sections (S-64-28, S-5828, S-70-28 and S-70-28) were built with the same job-mix formula (JMF), but with different binder grades. PG64-28 was the recommended binder grade based on weather and expected traffic conditions at the site. To evaluate the influence of binder grade on the rutting performance, PG58-28 and PG70-28 were used in two of the test sections. PG64-16 was used in one section to study the influence of binder grade on low-temperature cracking. In addition to these four sections, one section (M-AC-20) was built with AC-20 using Marshall mix design to compare the performance of the older mix design methodology with the newly introduced SUPERPAVE. Finally, 15\% recycled asphalt pavement (RAP) was added to section (R-15\%) with PG64-28 binder to evaluate the performance of RAP in comparison with the non-RAP control mixture and the other SUPERPAVE mixtures.

SUPERPAVE performance tests were conducted on plant-mix samples compacted to $7 \%$ and $3 \%$ air voids. These tests included creep compliance, indirect tensile strength, frequency sweep at constant height, simple shear at constant height and repeated shear at constant height. The parameters obtained from these tests; creep compliance, indirect tensile strength, critical pavement temperature, complex shear modulus, maximum shear deformation and permanent strain; were used to assess the relative performance of the mixtures.

Core samples were obtained from the field at six-month intervals and the layer thickness, percent air voids and binder content of these mixtures were determined. The binder from the surface layer was extracted and recovered in order to study the change in binder properties with age of the pavement. The properties of the recovered binders studied were penetration, viscosity, complex modulus, creep stiffness, fracture stress and failure strain.

In addition, distress surveys were conducted to evaluate the pavement condition at the end of 1.5 and 3.5 years. The distress surveys included transverse profiling, photographic surveys and manual surveys.

\section{Findings}

The results of field distress surveys at the end of 3.5 years indicated moderate transverse cracking in the section with the modified binder (S-70-28) and S-64-16. Minimal amount of transverse cracking was observed in M-AC-20, S-64-28 and R-15\%. S-58-28 exhibited no thermal cracking at the end of 3.5 years. In terms of longitudinal cracking, all sections 
except the Marshall section (M-AC-20) exhibited moderate amount of cracking in the wheel path and outside the wheel path. Marshall section did not exhibit any longitudinal cracking, while S-64-16 exhibited the highest amount of longitudinal cracking. All sections showed minimal amount of rutting. S-64-28 showed the highest rut depth in comparison with the other sections. M-AC-20 showed the least amount of rutting. R-15\% and S-70-28 showed "heaving" in the left wheel path of the driving lane.

Volumetric data from the field core samples obtained during the study period showed that the control section (S-64-28) had low initial air voids, which caused the air voids to drop below $3 \%$ at the end of one year. This could explain the higher degree of rutting observed in this section. Uniform mat thickness was indicated by surface and intermediate layer thickness data obtained from the cores. Neither excessive binder content, nor significant differences in binder content were observed between the SUPERPAVE test sections.

Most of the binder tests indicated binder stiffening with age, as expected. Penetration tests indicated that severe cracking may be expected in M-AC-20, R-15\%, S-70-28 and S64-16. While S-70-28 and S-64-16 did exhibit moderate cracking, M-AC-20, R-15\% and S-6428 showed only nominal amount of cracking.
The maximum passing high temperature determined from the Dynamic Shear Rheometer showed an increase with time in most of the binders, except for PG58-28. This increasing trend indicates an improvement in the rut resistance of the mixtures, which was validated by the minimal amount of rutting observed in the test sections. The relatively higher degree of rutting observed in S-64-28 may be attributed to the low in-situ air voids observed in the initial set of field cores and early-on in the life of the pavement. High degree of correlation was seen between critical temperature estimates obtained from Bending Beam Rheometer and AASHTO PP42 method.

Creep compliance and indirect strength tests predicted thermal cracking in M-AC-20 and S$64-16$, since the critical mixture temperature was warmer than the minimum pavement temperature observed at the site. However, some cracking was also observed in S-64-28, S-70-28 and R$15 \%$ to varying degrees, which was not predicted by critical mixture temperature estimates, at the two air voids levels tested. The higher rut depths observed in S-64-28 and S-58-28 was indicated by the higher amounts of plastic strain observed in the repeated shear test.

\section{Implementation}

These results show that increasing the binder high-temperature grade from PG58-xx to PG64-xx based on expected traffic volume was a necessary step to improve the rut resistance of mixture. Sections with PG64-xx and PG70-xx showed better rut resistance than section with PG58-xx, with the exception of S-64-28, the poor performance of which was probably a result of the low initial air voids. This emphasizes the point that even when the aggregates and binders used in construction are adequate for environment and expected traffic, improper placement could lead to premature pavement distress.

Section with PGxx-16 performed poorly in terms of thermal cracking as expected. Sections with PGxx-28 and PGxx-22 showed lower amount of thermal cracking in comparison, except for PG70-28. The section with the lowest binder viscosity, PG58-28, showed no lowtemperature cracking, while the section with the highest binder viscosity, PG70-28, showed the highest amount of low-temperature cracking. Although the low-temperature grade was the same in both cases, binder viscosity appears to play a significant role in determining the resistance of pavements to thermal cracking in service.

Permanent strain values obtained from repeated shear testing appears to be a better indicator of rutting performance in the field than complex shear modulus $\left(\left|\mathrm{G}^{*}\right|\right)$ from frequency sweep testing. All the mixtures satisfied the minimum $\left|\mathrm{G}^{*}\right|$ limit of $250 \mathrm{MPa}$ at $10 \mathrm{~Hz}$ and $40^{\circ} \mathrm{C}$, and showed nominal amounts of rutting in the field.

Based on the limited testing on unmodified and modified binders in this study, BBR tests on recovered binders appear to be adequate in predicting the low-temperature performance of the pavements. 


\section{Contacts}

For more information:

Prof. Jan Olek

Principal Investigator

School of Civil Engineering

Purdue University

West Lafayette, IN 47907

Phone: (765) 494-5015

Fax: (765) 496-1364

E-mail: olek@ecn.purdue.edu

Indiana Department of Transportation

Division of Research

1205 Montgomery Street

P.O. Box 2279

West Lafayette, IN 47906

Phone: (765) 463-1521

Fax: (765) 497-1665

\section{Purdue University}

Joint Transportation Research Project

School of Civil Engineering

550 Stadium Mall Drive

West Lafayette, IN 47907-1284

Phone: (765) 494-9310

Fax: (765) 496-7996

itrp@ecn.purdue.edu

http://www.purdue.edu/jtrp 


\section{TABLE OF CONTENTS}

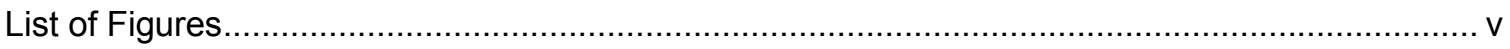

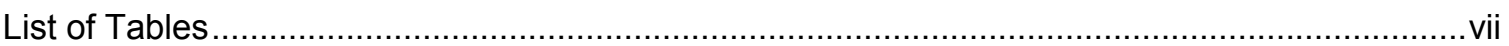

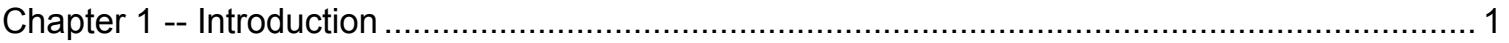

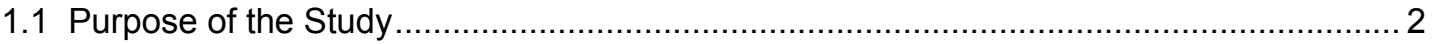

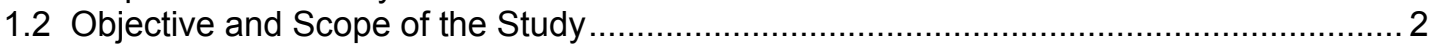

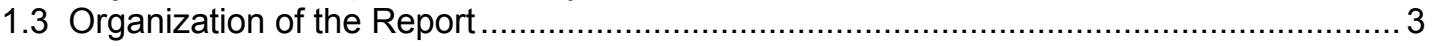

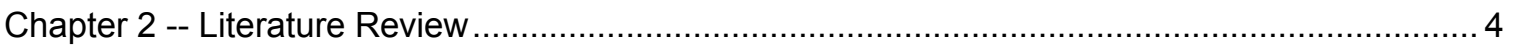

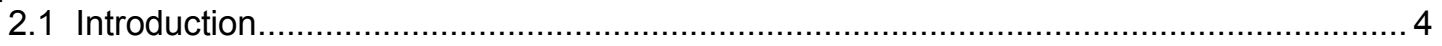

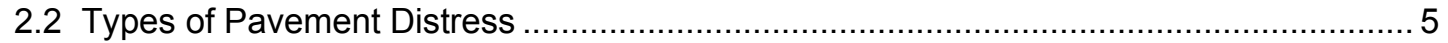

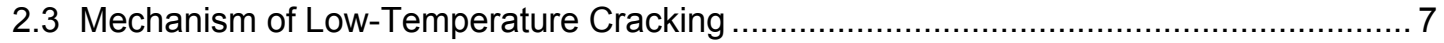

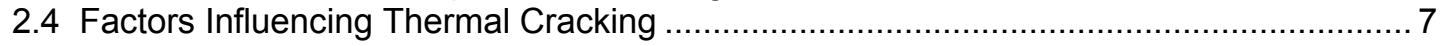

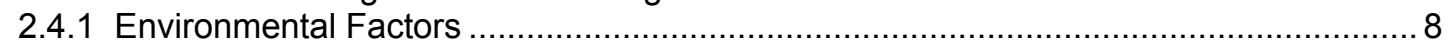

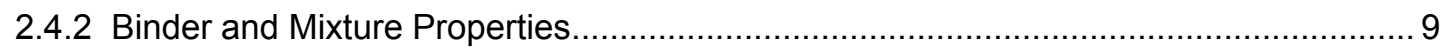

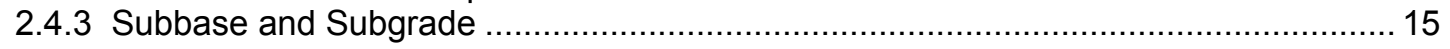

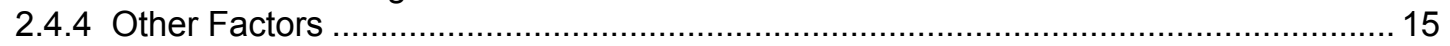

2.5 Test Methods Used to Quantify Thermal Cracking Potential ...................................... 16

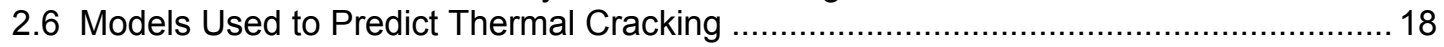

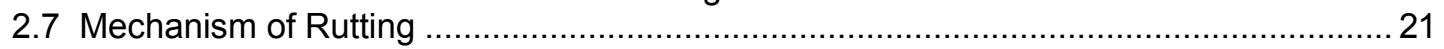

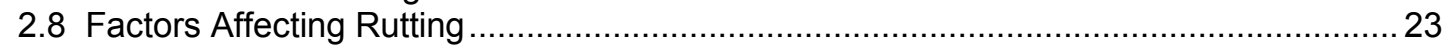

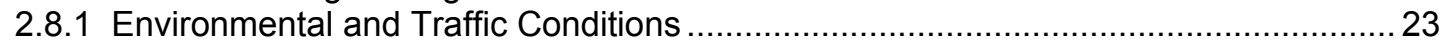

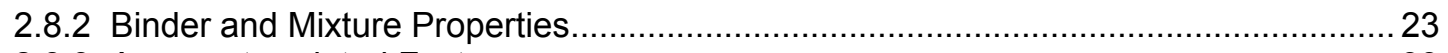

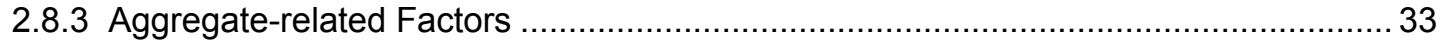

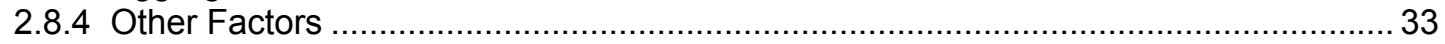

2.9 Test Methods Used to Quantify Rutting Potential .................................................... 34

2.10 Models Used to Predict Permanent Deformation...................................................... 36

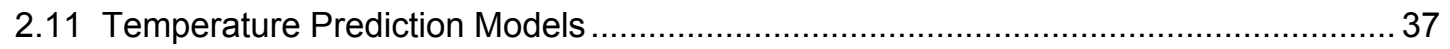

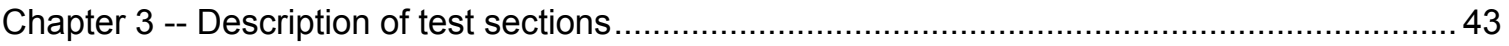

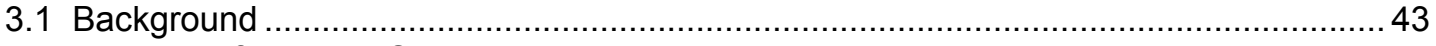

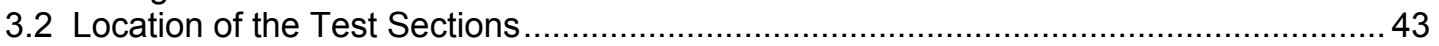

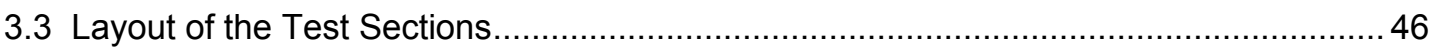

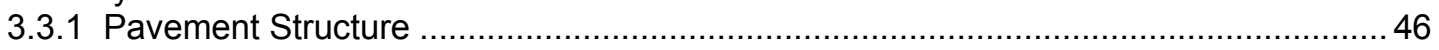

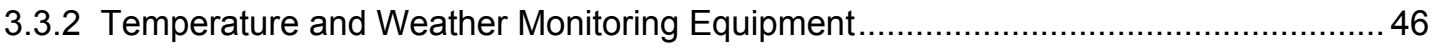

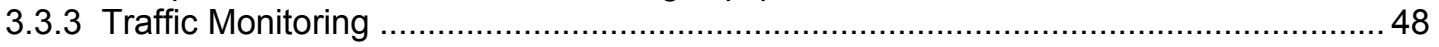

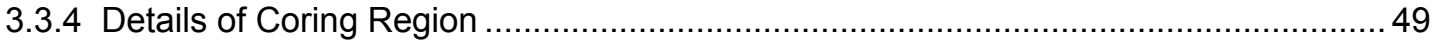

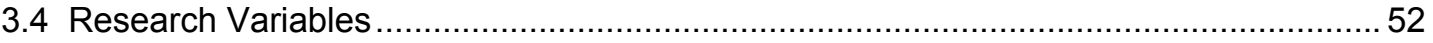

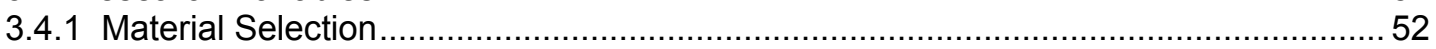

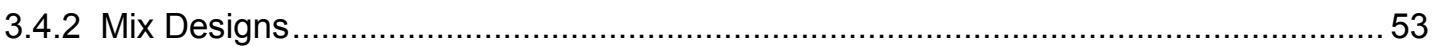

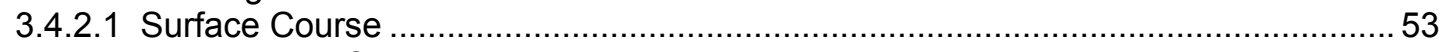

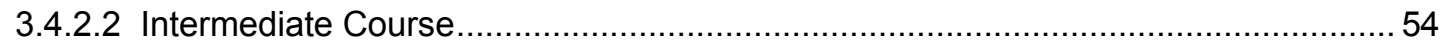

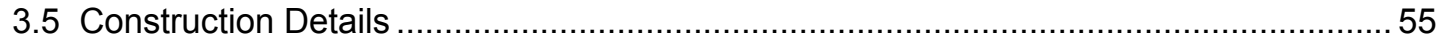

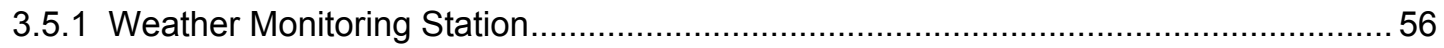

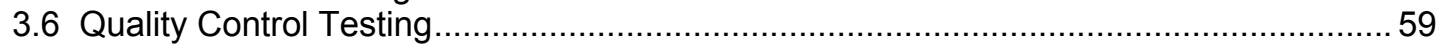

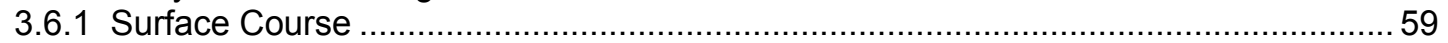

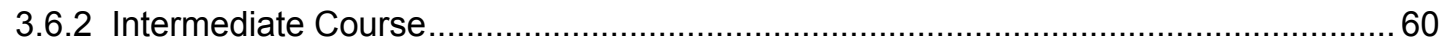




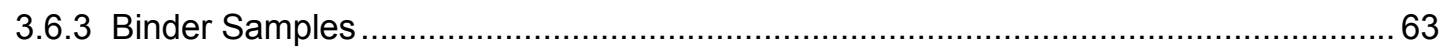

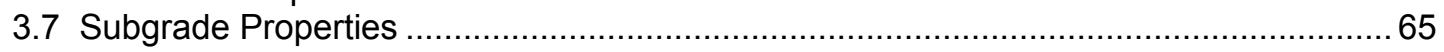

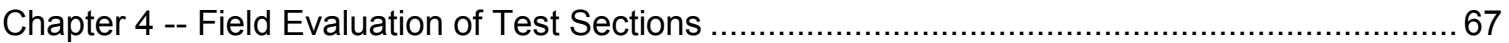

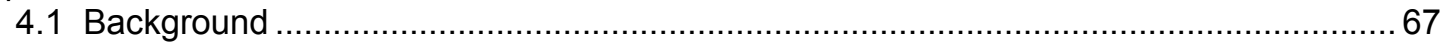

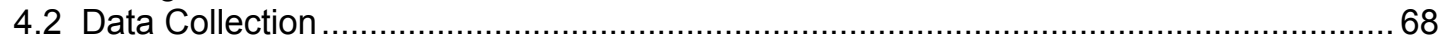

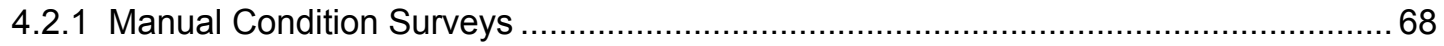

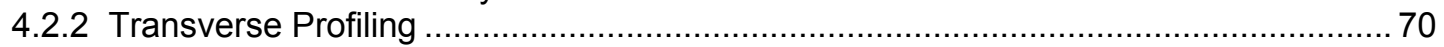

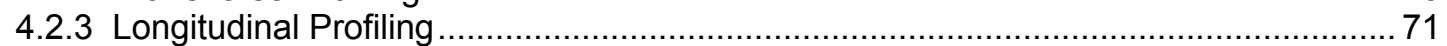

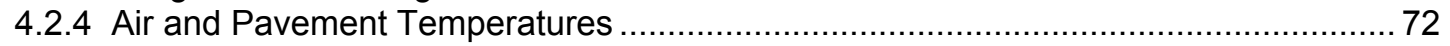

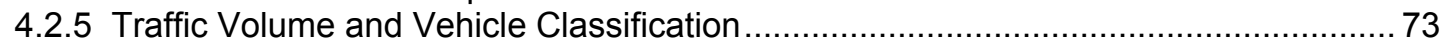

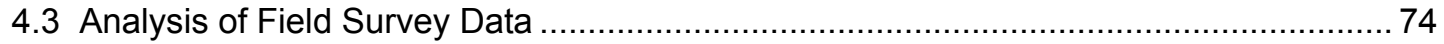

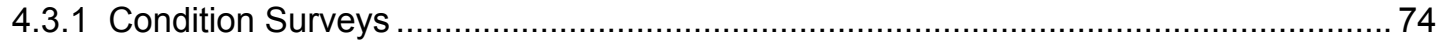

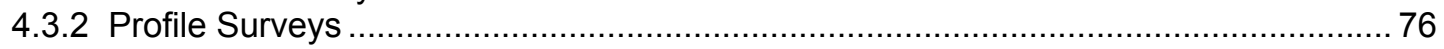

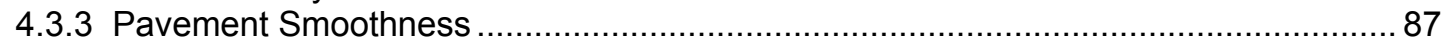

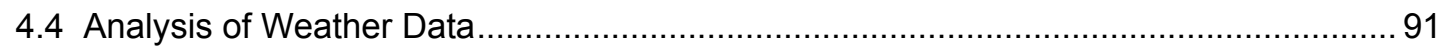

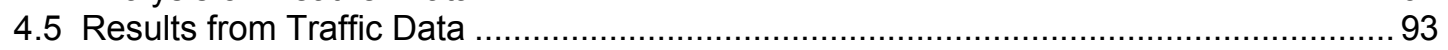

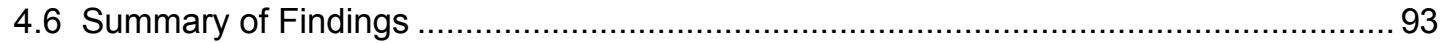

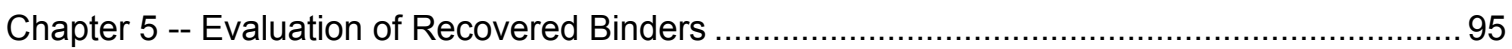

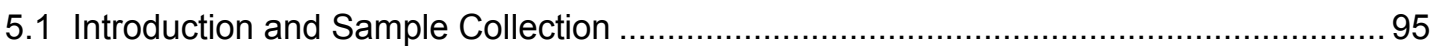

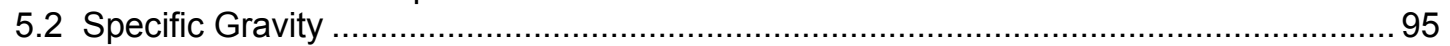

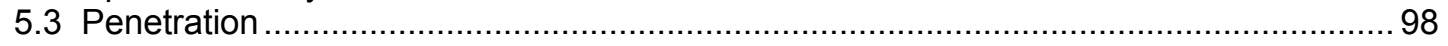

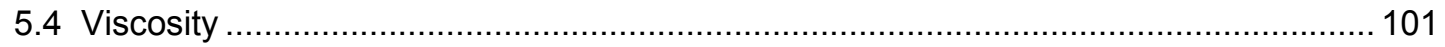

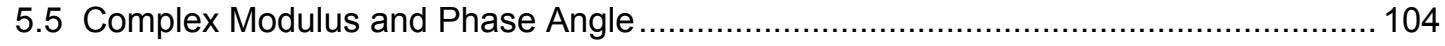

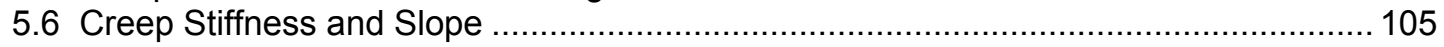

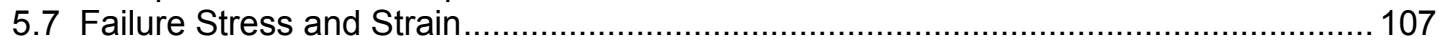

5.8 Summary of Binder Tests Results.................................................................. 111

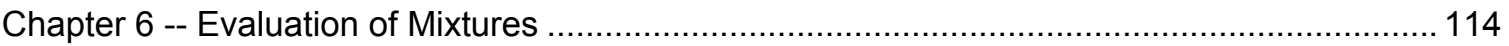

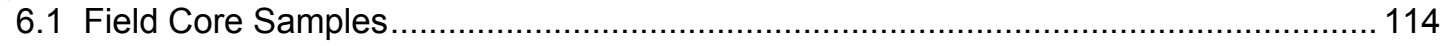

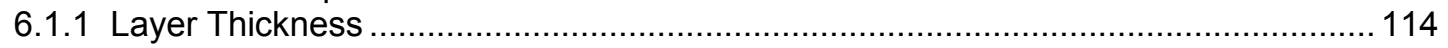

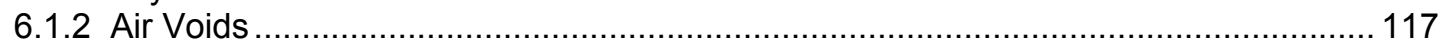

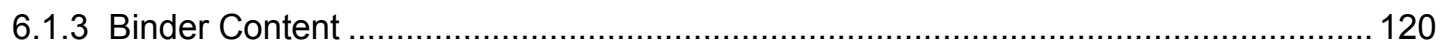

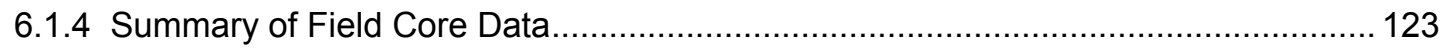

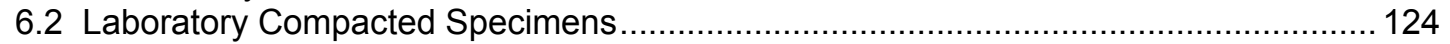

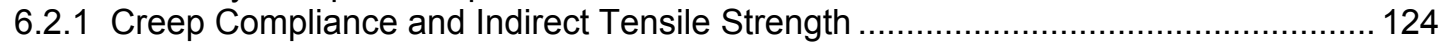

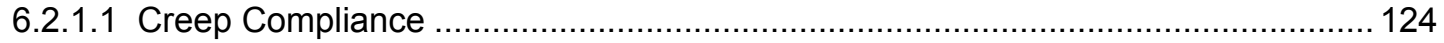

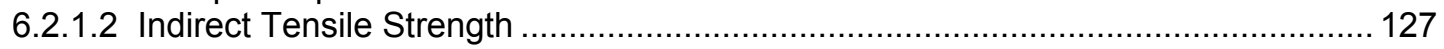

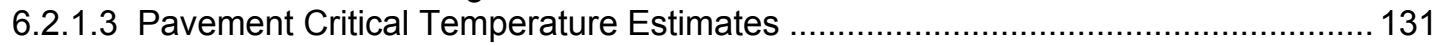

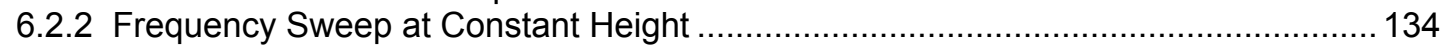

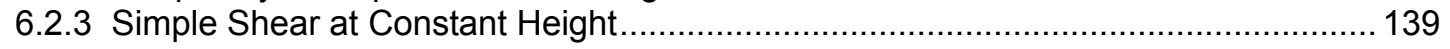

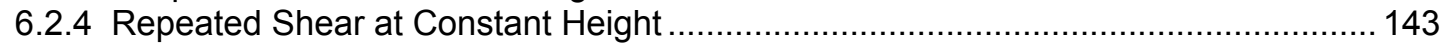

6.2.5 Summary of Performance Test Results ........................................................... 147

Chapter 7 -- Effect of Binder Grade on Observed Pavement Distress .................................... 150

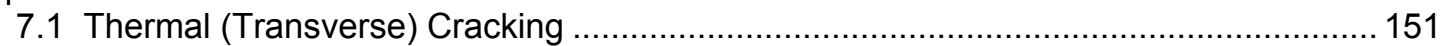

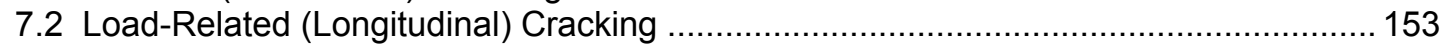

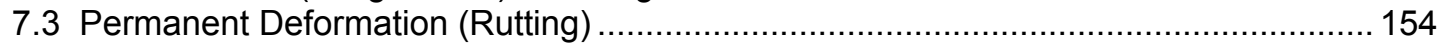

7.4 Laboratory Distress Indicators versus Observed Field Performance .......................... 157

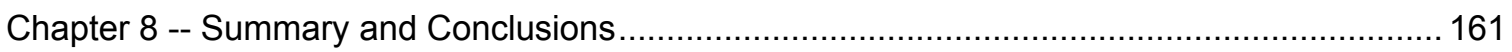

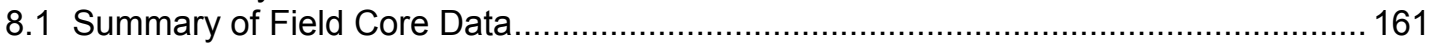

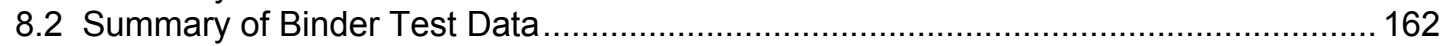




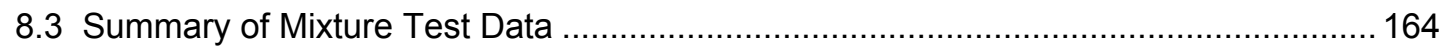

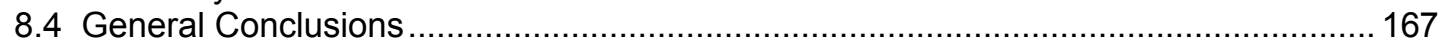

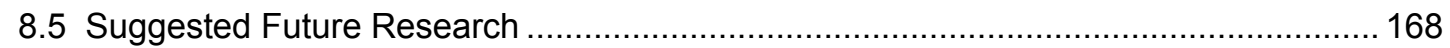

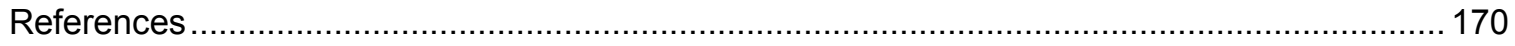

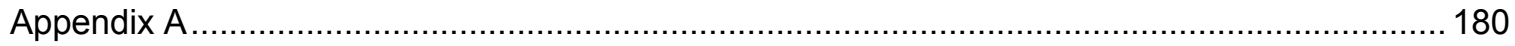

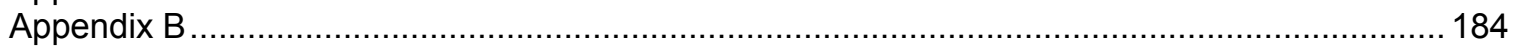




\section{LIST OF FIGURES}

Figure 2.1 -- Thermal cracking observed in an HMA pavement (4) ........................................... 6

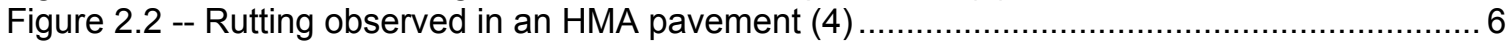

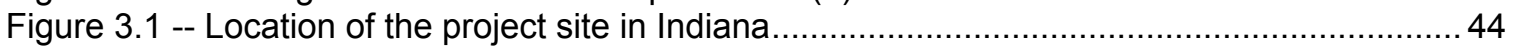

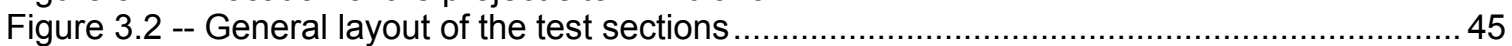

Figure 3.3 -- Cross section of the pavement at the test site .................................................. 46

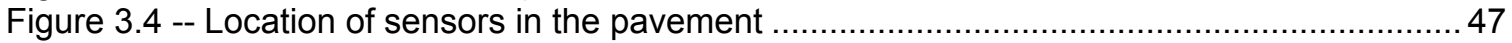

Figure 3.5 -- Weather station near the test site on I-70E

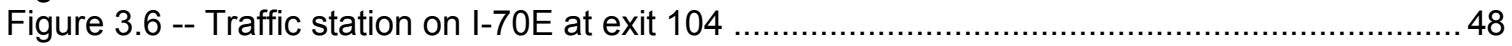

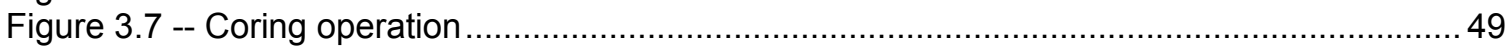

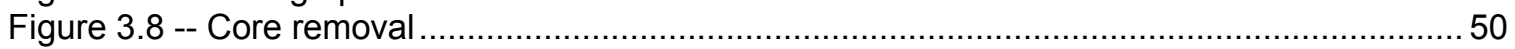

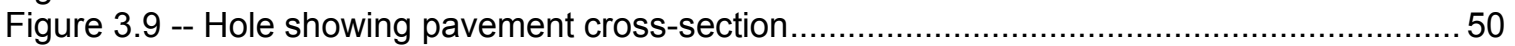

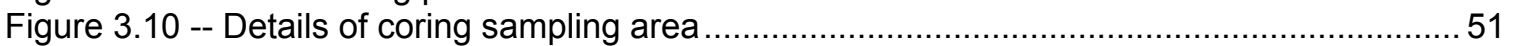

Figure 3.11 -- Core sampling location at all time intervals (A, B, C, D, E and F) ........................ 51

Figure 3.12 -- Gradation chart for the surface course mixtures ................................................. 53

Figure 3.13 -- Gradation chart for the intermediate course mixtures ........................................ 54

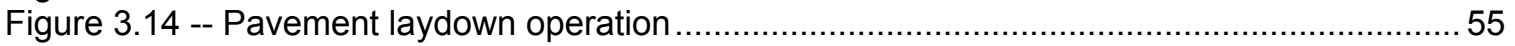

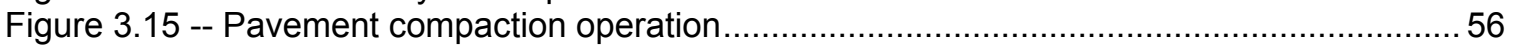

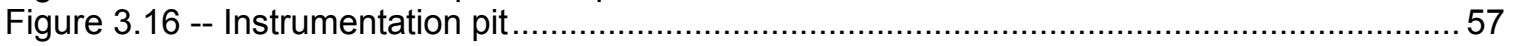

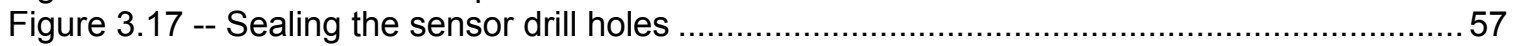

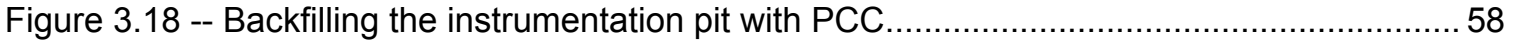

Figure 3.19 -- Steel box set flush with the intermediate layer encased in PCC.......................... 58

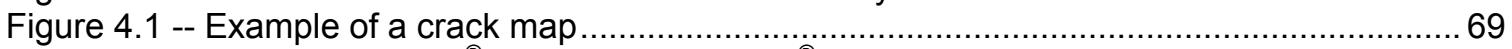

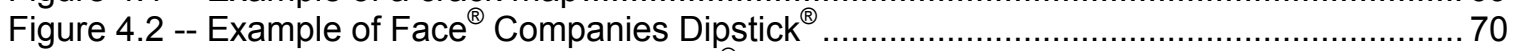

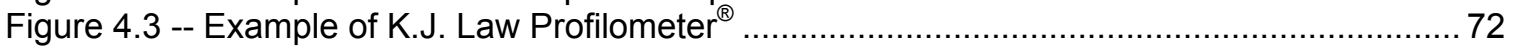

Figure 4.4-- Layout of traffic sensors on the exit and entry ramps ......................................... 74

Figure 4.5 -- Road profile of M-AC-20 at the end of 1.5 years (top) and 3.5 years (bottom)......... 78

Figure 4.6 -- Road profile of S-64-28 at the end of 1.5 years (top) and 3.5 years (bottom) .......... 79

Figure 4.7 -- Road profile of S-58-28 at the end of 1.5 years (top) and 3.5 years (bottom) .......... 80

Figure 4.8 -- Road profile of R-15\% at the end of 1.5 years (top) and 3.5 years (bottom) ............ 81

Figure 4.9 -- Road profile of S-70-28 at the end of 1.5 years (top) and 3.5 years (bottom) .......... 82

Figure 4.10 -- Road profile of S-64-16 at the end of 1.5 years (top) and 3.5 years (bottom) ........ 83

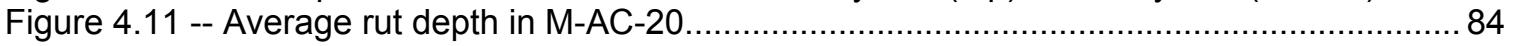

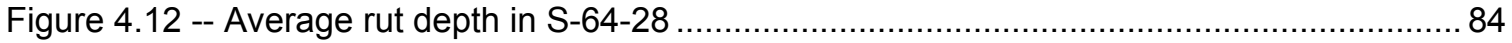

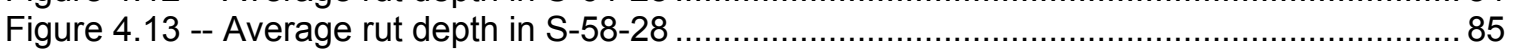

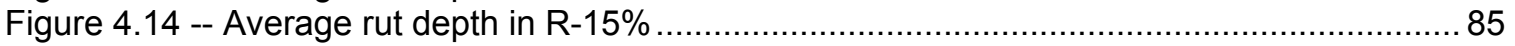

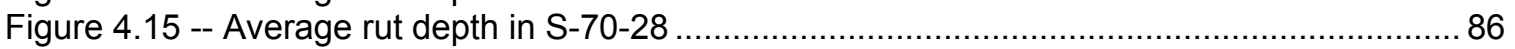

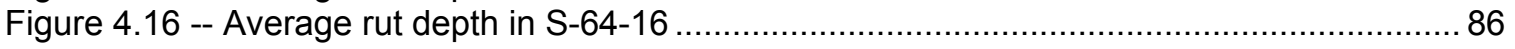

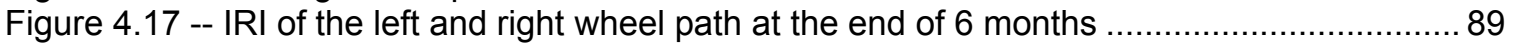

Figure 4.18 -- IRI of the left and right wheel path at the end of 4 years .................................... 89

Figure 4.19 -- Percent increase in IRI of the left and right wheel path at the end of 4 years ........ 90

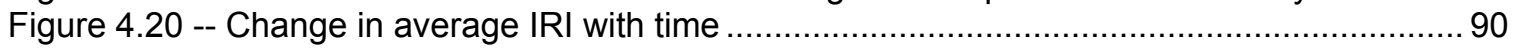

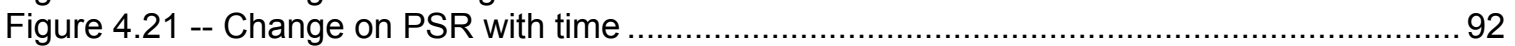

Figure 4.22 -- Trends in air and pavement temperature at the test site ................................... 93

Figure 5.1 -- Specific gravity of the tank binders and recovered binders at the end of 4 years ....96

Figure 5.2 -- Change in specific gravity of recovered binders with time ..................................... 97

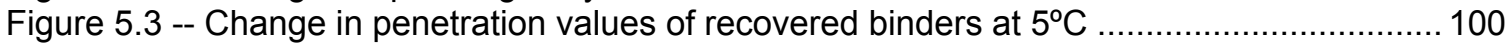

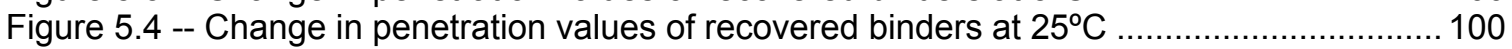

Figure 5.5 -- Trends in absolute viscosity of recovered binders with time ............................... 103

Figure 5.6 -- Trends in rotational viscosity of recovered binders with time............................... 103 
Figure 5.7 -- Change in maximum $T_{D S R}$ of the recovered binders with time ................................ 105

Figure 5.8 -- Change in minimum $\mathrm{T}_{\mathrm{BBR}}$ of the recovered binders with time .............................. 106

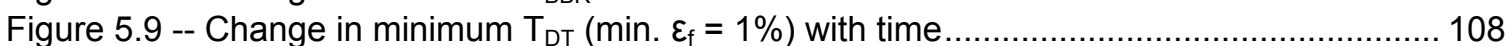

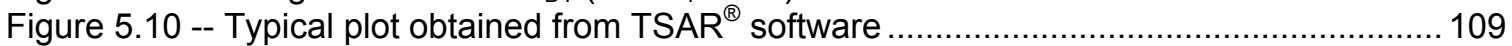

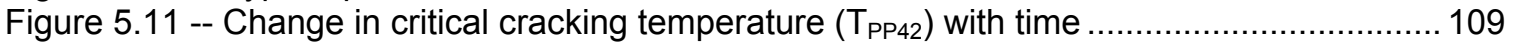

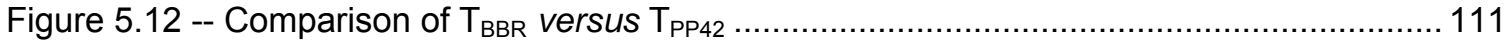

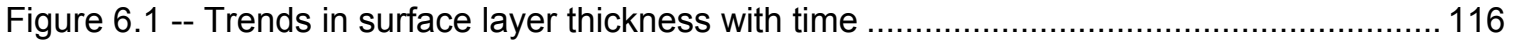

Figure 6.2 -- Trends in intermediate layer thickness with time .......................................... 116

Figure 6.3 -- Change in percentage of air voids in the surface layers with time $\ldots \ldots \ldots \ldots \ldots \ldots \ldots \ldots . . . . . . . . .118$

Figure 6.4 -- Change in percentage of air voids in the intermediate layers with time.................. 118

Figure 6.5 -- Percentage decrease in air voids at the end of 4 years .................................... 119

Figure 6.6 -- Change in binder content of the surface layer with time ................................... 122

Figure 6.7 -- Change in binder content of the intermediate layer with time .............................. 122

Figure 6.8 -- Ranking of the surface mixtures based on indirect tensile strength....................... 128

Figure 6.9 -- Ranking of the intermediate mixtures based on indirect tensile strength ................ 129

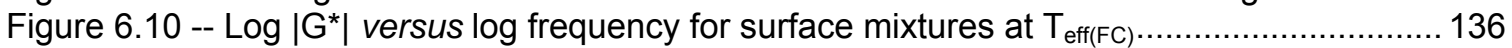

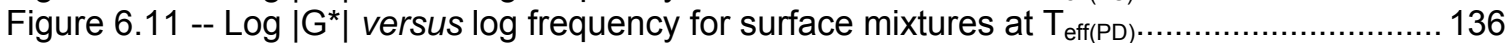

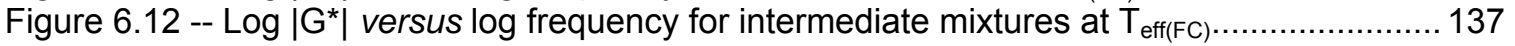

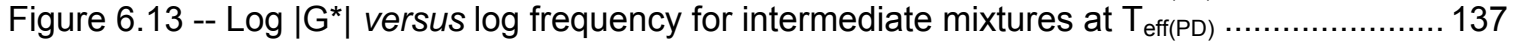

Figure 6.14 -- Shear deformation versus time for surface mixtures at $29.5^{\circ} \mathrm{C} . . . \ldots \ldots \ldots \ldots \ldots \ldots \ldots . . . . . . . . . . .141$

Figure 6.15 -- Shear deformation versus time for surface mixtures at $40.5^{\circ} \mathrm{C} \ldots \ldots \ldots \ldots \ldots \ldots \ldots \ldots . . . . . . . . . . .141$

Figure 6.16 -- Shear deformation versus time for intermediate mixtures at $29.5^{\circ} \mathrm{C} \ldots \ldots \ldots \ldots \ldots \ldots . . . .142$

Figure 6.17 -- Shear deformation versus time for intermediate mixtures at $40.5^{\circ} \mathrm{C} \ldots \ldots \ldots \ldots \ldots \ldots . . . . .142$

Figure 6.18 -- Cumulative permanent strain at $58^{\circ} \mathrm{C}$ for surface mixtures ............................... 145

Figure 6.19 -- Cumulative permanent strain at $54^{\circ} \mathrm{C}$ for intermediate mixtures ......................... 145

Figure 7.1 -- Total transverse crack length versus critical cracking temperature ........................ 152

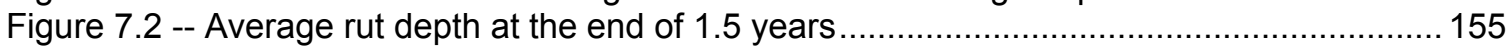

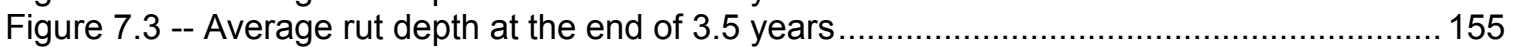




\section{LIST OF TABLES}

Table 3.1 -- Binder grade, aggregate type and design values used in the surface course ...........53

Table 3.2 -- Binder grade, aggregate type and design values used in the intermediate course ... 54

Table 3.3 -- Volumetric properties of the surface course mixtures .............................................60

Table 3.4 -- Results of sieve analysis of extracted aggregate from the surface mixtures .............60

Table 3.5 -- Volumetric properties of the intermediate course mixtures ..................................... 61

Table 3.6 -- Results of sieve analysis of extracted aggregate from the intermediate mixtures ..... 61

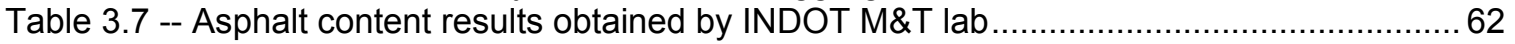

Table 3.8 -- Sieve analysis results obtained by M\&T lab for the surface mixes ............................ 62

Table 3.9 -- Sieve analysis results obtained by M\&T lab for the intermediate mixes ....................62

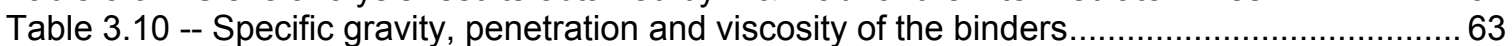

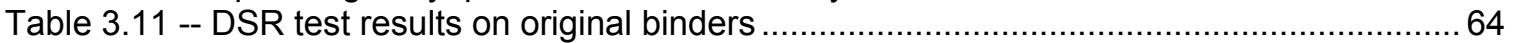

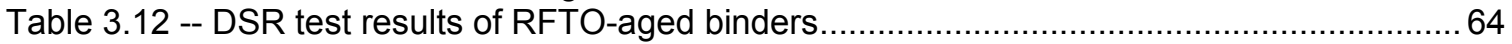

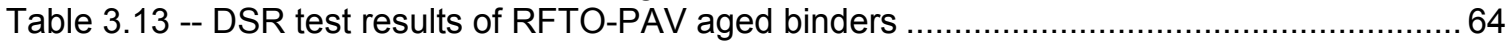

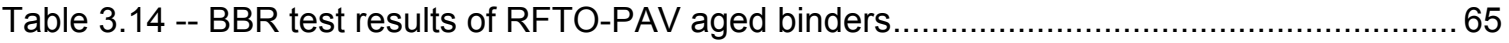

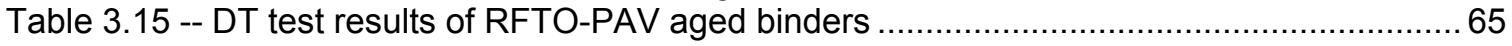

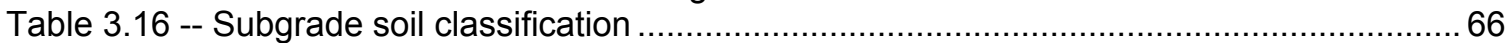

Table 3.17 -- AASHTO and ASTM criteria for the soil classifications shown in Table 3.16 .........66

Table 4.1 -- Magnitude of distress for each category (LTTP Tech Brief, November 2000)............69

Table 4.2 -- Number and lengths of transverse cracks observed .............................................. 75

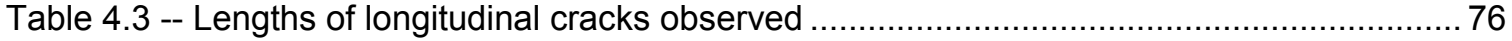

Table 4.4 -- Observed cooling rates in the test pavement ...................................................... 94

Table 5.1 -- Specific gravity of the binders from all sections at different ages ............................96

Table 5.2 -- Percent decrease in penetration value of recovered binders with time .................... 99

Table 5.3 -- T

Table 5.4 -- Distress predictions from binder tests and pavement temperature data.................. 113

Table 6.1 -- ANOVA results for differences in thickness between the test sections .................... 117

Table 6.2 -- ANOVA results for differences in thickness with time (age) ................................ 117

Table 6.3 -- ANOVA results for differences in air voids between the test sections .................... 120

Table 6.4 -- ANOVA results for differences in air voids with time (age) .................................... 120

Table 6.5 -- ANOVA results for differences in binder content between the test sections ............ 123

Table 6.6 -- ANOVA results for differences in binder content with time (age) ............................ 123

Table 6.7 -- Creep stiffness at $60 \mathrm{~s}$ of the surface mixtures with $7 \%$ and $3 \%$ air voids............... 126

Table 6.8 -- Creep stiffness at $60 \mathrm{~s}$ of the intermediate mixtures with $7 \%$ and $3 \%$ air voids....... 126

Table 6.9 -- Ranking of surface mixtures based on indirect tensile strength ............................. 127

Table 6.10 -- Ranking of intermediate mixtures based on indirect tensile strength.................... 128

Table 6.11 -- Results of ANOVA tests on surface mixtures strength data................................ 130

Table 6.12 -- Results of ANOVA tests on intermediate mixtures strength data........................ 131

Table 6.13 -- Pavement critical temperature estimates for surface and intermediate mixtures .. 133

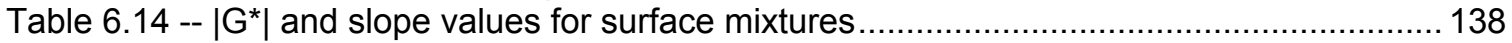

Table $6.15--\left|G^{*}\right|$ and slope values for intermediate mixtures.............................................. 138

Table 6.16 -- ANOVA results on complex shear modulus data from surface mixtures ............... 139

Table 6.17 -- ANOVA results on complex shear modulus data from intermediate mixtures ....... 139

Table 6.18 -- Maximum shear deformation, rank and resilience of surface mixtures ..................143

Table 6.19 -- Maximum shear deformation, rank and resilience of intermediate mixtures........... 143

Table 6.20 -- Maximum cumulative strain and slope values from RSCH testing........................ 146

Table 7.1 -- Transverse cracking observed at the end of 3.5 years ....................................... 151

Table 7.2 -- Longitudinal cracking observed at the end of 3.5 years ...................................... 154

Table 7.3 -- Low-temperature related distress predicted and observed ................................... 158

Table 7.4 -- High-temperature related and load-related distress predicted and observed .......... 159 
Table A1 -- Aggregate blend used in surface course of M-AC-20

Table A2 -- Aggregate blend used in intermediate course of M-AC-20

Table A3 -- Aggregate blend used in surface course of S-64-28, S-58-28, S-70-28 and S-64-16

Table A4 -- Aggregate blend used in intermediate course of S-64-28, S-58-28, S-70-28 and S-64-16

Table A5 -- Aggregate blend used in surface course of R-15\%

Table A6 -- Aggregate blend used in intermediate course of R-15\%

Table B1 -- IRI data from the left and right wheel paths of all sections

Table B2 -- Penetration values of the binders at all ages at $5^{\circ} \mathrm{C}$........

Table B3 -- Penetration values of the binders at all ages at $25^{\circ} \mathrm{C}$ 185

Table B4 -- Absolute viscosity values of the binders at all ages $60^{\circ} \mathrm{C}$. 186

Table B5 -- Rotational viscosity values of the binders at all ages at a $135^{\circ} \mathrm{C}$ 186

Table B6 -- Layer thickness of data for M-AC-20, S-64-28 and S-58-28 187

Table B7 -- Layer thickness data for R-15\%, S-70-28 and S-64-16 188

Table B8 -- Air void data for M-AC-20, S-64-28 and S-58-28. 189

Table B9 -- Air void data for R-15\%, S-70-28 and S-64-16 189

Table B10 -- Binder content data for M-AC-20, S-64-28 and S-58-28 191

Table B11 -- Binder content data for R-15\%, S-70-28 and S-64-16.... 192

Table B12 -- Frequency sweep test data for surface mixtures at $29.5^{\circ} \mathrm{C}$ 193

Table B13 -- Frequency sweep test data for surface mixtures at $40.5^{\circ} \mathrm{C}$ 193

Table B14 -- Frequency sweep test data for intermediate mixtures at $29.5^{\circ} \mathrm{C}$ 194

Table B15 -- Frequency sweep test data for intermediate mixtures at $40.5^{\circ} \mathrm{C}$

Table B16 -- Simple shear test data for surface mixtures at $29.5^{\circ} \mathrm{C}$ 194

Table B17 -- Simple shear test data for surface mixtures at $40.5^{\circ} \mathrm{C}$ 195

Table B18 -- Simples shear test data for intermediate mixtures at $29.5^{\circ} \mathrm{C}$ 195

Table B19 -- Simple shear test data for intermediate mixtures at $40.5^{\circ} \mathrm{C}$

Table B20 -- Repeated shear test data for surface mixtures at $58^{\circ} \mathrm{C}$ 196

Table B21 -- Repeated shear test data for intermediate mixtures at $58^{\circ} \mathrm{C}$ 


\section{CHAPTER 1 -- INTRODUCTION}

The SUPERPAVE system introduced the concept of performance-based binder selection program, in which the binder chosen for a particular site was required to satisfy certain performance-based criteria within a specified temperature range and traffic conditions that were specific to the site (location). The temperature range of interest depends on the yearly maximum and minimum air and pavement temperatures occurring at the site based on historical data collected at or in the vicinity of the test site. The greater the expected pavement temperature range, the more likely it is that the binder selected will be a modified binder.

After the initial introduction of the SUPERPAVE Binder Selection program, the low pavement temperature prediction model was found to be too conservative. This model assumed that the minimum temperature occurring at the pavement surface was equivalent to the minimum air temperature. This was found to be seldom true, particularly at higher latitudes. This led to further refinement of both the high and low pavement temperature models based on data

collected by the Seasonal Monitoring Program (SMP). While these models were a significant improvement over the previous models, the difference between predicted and measured maximum pavement temperatures were observed to vary by as much as $10^{\circ} \mathrm{C}$ in some cases. Since this difference could result in choice of a higher high-temperature binder grade or a lower low-temperature binder grade than actually needed, the increasing costs of modified binders make it necessary to estimate pavement temperatures more accurately. A pavement built with mixtures that satisfied the SUPERPAVE mix design guidelines would then be expected to perform satisfactorily in-service in terms of low-temperature cracking and rutting during the life of the pavement. 


\subsection{Purpose of the Study}

The purpose of this study was to investigate the influence of binder properties (grade) and mixture properties on the thermal cracking resistance and rutting resistance of asphalt mixtures. This was done in three parts; in the first part, six test sections were constructed as a part of Indiana SPS9-A experiment as described in Chapter 3. Field core samples were collected from the six test sections at six-month intervals for a period of two years. In addition, a final set was obtained at the end of 4 years. The volumetric properties of these cores were measured, after which the binder was extracted from the surface layers and subjected to a suite of binder tests. In the second part, performance testing was conducted on laboratory-compacted plant mixture samples and the virgin binder samples collected at the time of construction. And finally, field performance of the test sections was evaluated by distress surveys conducted over a period of 4 years.

\subsection{Objective and Scope of the Study}

The objective of this study was to quantify the effect of binder grade on thermal cracking and permanent deformation (rutting) of asphalt pavements by correlating the results of binder and mixture tests to the field performance of these mixtures. The secondary objective was to evaluate the validity of the existing temperature prediction models for assessing the susceptibility of the given binder to low-temperature cracking and rutting. The binders used in this study were

AC-20,

PG64-28,

PG58-28,

PG70-28 and

PG64-16. 
Finally, a comparison will also be made between the performance of the "control" SUPERPAVE test section and the Marshall test section and between the control section and the recycled asphalt pavement (RAP) section.

\subsection{Organization of the Report}

The first two chapters of this report cover the scope, objectives and literature review of this study. Chapters 3 and 4 deal with the layout and construction of the test sections and the field evaluation of the sections. In addition to construction details, Chapter 3 also contains details about the installation of the weather station and the traffic station, the material selection, and results of quality control tests on asphalt mixture and binder samples obtained at the time of construction. Chapter 4 deals with the pavement distress surveys conducted and presents the summary of field performance findings.

Chapters 5 and 6 present the results of the tests performed in the laboratory on compacted mixture samples, field cores and binders recovered from the field cores at different time intervals. In Chapter 7, the results from field and laboratory evaluations are compared and correlations are attempted with observed field performance. The report concludes with the summary and conclusions presented in Chapter 8. 


\title{
CHAPTER 2 -- LITERATURE REVIEW
}

\begin{abstract}
2.1 Introduction
The SUPERPAVE system was developed as a result of extensive asphalt research conducted by Strategic Highway Research Program (SHRP) (1) and uses a performance-oriented approach to material selection and mix design and analysis. In this approach, the binder and mixture selection process takes into account the environmental conditions (e. g., pavement and air temperatures) and traffic volume occurring at the pavement site. Binder selection process is specific to site location and requires that the binder selected passes a specified sequence of tests that evaluate its fundamental engineering properties believed to be related to pavement performance. This, combined with site-specific weather and traffic data, ensures that the selected binder will provide adequate performance under the project specific loading and environmental conditions.

The SUPERPAVE aggregate gradation requirements are designed to promote stone-to-stone contact and better interlocking between aggregate particles. This is done by blending crushed aggregate (having angular structure) and limiting the amount of fines (aggregate smaller than $2.36 \mathrm{~mm}$ ) in the hot mix asphalt (HMA). Pavements built according to SUPERPAVE specifications and methodology are expected to exhibit better long-term field performance with respect to permanent deformation, fatigue cracking and thermal distress (lowtemperature) in comparison with pavements built using empirical specifications and design methodology.
\end{abstract}

The SUPERPAVE binder selection program ensures that the chosen binder performs satisfactorily within the specified temperature range expected at the location. A specified binder viscosity not only ensures that the aggregate particles are completely covered 
with the binder during the mixing process, but also ensures that the HMA has sufficient viscosity for proper compaction in the field. While the aggregate skeleton provides shear resistance and strength to the mixtures at high temperatures, the low temperature behavior of bituminous mixtures is largely dependent on the binder properties.

The behavior of HMA mixture is dependent on the temperature, loading, and aging conditions. When bituminous mixtures are subjected to low-temperatures, high frequency loading cycles and low load levels, they behave as linear, visco-elastic material. Under warm temperatures, high load-levels and slow-loading rates, they behave as non-linear, viscoelastoplastic materials $(2,3)$. Pavement performance prediction models require the complete characterization of asphalt mixture's non-linear elastic, plastic and visco-elastic properties.

\subsection{Types of Pavement Distress}

Some of the commonly observed forms of distress in asphalt concrete pavements include permanent deformation (rutting), cracking (load and non-load related), stripping, ravelling, bleeding, shoving, etc. Load-related cracking observed in pavements may be due to the application of repeated loads (fatigue cracking) or simply due to the application of excessive heavy loads and high tire pressures (longitudinal cracking) on pavements with insufficient thickness, i. e., inadequate structural design. Non-load related cracking may be a result of (a) reflective cracking due to a cracked underlying pavement surface, (b) thermal stresses developed in the pavement due to variations in temperature, (c) age hardening of the binder due to loss of volatiles, (d) insufficient adhesion between the surface asphalt mix and the underlying layer (slippage) (4), or (e) a combination of these factors. Propensity for these forms of distresses (non-load and load related) can be reduced through proper design, material selection and construction process. Figures 2.1 and 2.2 show examples of thermal cracking and rutting observed in HMA pavements. Since the main objectives of this study were to validate the SUPERPAVE binder selection program and to evaluate the influence of binder grade on thermal cracking and permanent deformation (rutting), only these two types of distress will be discussed. 


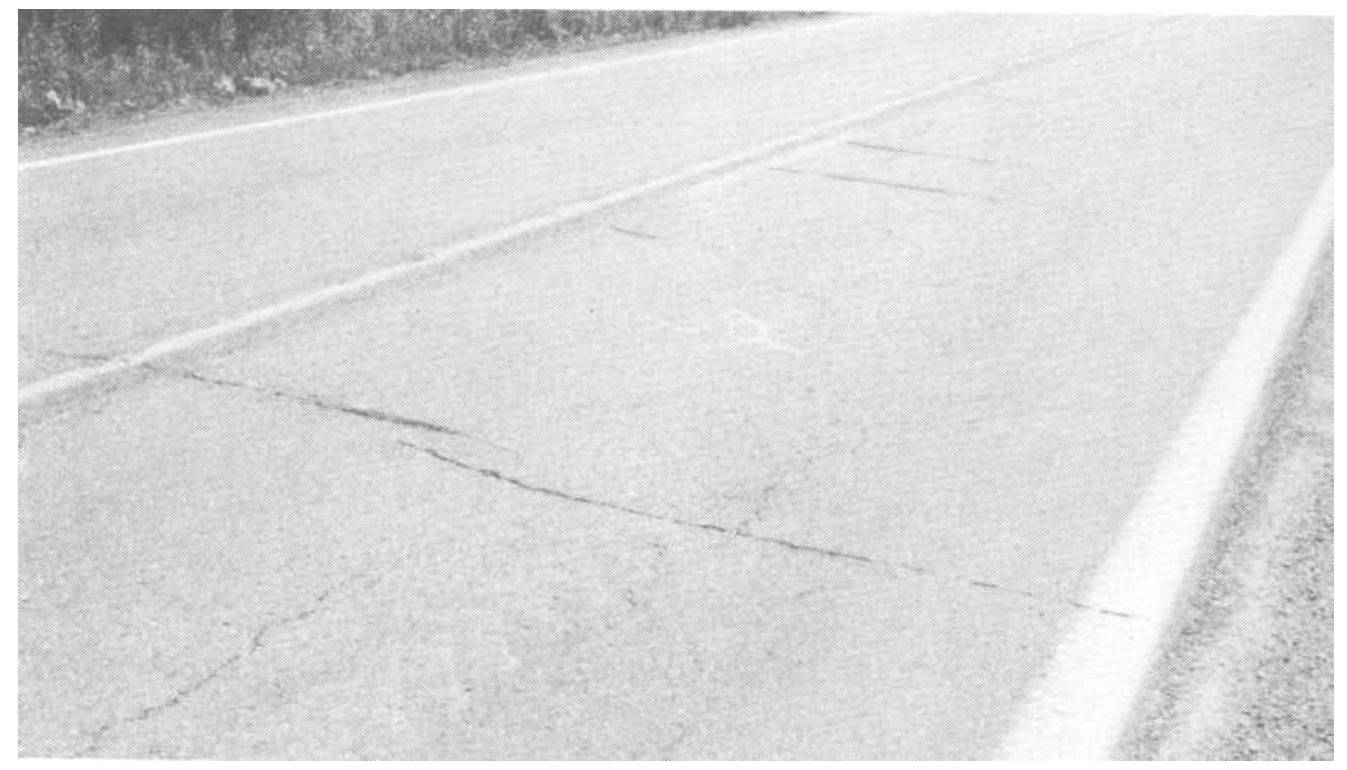

Figure 2.1 -- Thermal cracking observed in an HMA pavement (4)

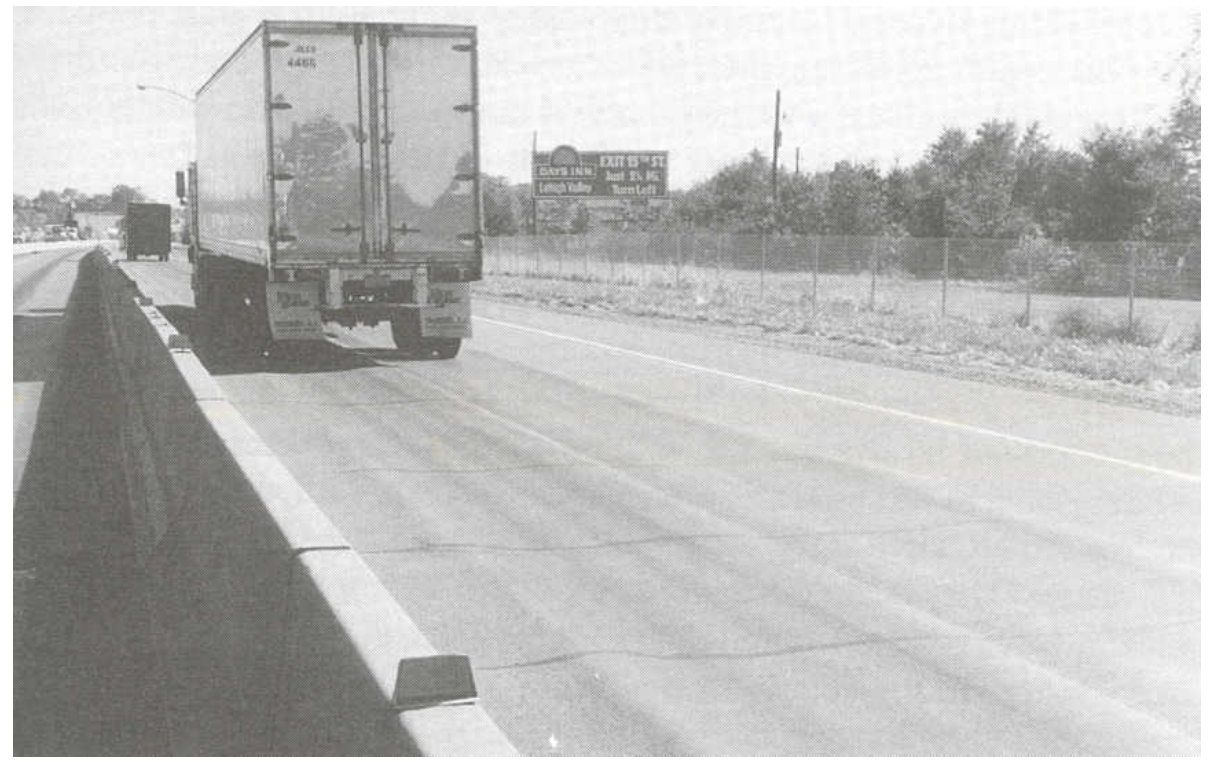

Figure 2.2 -- Rutting observed in an HMA pavement (4) 


\subsection{Mechanism of Low-Temperature Cracking}

Pavement surfaces are subjected to significant temperature variations, both daily and seasonal. Repeated heating and cooling cycles result in thermal stress build-up in the pavement layers. Shrinkage during a cooling period is restrained due to friction with underlying layers. This imparts tensile stresses to the asphalt layer, the stresses being greatest at the surface, where temperature changes are largest, and decrease with depth where the temperatures changes are lower $(5,6)$. The tensile strength of an HMA mixture at low temperature depends primarily on the ability of the asphalt binder to withstand tensile stresses without cracking. Binders exposed to environmental conditions in the field undergo hardening with age (due to oxidation and loss of volatiles) and become more brittle. When the thermal stresses in the pavement exceed the tensile or fracture strength of the binder, micro-cracks are formed in the binder phase of the pavement. Repeated daily heating and cooling cycles cause thermal fatigue in the pavement and further propagate the crack development and widening. In addition, these cracks can be subsequently widened by traffic loads. A well-chosen asphalt would be able to retain adequate elastic behavior at low temperatures, and allow for the pavement to relax stresses developed in the pavement layers without undergoing cracking.

\subsection{Factors Influencing Thermal Cracking}

Haas et al. (7) broadly classified the factors affecting low-temperature cracking into six categories; (a) climatic effects, (b) asphalt binder properties, (c) mix design/properties, (d) pavement design, (e) construction effects and (f) pavement age and traffic effects. Of these, they found that the main factors that influence thermal cracking were a combination of climatic effects, characteristics of the bituminous components, layer thickness and pavement age. Climatic or environmental conditions include the influence of the air and pavement temperature at the pavement location and the average cooling rate in the surface layer of the pavement. The binder properties that influence the susceptibility of the pavement to thermal cracking are binder stiffness

and elasticity at low temperatures and its fracture strength. The binder used in the pavement 
strongly influences the low temperature mixture properties such as the fracture strength, coefficient of thermal expansion and its stiffness behavior with temperature. Pavement design factors such as pavement thickness and type of subbase and subgrade soils influence thermal cracking to a lesser degree than the binder properties. Finally, the age of the pavement and the expected traffic volume during the service-life of the pavement are also important factors that should be considered during the design of an HMA pavement.

In the following sections, the factors influencing thermal cracking will be divided into four groups; (a) Environmental, (b) Binder and Mixture Properties (c) Subgrade and (d) Other Factors.

\subsubsection{Environmental Factors}

The range of maximum and minimum temperature occurring in the pavement has a strong influence on the occurrence of thermal cracking in the field. With the introduction of the SUPERPAVE Binder Selection program, the design high and low air temperatures and hence the expected pavement temperatures occurring at the test site are crucial to the binder selection process. As a part of the Strategic Highway Research Program, high and low pavement temperature algorithms were developed based on the air temperature and latitude at the test site (8). A conservative approach was adopted in the original SHRP low temperature model, by assuming the minimum pavement temperature $\left(T_{\min (p v m t)}\right)$ to be equal to the minimum air temperature $\left(T_{\min (a i r)}\right)$. For example, a PG64-28 binder was expected to perform satisfactorily (at a specified reliability level), as long as the low air temperature (and hence the low pavement temperature) did not fall below $-28^{\circ} \mathrm{C}$. At temperatures below $-28^{\circ} \mathrm{C}$, the binder is believed to lose its flexibility and exhibits brittle behavior leading to cracking in the pavement. The original SHRP low temperature model was later revised when air and pavement data collected indicated that the minimum pavement temperature was about 5 to $10^{\circ} \mathrm{C}$ warmer than the minimum air temperature.

Vinson et al. (6) observed higher incidence of cracking in pavements when the pavement temperature dropped below the glass transition temperature $\left(T_{g}\right)$ of the binder for 
extended periods. Rapid cooling rates occurring in the pavement due to sudden transition in surface temperature also appeared to yield higher incidence of thermal cracks, even if the lowtemperature grade of the binder selected was appropriate for the location. This is due to a slower rate of stress relaxation in comparison with the rapid cooling rate of the pavement. At temperatures above the $T_{g}$, the HMA mixture behaves as a visco-elastic solid. The stress relaxation phenomenon does not occur (or is negligible) when the temperature falls below the $T_{g}$ where the mixture behaves as an elastic solid; which in turn leads to cracking in the pavement $(9$, 10). Mixtures maintained at temperatures warmer than the $T_{g}$ exhibit stress relaxation at a higher rate than the rate of thermally-induced stresses and show better resistance to low-temperature cracking.

\subsubsection{Binder and Mixture Properties}

Binder properties are among the most significant factors influencing the performance of HMA mixtures at low temperatures. Before the introduction of the SUPERPAVE performance grading system, binders were either viscosity graded or penetration graded. The binder was called "soft" or "hard" depending on its penetration value and/or its viscosity. High penetration numbers and low viscosity values indicated soft binders. Soft binders are less temperature susceptible and perform better at low temperatures as they exhibit smaller gains in stiffness with decreasing temperatures and hence tend to be more resistant to thermal cracking (6). Penetration values at low temperature $\left(4^{\circ} \mathrm{C}, 200 \mathrm{~g}\right.$ for $\left.5 \mathrm{~s}\right)$ were found to be a strong indicator of mixture performance in terms of thermal cracking resistance (11). In the performance grading method, the more extreme the low or high temperature grade of the binder, the harder the binder was likely to be.

Binder properties depend largely on the crude source and the refining techniques used to obtain the binders. It was observed that air blowing refining technique produces the least temperature susceptible asphalts, whereas solvent extraction produces the most temperature 
susceptible asphalts. The temperature susceptibility of asphalts obtained from simple distillation falls in between the air blowing technique and the solvent extraction technique (11).

A joint study (12) was conducted by the states of Wisconsin, lowa and Minnesota, to evaluate the influence of using soft binders (PG52-34, PG52-40 and PG58-40) on the performance of new pavements and HMA overlays. Preliminary distress surveys conducted at the end of 2 years (one year, in some cases) showed a significant reduction in the amount of reflective cracking observed in the rehabilitated pavements in comparison with pavements built with local conventional mix designs. The new projects constructed using SUPERPAVE mix design methodology showed zero to minimal thermal cracking, unlike the conventional test sections.

Since the stiffness of the HMA mixtures depends strongly on the stiffness of the binder used, the use of softer binders result in softer mixtures. Faab's (13) investigation into the effect of binder and mixture properties on thermal cracking indicated that cracking occurs when the stiffness of the binder reaches a critical value regardless of its initial stiffness value. Haas and Phang (14) suggested that crack resistant mixes could be developed by using binders with lower stiffness (softer binders) or by using modified binders designed to retain their elastic behavior at low temperatures.

The use of modified binders to improve the low-temperature field performance of pavements was studied by Anderson et al. (15). They noted that elastomer-modified and fibermodified mixtures performed better than plastomer-modified mixtures and unmodified mixtures, in terms of cracking observed in the field. When observed, the poor performance of pavements was attributed to stiffening of the binders and the resulting brittleness of the mixtures. Comparison of critical temperatures obtained from Indirect Tensile Strength (IDT) testing correlated better with Bending Beam Rheometer (BBR) estimates rather than with Direct Tension (DT) estimates (conducted at $1 \%$ strain rate).

The concept of critical cracking (or fracture) temperature $\left(T_{c}\right)$ is widely used by asphalt researchers to define the minimum temperature that a HMA pavement can withstand 
before cracking (fracturing). It is assumed that cracks develop in the HMA pavement when the temperature of the pavement falls below the $T_{c}$ of the binder. At or below this temperature, the binder loses its flexibility and causes the pavement to undergo cracking due to the thermal stresses resulting from falling temperatures.

Anderson et al. (16) also conducted tests on five modified PG70-22 binders and compared the mixture stiffness with the corresponding binder stiffness at two test temperatures. The researchers observed poor correlation between binder stiffness and mixture stiffness at both test temperatures. However, good agreement was observed between fracture temperature estimates of mixtures obtained from IDT data and critical temperature values obtained from BBR tests for the binders used in this study. The same was not true for critical temperature estimates from the m-value. Their results also indicated that not all PG70-22 binders exhibit similar performance and that the method of producing the modified binders might influence their performance.

Instead of binder stiffness values, Hoare and Hesp (17) suggested using fracture energy of notched binder specimens to predict critical cracking temperatures and pavement performance. They observed that fracture energy was truly a material property, independent of specimen size and geometry. The addition of elastomers to binder was observed to increase the fracture properties of the binder at low temperatures, whereas the addition of plastomers caused a slight decrease in the fracture properties of the binder.

The importance of fracture properties of binders at low temperatures was also studied by Anderson et al. (18). They determined the critical cracking temperatures of binders with different percentages of modifiers using different methods, such as Direct Tension (DT), BBR and fracture toughness. No significant differences in critical temperature estimates were obtained from BBR and DT methods. However, the ranking obtained using fracture toughness values were different from that obtained using BBR and DT limiting criteria. In addition, they did not find any correlation between fracture toughness and failure stress or strain. 
The influence of $T_{g}$ of the binder and hence, the $T_{g}$ of the mixture on the low temperature behavior of HMA mixtures was studied by Schmidt and Santucci (19). The glass transition temperature plays a significant role in the coefficient of thermal expansion $(\alpha)$ of the binder $\left(\alpha_{b}\right)$ and the mixture $\left(\alpha_{\text {mix }}\right)$, which is used in estimation of the thermal stresses in the binder and resulting mixture. The value of $\alpha_{b}$ below $T_{g}$ was found to be typically different from the value at temperatures warmer than $T_{g}$. The commonly used value for $\alpha_{\text {mix }}$ based on assumption of isotropic material was 2 to $2.5 \times 10^{-5} /{ }^{\circ} \mathrm{C}$. However, a later study (20) has shown that this value is underestimated by a factor of two or three, resulting in underestimation of the thermal stresses by the same factor.

Haas and Phang (14) observed that $\alpha_{\text {mix }}$ and mixture stiffness were highly dependent on temperature and cooling rate. Lower values of $\alpha_{\text {mix }}$ were beneficial for a crackresistant mixture. They suggested that $\alpha_{\text {mix }}$ could be lowered by modifying the aggregate gradation. Gap-graded mixtures have lower $\alpha_{\text {mix }}$ compared with dense-graded mixtures. They noted that the influence of mixture characteristics on thermal cracking can be determined in the laboratory by closely simulating the cooling rate and minimum temperature that occur in the field.

The influence of cooling rate on induced thermal stresses and fracture strength was studied by Bahia et al. (21) and by Dongré et al. (22). They observed that ignoring the effect of cooling rate on the induced thermal stresses resulted in overestimation of the mixture fracture temperature by as much as 3 to $4^{\circ} \mathrm{C}$. Whereas, ignoring its effect on both thermal stresses and fracture strength, overestimated the fracture temperature by as much as 6 to $7^{\circ} \mathrm{C}$.

Dongré et al. (22) compared the critical temperatures estimated by BBR testing, from Thermal Stress Analysis Routine $\left(T_{S A R}{ }^{T M}\right)(23)$ and from Thermal Stress Restrained Specimen Test (TSRST) on mixtures and found good agreement in most cases. They also found good correlation between the critical temperatures predicted by these methods and the thermal cracking observed in the field.

Leahy et al. (24) conducted TSRST on mixtures, to relate binder properties to low temperature characteristics. These researchers concluded that fracture temperature, fracture 
strength, slope of thermal stress curve and transition temperature were the most influential factors on predicting thermal cracking, as was also shown elsewhere (25). High correlation was found between fracture temperature and $\mathrm{m}$-value of the binder (BBR test) and temperature at limiting stiffness. As the degree of aging of the mixtures was increased, the fracture temperature of the mixtures was also observed to increase.

The effect of the differential thermal expansion and contraction of asphalt and aggregate on fracture strength of mixtures was studied by El Hussein and El Halim (26), who theorized that the increase in strength at low temperatures was due to improved bond between asphalt and aggregate resulting from development of radial compressive stresses. However, they noted that prolonged exposure to low temperatures decreased the strength performance of the mixtures, whereas short-term exposure to low temperatures improved the strength performance. The commonly observed drop in tensile strength after reaching a peak value with decreasing temperature was attributed to the development of micro-cracks in asphalt matrix due to high tensile stresses.

While low mixture stiffness (i. e., higher compliance) provides better resistance to the low temperature cracking, high strength provides better resistance to fracture at low temperature when subjected to high traffic loads. Fortier and Vinson (10) observed a linear relationship between fracture strength and fracture temperature. Aging decreased the fracture strength and increased the fracture temperature of the HMA mixtures. The rate of stress build-up was also observed to decrease. They also noted that binder (BBR) testing alone was not sufficient to capture the influence of modifiers used on the binder properties and recommended accompanying binder tests with mixture testing.

A typical value of fracture strength of HMA mixtures is around 2.8 MPa (400 psi). Roque and Ruth (27) reported that cracking was observed in pavements (or was imminent) when the thermal stresses in the pavement exceed $55-60 \%$ of the fracture strength. Pavements, in which the thermal stresses never exceeded $30 \%$ of the fracture strength, were observed to show good performance with minimal or no cracking. 
Tests conducted at Oregon State University (28) using TSRST indicated that air void content and aggregate type had a significant influence on the fracture strength. In addition, the researchers also found that larger test samples had lower fracture strengths and colder fracture temperatures compared with smaller test samples. Mixture fracture temperature was strongly influenced by aging and asphalt content.

Mohammad and Paul (29) also found that the indirect tensile strength of HMA mixtures was dependent on type of asphalt and air void content, but independent of mixture type (similar gradation, different source aggregate) and test device.

In addition to fracture strength, the influence of failure strain or elongation on thermal cracking was recognized and studied by researchers $(21,30-32)$. Failure strain represents the ductility or brittleness of a binder and it dependent on the cooling rate. It was found to be more sensitive to temperature changes than the failure stress. Above the $T_{g}$, failure strain decreases and failure stress increases with decreasing temperature. Below the $T_{g}$, the failure strain continues to decrease whereas failure stress levels off. In contrast with failure strain, thermal strain was independent of thermal history. It was dependent only on initial temperature and current temperature.

Buttlar and Roque (33) conducted testing of HMA samples in the indirect tensile mode to study the accuracy of creep compliance $(D(t))$ and Poisson ratio values $(\mu)$ obtained from IDT testing. This study also served to evaluate the SHRP measurement and analysis system for IDT testing at low temperatures. Laboratory prepared mixtures with known properties, as well as field cores, were tested and analyzed as a part of this evaluation. They found that $D(t)$ and $\mu$ values obtained from IDT were in agreement with expected trends. Mixtures with higher air void content had lower $\mu$ and higher $\mathrm{D}(\mathrm{t})$ values. Mixtures with softer asphalts tested at higher temperatures showed higher compliance values and vice versa. Rather than using the common default values for Poisson's ratio in the prediction models, the researchers recommended the use of values measured directly from specimens during testing. 


\subsubsection{Subbase and Subgrade}

The effect of subgrade, base and subbase soil on thermal cracking, rutting and fatigue cracking was discussed by May and Killingsworth (34). They noted that the type of subgrade soil did not significantly influence the low temperature cracking. They also noted that clayey soils (e. g., AASHTO A7 soils) performed better in fatigue in comparison with sandy soils (AASHTO A1). This trend was opposite in terms of rutting performance, where pavements over A5 and A7 type soils experienced more rutting than pavement over A1 soils.

Cracking observed in pavements can either extend only in the surface layer of the pavement or extend into the underlying base layers as well. Cracks that extend along the width of the pavement and into the shoulder are thought to occur due to the contraction and expansion of the subbase, base and subgrade layers, rather than due to the expansion and contraction of the pavement surface layer (6). These latter types of cracks were observed to be at least a few centimeters wide. In newer pavements, the crack spacing ranges between $30-60$ $\mathrm{m}$, whereas in older pavements the spacing may be less than $5 \mathrm{~m}$.

\subsubsection{Other Factors}

The influence of other factors such as age, pavement width and thickness, asphalt content, aggregate gradation, etc., on thermal cracking was studied by other researchers. Vinson et al. (6) noted that the frequency of cracks was higher in older pavements and in pavements with thinner asphalt concrete layers and narrower widths. They found that mixtures with non-absorptive, angular aggregate showed higher resistance to thermal cracking than absorptive rounded aggregate. Gradation and asphalt content had little effect on low-temperature cracking potential.

Physical aging or hardening is a phenomenon that was observed to occur in materials such as bitumen, shellac and amorphous sugar, in addition to amorphous solids or materials that are in a glassy state. It is a function of time (age) and temperature and is known to influence the failure strength, failure strain and modulus of the material. Asphalts exhibit physical 
hardening above and below $\mathrm{T}_{\mathrm{g}}$, whereas, amorphous polymers show physical hardening only below the glass transition temperature (35).

Faab (13) showed that changes in aggregate gradation, dust/asphalt ratio, and asphalt content had no influence on the critical stiffness modulus of the mixture at fracture.

Mohammad and Paul (29) studied the influence of test devices on indirect tensile strength, indirect tensile creep, resilient modulus and Poisson's ratio. They found that the type of test device used for static testing did not significantly influence the results in mixtures with the same asphalt and similar gradation. In the case of dynamic testing, the effect of test device was found to be significant.

\subsection{Test Methods Used to Quantify Thermal Cracking Potential}

In the SUPERPAVE system, the test devices used to quantify low-temperature cracking potential of asphalt binders are the Bending Beam Rheometer (BBR) and Direct Tension Tester (DTT). In addition, researchers have also conducted fracture tests on notched and unnotched binder samples at low temperatures, and reported good results in correlating fracture properties to low-temperature pavement performance. Creep compliance testing and indirect tensile strength tests using the Indirect Tensile Tester (IDT) and Thermal Stress Restrained Specimen Test (TSRST) are the most commonly used methods to evaluate HMA mixtures at low temperatures. In this study, only the BBR, DTT and IDT tests were conducted. These tests will be briefly outlined in the following paragraphs.

In the BBR test, a simply supported asphalt beam $(127.0 \mathrm{~mm} \times 6.35 \mathrm{~mm} \times 12.7$ $\mathrm{mm}$ ) is subjected to a static creep load of $100 \mathrm{~g}$ for a period of $240 \mathrm{~s}$ (AASHTO TP1 (36)). This test is conducted at low temperatures $\left(e . g .,-12^{\circ} \mathrm{C},-18^{\circ} \mathrm{C}\right)$ depending on the binder grade of the sample being tested. The deflection, $\delta \mathrm{mm}$, is recorded during the entire test period and the stiffness of the binder, $S(t)$, is calculated by the BBR software at $8,15,30,60,120$ and $240 \mathrm{~s}$, using elastic beam theory. A limiting stiffness of $300 \mathrm{MPa}$ at $60 \mathrm{~s}$ specified in the SUPERPAVE

binder specifications was established based on previous literature. As the asphalt tends to 
become very brittle and stiff at low temperatures, the thermal stresses in the pavement will increase with falling temperatures. Imposing a limiting value on stiffness prevents the binder from becoming too brittle and prevents excessive stress build-up in the pavement. A minimum of 0.300 for the m-value (slope of the deflection curve at $60 \mathrm{~s}$ ) is the other criterion that must be satisfied by binders that meet the SUPERPAVE specifications. This defines the ability of the binder to exhibit stress relaxation. Lower $m$-values indicate decreased stress relaxation ability.

In the DT test, a dog-bone shaped binder sample ( $40 \mathrm{~mm}$ long and $6 \mathrm{~mm}$ thick) is subjected to uniaxial tension at a constant strain rate of $3 \% / \mathrm{min}$ until failure (AASHTO TP3 (37)). The test is conducted at temperatures corresponding to the BBR test temperatures or until a minimum of $1 \%$ strain is met, as per SUPERPAVE binder specifications. The DT software records failure stress, failure strain and the fracture energy for each sample tested. It was observed that the transition from ductile to the brittle phase occurred around the $1 \%$ strain limit (32). In addition to binder flexibility, ductility is also a necessary requirement for improved pavement performance at low temperatures. This allows the pavement to flex under the application of traffic loads at low temperatures without fracturing.

Test data from the BBR and DT can be used to determine the fracture temperature of the pavement $\left(T_{c}\right)$. The details of this procedure are outlined in AASHTO PP4201 (38) and referred to in several papers (18, 39 - 41). Commercially-available software, Thermal Stress Analysis Routine (TSAR) (23), developed using this procedure can be used to determine $T_{c}$. In this procedure, time-temperature superposition principle, applicable to linear visco-elastic materials, is used to horizontally shift the BBR isotherms and generate the stiffness master curve. The Arrhenius equation is used to model the shift factors (temperature dependency), as it was found to be provide a better fit below the glass transition temperature. Above the $T_{g}$, the WilliamLandel-Ferry (WLF) equation is preferred by researchers. Following the determination of the shift factors, the Christensen-Anderson-Marasteanu (CAM) model is used to fit the stiffness versus reduced time data (log-log scale). A robust, non-linear least squares optimization technique (Marquadt-Levenburg) is used in fitting the shifted stiffness data to the CAM model. The creep 
compliance master curve is generated by taking the inverse of the stiffness master curve. Creep compliance and relaxation modulus are related through a convolution integral, which is solved using the Hopkins and Hamming algorithm. The thermal stresses in the pavement are then computed from the relaxation modulus using numerical techniques.

The determination of creep compliance and indirect strength using IDT is typically performed on 50 -mm thick mixture samples compacted to $7 \%$ air voids (AASHTO TP9 (42)). The compliance test is a non-destructive test performed at $-20^{\circ} \mathrm{C},-10^{\circ} \mathrm{C}$ and $0^{\circ} \mathrm{C}$ for 100 seconds. The strength test is a destructive test performed at $-10^{\circ} \mathrm{C}$ (typically) after the completion of creep compliance testing. In both tests, the vertical movement of the load ram is at a rate of $12.5 \mathrm{~mm} / \mathrm{min}$. The data from the creep compliance tests are used to generate the master creep curve and ultimately, the thermal stress curve. The procedure followed in determining the thermal stress in the mixtures is similar to that followed with binder test data $(5$, 43 - 47), but differs in the following respects: (i) a power law was used to fit the shift factors, instead of the Arrhenius equation, (ii) an exponential series was fitted to the creep versus reduced time data using a non-linear least square optimization technique (Gauss-Newton), and (iii) the creep function (exponential series) and relaxation modulus are related through the inverse of Laplace transform for which an approximate solution is obtained using the "direct method". Further details of this procedure are given by Christensen (47). The intersection of the indirect tensile strength curve with the thermal stress curve yields the critical cracking temperature of the mixtures, since a pavement develops cracks when the thermal stresses in the pavement exceed its tensile strength.

\subsection{Models Used to Predict Thermal Cracking}

As a part of the work done by Hiltunen and Roque $(5,44)$ at Pennsylvania State University under the SHRP contract, a performance prediction model (TCMODEL) was developed to predict thermal cracking in HMA pavements. While earlier models were based on mostly empirical data from binder testing, the new model consisted of two parts: a mechanistic-based 
model and a probabilistic model. The mechanistic model incorporates the time-dependent behavior of the mixtures, pavement temperature, stress relaxation and cooling rate to predict the thermal stresses in the pavement and the hence the amount of cracking as a function of time. The probabilistic model predicts the total amount of cracking that is likely to be observed in the field given the current crack depth and crack distribution at the pavement surface.

The visco-elastic properties of HMA mixtures that are needed as inputs in the mechanistic model are determined by creep compliance testing at different temperature using the IDT. The 1000-second creep test initially proposed by Roque et al. (45) did not always provide sufficient overlap in the construction of master curve and hence, led to errors in estimation of the shift factors. The problem was overcome by using binder (BBR) test data and developing a relationship between binder stiffness and mixture stiffness. This allowed the mixture creep test to be shortened to 100 seconds.

Buttlar and Roque (46) evaluated the commonly used binder-mixture stiffness relationships and other empirical and theoretical models used to estimate mixture stiffness from binder stiffness and volume concentration of the components by testing 28 mixtures and binders. They observed wide variations in mixture stiffness, which was accounted for by the variability in air content of the mixtures tested and other factors such as, aggregate structure and volume concentrations of the mixture components. They found that the current, empirical mixture stiffness prediction relationships tended to underestimate the stiffness values and were applicable only at high binder stiffnesses. The theoretical models evaluated also predicted values that deviated from the observed stiffness values, except at high binder stiffnesses. The single power law fitting model used in SUPERPAVE ${ }^{\mathrm{TM}}$ cracking prediction model (TCMODEL) greatly overpredicted the extent of cracking due to errors in estimation of shift factors needed for the construction of the master curves. They proposed a multi-power law model that was developed based on the single power law model and provided better estimates of the amount of cracking with time. The researchers concluded that binder stiffness could not be used to adequately predict mixture stiffness. 
Mixture properties used to evaluate thermal cracking potential within SUPERPAVE system include data from binder testing (BBR) and mix properties from IDT testing, in addition to volumetric properties data (45). Air and pavement temperature (environmental information), layer thickness (structural information), etc, are also required in crack propagation prediction model.

To illustrate the validity of the binder selection program of SUPERPAVE and thermal cracking prediction software, Roque et al. (45) compared the performance of three out of the seven test sections constructed in Alberta, Canada. These sections had the same mix design and aggregate type, but different binders. SUPERPAVE ${ }^{T M}$ TCMODEL predicted the least amount of cracking in Section 3, which was verified by field observations at the end of three years. This section had the lowest stiffness and the highest BBR m-value. Although the binders used in the other two sections had similar m-values, their stiffnesses were not equal. The section with the higher stiffness exhibited severe cracking, as predicted by the model.

However, a study comparing different thermal cracking models by Raad et al. (48) indicated that TCMODEL showed very poor correlation with observed cracking in various test sites in Alaska. They proposed a model based on TSRST strength, fracture temperature, pavement age, minimum air temperature data and limited field data. Due to limited quantity of field data available to them, further validation of their model was not possible. They noted that addition of polymer modifiers to the binder improved the low-temperature cracking performance of the binder.

The TCMODEL model was calibrated with test data from field cores most of which were over 15 years old, whereas, most testing done involved testing of aged laboratory or plant mixture samples. TCMODEL estimates based on these samples would under-predict the amount of cracking (49). Buttlar et al. (50) developed an automated procedure called MASTER for determining the shift factors and verified its robustness by comparing the cracking predictions obtained by using manually-shifted shift factors. The researchers recommend that this proposed technique be incorporated into the revisions to the SUPERPAVE ${ }^{\mathrm{TM}}$ software. 
Christensen (47) modified the original analysis technique proposed by Hiltunen and Roque to make it more robust. He used non-linear least squares to fit a power law model to the compliance data. Validation of this model was done using test data from laboratory compacted specimens, which indicated that the predicted compliances fit the shifted data quite well as was evidenced by the low standard error values obtained, in spite of insufficient overlap in the compliance data.

Comparison of measured versus predicted thermal cracking was also performed by Epps (51), who compared the fracture temperatures predicted by BBR, IDT and TSRST tests for unmodified and modified crumb rubber mixtures. She observed that the fracture temperatures estimated from BBR testing agreed fairly well with those obtained from IDT testing in most of the mixtures tested, at the three different cooling rates studied. The fracture temperatures estimated from TSRST were higher in comparison with BBR and IDT test estimates. But TSRST could differentiate (was more sensitive to) between the different types of mixtures better than BBR and IDT tests. She noted that BBR testing alone could not capture the effect of binder modification at low temperatures and suggested accompanying the binder tests with mixture tests as well. These results could not be verified with field data due to lack of field distress surveys.

Bahia et al. (21) studied the influence of failure stress, failure strain, cooling rate and glass transition temperature on thermal cracking prediction models. They noted that using the failure strain criteria in predicting fracture temperature yielded temperatures that were about $15^{\circ} \mathrm{C}$ warmer and hence more conservative than those predicted by failure stress criteria. In some cases, the failure stress criteria gave unreasonably low fracture temperature estimates. The differences in $\alpha_{\text {mix }}$ and $\alpha_{b}$ values before and after $T_{g}$, resulted in differences in fracture temperature by as much as $5^{\circ} \mathrm{C}$ for a cooling rate of $1^{\circ} \mathrm{C} / \mathrm{hr}$.

\section{$\underline{2.7 \text { Mechanism of Rutting }}$}

Rutting is caused when pavement surfaces are subjected to repetitive wheel loads, which causes pavement consolidation or plastic flow. Rutting is a stress-controlled, 
repeated-loading phenomenon, resulting in densification of the pavement layers followed by accumulation of plastic deformation (shear failure) in one or more of the pavement structural layers. Rutting may occur due to any one or a combination of the following conditions: a) high or low air void content, b) excessive asphalt content, c) excessive fines d) high percentages of rounded aggregates (natural sands and bank-run gravel) e) weak subgrade, f) low binder stiffness, etc (52). A well-designed HMA should contain sufficient asphalt content to ensure durability without sacrificing shear resistance and to completely coat the aggregate particles. It should also have sufficient initial air voids to allow for densification in the field without causing bleeding or losing shear resistance. Rutting potential is largely influenced by aggregate properties and structure (43). Angular, rough-textured aggregates will develop an aggregate structure with high internal friction that will be more rut-resistant. Excessive fines and high asphalt contents may result in a tender mix, which will be more prone to rutting. Using a stiffer grade of asphalt may provide improved rut resistance, but it is not the primary controlling factor. Polymer-modified binders may reduce rutting; however, they are more expensive than conventional binders.

With the introduction of SUPERPAVE, the susceptibility of HMA to rutting and fatigue cracking can be evaluated using the Superpave Shear Tester (SST). Parameters obtained from SST tests are used to develop relationships between predicted rut depth and Equivalent Single Axle Loads ( $1 \mathrm{ESAL}=80 \mathrm{kN}=18 \mathrm{kip}$ ) and percent fatigue cracking and ESALs. The rut resistance of mixtures tested in repeated shear at constant height was found to improve at lower percent air voids with an optimum around 3\%. Studies reported by Sousa et al. (53) have shown that the critical percent air voids of the mixtures for rutting was between $2.5 \%$ and $4.0 \%$. A given mixture is deemed fit or unfit for given set of project-specific conditions under each distress category, based on owner-specified allowable distress levels. 


\section{$\underline{2.8 \text { Factors Affecting Rutting }}$}

The factors that influence the severity of rutting can be broadly classified into environmental and traffic conditions, binder and mixture properties, aggregate-related properties and other factors. High pavement temperatures and excessive loads cause rutting in poorlydesigned mixtures. Excessive asphalt content is the leading contributor of rutting in asphalt pavements (4). Rutting resulting from unstable mixtures can be identified by placing a straightedge across the pavement lane. If the straight-edge is elevated due to "heave" between wheel paths, it is a clear indication of a poorly designed mix. On the other hand, if the straight-edge is horizontal, it indicates consolidation of the base layers (52). Pavements typically undergo an additional $2 \%$ compaction due to traffic loads, regardless of initial compaction level after construction. This additional compaction is generally considered insignificant in comparison with the other causes $(4,52)$.

\subsubsection{Environmental and Traffic Conditions}

Since asphalt tends to have reduced viscosity at higher temperatures, asphalt mixtures tend to become soft when exposed to high temperatures, especially for prolonged periods of time. Under such conditions, pavements constructed with softer binders are more prone to rutting. Presence of moisture in the pavement was also found to aggravate the problem (54). While it is generally accepted that stability of aggregate skeleton in an asphalt mixture controls the rutting behavior, researchers (55) showed that the environment (range of maximum air and pavement temperatures) plays a more important role than aggregate gradation on rutting observed in the field.

\subsubsection{Binder and Mixture Properties}

In SUPERPAVE methodology, the binder grade specifies the range of temperatures within which a given binder can perform satisfactorily without exhibiting distress. Stiffer binders typically perform well at high temperatures. With respect to rut susceptibility, high 
binder stiffness is desirable as it allows the mixtures to withstand heavy loads and high temperatures without undergoing permanent deformation. Binders with low penetration and high viscosity values provide better resistance to rutting. Conventional binders can be modified to perform well at both high and low pavement temperatures.

Valkering et al. (56) studied the influence of modified binders on improving the rutting performance of mixtures by conducting creep-recovery tests and wheel-tracking tests in the laboratory. They found good correlation between rutting rate ( $\mathrm{mm}$ rut per wheel pass) and viscosity of the conventional binders at test temperature. They noted that the rheological behavior of modified binders was different from that of conventional binders and a simple creep test could not truly capture the influence of modifiers in the mixtures. Instead they proposed a creep and recovery test to assess the influence of the thermoplastic rubber modifier (SBS) on rutting performance. Addition of $3-7 \%$ polymers to the binders reduced the rut depth by as much as $60-70 \%$.

Rubber-modified asphalt mixtures were also observed to perform better than conventional mixtures, in a laboratory study conducted by Harvey and Monismith (57). In addition, mixtures with low air-void content, with low fines content and with angular, rougher aggregate were observed to perform better than mixtures with smooth, rounded aggregate, or with higher fines and higher air-void content. Asphalt mixtures become unstable when air-void content approaches or fall below 2 - 3\% (58). This stage is typically indicated by a change in the slope of the line (flattening) on a log permanent strain versus log load repetitions plot. Carpenter's field evaluation study (58) also showed that rutting observed at early age of the pavement was not a sufficient indicator of pavement performance at later age.

Little et al. (59) conducted uniaxial creep tests to study the influence of change in mixture properties on permanent deformation. Mixture air-void content, followed by aggregate type, was found to have the most significant influence on the permanent strain at the end of $1 \mathrm{~h}$ loading and on the slope of the steady-state creep curve. Under their test conditions, mixtures with creep moduli greater than $69 \mathrm{MPa}$ were considered rut resistant. 
Mohamed et al. (60) proposed the use of the parameter, $\mathrm{K}$, in identifying the rut susceptibility of HMA. The parameter, $\mathrm{K}$, defined as the rate of permanent strain accumulation in the secondary flow region, was found to be unique for each mixture tested at a given temperature under repeated load conditions. They found that specimen height had no influence on the value of $\mathrm{K}$, at the two test temperatures used in their study. Increase in compactive effort (number of gyrations) decreased the value of $\mathrm{K}$. The researchers further compared the effect of lab compaction versus field compaction procedures. Although both procedures gave similar $\mathrm{K}$ values at $25^{\circ} \mathrm{C}$ and $40^{\circ} \mathrm{C}$, there was noticeable deviation in tertiary flow behavior of the two mixes. Rut performance of laboratory compacted SGC samples was similar to that of field core samples.

The influence on air voids, aggregate type and gradation on rut potential was studied by Mallick et al. (61) using the dynamic creep testing. The loading conditions used by these researchers were designed to simulate normal truck tire pressures and aircraft tire pressure. Tests conducted on laboratory compacted samples at different percentage of air voids showed good correlation with rutting observed in the field. Pavement initially compacted to higher air voids (typically around 7\%) showed a decrease in air void content at the end of dynamic, confined creep testing, as is expected due to consolidation. On the other hand, pavement with low initial air void content (less than 3\%) showed an increase in air void content at the end of the test. This is due to lateral migration of material in the wheel paths (shoving action) and is typically observed in the field. Tests of field cores obtained outside the wheel path (shoulders) also exhibited similar behavior. As shown by earlier studies, these researchers also found that mixtures with natural sand and crushed gravel showed poor rut resistance in comparison with mixtures with crushed aggregate.

Kim et al. (62) studied the influence of aggregate type, gradation, asphalt content, air void content, temperature, stress level and interaction between these variables on permanent deformation using the uniaxial creep test. ANOVA tests conducted on main factors indicated that aggregate type and gradation had significant influence on rutting behavior. Interactions between these two main variables and the other variables were also studied, which 
indicated that interactions between aggregate type and gradation, aggregate type and asphalt type, aggregate type and air void content, and aggregate type and temperature were most significant. The researchers noted that low viscosity binders tend to produce larger deformation in the corresponding mixture samples.

Karakouzian et al. (63) studied rut depth data collected at four projects with similar traffic volume, subgrade properties and pavement structure around the state of Nevada. The main variables in these four projects were the type of binder and shape of the gradation curve (continuous coarse-graded to skip (gap) coarse-graded). From their study, they observed that mixtures showed higher rut resistance if the slope of the gradation curve between the No. 4 sieve $(4.75 \mathrm{~mm})$ sieve and the largest aggregate size was steeper than the maximum density line. They reasoned that if the slope was lower than the maximum density line, the aggregate particles larger than No.4 tended to float in the asphalt matrix and did not develop stone-to-stone contact, thereby lowering the rut resistance of those mixtures. They further noted that aggregate filler and binder do not add significantly to the load-bearing capacity of HMA.

Attempts were made by researchers (64) to correlate $\left|G^{*}\right| / \sin \delta$ parameter obtained from Dynamic Shear Rheometer (DSR) testing with rutting susceptibility of mixtures tested in the laboratory using Gyratory Testing Machine (GTM), as well as several wheel tracking devices, such as Hamburg Wheel-Tracking Device (HW), French Pavement Rutting Tester (LCPC) and Georgia Loaded-Wheel Tester (GLWT). Creep slope (number of wheel-passes required to create a $1-\mathrm{mm}$ rut depth) was used to assess rut susceptibility using $\mathrm{HW}$ device and slope of rut-depth versus number of cycles plotted on a log-log scale was used for LCPC. To study the influence of varying binder type on rutting performance, three conventional binders and two modified binders were used in different mixtures with the same aggregate type and gradation. In addition, two of the conventional binders were also used with a higher nominal maximum aggregate size (NMAS) to verify the effect of aggregate size on rut susceptibility. The researchers concluded that $\left|\mathrm{G}^{*}\right| / \sin \delta$ was a good indicator of rut susceptibility since mixtures prepared with low $\left|G^{*}\right| / \sin \delta$ binders showed poor resistance to rutting in all cases. Among the 
wheel-tracking devices used, HW test parameter showed good correlation with observed rut depth. Changing the NMAS was not observed to alter the rut susceptibility of the mixtures, nor did it lessen the influence of asphalt type on rutting performance.

Contrary to the findings of Stuart and Izzo, Leahy et al. $(65,66)$ found very poor correlation between binder $\left|\mathrm{G}^{*}\right| / \sin \delta$ values and rut depths (and rut rates) obtained from the wheel-tracking device. The researchers conducted repeated shear at constant height tests (RSCH) and wheel-tracking tests using a device developed at the University of Nottingham, in collaboration with SWK Pavement Engineering, Ltd. (SWK/UN) to study the influence of asphalt type, percent air voids, and aggregate type on the rutting performance. Large variability in wheeltracking test data was observed. When the influence of aggregate was reduced by reducing the inter-particle friction (e. g., at $7 \%$ air voids) along with higher test temperature $\left(70^{\circ} \mathrm{C}\right.$ ), the influence of binder was more apparent. $\mathrm{RSCH}$ testing showed that shear response was largely influenced by asphalt source, aggregate source, and air-void content. The researchers emphasized the importance of supplementing binder tests with performance tests on corresponding asphalt mixtures.

Sherwood et al. (67) also attempted to correlate $\left|\mathrm{G}^{*}\right| / \sin \delta$ (at $2.25 \mathrm{rad} / \mathrm{s}$ ) to the number of load passes required to cause $10 \%$ permanent deformation in mixtures tested at the FHWA's Accelerated Loading Facility (ALF). Eight lanes with five different binders and two gradations were constructed at the test facility to study the influence of changing binder grade and gradation on rutting and tested at different test temperatures depending on the binder grade used in the mixture. Results indicated a good correlation between the two parameters, which was sensitive to binder grade and aggregate gradation. Results also indicated that binders that did not meet the $2.2 \mathrm{kPa}$ specification requirement needed less number of passes to attain the $10 \%$ deformation limit.

However, researchers $\left(68\right.$ - 71) have reported that the DSR parameter, $\left|G^{*}\right| / \sin \delta$, did not truly capture the improved high temperature behavior of modified binders. Instead a creep and recovery test was recommended by them and a new parameter, $\left|G^{*}\right| /(1-1 / \tan \delta \sin \delta)$, 
was proposed by Shenoy (71). Shenoy showed that the information provided by this parameter was equivalent to the information obtained from a creep and recovery test.

In an attempt to evaluate the SUPERPAVE performance models, Zhang et al. (3) conducted performance tests, such as frequency sweep at constant height (FSCH), simple shear at constant height $(\mathrm{SSCH})$, etc., using the Superpave Shear Tester (SST) and determined the linear and non-linear elastic, visco-elastic and plastic properties of different mixtures. The mixtures used in their study were made with the same aggregate, gradation and asphalt content, but with different binder grades. The researchers found that $\mathrm{m}$, slope of log of dynamic shear modulus versus log of frequency used in the SUPERPAVE model, obtained for FSCH testing was temperature dependent and not a reliable indicator of rut susceptibility of the mixtures. Improper choice of temperatures could lead to errors in rut depth estimates. In addition, they also concluded that (a) the influence of binder on mixture performance above $50^{\circ} \mathrm{C}$ was insignificant in comparison with the influence of aggregate and (b) at low loading rates $(0.01 \mathrm{~Hz})$ and high temperatures, $\left|G^{*}\right|$ was not susceptible to binder grade and temperature. Rut depth predictions using the models gave unreasonable estimates due to errors in parameter m estimates.

Shatnawi and Lancaster (72) conducted repeated shear at constant height $(\mathrm{RSCH})$, repetitive direct tension tests and the LCPC wheel-tracking tests on mixtures with two gradations (Caltrans and SUPERPAVE) and binder grades, to evaluate the Level One SUPERPAVE mix design procedures. The criteria used to evaluate mixtures tested in LCPC were (a) the shape of the percent rut depth versus cycles on a log-log scale and (b) a rut depth less than $10 \%$ of slab thickness after 30000 cycles. Results from LCPC testing conducted at $55^{\circ} \mathrm{C}$ indicated that SUPERPAVE mixtures performed better than Caltrans mixtures. Results from $\mathrm{RSCH}$ testing were analyzed after converting permanent shear strain into rut depth and number of cycles into ESALs. All the four mixtures tested in $\mathrm{RSCH}$ showed good rut resistance in general, but Caltrans mix showed lower permanent deformation than the corresponding SUPERPAVE mix with the same binder. The researchers emphasized the importance of performance testing and mechanistic analysis, in addition to volumetric properties. Although all 
mixes passed the limits placed on rutting and fatigue, differences in gradation and percent air voids delineated their relative performance. The researchers concluded that a gradation passing through the restricted zone does not necessarily imply a tender mix and low resistance to rutting, as was shown by the generally better performance of Caltrans mix as opposed to SUPERPAVE mixes. Results from laboratory testing appeared to correspond with field performance of the same mixtures.

Romero and Mogawer (73) conducted FSCH, SSCH and RSCH tests using SST and wheel-tracking tests at the ALF to determine the sensitivity of the shear tester to changes in aggregate size (NMAS) in mixtures with the same binder. From SSCH tests, they used two parameters; shear modulus (ratio of applied stress to maximum strain) and percent recovered strain (ratio of recovered strain at the end of $10 \mathrm{~s}$ unloading to maximum strain); to relate to pavement performance. From $\mathrm{FSCH}$ test data, they used the $\left|\mathrm{G}^{*}\right|$ at $10 \mathrm{~Hz}$ and the slope for log $\left|G^{*}\right|$ versus log frequency to assess the rut resistance of the mixtures. A standard rutting model was fit to the $\mathrm{RSCH}$ data and the slope of the curve along with the maximum permanent strain were used to compare the performance of the mixtures with ALF test results. Inconsistent shear modulus and percent recovered strain results at the two test temperatures indicated that $\mathrm{SSCH}$ testing could not delineate mixtures with the same binder and different gradation. Moreover, the results did not correspond with ALF results, which was sensitive to such changes in mixtures. The slope of $\left|G^{*}\right|$ versus frequency was higher for the coarser mixtures only at one temperature and one binder. The results at other temperatures and for the other binder were inconclusive and inconsistent. The researchers found that the value of $\left|\mathrm{G}^{*}\right|$ at $10 \mathrm{~Hz}$ appeared to be the most sensitive to changes in binder grade and gradation. The variability in $\mathrm{RSCH}$ data was too high to allow for reasonable assessment of the rut performance of the mixtures. The researchers concluded that the SST could not be used to identify changes in NMAS of mixtures with the same binder grade and the results of the SST did not coincide with those of the ALF.

To study the sensitivity of SUPERPAVE mixes to changes in volumetric and mechanical properties, Anderson et al. (74) conducted $\mathrm{FSCH}, \mathrm{SSCH}$ and $\mathrm{RSCH}$ tests on 
mixtures with varying asphalt contents, gradations, and ratios of natural and crushed sands. The effect of these variables on volumetric properties of Superpave Gyratory Compactor (SGC) specimens was also studied. Results from $\mathrm{RSCH}$ test showed increasing permanent shear strain and its rate of accumulation with increasing asphalt content. SSCH tests indicated increasing values of maximum shear strain $\left(\gamma_{\max }\right)$ with increasing asphalt content. Values of complex shear modulus obtained from FSCH test were affected by changes in coarse gradation and asphalt content. Increasing asphalt content decreased the stiffness of the mix when tested at $26^{\circ} \mathrm{C}$ and $41^{\circ} \mathrm{C}$.

No relationship was found between rut rate results obtained from Asphalt Pavement Analyzer (APA) and rate of permanent strain obtained from $\mathrm{RSCH}$ testing, in a study conducted by Blankenship et al. (75) on five PG70-22 binders modified by different methods. The researchers justify this lack of correlation by stating that while the $\mathrm{RSCH}$ test was designed to simulate pavement loading, the APA was simply designed to give pass/fail criteria. However, the researchers found that the mixture rankings obtained from $\mathrm{RSCH}$ and $\mathrm{FSCH}$ tests were similar. They suggested using these tests for comparative ranking purposes in the absence of the completed SUPERPAVE models. Although the wheel tracking tests gave similar results, they were not quantifiable.

Poor correlation was seen between GLWT and LCPC test results and observed field performance in two test sites in a study conducted in North Carolina (76). Although the wheel-tracking tests indicated high rut susceptibility of one of the mixtures, no rutting was actually observed in the field. However, results from $\mathrm{RSCH}$ testing indicated a rut-resistant mixture. Mixture from the other section performed poorly in all the three (GLWT, LCPC and RSCH) tests. Field core samples obtained from the wheel path for these two sections indicated low percent air voids in the section that showed severe rutting. In addition, this section also had higher percentage of fines and filler content, which contributed to its high rut susceptibility. The researchers conducted limited repeated shear testing at higher frequency $(5 \mathrm{~Hz})$ than that recommended in AASHTO TP7 protocol $(1.43 \mathrm{~Hz})$ and concluded that both tests gave similar 
results, in general. The researchers further recommended running the RSCH test until 100000 cycles in order to capture tertiary flow.

The SUPERPAVE performance tests were originally intended to provide material properties that would be used input in the pavement performance model. However, due to many critical errors, the model either gave unreasonable distress estimates or in some cases, could not be executed. However, many researchers, as discussed above, have since been using the SUPERPAVE performance tests to evaluate the mechanical properties of mixtures to make relative comparisons about the quality of the mixtures being tested. In one such attempt, Anderson et al. (77) studied four typical mixtures from different states in the U. S. with different mix designs and binder grades. One of the mixtures was a Marshall mix, while the other three were SUPERPAVE mixtures. While the three SUPERPAVE mixtures showed a decrease in complex shear modulus, $\left|G^{*}\right|$, with increase in binder content, the Marshall mixture did not show any change. While this could be explained by the fact that it was designed for higher traffic volume, one of the SUPERPAVE mixtures was designed for similar traffic volume and with a stiffer binder grade showed the lowest $\left|G^{*}\right|$ among the four mixtures studied. The researchers also observed that laboratory prepared samples had higher complex shear modulus than field produced samples.

Wang et al. (78) used Superpave Shear Tester to run SUPERPAVE performance tests on a typical mixture used in Taiwan and two SUPERPAVE mixtures to assess their rutting susceptibility. They calculated parameters such as, initial shear strain rate, final slope and peak shear strain $\left(\gamma_{\max }\right)$ obtained from SSCH testing and predicted rut depth and ESALs from RSCH testing to assess the relative performance of these mixtures. They found that SUPERPAVE mixtures performed better than the typical Taiwan mixture and that these calculated parameters were sensitive to changes in mix design.

Kern and Carpenter (79) derived a simple relationship between rut depth obtained from GLWT at $40^{\circ} \mathrm{C}$ and the difference between performance grade temperature and the test temperature at which RTFO-aged binder satisfies the specification limit. They noted that 
the frequency of temperature distribution at a given test site determines the rutting performance of a mixture, rather than the 7-day mean high temperature used in SUPERPAVE binder selection. Identical mixtures placed in cities with similar traffic conditions and similar 7-day mean high temperature would show different permanent deformation, which would depend on the frequency distribution of high temperature at the site.

Performance of four SUPERPAVE mixtures in SST testing was evaluated by comparing with the field performance of the same mixtures at the end of seven years in service (80). Although some amount of rutting was observed in the field, it was considered minimal. $\mathrm{FSCH}$ and $\mathrm{SSCH}$ tests were conducted at $\mathrm{T}_{\text {eff(FC) }}$ and $\mathrm{T}_{\text {eff(}(\mathrm{PD})}$ on laboratory samples made from original mix collected at the time of construction. Strong correlations were found between $\gamma_{\max }$ and rut depth, $\gamma_{\max }$ and rut rate, and elastic recovery and rut rate at $\mathrm{T}_{\text {eff(PD) }}$. Mixture that exhibited the highest $\gamma_{\max }$ also had the lowest stiffness in $\mathrm{FSCH}$ testing, as expected. A plot of $\log \left|\mathrm{G}^{*}\right|$ and rut depth also showed a high degree of correlation. The researchers concluded that behavior of the mixtures in $\mathrm{FSCH}$ and $\mathrm{SSCH}$ testing corresponds with that observed in the field. The amount of fatigue and low temperature cracking could not be quantified, as these pavements were HMA overlays over existing concrete pavements that were not prepared by crack-and-seat operation prior to placement of the overlay.

Viscosity of the binder used in the mixture was commonly considered a strong indicator of rut resistance of the mixture. The absolute viscosity of conventional (neat, unmodified) binders at $60^{\circ} \mathrm{C}$ was found to be strongly related to a rut parameter determined in the laboratory at $45^{\circ} \mathrm{C}, \mathrm{N}_{10}$ (number of wheel passes required to cause a $10 \mathrm{~mm}$ rut). Since zeroshear viscosity (ZSV) was thought to be a true material property and independent of test conditions, Sybilski (81) attempted to correlate ZSV with permanent deformation. He found that zero-shear viscosity of modified and unmodified binders at $60^{\circ} \mathrm{C}$ was directly proportional to $\mathrm{N}_{10}$. 


\subsubsection{Aggregate-related Factors}

Effect of aggregate gradation on rutting performance was studied by Matthews and Monismith (55), who concluded that medium-graded mixtures perform better than coarse graded mixtures. For dense-graded asphalt mixtures, good grain-to-grain contact between the aggregate particles is responsible for providing shear resistance, which in turn lowers the permanent deformation in the mixtures. However, the presence of high percentage of fines reduces the contact between aggregate particles and increases the rut susceptibility of the mixture. Due to the absence of aggregate interlocking in porous mixtures, the binder provides the shear resistance in such mixtures (57).

During the early periods of SUPERPAVE implementation, it was suggested that the gradation curve should either pass above of below the restricted zone to avoid tender mixes that are prone to rutting. However, a synopsis of studies conducted by various researchers written by Hand and Epps (83) with gradations passing through, above and below the RZ indicates that the RZ did not influence the rutting or fatigue performance of the SUPERPAVE mixtures. Similar results were also found by Chowdhury et al. (84) who conducted shear tests (SST) and wheel-tracking tests using the APA on 12 mixtures (3 gradations with four aggregate type each).

\subsubsection{Other Factors}

Type of compactor used to produce samples for permanent shear deformation tests has a strong influence on the test results. Gyratory compacted samples have the least rut resistance, while kneading compacted samples have the highest rut resistance (57). Linear, rolling compactors produce stiffer mixtures at optimum binder viscosity and with lower fines. On the other hand, kneading compactors produce stiffer mixtures at higher viscosity and normal

amount of fines. At low air-void content, kneading compacted specimens perform poorly due to crushing of aggregate during the compaction process. 
The influence of sample size, sample aging, sample preparation, and sample compaction technique (SGC versus field) on rutting was studied by Harvey et al. (82). No clearcut results were obtained regarding the influence of specimen size or shape on permanent strain from the RSCH test. Laboratory samples prepared by reheating field mix samples were found to be stiffer and hence more rut resistant the field core samples. They found higher variability in rut resistance of samples compacted in the laboratory, rather than in the field core samples taken six months after construction. They suggested limiting the percent air voids in the laboratory prepared samples to help in lowering the observed variability. This was also recommended by other researchers (85), who suggested increasing the number of replicates to five and using a trimmed-mean procedure for analyzing the data.

\subsection{Test Methods Used to Quantify Rutting Potential}

In the SUPERPAVE system, the test used to assess the rutting potential of binders is the Dynamic Shear Rheometer (DSR). Binder tests are also accompanied by some mixture testing using the Superpave Shear Tester (SST). Mixture tests typically conducted are Frequency Sweep at Constant Height (FSCH), Simple Shear at Constant Height (SSCH) and Repeated Shear at Constant Height (RSCH). In addition, some optional testing using wheeltracking devices are preferred by some researchers who have reported good predictions in some cases and not in others. Only the SUPERPAVE test methods are briefly outlined below.

In the DSR test, a binder sample (25 mm dia. $x 1 \mathrm{~mm}$ thick) is subjected to a prescribed oscillatory motion (10 rad/s) between two parallel plates (AASHTO TP5 (86)). This test is typically conducted at high temperatures $\left(>52^{\circ} \mathrm{C}\right)$ on original binder and RTFO-aged binder samples in stress-controlled or strain-controlled mode. The applied stress and the lag in observed strain are recorded and used to determine the complex shear modulus $\left(\left|\mathrm{G}^{*}\right|\right)$ and phase angle $(\delta)$ of the binders. The $\left|G^{*}\right|$ and $\delta$ values represent the stiffness and the measure of the elastic (or viscous) behavior of the binder at the test temperature. Higher $\left|G^{*}\right|$ indicates higher stiffness and a better ability to resist permanent deformation. Higher $\delta$ indicates a larger lag 
between applied stress and observed strain and more viscous behavior. A lower value of $\delta$ is preferred as this indicates better resilience. A limiting value of $\left|\mathrm{G}^{*}\right| / \sin \delta=1.0 \mathrm{kPa}$ for unaged binders and $2.2 \mathrm{kPa}$ for RTFO-aged binders is required at the minimum passing grade of the binder.

In the FSCH test, a mixture sample (150 mm dia. x $50 \mathrm{~mm}$ thick) compacted to the desired percent air voids (typically $7 \% \pm 0.5$ ) is subjected to dynamic shear loading by applying a repeated sinusoidal shear strain of $\pm 0.005 \%$ ( 0.0001 peak-to-peak amplitude) and the complex shear modulus $\left(\left|G^{*}\right|\right)$ and phase angle $(\delta)$ of the mixture are determined. Since the mixture exhibits a tendency to dilate under shear load, the axial stress is adjusted to maintain a constant sample height. This test is conducted at 10 different frequencies $(10,5,2,1,0.5,0.2$, $0.1,0.05,0.02$ and $0.01 \mathrm{~Hz}$ ) with a set number of cycles at each frequency. The typical test temperatures are $20^{\circ} \mathrm{C}$ and $40^{\circ} \mathrm{C}$, however the test may also be conducted at $T_{\text {eff(PD) }}$ and $T_{\text {eff( }(F C)}$ or at any other test temperature of choice. The $\left|\mathrm{G}^{\star}\right|$ value at $10 \mathrm{~Hz}$ is typically used to make comparison between mixtures. As in the case of DSR testing, higher $\left|G^{*}\right|$ and lower $\delta$ are preferred for improved rut resistance.

The SSCH test is typically conducted on same sample after the completion of $\mathrm{FSCH}$ testing at the same test temperature. The $\mathrm{SSCH}$ test is a static shear test, in which a constant shear load is applied at the rate of $70 \mathrm{kPa} / \mathrm{s}$ until a maximum of $105 \mathrm{kPa}$ at $20^{\circ} \mathrm{C}$ or 35 $\mathrm{kPa}$ at $40^{\circ} \mathrm{C}$ is reached. The load is held constant for $10 \mathrm{~s}$ and then decreased at the rate of 25 $\mathrm{kPa} / \mathrm{s}$ and held at $0 \mathrm{kPa} / \mathrm{s}$ for an additional $10 \mathrm{~s}$. The corresponding shear deformation during the entire duration of test is recorded. The maximum shear strain $\left(\gamma_{\max }\right)$ and the ratio of recovered strain to $\gamma_{\max }$ are used to assess the rut resistance of the mixture. A low $\gamma_{\max }$ is desired as this indicates a stiffer mixture (less susceptible to permanent deformation). The ratio of recovered strain to $\gamma_{\max }$ gives a measure of the resiliency or elasticity of the mixture. Evidently, a high resilience value is desired.

The RSCH test is an optional AASHTO test procedure that has gained favor among researchers. It is typically conducted on $150 \mathrm{~mm} \times 50 \mathrm{~mm}$ samples compacted to $3 \pm$ 
$0.5 \%$ air voids. However, samples compacted to field air voids or field core samples may also be tested in $\mathrm{RSCH}$. It is a repeated load test in which a shear stress amplitude of $68 \pm 5 \mathrm{kPa}$ is applied for $0.1 \mathrm{~s}$ followed by a rest period of $0.6 \mathrm{~s}$ to allow the sample to recover. This test is run until 5000 cycles or until $5 \%$ is reached. The test may be conducted at $58^{\circ} \mathrm{C}$ or at the maximum 7-day pavement temperature occurring at the test site of interest. As in the case of FSCH and $\mathrm{SSCH}$ tests, the axial load is adjusted to maintain constant sample height. The accumulated permanent strain $\left(\gamma_{\text {perm }}\right)$ is recorded during the test. A lower permanent strain indicates rut resistant mixtures. The slope of plot of log $\gamma_{\text {perm }}$ versus log load cycles is used to assess the quality of mixtures.

\subsection{Models Used to Predict Permanent Deformation}

The models used to predict permanent deformation were developed as a part of the SUPERPAVE performance prediction program $(87,88)$. These models relate the permanent strain accumulated to the number of load applications on a log-log scale. Permanent strain data from $\mathrm{RSCH}$ testing is converted into rut depth $(\mathrm{mm})$ and the number of load cycles is converted into ESALs. These equations are represented below:

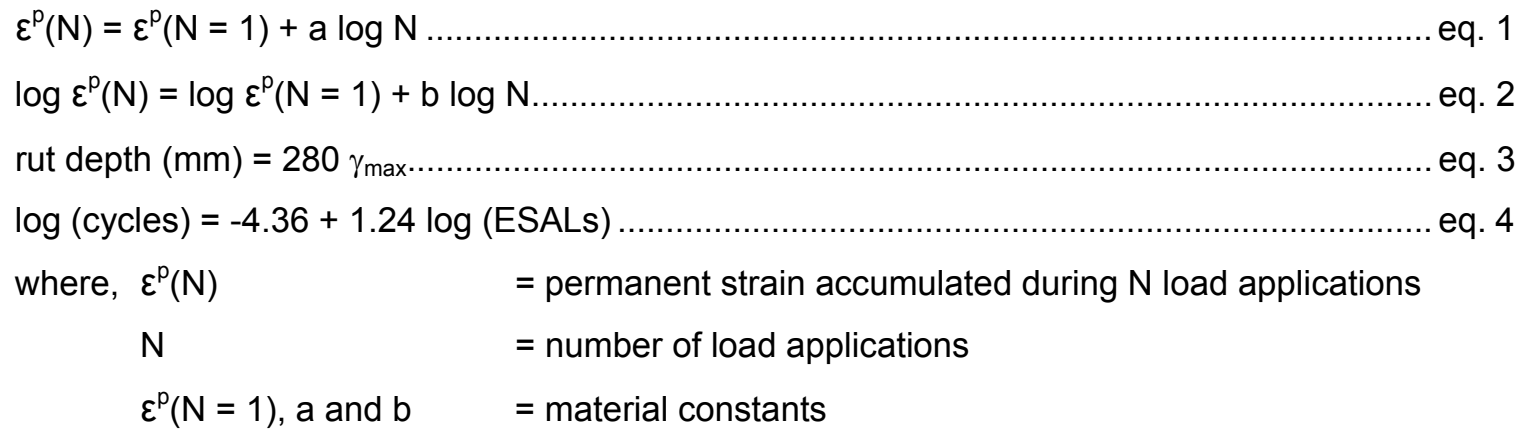

As discussed in the earlier section, many researchers have used these models to correlate results from RSCH data to results from wheel-tracking tests with limited success. Very few attempts have been made to correlate field performance with rut depth predictions using these equations. 
In addition to the SUPERPAVE models, Asphalt Institute (89) proposed the following relationship to define the failure criterion for permanent deformation.

$\mathrm{N}_{\mathrm{d}}=1.365 \times 10^{-9}\left(\varepsilon_{\mathrm{c}}\right)^{-4.477}$ eq. 5

where, $N_{d}=$ allowable number of load applications to reach permanent deformation

$\varepsilon_{\mathrm{c}}=$ compressive strain at the top of subgrade

Results from the Al model along with pavement structure data, weather data, traffic conditions and creep compliance data can be used as input in the KENLAYER program to get pavement performance analysis. This approach, however, is not sensitive to changes in mixtures composition and hence cannot distinguish the performance of different mixtures (89).

Numerous other researchers have attempted to formulate models based on laboratory repeated-load testing and wheel-tracking tests with varying degrees of success. Efforts are still on-going to develop a comprehensive pavement performance prediction model that would enable the prediction of observed distress, such as permanent deformation, fatigue cracking and low temperature cracking, as a function a time. It is expected that the new model will be released in a couple of years (90).

\subsection{Temperature Prediction Models}

The binder selection program introduced in the SUPERPAVE design methodology required an estimate of the average air and pavement temperature occurring at the test site under consideration. For this purpose, data from 6,500 weather stations located in the United States and Canada were used to develop algorithms, for predicting the design minimum and maximum pavement temperature based air temperature, solar radiation, latitude, etc, using theoretical energy balance principles. Weather stations with less than 20 years of data were not used in developing these algorithms.

The concept of single-event cracking was used by SHRP researchers to define the design minimum pavement temperature. Thermal cracking in HMA pavements is initiated when pavement temperature falls below the critical or fracture temperature of the pavement (8). Therefore, the SHRP researchers initially took a conservative approach and recommended the 
use of minimum air temperature as the design minimum pavement temperature at the surface (eq. 6). The minimum air temperature, $T_{\text {air(min) }}$, at a location was defined as the average of the yearly minimum temperature that occurred at the site. The standard deviation of the minimum air temperature was found to be around $5^{\circ} \mathrm{C}$.

$\mathrm{T}_{\mathrm{s}(\min )}=\mathrm{T}_{\text {air(min })}$ eq. 6

To determine the minimum pavement temperature at different depths in the pavement, the following equation was recommended.

$T_{d(\min )}=T_{s(}(\min )+0.051 d-0.000063 d^{2}$ eq. 7

This approach was found to be a very conservative, especially in Canada, where Canadian SHRP researchers $(91-93)$ found that the minimum pavement temperature was always warmer than minimum air temperature. They observed that the air temperature was the most significant factor influencing minimum pavement temperature, while sunlight (solar radiation) had only a small, insignificant effect. They recommended the C-SHRP model (eq. 8) for predicting the minimum pavement temperature at the surface, with built-in factor for different reliability levels (n). Equation 9 may be used to calculate the minimum pavement temperature at any depth below the surface with $50 \%$ reliability.

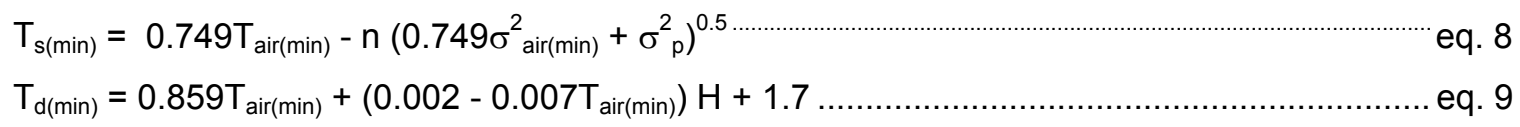

where, $\mathrm{T}_{\mathrm{s}(\min )}=$ minimum pavement temperature at the surface, ${ }^{\circ} \mathrm{C}$

$\mathrm{T}_{\mathrm{d}(\min )}=$ minimum pavement temperature at any depth, ${ }^{\circ} \mathrm{C}$

$T_{\text {air(min) }}=$ mean low air temperature, ${ }^{\circ} \mathrm{C}$

$\mathrm{H} \quad$ = depth from surface, $\mathrm{mm}$

$\sigma_{\text {air(min) }}=$ standard deviation of minimum air temperature

$\sigma_{\mathrm{p}} \quad=$ standard error of pavement temperature estimate

The maximum pavement temperature algorithm was developed by heat transfer modelling, by taking into consideration factors such as air temperature, solar radiation, thermal conductivity, pavement surface emissivity, etc. Rutting, the most commonly observed hightemperature pavement distress mechanism, was observed to occur in pavements when exposed to prolonged high temperature spells. In addition, it is also observed that maximum stresses 
occurred at a depth of $20 \mathrm{~mm}$ below the surface. Therefore, the design air temperature was calculated by taking a running average of the 7-day maximum air temperatures for a whole year, at a depth of $20 \mathrm{~mm}$. Next, the highest of the 7-day average each year was taken and the mean value was calculated for a given number of years. This was defined at the design maximum air temperature, $T_{\text {air(max) }}$. The design air temperature and solar radiation were found to be the most significant factors influencing the maximum temperature. Equation 10 was recommended by SHRP researchers to estimate the 7-day maximum pavement temperature (1).

$\mathrm{T}_{\mathrm{s}(\max )}=\mathrm{T}_{\text {air }(\max )}-0.00618 \phi^{2}+0.2289 \phi+24.4$

The effect of solar radiation on maximum pavement temperature was introduced in the model in terms of latitude of the test site, $\phi$ degrees. This equation represents a simplified form of the original model made with the following assumptions:

$$
\begin{array}{ll}
\text { radiation transmissivity coefficient, } \tau & =0.81 \text { (assumes clear, sunny day) } \\
\text { pavement surface absorptivity, } \alpha & =0.9 \\
\text { pavement surface emissivity, } \varepsilon & =0.9 \\
\text { surface heat transfer coefficient, } \mathrm{h}_{\mathrm{c}} & =19.88 \mathrm{~W} / \mathrm{m}^{2}{ }^{\circ} \mathrm{C} \\
\text { thermal conductivity coefficient, } \mathrm{k} & =1.38 \mathrm{~W} / \mathrm{m}^{\circ} \mathrm{C}
\end{array}
$$

SHRP researchers recommended the following equation to determine the maximum pavement temperature at any depth, $\mathrm{d} \mathrm{mm}$.

$T_{d(\max )}=\left[T_{\text {air }(\max )}+17.8\right]\left[1-2.48 \times 10^{-3} d+1.085 \times 10^{-5} d^{2}-2.441 \times 10^{-8} d^{3}\right]-17.8$ eq. 11

The SHRP pavement temperature prediction models initially introduced with the introduction of SUPERPAVE Binder Selection Program were theoretical models. This was due to lack of, and in some cases, almost minimal amount of pavement temperature data available to the researchers at that time. To further evaluate and refine the SHRP temperature algorithms, the Seasonal Monitoring Program (SMP) was initiated under the Long Term Pavement Performance (LTPP) program. Under this program, 30 sites throughout North America were instrumented to record climatic factors and pavement temperatures at different depths. One of the main objectives of this program was to provide field validation for models that relate the environmental conditions to the properties of the pavement at the test site. This project was 
completed in 1995 and led to the development of LTPP-SMP algorithms (94 - 96), which have since replaced the original SHRP models in the Binder Selection Program. These low and high pavement temperature models for any depth, $d$, are shown in equations 12 and 13, respectively.

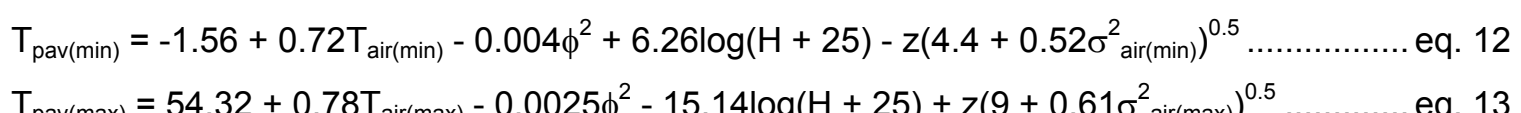

where, $\mathrm{T}_{\text {pav(min) }}=$ Minimum HMA pavement temperature, ${ }^{\circ} \mathrm{C}$

$\mathrm{T}_{\text {pav(max) }}=$ Maximum HMA pavement temperature, ${ }^{\circ} \mathrm{C}$

$\sigma_{\text {air(min) }}^{2}=$ Standard deviation of the mean low temperature, ${ }^{\circ} \mathrm{C}$

$\sigma_{\text {air(max })}^{2}=$ Standard deviation of the mean 7-day average high temperature, ${ }^{\circ} \mathrm{C}$

$z=2.055$ for $98 \%$ reliability, from the standard normal distribution table

All other terms are as defined earlier.

Equation 12 used in the determination of $\mathrm{T}_{\text {pav(min) }}$ has an $\mathrm{r}$-squared value of $96 \%$ and a standard error of estimate (SE) of 2.1, for 411 data points (N). Equation 13 used in the determination of $\mathrm{T}_{\operatorname{pav}(\max )}$ has r-squared value, $\mathrm{SE}$ and $\mathrm{N}$ of $76 \%, 3.0$ and 309 , respectively.

Comparison of SHRP and C-SHRP low temperature model predictions with the LTPP model predictions indicated that SHRP estimates were overly conservative (by as much as $\left.15^{\circ} \mathrm{C}\right)$. C-SHRP estimates were close to LTPP model only at higher latitudes $\left(50^{\circ}\right)$. This was to be expected as most of the data used in developing the C-SHRP model came from weather stations located at those latitudes. At latitudes below $50^{\circ}$, the difference between the improved model estimates and C-SHRP estimates were about $10^{\circ} \mathrm{C}$. As most of the United States is below the 50-degree latitude, the LTPP model was adopted into the United States and incorporated into the revised Binder Selection Program (LTPPBind).

The high pavement temperature estimates using the SHRP model were comparable with LTPP model estimates at air temperatures less than $25^{\circ} \mathrm{C}$. But at higher air temperatures, the difference observed was as much as $5^{\circ} \mathrm{C}$, which is almost one temperature grade higher.

Prior to the introduction of the SHRP models, Solaimanian and Kennedy (97) developed a model using the method of energy balance at the pavement surface for calculating maximum pavement temperature from maximum air temperature and solar radiation. They 
assumed the same values of absorptivity $(\alpha)$, emissivity $(\varepsilon)$, thermal conductivity $(k)$ and transmission coefficient $(\tau)$ mentioned earlier in the LTPP models. However, the value of surface heat transfer coefficient $\left(h_{c}\right)$ assumed by them was much lower $\left(3.5 \mathrm{~W} / \mathrm{m}^{2}{ }^{\circ} \mathrm{C}\right)$ then that used in the simplified LTPP model $\left(19.88 \mathrm{~W} / \mathrm{m}^{2}{ }^{\circ} \mathrm{C}\right)$. They observed good correlation $\left(2.8^{\circ}\right.$ to $3.4^{\circ} \mathrm{C}$ difference) between predicted and observed high temperature in the pavement up to a depth of $20 \mathrm{~cm}$. Sensitivity analysis indicated that change in $\alpha$ value by 0.1 changed the predicted temperature by about $7^{\circ} \mathrm{F}$, and an increase in $\varepsilon$ by 0.1 increased the predicted temperature by $5^{\circ} \mathrm{F}$. For the minimum pavement temperature, however, they recommended the use of minimum air temperature as the minimum pavement temperature, since they observed that maximum difference between the two was about $1^{\circ}-2^{\circ} \mathrm{C}$.

Given the relatively moderate r-squared value of $76 \%$ for the LTPP hightemperature model and the increasing costs of modified binders, researchers in other states have attempted to correlate the air and pavement temperature occurring locally within their states or districts.

Bosscher et al. (98) instrumented a test section in Trempealeau County, Wisconsin and used the data collected for 22 months to develop a statistical model for the estimation of high and low pavement temperature based on weather data. Their model estimates showed good correlation with the LTPP low temperature model estimates, but not with the high temperature model. They found that the LTPP and the SHRP models underestimated pavement temperatures when the air temperature was above $30^{\circ} \mathrm{C}$. In addition, they found that the assumption of equal standard deviation value for both air and pavement temperature made in LTPPBind software was not valid. At high temperatures, the standard deviation of pavement temperature was much greater than that of air temperature. The reverse was observed to be true at low temperatures. They further stressed the importance of daily peak solar radiation and the daily total solar radiation in estimation of maximum air temperatures. Their high temperature model, which incorporated these two terms, had an r-squared value of $92 \%$. 
Lukaken et al. (99) independently developed a pavement temperature prediction model using data available from the Seasonal Monitoring Program (SMP) sites. Their models gave results comparable with the results predicted by the FHWA team models (LTPP-SMP). The model r-squared values were also similar to those obtained by FHWA team. The authors found that latitude and depth played the most significant role in pavement high temperature prediction. On the other hand, minimum pavement temperature was most affected by the air temperature.

Bartha (100) investigated the fluctuations in temperature gradient in the surface layer of an asphalt pavement in Hungary. He observed that the highest heating and cooling rates during the summer months occurred between 8:00 a. m. to noon and 4:00 p. m. to 8:00 p. m., respectively. A heating rate of 4 to $5^{\circ} \mathrm{C} / \mathrm{hr}$ and a cooling rate of -3 to $-4^{\circ} \mathrm{C} / \mathrm{hr}$ were found to occur most frequently in the surface layer. This agrees closely with cooling rate of the pavement $\left(10^{\circ} \mathrm{F} / \mathrm{hr}\right)$ selected by Christensen in his IDT creep compliance data analysis.

Wahhab and Balghunaim (101) investigated the influence of air temperature on HMA pavement temperature in inland and coastal HMA pavements in the arid climate of Saudi Arabia. In the inland pavements, the maximum air and pavement temperature occurred in July, whereas in the coastal pavements the maximum temperature occurred in August. The maximum pavement temperature was observed to occur at a depth of $2 \mathrm{~cm}$ into the pavement, but not the pavement surface. Thinner slabs experienced higher temperatures than thicker slabs. The difference between maximum air and pavement temperatures in the inland and coastal pavements was about $16^{\circ} \mathrm{C}$ and $10^{\circ} \mathrm{C}$, respectively. The minimum temperature occurred in January, in both the coastal and the inland pavements. 
REFERENCES 


\section{REFERENCES}

1 T. W. Kennedy, G. A. Huber, E. T. Harrigan, R. J. Cominsky, C. S. Hughes, H. von Quintus and J. S. Moulthrop, "Superior Performing Asphalt Pavements (Superpave): The Product of the SHRP Asphalt Research Program", SHRP-A-410, Strategic Highway Research Program, National Research Council, 156 p., 1994.

2 "Engineering Principles of Mix Analysis", in Superpave Asphalt Mixture Analysis--Course Text, Asphalt Institute Research Center, Lexington, KY, May 1996.

3 X. Zhang, A. J. Kriech and G. A. Huber, "Critical Evaluation of the Superpave Performance Prediction Model for Permanent Deformation and Supporting Theory", in Progress of Superpave (Superior Performing Asphalt Pavement): Evaluation and Implementation, ASTM STP 1322, Editor R. N. Jester, American Society for Testing and Materials, pp. 169 - 185, 1997.

4 F. L. Robert, P. S. Kandhal, E. R. Brown, D. Lee and T. W. Kennedy, "HMA materials, mixture design and construction", $2^{\text {nd }}$ edition, 1996, pp. $494-510$.

5 D. R. Hiltunen and R. Roque, "A Mechanistic-Based Prediction Model for Thermal Cracking of Asphaltic Concrete Pavements", in Association of Asphalt Paving Technologists, Vol. 63, 1994, pp. 81 - 117.

6 T. S. Vinson, R. G. Hicks and V. C. Janoo, "Low Temperature Cracking and Rutting in Asphalt Concrete Pavements", in Roads and Airfields in Cold Regions, Technical Council on Cold Regions Engineering Monograph, ASCE, 1996, pp. 203 - 248.

7 R. C. G. Haas, F. Meyer, G. Assaf and H. Lee, "A Comprehensive Study of Cold Climate Airport Pavement Cracking", in Journal of Association of Asphalt Paving Technologists, Vol. 56, pp. 198 - 245, 1987.

8 D. A. Anderson and T. W. Kennedy, "Development of SHRP Binder Specifications", in Journal of Association of Asphalt Paving Technologists, Vol. 62, pp. 481 - 507, 1993.

9 T. Sugawara and A. Moriyoshi, "Thermal Fracture of Bituminous Mixture", in Proceedings of Canada-Japan Paving in Cold Areas, Mini-Workshop, pp. 291 - 320, 1994.

10 R. Fortier and T. S. Vinson, "Low-Temperature Cracking and Aging Performance of Modified Asphalt Concrete Specimens", in Transportation Research Record, No. 1630, pp. 77 - 86, 1998.

11 D. S. Decker and J. L. Goodrich, "Asphalt Cement Properties Related to Pavement Performance", in Journal of Association of Asphalt Paving Technologists, Vol. 58, pp. 503 - 518, 1989. 

Superpave Performance-Graded Asphalt Binders", in Transportation Research Record, Vol. 1661, pp. 75 - 82, 1999.

13 T. R. J. Faab, "The Influence of Mix Composition, Binder Properties and Cooling Rate on Asphalt (Concrete) Cracking at Low Temperatures", in Journal of Association of Asphalt Paving Technologists, Vol. 43, pp.xxxxx, 1974.

14 R. C. G. Haas and W. A. Phang, "Relationship Between Mix Characteristics and LowTemperature Pavement Cracking", in Journal of Association of Asphalt Paving Technologists, Vol. 57, pp. 290 - 303, 1988.

15 D. A. Anderson, D. Maurer, T. Ramirez, D. W. Christensen, M. O. Marasteanu and Y. Mehta, "Field Performance of Modified Asphalt Binders Evaluated with Superpave Test Methods--I-80 Test Project", in Transportation Research Record, Vol. 1661, pp. 60 - 68, 1999.

16 R. M. Anderson, D. E. Walker and P. A. Turner, "Low Temperature Evaluation of Kentucky PG70-22 Asphalt Binders", in Transportation Research Record, No. 1661, pp. 69 - 74, 1999.

17 T. Hoare and S. A. M. Hesp, "Low-Temperature Fracture Testing of Asphalt Binders", in Transportation Research Record, Vol. 1728, pp. 36 - 42, 2000.

18 D. A. Anderson, L. Lapalu, M. O. Marasteanu, Y. M. Le Hir, J-P. Planche and D. Martin, "Low-Temperature Thermal Cracking of Asphalt Binders as Ranked by Strength and Fracture Properties", in Transportation Research Record, Vol. 1766, pp. 1 - 6, 2001.

19 R. J. Schmidt and L. E. Santucci, "A Practical Method for Determining the Glass Transition Temperature of Asphalts and Calculation of their Low Temperature Viscosities", in Journal of Association of Asphalt Paving Technologists, Vol. 35, pp. 61 - xx, 1967.

20 H. Zeng and T. S. Vinson, 1995.

21 H. U. Bahia, M. Zeng and K. Nam, "Consideration of Strain at Failure and Strength in Prediction of Pavement Thermal Cracking", in Journal of Association of Asphalt Paving Technologists, Vol. 69, pp. 497 - 534, 2000.

22 R. Dongré, M. G. Bouldin and D. A. Maurer, "Field Validation of New Superpave LowTemperature Binder Specification Procedure", in Transportation Research Record, Vol. 1728 , pp. $60-67,2000$.

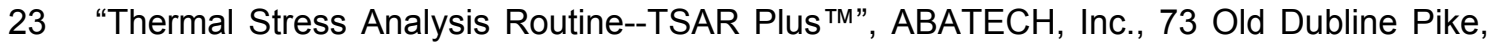
\#312, Doylestown, PA 18901, e-mail: info@abatech.com.

24 R. B. Leahy, C. L. Monismith and J. R. Lundy, "Performance-Based Properties of Asphalt Concrete Mixes", in Engineering Properties of Asphalt Mixtures and the Relationship to Their Performance, ASTM STP 1265, G. A. Huber and D. S. Decker (Eds.), pp. 37 - 53, 1995.

25 D. H. Jung and T. S. Vinson, "Low-Temperature Cracking: Binder Validation", Report No. SHRP-A-399, Strategic Highway Research Program, National Research Council, Washington D.C., 106 p., 1994. 
26 H. M. El Hussein and A. O. A. El Halim, "Differential Thermal Expansion and Contraction: A Mechanistic Approach to Adhesion in Asphalt Concrete", in Canadian Journal of Civil Engineering, Vol. 20, pp. 366 - 373, 1993.

27 R. Roque and B. E. Ruth, "Mechanisms and Modeling of Surface Cracking in Asphalt Pavements", in Journal of Association of Asphalt Paving Technologists, Vol. 59, pp. 396 421, 1990.

28 D. Jung and T. S. Vinson, "Thermal Stress Restrained Specimen Test to Evaluate LowTemperature Cracking of Asphalt-Aggregate Mixtures", in Transportation Research Record, No. 1417, pp. 12 - 20, 1996.

29 L. N. Mohammad and H. R Paul, "Evaluation of Indirect Tensile Test for Determining Structural Properties of Asphalt Mix", in Transportation Research Record, No. 1417, pp. 58 - 63, 1993.

30 W. Heukelom, "Observations of Rheology and Fracture of Bitumens and Asphalt Mixes", in Journal of Association of Asphalt Paving Technologists, Vol. 35, pp. 258 - 399, 1966.

31 R. Dongre, "Development of Direct Tension Test Method to Characterize Failure Properties of Asphalt Cements", Ph. D. Thesis, Pennsylvania State University, 1994.

32 D. A. Anderson, D. W. Christensen, H. U. Bahia, R. Dongré, M. G. Sharma, C. E. Antle and J. Button, "Binder Characterization and Evaluation, Volume 3, Physical Characterization”, SHRP-A-369, Strategic Highway Research Program, National Research Council, Washington D. C.

33 W. G. Buttlar and R. Roque, "Development and Evaluation of the Strategic Highway Research Program Measurement and Analysis System for Indirect Tensile Testing at Low Temperatures", in Transportation Research Record, No. 1454, pp. 163 - 171, 1994.

34 R. W. May and B. M. Killingsworth, "Superpave Performance Prediction - A First Look at Utility, Sensitivity and Repeatability", in Journal of Association of Asphalt Paving Technologists, Vol. 64, pp. 669 - 717, 1996.

35 D. A. Anderson and M. O. Marasteanu, "Physical Hardening of Asphalt Binders Relative to Their Glass Transition Temperatures", in Transportation Research Record, Vol. 1661, pp. 27 - 34, 1999.

36 AASHTO TP1-93 (now AASHTO T313-02), "Standard Test Method for Determining the Flexural Creep Stiffness of Asphalt Binder Using the Bending Beam Rheometer (BBR)", American Association of State Highway and Transportation Officials (AASHTO) Provisional Standards, $3^{\text {rd }}$ edition, June, 1996.

37 AASHTO TP3-93 (now AASHTO T314-02), "Standard Test Method for Determining the Fracture Properties of Asphalt Binder in Direct Tension (DT)", American Association of State Highway and Transportation Officials (AASHTO) Provisional Standards, $3^{\text {rd }}$ edition, June, 1996.

38 AASHTO PP42-01, "Standard Practice for Determining of Low-Temperature Performance Grade (PG) of Asphalt Binders", American Association of State Highway and Transportation Officials (AASHTO) Provisional Standards, Interim edition, April, 2001. 
39 G. M. Rowe, M. J. Sharrock, M. G. Bouldin and R. N. Dongré, "Advanced Techniques to Develop Asphalt Master Curves from the Bending Beam Rheometer", in proceedings of the $39^{\text {th }}$ International Petroleum Conference, Bratislava, September 20 - 23, 1999.

40 M. O. Marasteanu and D. A. Anderson, "Improved Model for Bitumen Rheological Characterization", in proceedings of Eurobitume Workshop on Performance Related Properties for Bituminous Binders, Luxembourg, 1999.

41 M. G. Bouldin, R. N. Dongré, G. M. Rowe, M. J. Sharrock and D. A. Anderson, "Predicting Thermal Cracking of Pavements from Binder Properties: Theoretical Basis and Field Validation", in Journal of Association of Asphalt Paving Technologists, Vol. 69, pp. 455 496, 2000.

42 AASHTO TP9-94, "Standard Test Method for Determining the Creep Compliance and Strength of Hot Mix Asphalt (HMA) Using the Indirect Tensile Test Device", American Association of State Highway and Transportation Officials (AASHTO) Provisional Standards, $3^{\text {rd }}$ edition, June, 1996.

43 R. Roque, D. R. Hiltunen, and W. G. Buttlar, "Thermal Cracking Performance and Design of Mixtures using Superpave", in Association of Asphalt Paving Technologists, Vol. 64, 1996, pp. $718-735$.

44 D. R. Hiltunen and R. Roque, "The Use of Time-Temperature Superposition to Fundamentally Characterize Asphaltic Concrete Mixtures at Low Temperatures", in Engineering Properties of Asphalt Mixtures and the Relationship to their Performance, ASTM STP 1265, Editors G. A. Huber and D. S. Decker, American Society for Testing and Materials, pp. 74 - 93, 1995.

45 R. Roque, D. R. Hiltunen and W. G. Buttlar, "Thermal Cracking Performance and Design of Mixtures Using Superpave ${ }^{\mathrm{TM}}$ ", in Journal of Association of Asphalt Paving Technologists, Vol. 64, pp. 718 - 735, 1996.

46 W. G. Buttlar and R. Roque, "Evaluation of Empirical and Theoretical Models to Determine Asphalt Mixture Stiffnesses at Low Temperatures", in Journal of Association of Asphalt Paving Technologists, Vol. 65, pp. 99 - 141, 1996.

47 D. Christensen, "Analysis of Creep Data from Indirect Tension Test on Asphalt Concrete", in Journal of Association of Asphalt Paving Technologists, Vol. 67, pp. 458 - 492, 1998.

48 L. Raad, S. Saboundjian, P. Sebaaly and J. Epps, "Thermal Cracking Models for AC and Modified AC Mixes in Alaska", in Transportation Research Record, No. 1629, pp. 117 126, 1998.

49 M. W. Witzack, H. Von Quintus, C. Schwartz and E. Harrigan, "Models Evaluation Report (Draft), Vol. 1: Key Findings and Recommendations", University of Maryland, College Park, Maryland, 1-3 pp., 1996.

50 W. Buttlar, R. Roque and B. Reid, "Automated Procedure for Generation of Creep Compliance Master Curve for Asphalt Mixtures", in Transportation Research Record, No. 1630, pp. 28 - 36, 1998.

51 A. Epps, "A Comparison of Measured and Predicted Low Temperature Cracking Conditions", in Journal of Association of Asphalt Paving Technologists, Vol. 67, pp. 227 296, 1998. 
53 J. Sousa, J. Deacon, S. Weissman, J. Harvey, C. Monismith, R. Leahy, G. Paulsen and J. Coplantz, "Permanent Deformation Response of Asphalt-Aggregate Mixes", in SHRP Report No. A-414, National Research Council, Washington D. C., 1994.

54 N. C. Krutz and M. Stroup-Gardiner, "Relationship Between Permanent Deformation of Asphalt Concrete and Moisture Sensitivity", in Transportation Research Record, No. 1259, pp. $169-177,1990$.

55 J. M. Matthews and C. L. Monismith, "The Effect of Aggregate Gradation on the Creep Response of Asphalt Mixtures and Pavement Rutting Estimates", in Effects of Aggregate and Mineral Fillers on Asphalt Mixture Performance, ASTM STP 1147, Editor R. C. Meininger, American Society of Testing and Materials, pp. 329 - 347, 1992.

56 C. P. Valkering, D. J. L. Lancon, E. deHilster and D. A. Stoker, "Rutting Resistance of Asphalt Mixes Containing Non-Conventional and Polymer-Modified Binders", in Journal of Association of Asphalt Paving Technologists, Vol. 59, pp. 590 - 609, 1990.

57 J. Harvey and C. L. Monismith, "Effects of Laboratory Asphalt Concrete Specimen Preparation Variables in Fatigue and Permanent Deformation Test Results Using Strategic Highway Research Program A-003A Proposed Testing Equipment", in Transportation Research Record, No. 1417, pp. 38 - 48, 1993.

58 S. H. Carpenter, "Permanent Deformation: Field Evaluation", in Transportation Research Record, No. 1417, pp. 135 - 143, 1993.

59 D. N. Little, J. W. Button and H. Youssef, "Development of Criteria to Evaluate Uniaxial Creep Data and Asphalt Concrete Permanent Deformation Potential", in Transportation Research Record, No. 1417, pp. 49- 57, 1993.

60 E. H. Mohamed and Z. Yue, "Criteria for Evaluation of Rutting Potential Based on Repetitive Uniaxial Compression Test", in Transportation Research Record, Vol. 1454, pp. $74-81,1994$.

61 R. B. Mallick, R. Ahlrich and E. R. Brown, "Potential of Dynamic Creep to Predict Rutting", in Engineering Properties of Asphalt Mixtures and the Relationship to their Performance, ASTM STP 1265, Editors G. A. Huber and D. S. Decker, American Society for Testing and Materials, pp. $194-212,1995$.

62 Y. R. Kim, N. Kim and N. P. Khosla, "Effects of Aggregate Type and Gradation on Fatigue and Permanent Deformation of Asphalt Concrete", in Effects of Aggregate and Mineral Fillers on Asphalt Mixture Performance, ASTM STP 1147, Editor R. C. Meininger, American Society of Testing and Materials, pp. 310 - 327, 1992.

63 M. Karakouzian, M. R. Dunning, R. L. Dunning and J. D. Stegeman, "Performance of Hot Mix Asphalt Using Coarse and Skip Graded and Aggregates", in Journal of Materials in Civil Engineering, Vol. 8, No. 2, pp. 101 - 107, May 1996.

64 K. D. Stuart and R. P. Izzo, "Correlation of Superpave $\left|G^{*}\right| /$ sin $\delta$ with Rutting Susceptibility from Laboratory Mixture Tests", in Transportation Research Record, No. 1492, pp. 176 183, 1995. 
65 R. B. Leahy, C. L. Monismith and J. R. Lundy, "Performance-Based Properties of Asphalt Concrete Mixes", in Engineering Properties of Asphalt Mixtures and the Relationship to Their Performance, ASTM STP 1265, Editors G. A. Huber and D. S. Decker, pp.37 - 53, 1995.

66 "Stage 1 Validation of the Relationship Between Asphalt Properties and AsphaltAggregate Mix Performance", Report No. SHRP-A-398, Strategic Highway Research Program, National Research Council, Washington D.C., 235 p., 1994.

67 J. A. Sherwood, N. L. Thomas and X. Qi, "Correlation of Superpave G*/Sin $\delta$ with Rutting Test Results from Accelerated Loading Facility", in Transportation Research Record, Vol. 1630, pp. 53 - 61, 1998.

68 H. U. Bahia, M. Zeng, H. Zhai and A. Khatri, "Superpave Protocols for Modified Asphalt Binders", in NCHRP 9-10, Washington D. C.

69 M. G. Bouldin, R. Dongré, L. Zanzotto, G. M. Rowe, "The Application of Visco-elastic Models to Predict the Relative Performance of Binders for Grading Purposes", in Proceedings of the $2^{\text {nd }}$ Eurasphalt and Eurobitumen Congress, Barcelona, Spain, book 1, pp. 74 - 82, 2000.

70 K. D. Stuart and W. S. Mogawer, "Validation of Asphalt Binder and Mixture Tests that Predict Rutting Susceptibility Using FHWA Accelerated Loading Facility", in Journal of Association of Asphalt Paving Technologists, Vol. 66, pp. 109 - 152, 1997.

71 A. Shenoy, "Refinement of the Superpave Specification Parameter for Performance Grading of Asphalt", in Journal of Transportation Engineering, Vol. 127, pp. 357 - 362, 2001.

72 S. R. Shatnawi and F. Lancaster, "Field and Laboratory Evaluation of Superpave Level One Mix Design in California", in Progress of Superpave (Superior Performing Asphalt Pavement): Evaluation and Implementation, ASTM STP 1322, Editor R. N. Jester, American Society for Testing and Materials, pp. 64 - 79, 1997.

73 P. Romero and W. S. Mogawer, "Evaluation of Ability of Superpave Shear Tester to Differentiate Between Mixtures with Different Aggregate Sizes", in Transportation Research Record, Vol. 1630, pp. 69 - 76, 1998.

74 R. M. Anderson, R. J. Cominsky, B. M. Killingsworth, "Sensitivity of Superpave Mixture Tests to Changes in Mixture Components", in Journal of Association of Asphalt Paving Technologists, Vol. 67, pp. 153 - 188, 1998.

75 P. B. Blankenship, A. Myers, A. Clifford, T. W. Thomas, D. Walker, H. King and G. King, "Are all PG70-22's the Same? Lab Tests on KY I-64 Field Samples", in Journal of Association of Asphalt Paving Technologists, Vol. 67, pp. 493 - 552, 1998.

76 A. A. Tayebali, N. P. Khosla, G. A. Malpass and H. F. Waller, "Evaluation of Superpave Repeated Shear at Constant Height Test to Predict Rutting Potential of Mixes-Performance of Three Pavement Sections in North Carolina", in Transportation Research Record, Vol. 1630, pp. 97 - 105, 1999.

77 R.M. Anderson, J. R. Bukowski and P. A. Turner, "Using Superpave Performance Tests to Evaluate Asphalt Mixtures", in Transportation Research Record, Vol. 1681, pp. 106 - 112, 1999. 
78 J-N. Wang, T. W. Kennedy and R. B. McGennis, "Volumetric and Mechanical Performance Properties of Superpave Mixtures", in Journal of Materials in Civil Engineering, Vol. 12, No. 3, pp. 238 - 244, August 2000.

79 J. S. Kern and S. H. Carpenter, "Performance-Graded High-Temperature Selection Criterion--Can We Do It Better?", in Transportation Research Record, Vol. 1661, pp. 122 131, 1999.

80 R. M. Anderson, G. A. Huber, D. E. Walker and X. Zhang, "Mixture Testing, Analysis, and Field Performance of the Pilot Superpave Projects: The 1992 SPS-9 Mixtures", in Journal of Association of Asphalt Paving Technologists, Vol. 69, pp. 177 - 211, 2000.

81 D. Sybilski, "Zero-Shear Viscosity of Bituminous Binder and Its Relation to Bituminous Mixture's Rutting Resistance", in Transportation Research Record, Vol. 1535, pp. 15 - 21, 1996.

82 J. Harvey, I. Guada and F. Long, "Effects of Material Properties, Specimen Geometry, and Specimen Preparation Variables on Asphalt Concrete Tests for Rutting", in Journal of Association of Asphalt Paving Technologists, Vol. 69, pp. 236 -280, 2000.

83 A. J. Hand and A. L. Epps, "Impact of Gradation Relative to Superpave Restricted Zone on Hot-Mix Asphalt Performance" in Transportation Research Record, Vol. 1767, pp. 158 166, 2001.

84 A. Chowdhury, J. D. C. Grau, J. W. Button and D. N. Little, "Effect of Aggregate Gradation on Permanent Deformation of Superpave HMA", submitted for presentation at the $80^{\text {th }}$ Transportation Research Board Annual Meeting, 2001.

85 P. Romero and R. M. Anderson, "Variability of Asphalt Mixture Tests Using Superpave Shear Tester Repeated Shear at Constant Height Test", in Transportation Research Record, Vol. 1767, pp. 95 - 101, 518 p., 2001.

86 AASHTO TP5-93, "Standard Test Method for Determining the Rheological Properties of Asphalt Binder Using Dynamic Shear Rheometer (DSR)", American Association of State Highway and Transportation Officials (AASHTO) Provisional Standards, $3^{\text {rd }}$ edition, June, 1996.

87 R. L. Lytton, J. Uzan, E. G. Fernando, R. Roque, D. Hiltunen, S. M. Stoffels, "Development and Validation of Performance Prediction Models and Specifications for Asphalt Binders and Paving Mixes", SHRP-A-357, National Research Council, 1993.

88 J. B. Sousa, R. B. Leahy, J. Harvey and C. L. Monismith, "Permanent Deformation Response of Asphalt-Aggregate Mixes", SHRP-A-415, National Research Council, 438 p., 1994.

89 J-N. Wang, C-K. Yang and T-Y. Luo, "Mechanistic Analysis of Asphalt Pavements, Using Superpave Shear Tester and Hamburg Wheel-Tracking Device", in Transportation Research Record, Vol. 1767, pp. 102 - 110, 2001.

90 "AASHTO 2002 Design Guide For Mechanistic Pavement Design", principal investigator, R. Gary Hicks, National Cooperative Highway Research Program, NCHRP Project 1-37A. 
91 W. Robertson and Associates, "Determining the Winter Design Temperature for Asphalt Pavements", in TAC Research Report, Transportation Association of Canada (TAC), 19 p., April 1997.

92 "Revised Low-Temperature Algorithms for SUPERPAVE Mix Design System", in Technical Brief \#15, Canadian Strategic Highway Research Program (C-SHRP), 8 p., October 1998.

93 W. D. Robertson, "Using the SHRP Specification to Select Asphalt Binders for Low Temperature Service", in Proceedings of the Canadian Technical Asphalt Association, Vol. 40, 170, 1995.

94 "LTPP Seasonal Asphalt Concrete (AC) Pavement Temperature Models", FHWA-RD-97103, September 1998.

95 A. Mohseni and M. Symons, "Improved AC Pavement Temperature Models from LTPP Seasonal Data", presented at the $77^{\text {th }}$ Annual Meeting of the Transportation Research Record, 1998.

96 A. Mohseni and M. Symons, "Effect of Improved LTPP AC Pavement Temperature Models on SUPERPAVE Performance Grades", presented at the $77^{\text {th }}$ Annual Meeting of the Transportation Research Record, 1998.

97 M. Solaimanian and T. W. Kennedy, "Predicting Maximum Pavement Surface Temperature Using Maximum Air Temperature and Hourly Solar Radiation", in Transportation Research Record, No. 1417, pp. 1 - 11, 1993.

98 P. J. Bosscher, H. U. Bahia, S. Thomas and J. S. Russell, "Relationship Between Pavement Temperature and Weather Data: Wisconsin Field Study to Verify Superpave Algorithm", in Transportation Research Record, No. 1609, pp. 1 - 11, 1998.

99 E. O. Lukanen, C. Han and E. L. Skok, Jr., "Probabilistic Method of Asphalt Binder Selection Based of Pavement Temperature", in Transportation Research Record, No. 1609, pp. 12 - 20, 1998.

100 G. Bartha, "Temperature Changes in Asphalt Pavements in Summer", in Periodica Polytechnica Series Civil Engineering, Vol. 46, No. 1, pp 43 - 52, 2002.

101 H. I. Al-Abdul Wahhab and F. A. Balghunaim, "Asphalt Pavement Temperature Related to Arid Saudi Environment", in Journal of Materials in Civil Engineering, Vol. 6, No. 1, pp. 1 14, February 1994.

102 AASHTO MP2-95, "Standard Specification for Superpave Volumetric Mix Design", American Association of State Highway and Transportation Officials (AASHTO) Provisional Standards, $3^{\text {rd }}$ edition, June, 1996.

103 AASHTO MP1-93, "Standard Specification of Performance Graded Binder", American Association of State Highway and Transportation Officials (AASHTO) Provisional Standards, $3^{\text {rd }}$ edition, June, 1996.

104 AASHTO PP6-93, "Standard Practice for Grading and Verifying the Performance Grade of an Asphalt Binder", American Association of State Highway and Transportation Officials (AASHTO) Provisional Standards, $3^{\text {rd }}$ edition, June, 1996. 
105 AASHTO M145, "Standard Specification of Classification Soils and Soil-Aggregate Mixtures for Highway Construction Purposes", American Association of State Highway and Transportation Officials (AASHTO), 1995.

106 ASTM D2488, "Standard Practice for Description and Identification of Soils (Visual-Manual Procedure)", American Society of Tests and Materials (ASTM), 1995.

107 J. S. Miller and W. Y. Bellinger, "Distress Identification Manual for Long-Term Pavement Performance Project", FHWA-RD-03-031 (SHRP-P-338), $4^{\text {th }}$ revised edition, 164 p., 2003.

108 "Manual for Profile Measurement: Operational Field Guidelines", Strategic Highway Research Program, SHRP-P-378, 130 p. February, 1994.

109 W. L. Gamling and J. E Hunt, "Photographic Pavement Distress Record Collection and Transverse Profile Analysis", Strategic Highway Research Program, SHRP-P-660, 113 p., June, 1993.

110 N. Al-Omari and M. I. Darter, "Relationship Between International Roughness Index and Present Serviceability Rating", in Transportation Research Record, No. 1435, pp. 130 136, 1994.

111 ASTM D2172, "Standard Test Methods for Quantitative Extraction of Bitumen from Bituminous Paving Mixtures", American Society of Tests and Materials (ASTM), 1995.

112 ASTM D5404, "Standard Practice for Recovery of Asphalt from Solution using the Rotary Evaporator", American Society of Tests and Materials (ASTM), 1997.

113 AASHTO T228, "Standard Method of Test for Specific Gravity of Semi-Solid Bituminous Materials-HM-22; Part IIB", American Association of State Highway and Transportation Officials (AASHTO), 1996.

114 D. C. Montgomery, "Design and Analysis of Experiments", John Wiley and Sons, Inc., $4^{\text {th }}$ edition, 704 p., 1996.

115 AASHTO T49, "Standard Method of Test for Penetration of Bituminous Materials-HM-22; Part IIA", American Association of State Highway and Transportation Officials (AASHTO), 1997.

116 J. Y. Welborn, "Relationship of Asphalt Cement Properties to Pavement Durability", Transportation Research Board, NCHRP Report No. 59, 1979.

117 P. S. Kandhal, "Low-Temperature Ductility in Relation to Pavement Performance", American Society of Tests and Materials, STP 628, 1977.

118 P. Hubbard and H. Gollomb, "The Hardening of Asphalt with Relation to Development to Cracks in Asphalt Pavements", in Journal of Association of Asphalt Paving Technologists, Vol. 9, pp. 165 - 194, 1937.

119 AASHTO T202, "Standard Method of Test for Viscosity of Asphalt by Vacuum Capillary Viscometer-HM-22; Part IIB", American Association of State Highway and Transportation Officials (AASHTO), 1991. 
120 AASHTO TP48, "Standard Test Method for Viscosity Determination of Asphalt Binder Using Rotational Viscometer", American Association of State Highway and Transportation Officials (AASHTO), 1997.

121 AASHTO MP1a, "Standard Specification of Performance Graded Asphalt Binder", American Association of State Highway and Transportation Officials (AASHTO), Interim Edition, April 2001.

122 "Superpave Asphalt Mixture Analysis", Course Text, National Asphalt Training Center (NCAT) II, Asphalt Institute Research Center, Lexington, KY, May 1996. 


\section{CHAPTER 3 -- DESCRIPTION OF TEST SECTIONS}

\subsection{Background}

The materials used in this research, along with the field cores and distress observations, were all collected from the six experimental test sections constructed as a part of the Indiana SPS9-A studies. Detailed description of the test sections is provided below.

The SPS9-A experiments were set up to provide validation of SHRP binder specifications through controlled test sections. In addition, SPS9-A studies also provided a direct comparison between the existing (conventional) mixture design procedures and SUPERPAVE mixture design and binder specifications in terms of performance. Long-term performance data collected at the SPS9-A sites allow for the evaluation and modification of binder specifications at the local, regional and national level and for the refinement of the SUPERPAVE models.

Indiana's pilot SPS9-A project was constructed to evaluate the performance of a test section built using Marshall mix design procedures with the performance of sections built with newly introduced SUPERPAVE mix design procedures. Marshall mix design procedures and viscosity-graded asphalts were commonly used in Indiana at the time this study was being considered. As per SPS9-A test site requirements, the supplemental sections were constructed with binders that were one or two grades away from the design grade at the test site. Finally, the Indiana Department of Transportation (INDOT) was also interested in the performance of pavements built with recycled asphalt pavement (RAP) material.

\subsection{Location of the Test Sections}

The Indiana SPS9-A project was constructed in the summer of 1997 near Indianapolis on I-70 E in Hancock county. The site is $2.5 \mathrm{~km}$ (1.6 miles) long and is located about 
$22.5 \mathrm{~km}$ (14 miles) east of the I-465 loop around Indianapolis. Figure 3.1 shows the location of the test site and Figure 3.2 shows the general layout of the test sections. The test site consists of six test sections, each $300 \mathrm{~m}$ (984 ft) long. Each test section is further subdivided into a $150-\mathrm{m}$ long (492 ft) monitoring region (MR) and two 75-m long (246 ft) coring regions (CR) located on both sides of monitoring region. The test sections are separated by a $115 \mathrm{~m}(377 \mathrm{ft})$ transition region (TR). The contractor (INDOT contract \# R-22923) in charge of construction of this project was E \& B Paving, Inc.

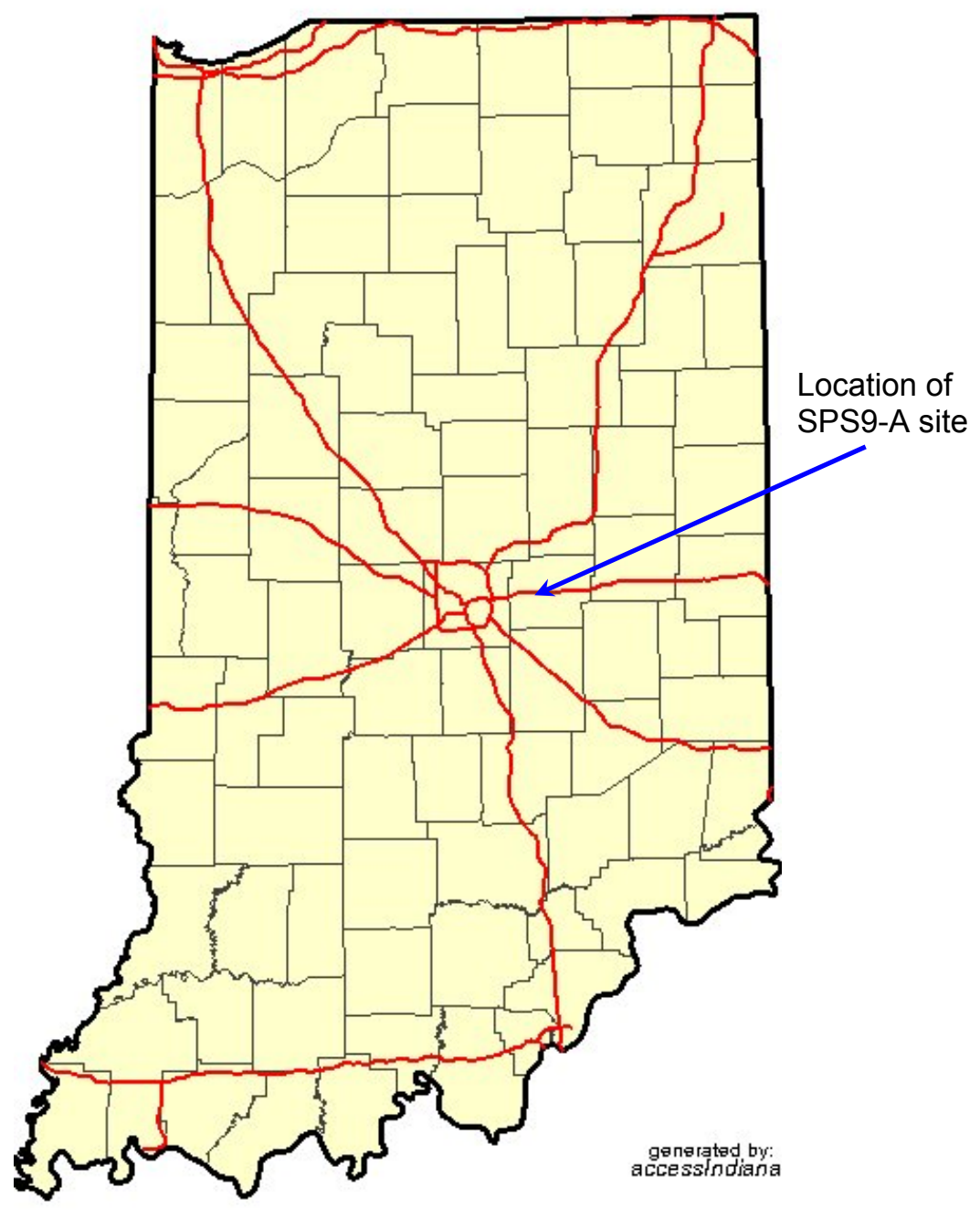

Figure 3.1 -- Location of the project site in Indiana 

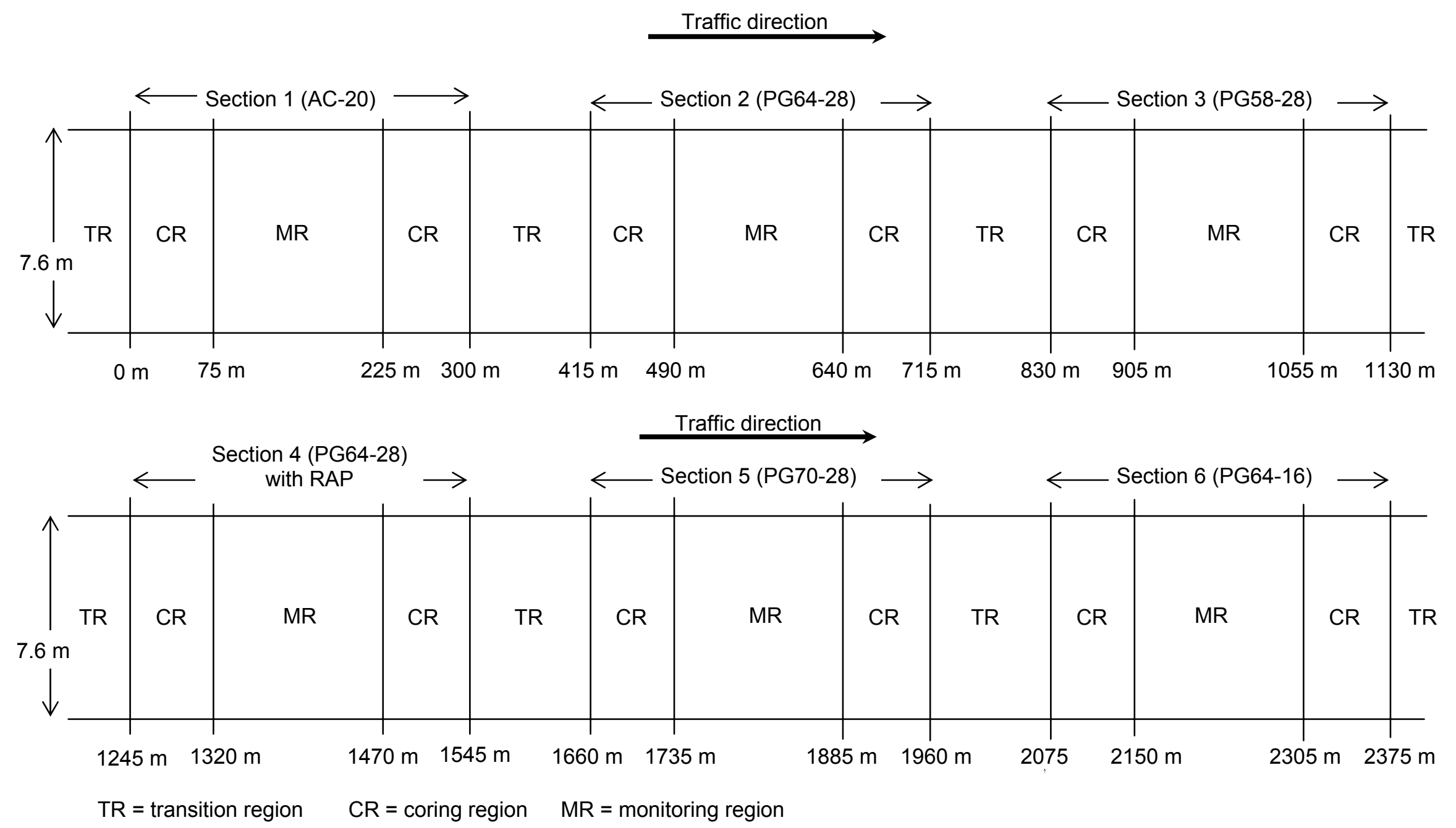

Figure 3.2 -- General layout of the test sections 


\subsection{Layout of the Test Sections}

This section gives a brief outline of the pavement cross section, coring operation and equipment used in traffic and weather monitoring. Further details regarding the construction and instrumentation are given later in this chapter.

\subsubsection{Pavement Structure}

The new pavement installed at the study site was a part of the two-lane highway consisting of a surface and an intermediate layers built over cracked and seated jointed reinforced concrete pavement (JRCP) that was used as a base course. The surface layer was about $55 \mathrm{~mm}(2.2 \mathrm{in}$.) thick and the intermediate layer was about $110 \mathrm{~mm}(4.3 \mathrm{in}$.$) thick. The$ cross-section of the pavement is shown in Figure 3.3.

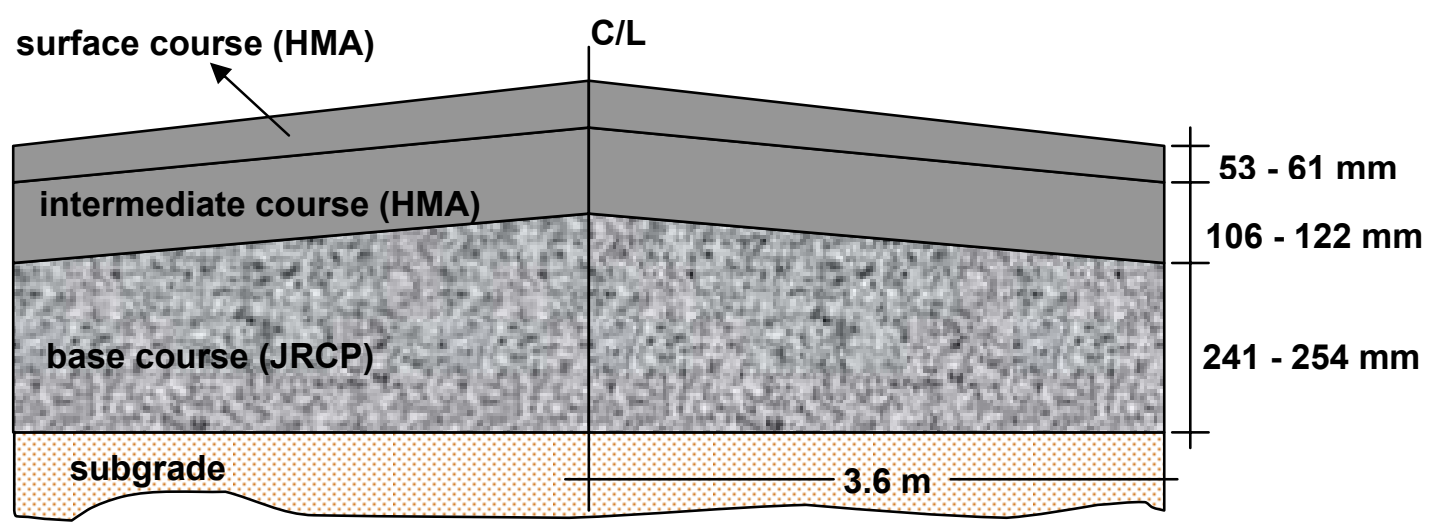

Figure 3.3 -- Cross section of the pavement at the test site

\subsubsection{Temperature and Weather Monitoring Equipment}

A weather station was set up adjacent to the test site to monitor air and pavement temperatures. Temperature sensors were installed at various pavement depths (see Figure 3.4) in the Section 3. In addition, the weather station shown in Figure 3.5 was also set up to monitor other climatic data such as relative humidity, wind speed, wind direction and solar radiation. A data acquisition unit (CR10x) was used to record the signals from these sensors at 
15-minute intervals. Data from the CR10x unit was downloaded remotely from Purdue University via modem link. All these sensors and instruments were purchased from Campbell Scientific, Inc.

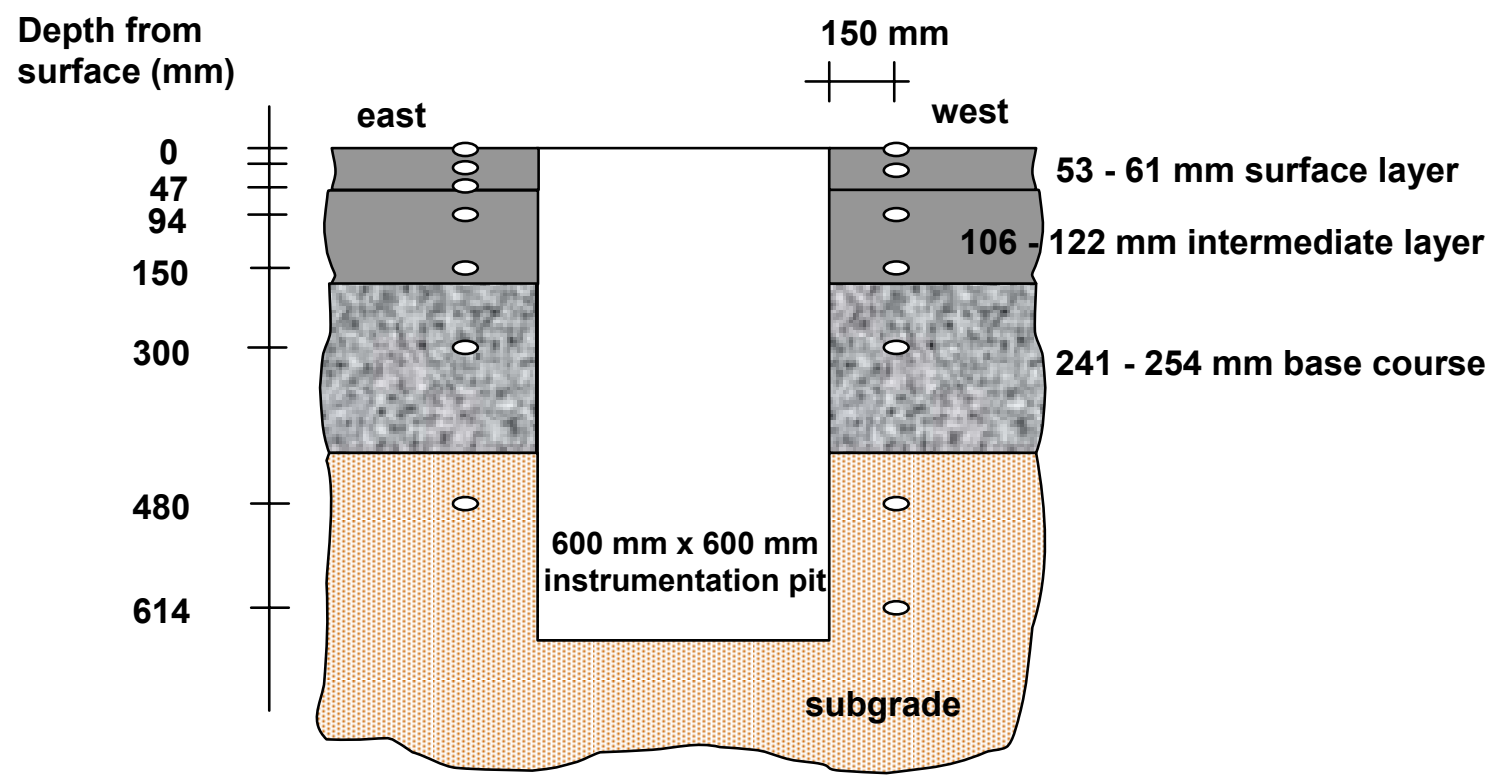

Figure 3.4 -- Location of sensors in the pavement

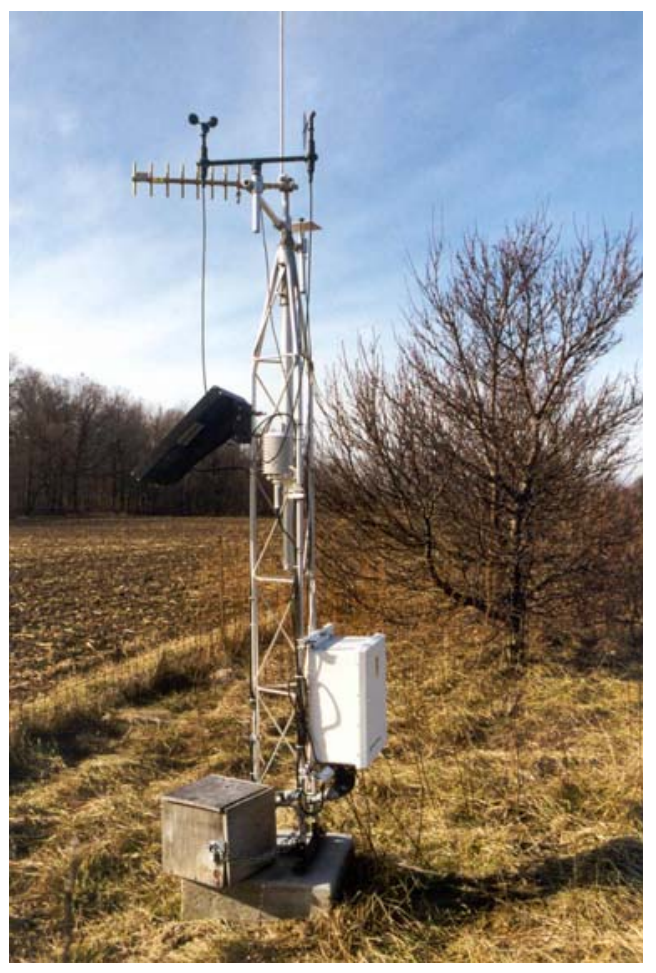

Figure 3.5 -- Weather station near the test site on I-70E 


\subsubsection{Traffic Monitoring}

To get a reliably accurate estimate of the traffic volume at the test site, the data from a nearby weigh-in-motion (WIM) station located a few miles east of the study site was used to calculate the number of ESALs. However, due to the presence of an exit and entry ramp in between the WIM station and the study site, additional traffic counters were installed on the exit and entry ramps to estimate the number of vehicles exiting the highway before the WIM station and entering the highway after the location of the study site. Data from these traffic counters was recorded on Automatic Data Recorders (ADR) and collected on a bi-monthly basis. Figure 3.6 shows the traffic station and the ADR unit.

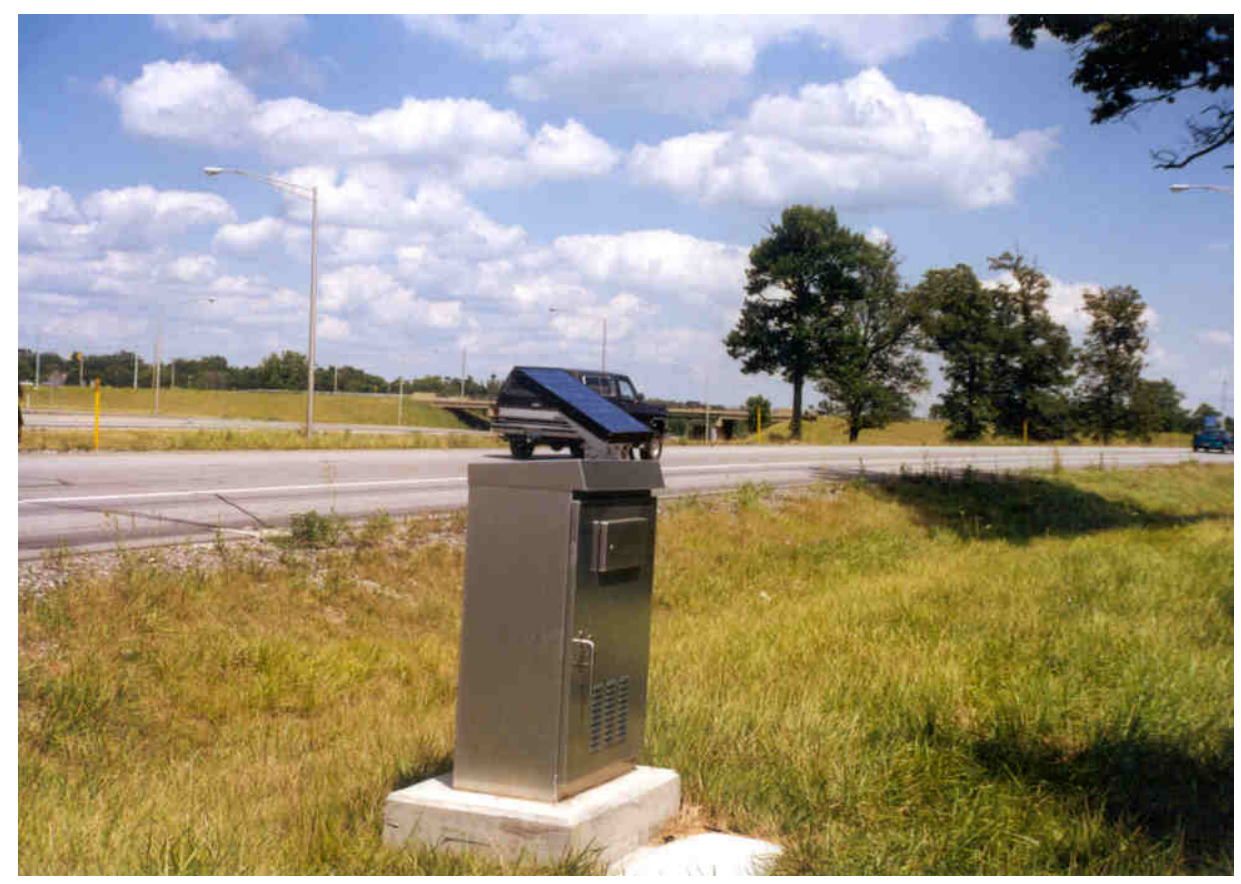

Figure 3.6 -- Traffic station on I-70E at exit 104 


\subsubsection{Details of Coring Region}

Field cores were obtained from the coring region every six months for a period of two years following construction. A final set of field cores was obtained at the end of four years. The cores were obtained from the wheel path of the driving lane. Figures 3.7 through 3.9 and show the coring operation. These core sets were coded as follows:

- $\mathrm{A}=$ obtained soon after construction (within 2 weeks)

- $\quad \mathrm{B}=$ obtained 8 months after construction

- $\quad \mathrm{C}=$ obtained 1 year after construction

- $\quad \mathrm{D}=$ obtained 1.5 years after construction

- $\quad E=$ obtained 2 years after construction

- $\mathrm{F}=$ obtained 4 years after construction

Each set of field cores consisted of eight 6" diameter cores from each test section. Four out of the eight cores were obtained from the coring region (75 m long) before the monitoring region of each test section and the remaining four were obtained from the coring region (75 $\mathrm{m}$ long) after the monitoring region. Figure 3.10 shows the sampling area within each $75 \mathrm{~m}$ of coring region. Figure 3.11 shows the location of each core within the 8-m sampling area at each time (interval).

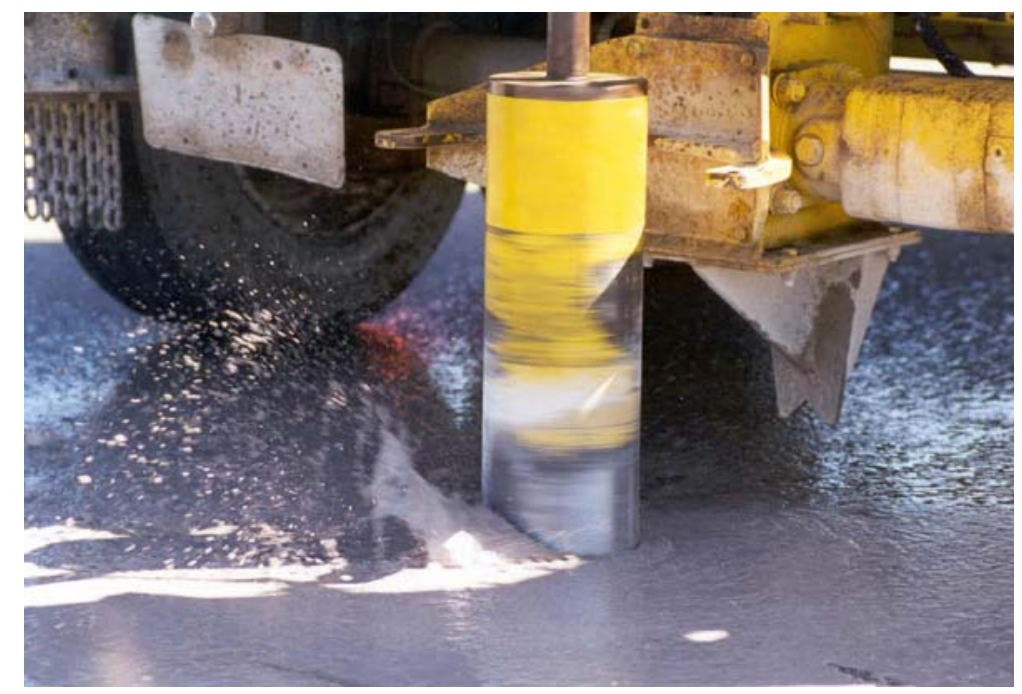

Figure 3.7 -- Coring operation 


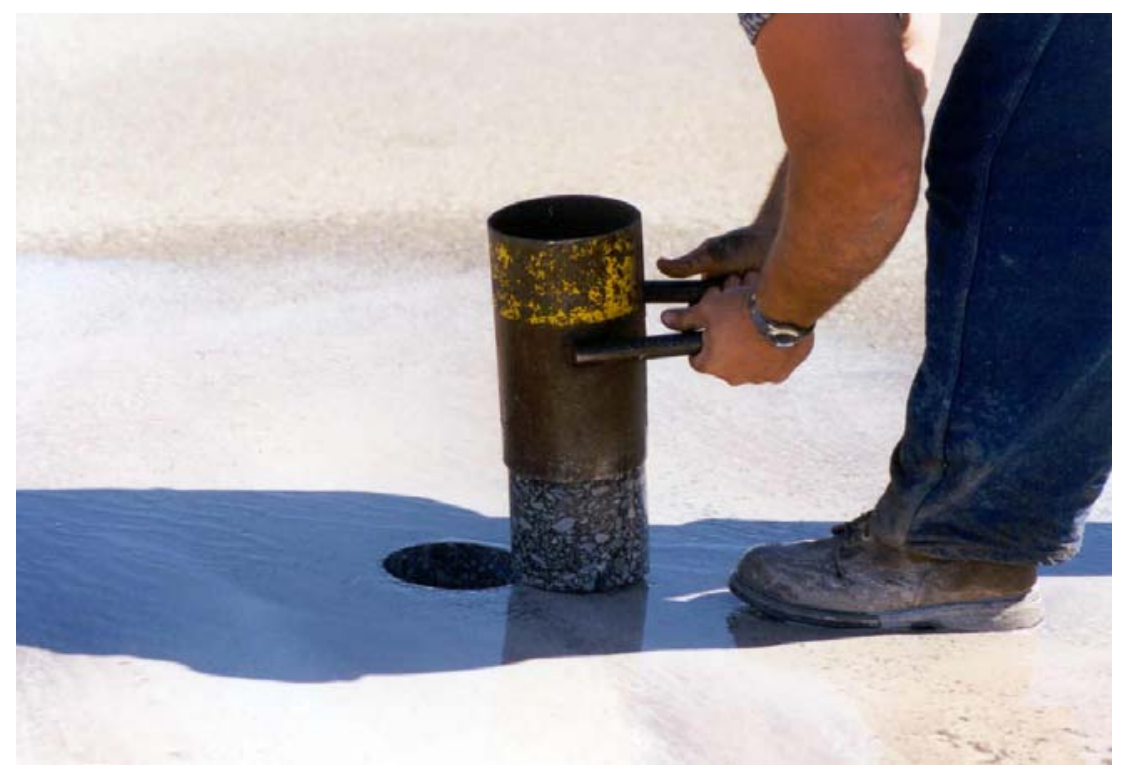

Figure 3.8 -- Core removal

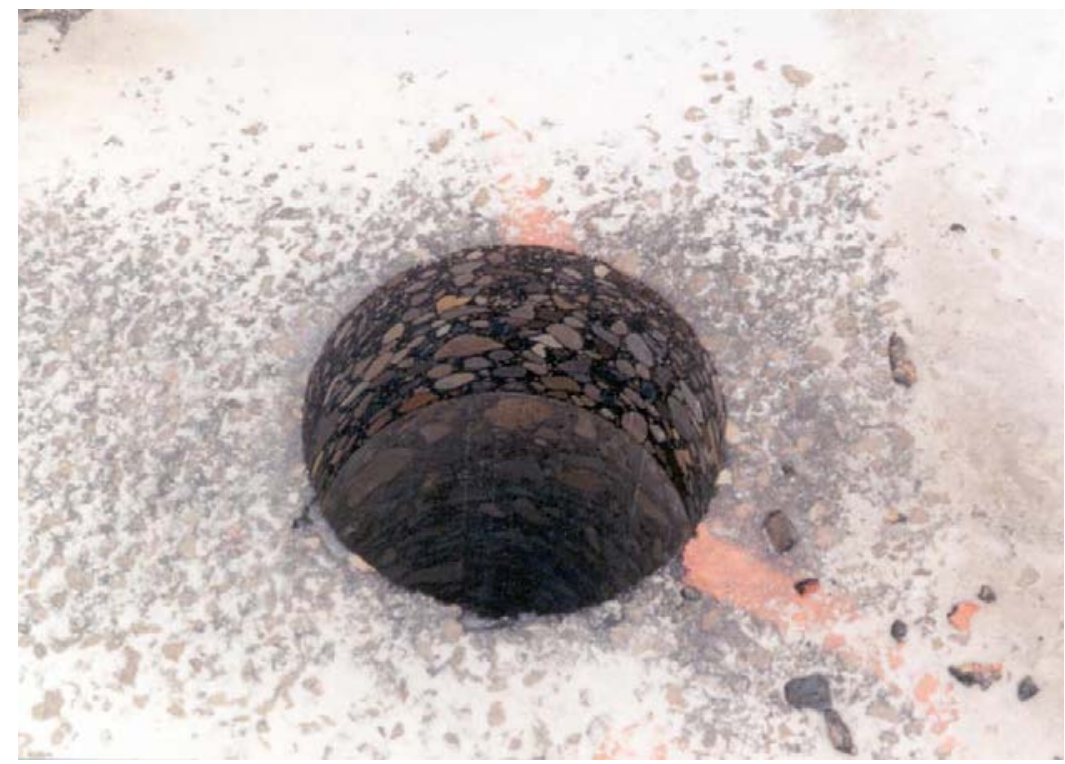

Figure 3.9 -- Hole showing pavement cross-section 


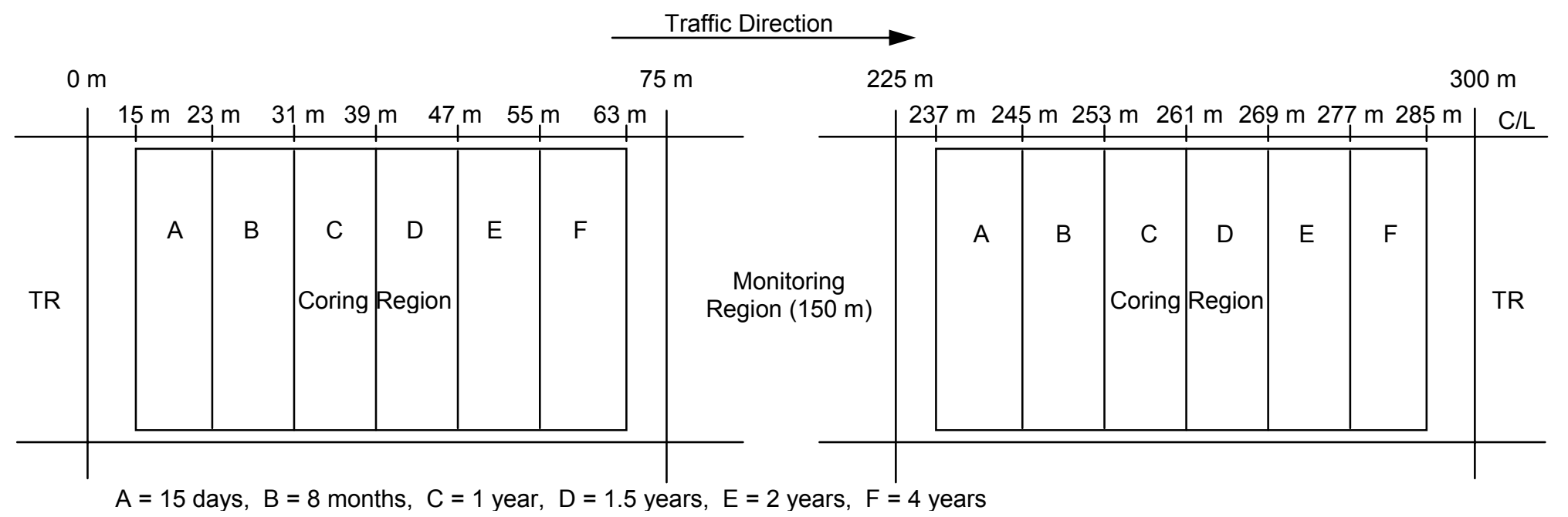

Figure 3.10 -- Details of coring sampling area

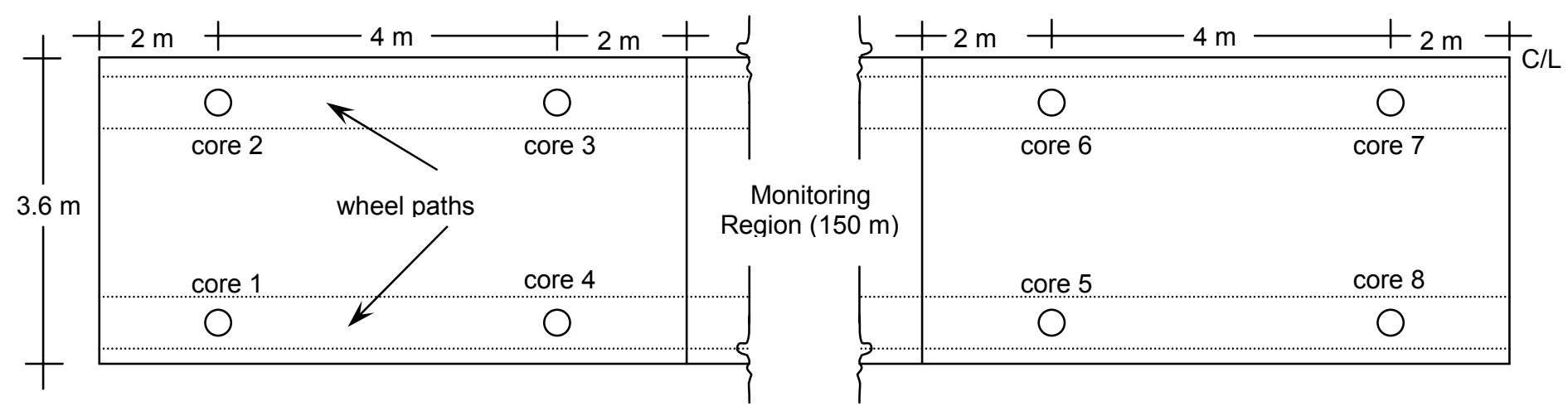

Figure 3.11 -- Core sampling location at all time intervals (A, B, C, D, E and F) 


\subsection{Research Variables}

\subsubsection{Material Selection}

The binder selected for the control SUPERPAVE section was based on expected traffic volume and temperature data from LTPPBind, formerly known as SHRPBIND. LTPPBind is a software product that calculates the design pavement temperature with $50 \%$ reliability at any given test site, based on historical temperature data collected at or around the vicinity of the test site. The recommended binder grade for this study site based on weather data alone was PG58-16, at 50\% reliability and PG58-28 at 98\% reliability. However, due to the expected traffic volume of 30 million to 100 million ESALs during the service life of the pavement, the high temperature grade was increased resulting in a PG64-28 binder, which was the binder used in Section 2 (control section).

To study the effect of binder grade on thermal cracking, a binder with a lower low-temperature grade (PG64-16) than the control was used in Section 6. To evaluate the influence of binder grade on rutting performance of the mixtures, two additional sections were

constructed; Section 5 with a higher high-temperature grade (PG70-28) and Section 3 with a lower high-temperature grade (PG58-28) than the binder used in the control section (PG64-28). The binder used in Section 5 was a Styrene-Butadiene-Styrene (SBS) modified binder with a gellant.

Marshall mix design with AC-20 binder was used in the construction of Section 1. AC-20 was the typical binder grade used in this part of Indiana prior to the introduction of SUPERPAVE mix design methodology. This section was constructed to compare the performance of the local state highway agency's binder and mixture design with that of the new SUPERPAVE binder and mixture design specifications. A test section with 15\% RAP and PG64-28 binder was also constructed to evaluate the performance of RAP section (Section 4) with the control section (Section 2). Sections 1 through 6 will be referred to as M-AC-20, S-64$28, \mathrm{~S}-58-28, \mathrm{R}-15 \%, \mathrm{~S}-70-28$ and S-64-16, respectively, in the remainder of the report. 


\subsubsection{Mix Designs}

\subsubsection{Surface Course}

Three different mix designs were employed in the construction of the surface courses. Of these, one was a Marshall mix design and the other two were SUPERPAVE mix designs; one without RAP and the other with 15\% RAP. Table 3.1 shows the binder grade, aggregate type, design asphalt content $\left(\mathrm{P}_{\mathrm{b}(\mathrm{des})}, \%\right)$, design voids in the mineral aggregate $\left(\mathrm{VMA}_{\text {(des) }}, \%\right)$ and the design voids filled with asphalt $\left(\mathrm{VFA} \mathrm{A}_{(\mathrm{des})}, \%\right)$. Figure 3.12 shows the aggregate gradation for the three mix designs used. The nominal maximum aggregate size (NMAS) of the surface course mixtures was $9.5 \mathrm{~mm}$.

Table 3.1 -- Binder grade, aggregate type and design values used in the surface course

\begin{tabular}{|c|c|c|c|c|c|c||}
\hline Mix Design & $\begin{array}{c}\text { Section } \\
\text { ID }\end{array}$ & $\begin{array}{c}\text { Aggregate } \\
\text { Type }\end{array}$ & Binder Grade & $\begin{array}{c}\mathbf{P}_{\text {b(des) }} \\
\%\end{array}$ & $\begin{array}{c}\text { VMA }_{\text {(des) }} \\
\%\end{array}$ & $\begin{array}{c}\text { VFA } \\
\%\end{array}$ \\
\hline \hline Marshall & M-AC-20 & $\begin{array}{c}\text { slag, dolomite, } \\
\text { natural sand }\end{array}$ & AC-20 & 6.2 & 16.5 & 62.4 \\
\hline SUPERPAVE & $\begin{array}{c}\text { S-64-28 } \\
\text { S-58-28 } \\
\text { S-70-28 } \\
\text { S-64-16 }\end{array}$ & $\begin{array}{c}\text { slag, dolomite, } \\
\text { dolomitic sand } \\
\text { and ag lime }\end{array}$ & $\begin{array}{c}\text { PG64-28 } \\
\text { PG58-28 } \\
\text { PG70-28 } \\
\text { PG64-16 }\end{array}$ & 6.5 & 15.0 & 56.7 \\
\hline SUPERPAVE & R-15\% & $\begin{array}{c}\text { slag, dolomite, } \\
\text { dolomitic sand } \\
\text { and RAP }\end{array}$ & $\begin{array}{c}\text { PG64-28 with } \\
15 \% \text { RAP }\end{array}$ & 6.4 & 15.4 & 58.4 \\
\hline
\end{tabular}

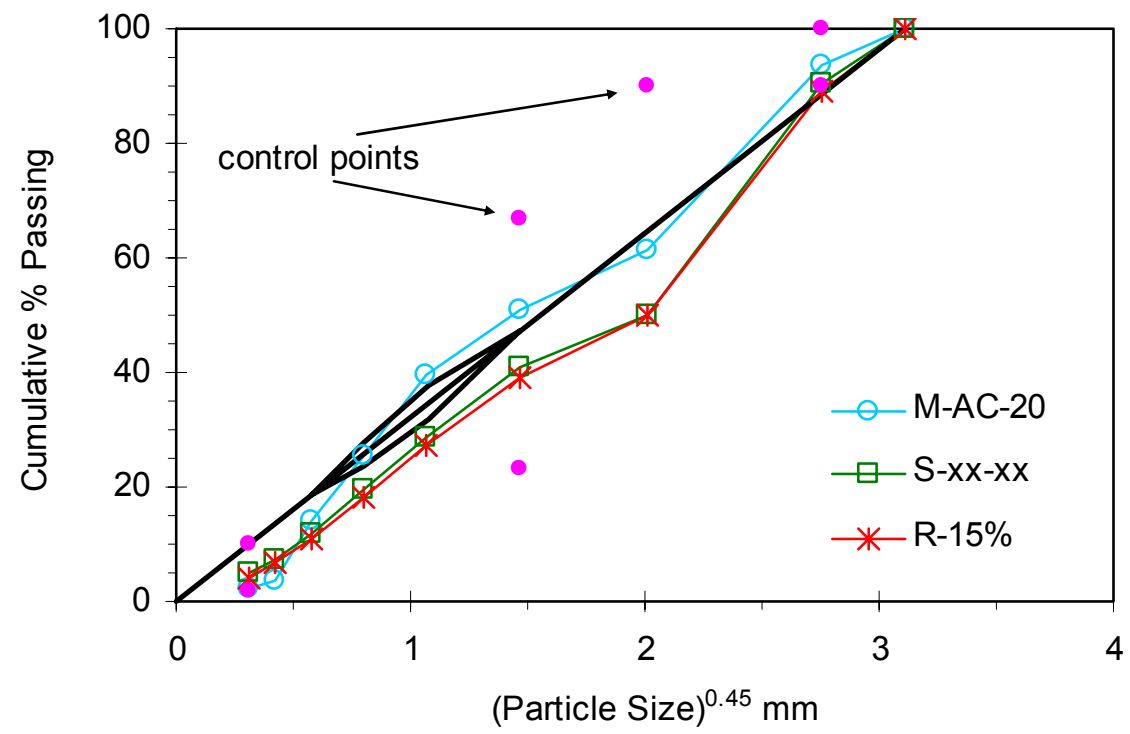

Figure 3.12 -- Gradation chart for the surface course mixtures 


\subsubsection{Intermediate Course}

Similar to the surface course mixtures, three mix designs were also employed in the intermediate course mixtures. The same binder was used in both the surface and intermediate mixtures of each section. The NMAS of the intermediate course was $19 \mathrm{~mm}$. Table 3.2 shows the binder grade, the aggregate type and the design volumetric data for intermediate course mixtures and Figure 3.13 shows the gradation chart for the intermediate course aggregate. The blending charts for both the surface and the intermediate courses are shown in Appendix A.

Table 3.2 -- Binder grade, aggregate type and design values used in the intermediate course

\begin{tabular}{|c|c|c|c|c|c|c||}
\hline Mix Design & $\begin{array}{c}\text { Section } \\
\text { ID }\end{array}$ & Aggregate Type & Binder Grade & $\begin{array}{c}\mathbf{P}_{\text {b(des) }} \\
\%\end{array}$ & $\begin{array}{c}\text { VMA }_{\text {(des) }} \\
\%\end{array}$ & $\begin{array}{c}\text { VFA } \\
\%\end{array}$ \\
\hline \hline Marshall & $\begin{array}{c}\text { M-AC- } \\
20\end{array}$ & $\begin{array}{c}\text { crushed stone and } \\
\text { natural sand }\end{array}$ & AC-20 & 4.3 & 14.8 & 69.6 \\
\hline SUPERPAVE & $\begin{array}{c}\text { S-64-28 } \\
\text { S-78-28 }\end{array}$ & $\begin{array}{c}\text { crushed stone and } \\
\text { stone sand }\end{array}$ & $\begin{array}{c}\text { PG64-28 } \\
\text { PG58-28 } \\
\text { PG70-28 } \\
\text { PG64-16 }\end{array}$ & 5.0 & 15.5 & 65.8 \\
\hline SUPERPAVE & R-15\% & $\begin{array}{c}\text { crushed stone, } \\
\text { stone sand and } \\
\text { RAP }\end{array}$ & $\begin{array}{c}\text { PG64-28 with } \\
15 \% \text { RAP }\end{array}$ & 4.7 & 14.9 & 66.4 \\
\hline
\end{tabular}

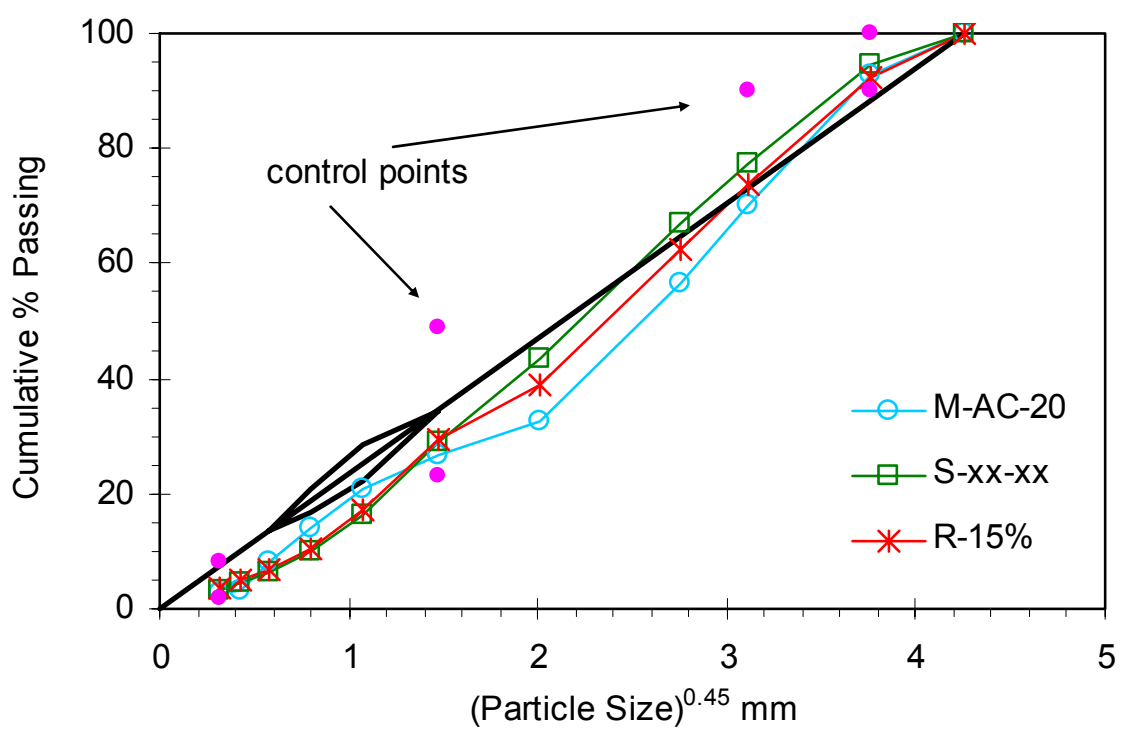

Figure 3.13 -- Gradation chart for the intermediate course mixtures 


\subsection{Construction Details}

The existing pavement at the test site was an HMA overlay over a jointed reinforced concrete pavement (JRCP) base course. In preparation for the construction of the test sections, the existing HMA pavement was milled out prior to cracking-and-seating of the JRCP base layer. The new HMA overlay was placed in two layers surface and intermediate, of variable thickness over the cracked-and-seated JRCP base. The surface layer was placed in a single lift of $53-61 \mathrm{~mm}\left(2.1^{\prime \prime}-2.4 "\right)$ thickness and the intermediate layer was placed in two lifts of $53-61$ $\mathrm{mm}$ each (see Figure 3.3). The lift thickness was greater along the centerline of the pavement and lower along the edge (shoulder) of the pavement. Figures 3.14 and 3.15 show the pavement laydown and compaction.

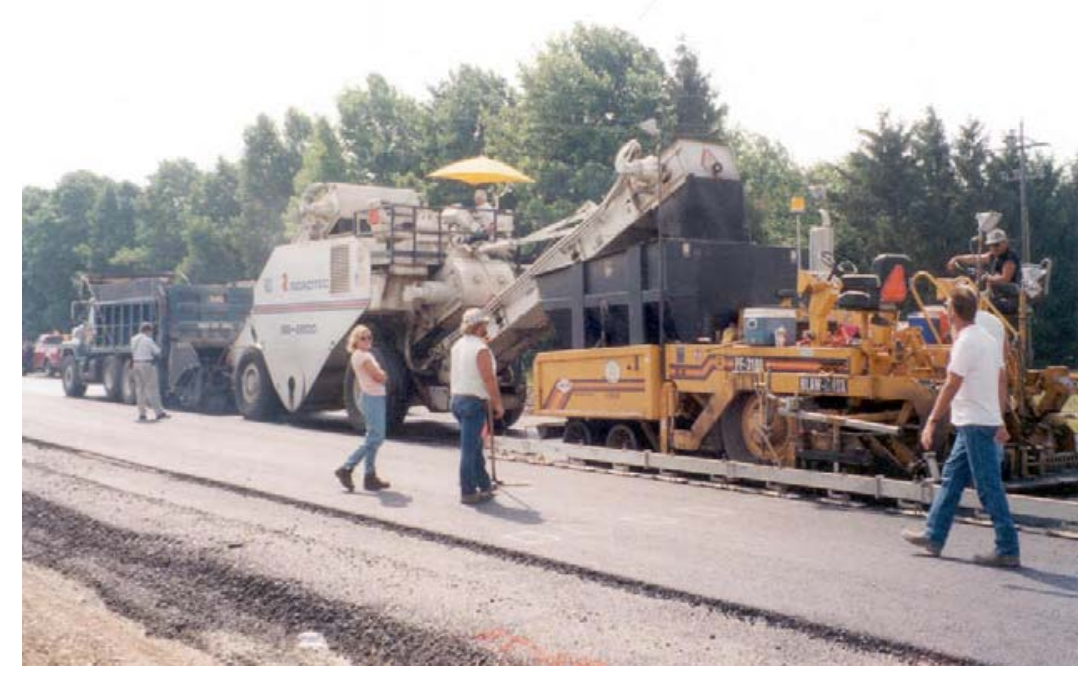

Figure 3.14 -- Pavement laydown operation 


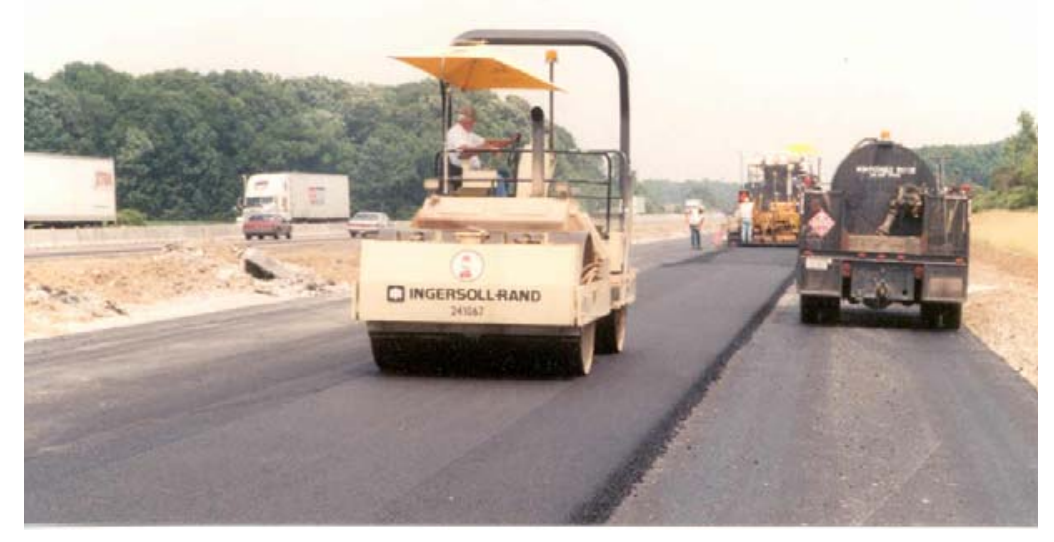

Figure 3.15 -- Pavement compaction operation

\subsubsection{Weather Monitoring Station}

A $600 \mathrm{~mm} \times 600 \mathrm{~mm}$ pit that was approximately 1-m deep was excavated in the middle of the driving lane of test Section 3 for instrumentation purposes (Figure 3.16) after the construction of the intermediate layer. A 50-mm diameter steel pipe was inserted into the side of the pit to run the sensors cables to the weather station located at the side of the road. Two sets of sensors, Type-T thermocouples and thermistors, were installed at each depth to provide redundancy in the temperature readings obtained.

Small holes for sensors were drilled at pre-determined depths into the sides of the instrumentation pit, using a power drill. Two thermocouples, labelled east and west were placed on opposite sides of the hole at each depth. The thermistors were also placed on the south side of the hole at approximately the same depth as the thermocouples. After the sensors were installed at their locations, each sensor hole was filled with silicone and sealed. Figure 3.17 shows the sealing operation in progress. The sensors for the surface layer were enclosed in a steel box that was placed flush with the top of the intermediate layer (Figure 3.18) and the 
instrumentation hole was backfilled with portland cement concrete (PCC) and allowed to set (Figure 3.19).

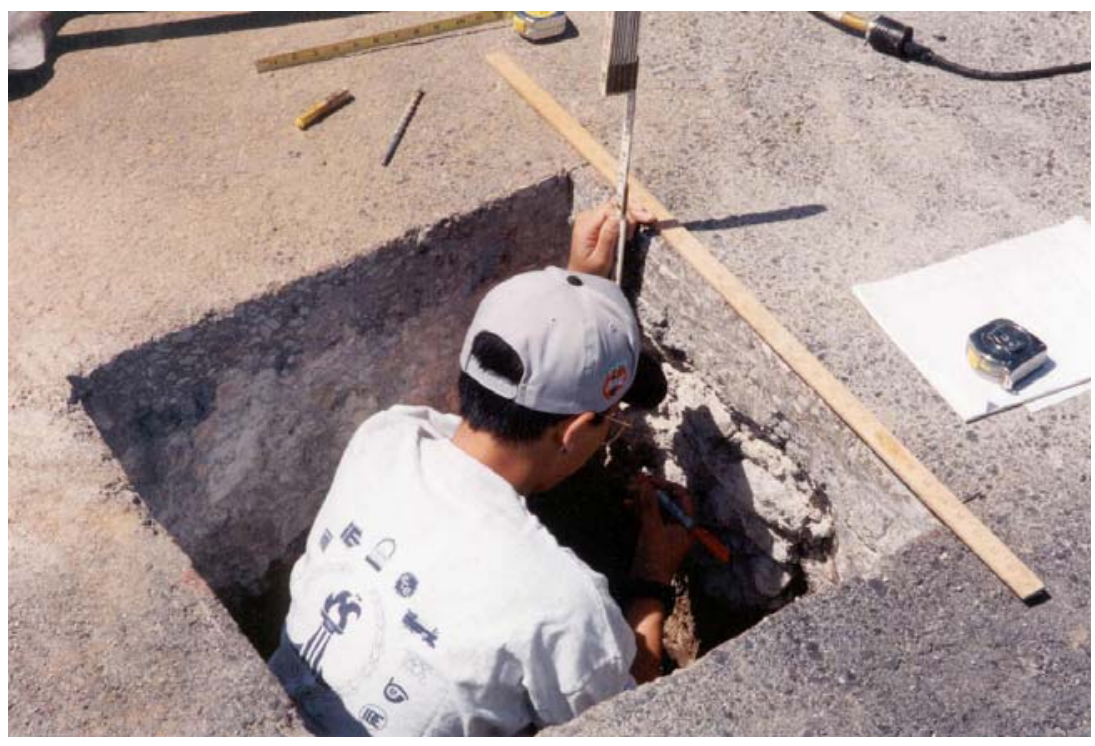

Figure 3.16 -- Instrumentation pit

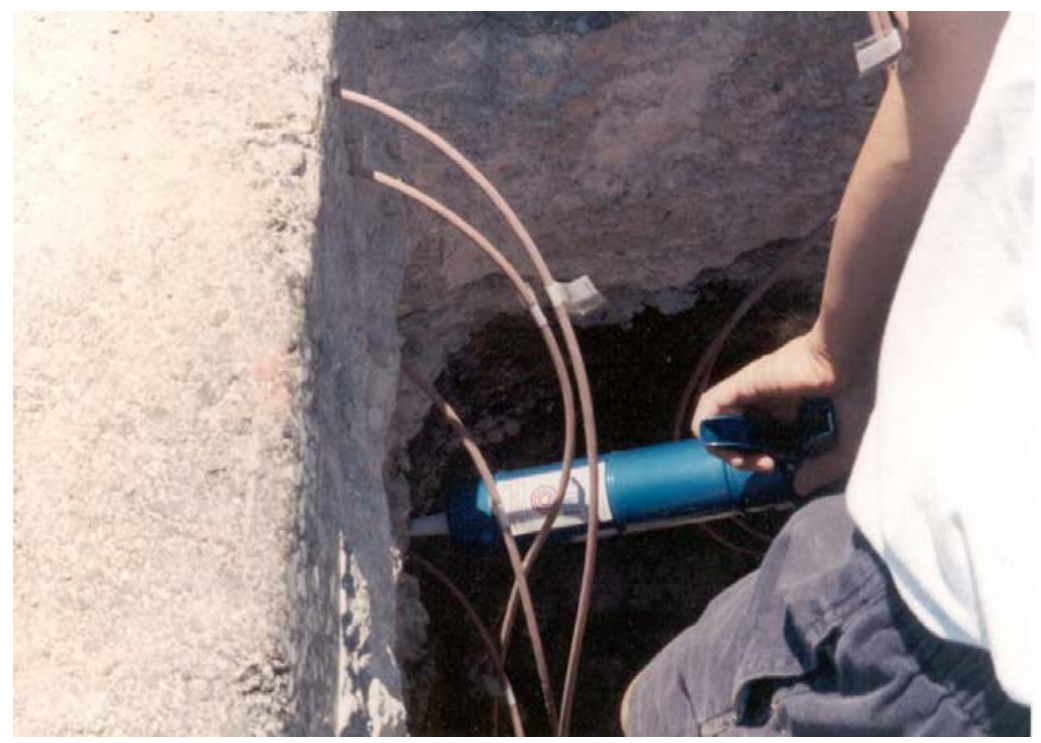

Figure 3.17 -- Sealing the sensor drill holes 
After the surface layer was compacted, the steel box was exposed by cutting and removing the upper layer on top of the box. The top two sensors were then removed from the box and installed into the holes drilled into the surface layer. After installation of the sensors in the surface layer, the holes were sealed with silicone and the exposed area was filled with bituminous patching material and compacted.

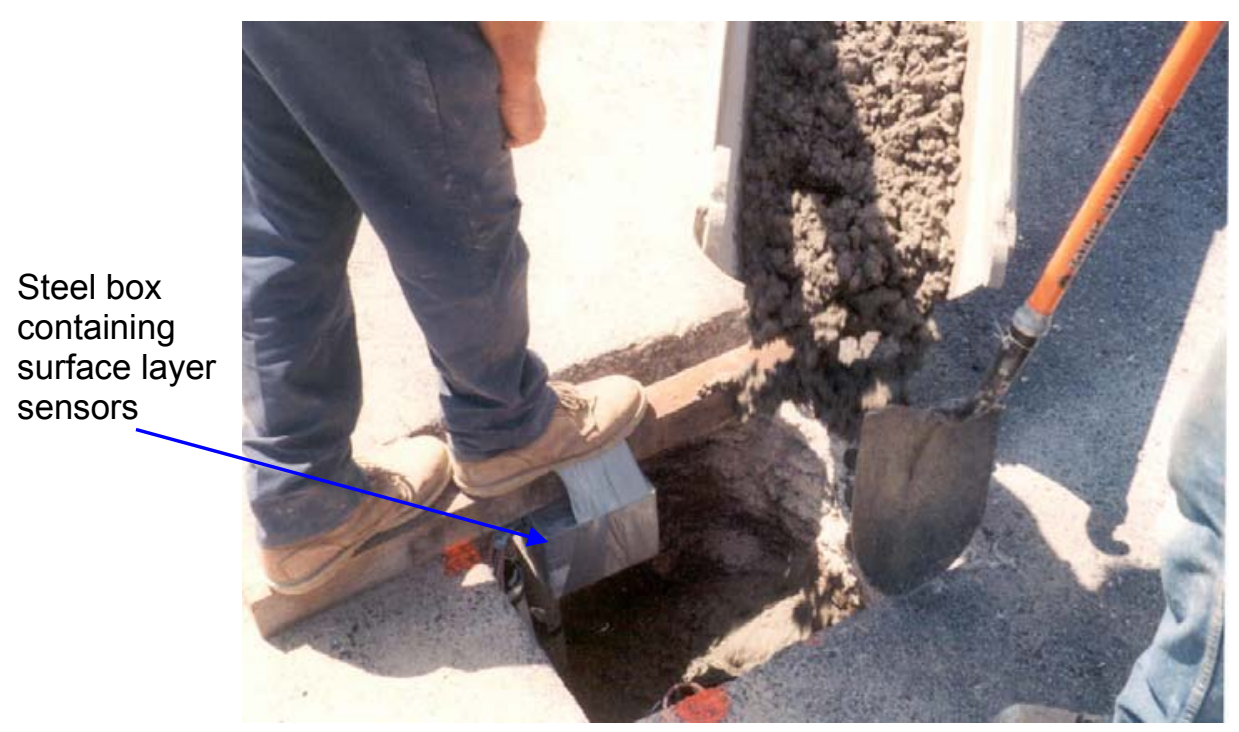

Figure 3.18 -- Backfilling the instrumentation pit with PCC

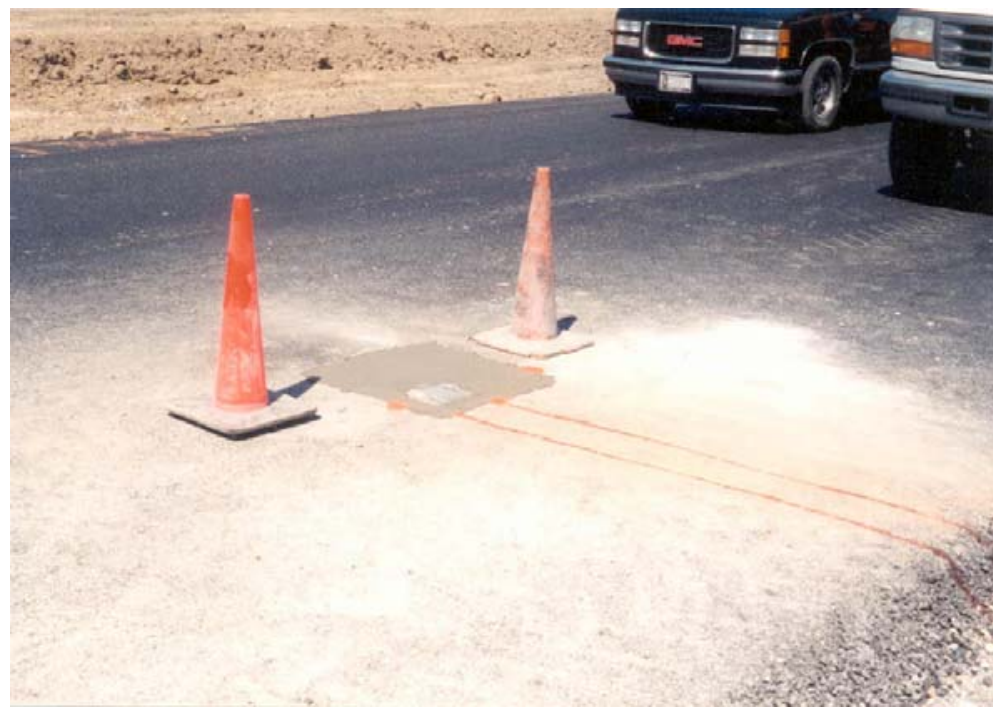

Figure 3.19 -- Steel box set flush with the intermediate layer encased in PCC 


\subsection{Quality Control Testing}

Quality control testing was conducted on plant mixture (truck) samples and the original binder samples collected at the time of construction. Tests on the loose and compacted mixtures samples included the determination of (a) maximum theoretical specific gravity $\left(G_{m m}\right)$, (b) asphalt content $\left(P_{b}\right)$, (c) bulk specific gravity $\left(G_{m b}\right)$, (d) gradation of extracted aggregate and (e) calculation of volumetric properties ( $\left.P_{a}, V M A, V F A\right)$. The original binders was tested to verify their performance grades, in addition to other tests such as, (a) specific gravity, (b) penetration, (c) absolute viscosity and (d) kinematic viscosity.

\subsubsection{Surface Course}

Table 3.3 shows the $G_{m m}, G_{m b}, P_{b(Q C)}$ and the volumetric properties of the surface course mixtures. The $G_{m m}$ and $P_{b(Q C)}$ data shown in Table 3.3 is average of two test results. The bulk specific gravity values shown in this table are the average values of six samples compacted to $\mathrm{N}_{\max }$ of 204 , from which $\mathrm{G}_{\mathrm{mb}}$ at $\mathrm{N}_{\text {des }}$ of 126 were estimated. The $\mathrm{P}_{\mathrm{q}(\mathrm{QC})}, \mathrm{VMA}_{(\mathrm{QC})}$ and $\mathrm{VFA}(\mathrm{QC})$ shown are estimated at $N_{\text {des }}$ by back-calculation. Table 3.4 shows the results of the sieve analysis performed on the extracted aggregate from each section of the surface courses. This table also shows the allowable tolerance values for the sieve sizes, per 1995 Indiana Standard Specifications 401.04, Acceptance of Mixtures.

The asphalt content values obtained from quality control (QC) tests was within the acceptable tolerance of $\pm 0.5 \%$ of the design value (shown in Table 3.1 ) in all surface mixtures, except the Marshall section (M-AC-20). The $\mathrm{P}_{\mathrm{a}(\mathrm{QC})}$ of S-64-28 mixture fell below the design $\mathrm{P}_{\mathrm{a}}$ of $4.0 \%$ at $\mathrm{N}_{\text {des }}$, specified in AASHTO MP2 (102). Low $\mathrm{P}_{\mathrm{a}(\mathrm{QC})}$ at $\mathrm{N}_{\text {des }}$ is indicative of potential for rutting problems early on in the life of the pavement. The $\mathrm{P}_{\mathrm{a}(\mathrm{QC})}$ of S-70-28 and S-6416 was much higher than the desired value, while the $P_{a(Q C)}$ of $S-58-28$ and $R-15 \%$ were close to 4.0\%. Only S-70-28 satisfied the minimum VMA requirement of $\geq 15.0$ (AASHTO MP2-95). The VMA of the remaining sections was below the minimum requirement. 
Table 3.3 -- Volumetric properties of the surface course mixtures

\begin{tabular}{|c|c|c|c|c|c|c|c|}
\hline \multirow{2}{*}{ Section ID } & \multirow{2}{*}{$\mathbf{G}_{\mathrm{mm}}$} & \multirow{2}{*}{$\begin{array}{c}P_{b(Q C)} \\
\%\end{array}$} & \multicolumn{2}{|c|}{$\mathbf{G}_{\mathrm{mb}}$} & \multirow{2}{*}{$\begin{array}{l}P_{\mathrm{a}(\mathrm{QC})} \\
\%\end{array}$} & \multirow{2}{*}{$\begin{array}{c}\operatorname{VMA}_{(Q C)} \\
\%\end{array}$} & \multirow{2}{*}{$\begin{array}{c}\operatorname{VFA}_{(Q C)} \\
\%\end{array}$} \\
\hline & & & $\mathbf{N}_{\max }$ & $\mathbf{N}_{\text {des }}$ & & & \\
\hline M-AC-20 & 2.474 & 5.5 & 2.307 & 2.265 & 7.6 & 14.8 & 2.474 \\
\hline S-64-28 & 2.438 & 6.8 & 2.391 & 2.340 & 3.0 & 14.4 & 2.438 \\
\hline S-58-28 & 2.482 & 6.8 & 2.406 & 2.358 & 4.3 & 13.9 & 2.482 \\
\hline R-15\% & 2.484 & 6.3 & 2.409 & 2.361 & 4.4 & 13.5 & 2.484 \\
\hline S-70-28 & 2.457 & 6.2 & 2.367 & 2.305 & 5.1 & 15.0 & 2.457 \\
\hline S-64-16 & 2.493 & 6.6 & 2.392 & 2.323 & 5.5 & 14.5 & 2.493 \\
\hline
\end{tabular}

Table 3.4 -- Results of sieve analysis of extracted aggregate from the surface mixtures

\begin{tabular}{|c|c|c|c|c||}
\hline \multirow{2}{*}{ Section ID } & \multicolumn{2}{|c|}{ Percent passing 4.75 mm } & \multicolumn{2}{c|}{ Percent passing 75 $\mathbf{~ m m}$} \\
\cline { 2 - 4 } & measured & $\begin{array}{c}\text { allowable } \\
\text { range }\end{array}$ & measured & $\begin{array}{c}\text { allowable } \\
\text { range }\end{array}$ \\
\hline \hline M-AC-20 & 62.5 & $56.0-67.1$ & 3.3 & $1.8-3.2$ \\
\hline S-64-28 & 60.4 & \multirow{2}{*}{$44.2-55.6$} & 5.1 & \multirow{2}{*}{$4.3-5.7$} \\
\hline S-58-28 & 59.0 & & 5.1 & \\
\hline R-15\% & 56.0 & $44.1-55.5$ & 5.5 & \multirow{2}{*}{$3.4-4.8$} \\
\hline S-70-28 & 50.2 & \multirow{2}{*}{$44.2-55.6$} & 4.8 & \multirow{2}{*}{$4.3-5.7$} \\
\cline { 1 - 1 } S-64-16 & 56.7 & 5.5 & \\
\hline
\end{tabular}

*per Indiana Standard Specifications 401.04

As is evident from Table $3.4, \mathrm{~S}-70-28$ was the only section that satisfied the tolerance criteria in both the sieve sizes, while R-15\% satisfied neither of the criteria. The results of the remaining sections were mixed.

\subsubsection{Intermediate Course}

Tables 3.5 and 3.6 show the volumetric properties of the intermediate course mixtures and the results from the sieve analysis, respectively. As in the case of the surface mixtures, the $\mathrm{P}_{\mathrm{a}(\mathrm{QC})}, \mathrm{VMA}_{(\mathrm{QC})}$ and $\mathrm{VFA} \mathrm{A}_{(\mathrm{QC})}$ shown here are the estimated values at $\mathrm{N}_{\text {des. }}$.

The $P_{b(Q C)}$ of M-AC-20, S-64-28, S-58-28 and S-70-28 satisfied the $\pm 0.5 \%$ tolerance range around the design value shown in Table 3.2, while R-15\% and S-64-16 did not. The $\mathrm{P}_{\mathrm{a}(\mathrm{QC})}$ of all the test sections fell below the minimum requirement of $4.0 \%$ (AASHTO MP2). $\mathrm{R}-15 \%$ did not satisfy the VMA and the VFA requirements of $\geq 13.0$ and $65-75$, respectively. All the other sections satisfied the VMA requirement, but showed mixed results in regard to VFA. 
Table 3.5 -- Volumetric properties of the intermediate course mixtures

\begin{tabular}{|c|c|c|c|c|c|c|c|}
\hline \multirow{2}{*}{ Section ID } & \multirow{2}{*}{$\mathbf{G}_{\mathrm{mm}}$} & \multirow{2}{*}{$\begin{array}{l}P_{b} \\
\%\end{array}$} & \multicolumn{2}{|c|}{$\mathbf{G}_{\mathrm{mb}}$} & \multirow{2}{*}{$\begin{array}{l}P_{a} \\
\%\end{array}$} & \multirow{2}{*}{$\begin{array}{c}\text { VMA } \\
\%\end{array}$} & \multirow{2}{*}{$\begin{array}{c}\text { VFA } \\
\%\end{array}$} \\
\hline & & & $\mathbf{N}_{\max }$ & $\mathbf{N}_{\text {des }}$ & & & \\
\hline M-AC-20 & 2.489 & 5.0 & 2.440 & 2.346 & 3.6 & 13.4 & 74.4 \\
\hline S-64-28 & 2.459 & 5.4 & 2.441 & 2.360 & 2.2 & 13.9 & 84.5 \\
\hline S-58-28 & 2.462 & 5.4 & 2.442 & 2.348 & 3.6 & 14.2 & 74.4 \\
\hline R-15\% & 2.499 & 4.2 & 2.488 & 2.392 & 2.0 & 11.3 & 82.6 \\
\hline S-70-28 & 2.453 & 5.4 & 2.428 & 2.339 & 2.6 & 14.5 & 82.2 \\
\hline S-64-16 & 2.480 & 4.6 & 2.440 & 2.346 & 3.2 & 13.4 & 76.2 \\
\hline
\end{tabular}

Table 3.6 -- Results of sieve analysis of extracted aggregate from the intermediate mixtures

\begin{tabular}{|c|c|c|c|c|c|c|}
\hline \multirow{2}{*}{$\begin{array}{l}\text { Section } \\
\text { ID }\end{array}$} & \multicolumn{2}{|c|}{$\begin{array}{l}\text { Percent passing } \\
12.5 \mathrm{~mm} \text { sieve }\end{array}$} & \multicolumn{2}{|c|}{$\begin{array}{l}\text { Percent passing } \\
4.75 \mathrm{~mm} \text { sieve }\end{array}$} & \multicolumn{2}{|c|}{$\begin{array}{l}\text { Percent passing } \\
75 \mu \mathrm{m} \text { sieve }\end{array}$} \\
\hline & measured & $\begin{array}{l}\text { allowable } \\
\text { range }\end{array}$ & measured & $\begin{array}{l}\text { allowable } \\
\text { range }\end{array}$ & measured & $\begin{array}{l}\text { allowable } \\
\text { range }\end{array}$ \\
\hline M-AC-20 & 76.8 & $64.3-75.7$ & 39.9 & $27.0-38.4$ & 3.7 & $1.8-3.2$ \\
\hline S-64-28 & 69.3 & \multirow{2}{*}{$71.8-83.5$} & 40.5 & \multirow{2}{*}{$37.8-49.2$} & 4.5 & \multirow{2}{*}{$2.6-4.0$} \\
\hline S-58-28 & 67.7 & & 41.0 & & 5.2 & \\
\hline R-15\% & 63.4 & $68.1-79.5$ & 34.8 & $33.0-44.4$ & 5.0 & $2.8-4.2$ \\
\hline S-70-28 & 77.1 & \multirow{2}{*}{$71.8-83.5$} & 45.3 & \multirow{2}{*}{$37.8-49.2$} & 4.5 & \multirow{2}{*}{$2.6-4.0$} \\
\hline S-64-16 & 70.0 & & 40.1 & & 4.7 & \\
\hline
\end{tabular}

All the test sections failed to meet the allowable range for percent passing the 75- $\mu \mathrm{m}$ sieve. All the sections, except M-AC-20, satisfied the criteria for $4.75 \mathrm{~mm}$ sieve. Whereas, all the sections, except S-70-28, did not satisfy the criteria for $12.5 \mathrm{~mm}$ sieve.

Independent quality control testing was also conducted by the INDOT Materials and Test Division (M\&T) at Indianapolis. These results, based on one sample, are presented in Tables 3.7 through 3.9. The $\mathrm{P}_{\mathrm{b}(\mathrm{des})}$ values from the job-mix formula (JMF) is also shown in Table 3.7 for comparison. These results indicate that the mixtures used in the field satisfied the gradation specification requirements and that the binder content was close to the JMF values shown, in most cases. Difference in $\mathrm{P}_{\mathrm{b}(\mathrm{QC})}$ values obtained by the M\&T laboratories and Purdue University laboratories (reported earlier in Tables 3.3 through 3.6) may be attributed to differences in extraction technique and day of mixture sample collection. In addition, the M\&T lab 
conducted only one trial run while the Purdue University lab conducted 2 trials and reported the average values.

Table 3.7 -- Binder content results obtained by INDOT M\&T lab

\begin{tabular}{|c|c|c||c|c||}
\hline \multirow{2}{*}{ Section ID } & \multicolumn{2}{|c|}{ Surface Course } & \multicolumn{2}{c|}{ Intermediate Course } \\
\cline { 2 - 5 } & M\&T Lab & JMF & M\&T Lab & JMF \\
\hline \hline M-AC-20 & 5.6 & 6.2 & 4.3 & 4.3 \\
\hline S-64-28 & 6.5 & 6.5 & 5.2 & 5.0 \\
\hline S-58-28 & 6.2 & 6.5 & 5.6 & 5.0 \\
\hline R-15\% & 6.5 & 6.4 & 4.8 & 4.7 \\
\hline S-70-28 & 6.2 & 6.5 & 4.5 & 5.0 \\
\hline S-64-16 & 6.6 & 6.5 & 4.5 & 5.0 \\
\hline
\end{tabular}

Table 3.8 -- Sieve analysis results obtained by M\&T lab for the surface mixes

\begin{tabular}{|c||c|c||c|c||c|c|c|c|c||}
\hline Sieve Size & $\begin{array}{c}\text { Req. \% } \\
\text { pass }\end{array}$ & M-AC-20 & $\begin{array}{c}\text { Req. \% } \\
\text { pass }\end{array}$ & R-15\% & $\begin{array}{c}\text { Req. \% } \\
\text { pass }\end{array}$ & S-64-28 & S-58-28 & S-70-28 & S-64-16 \\
\hline \hline $\mathbf{4 . 7 5} \mathbf{~ m m}$ & $48-71$ & 66.1 & -- & -- & -- & -- & -- & -- & - \\
\hline $\mathbf{2 . 3 6} \mathbf{~ m m}$ & -- & -- & $24-55.2$ & 46.1 & $24-55$ & 41.5 & 39.9 & 39.9 & 41.3 \\
\hline $\mathbf{6 0 0} \mathbf{~} \mathbf{m}$ & $6-39$ & 26.4 & $0-27.5$ & 21.2 & $0-27.5$ & 20.8 & 19.5 & 19.5 & 20.1 \\
\hline $\mathbf{7 5} \mathbf{~ m m}$ & $0-4.5$ & 3.6 & $1-11$ & 5.9 & $1-11$ & 6.9 & 5.4 & 5.4 & 5.5 \\
\hline
\end{tabular}

Table 3.9 -- Sieve analysis results obtained by M\&T lab for the intermediate mixes

\begin{tabular}{|c||c|c||c|c||c|c|c|c|c||}
\hline Sieve Size & $\begin{array}{c}\text { Req. \% } \\
\text { pass }\end{array}$ & M-AC-20 & $\begin{array}{c}\text { Req. \% } \\
\text { pass }\end{array}$ & R-15\% & $\begin{array}{c}\text { Req. \% } \\
\text { pass }\end{array}$ & S-64-28 & S-58-28 & S-70-28 & S-64-16 \\
\hline $\mathbf{1 9} \mathbf{~ m m}$ & $80-98$ & 95.3 & $90-100$ & 95.9 & $90-100$ & 94.9 & 96.4 & 92.9 & 95.1 \\
\hline $\mathbf{1 2 . 5} \mathbf{~ m m}$ & $46-90$ & 77.8 & -- & -- & -- & -- & -- & -- & -- \\
\hline $\mathbf{4 . 7 5} \mathbf{~ m m}$ & $15-50$ & 40.9 & -- & -- & -- & -- & -- & -- & - \\
\hline $\mathbf{2 . 3 6} \mathbf{~ m m}$ & -- & -- & $13-44.6$ & 30.7 & $13-44.6$ & 32.7 & 28.0 & 27.0 & 31.6 \\
\hline $\mathbf{6 0 0} \mathbf{~} \mathbf{m}$ & $0-30$ & 17.8 & $0-22.7$ & 13.5 & $0-22.7$ & 13.8 & 11.7 & 11.3 & 13.2 \\
\hline $\mathbf{7 5} \mathbf{~} \mathbf{m}$ & $0-6$ & 4.8 & $0-10$ & 5.6 & $0-10$ & 5.6 & 4.9 & 5.2 & 5.2 \\
\hline
\end{tabular}




\subsubsection{Binder Samples}

Quality control tests were also conducted on the original binders used in the project to verify their performance grade. In addition, other properties of the original binder samples were also determined to provide complete characterization of the binder. These tests are listed below:

- specific gravity at $16^{\circ} \mathrm{C}, \mathrm{G}_{\mathrm{b}}$ (AASHTO T228),

- penetration at $5^{\circ} \mathrm{Cand} 25^{\circ} \mathrm{C}(\mathrm{AASHTO} \mathrm{T} 49)$,

- rotational viscosity at $135^{\circ} \mathrm{C}$ and $165^{\circ} \mathrm{C}$ (AASHTO TP48),

- absolute viscosity at $60^{\circ} \mathrm{C}$ (AASHTO T202),

- $\quad$ kinematic viscosity at $135^{\circ} \mathrm{C}$ (AASHTO T201),

- complex shear modulus, $\left|G^{*}\right|$ (AASHTO TP5) using the DSR,

- flexural creep stiffness, S (AASHTO TP1) using the BBR and

- failure stress and strain, $\sigma_{f}$ and $\varepsilon_{f}$ (AASHTO TP3) using the DTT.

Table 3.10 shows the penetration and viscosity test data for the binders used in this project. The viscosity data were later used to determine the mixing and compaction temperature range for each binder. The rotational viscosity of all the binders was below the limit of 3 Pa-s specified in AASHTO MP1 (103). It is noteworthy that the specific gravity of the modified binder, PG70-28, was less than 1.000 and that this binder exhibited the tendency to form very long, unbroken strings.

Table 3.10 -- Specific gravity, penetration and viscosity of the binders

\begin{tabular}{|c|c|c|c|c|c|c|c|}
\hline \multirow{3}{*}{$\begin{array}{l}\text { Binder } \\
\text { Grade }\end{array}$} & \multirow{3}{*}{$\mathbf{G}_{\mathrm{b}}$} & \multicolumn{2}{|c|}{ Penetration $(0.1 \mathrm{~mm})$} & \multicolumn{4}{|c|}{ Viscosity } \\
\hline & & \multirow{2}{*}{$@ 5^{\circ} \mathrm{C}$} & \multirow{2}{*}{$@ 25^{\circ} \mathrm{C}$} & \multirow{2}{*}{$\begin{array}{l}\text { Absolute } \\
\text { (P) }\end{array}$} & \multirow{2}{*}{$\begin{array}{l}\text { Kinematic } \\
\text { (cSt) }\end{array}$} & \multicolumn{2}{|c|}{ Rotational (Pa-s) } \\
\hline & & & & & & $135^{\circ} \mathrm{C}$ & $165^{\circ} \mathrm{C}$ \\
\hline$A C-20$ & 1.026 & 26 & 89 & 1569 & 624 & 456 & 113 \\
\hline PG64-28 & 1.023 & 36 & 79 & 1118 & 556 & 408 & 92 \\
\hline PG58-28 & 1.017 & 53 & 124 & 656 & 263 & 273 & 73 \\
\hline PG70-28 & 0.962 & 56 & 68 & 4171 & 593 & 529 & 119 \\
\hline PG64-16 & 1.032 & 16 & 31 & 2343 & 454 & 425 & 98 \\
\hline
\end{tabular}


Tables $3.11,3.12$ and 3.13 show the results of DSR testing of the original, RFTO-aged and RFTO-PAV aged binders, respectively. The BBR test results are presented in Table 3.14. These data indicate that AC-20 can be classified as a PG64-22 using the performance grading system. The results of these performance tests indicate that the binders used in the study satisfy the performance criteria at the specified temperature grade of the binder, as per AASHTO PP6 (104).

Table 3.11 -- DSR test results of original binders

\begin{tabular}{|c|c|c|c|c|c||}
\hline \multirow{2}{*}{$\begin{array}{c}\text { Test } \\
\text { Temperature } \\
{ }^{\circ} \mathbf{C}\end{array}$} & \multicolumn{5}{|c|}{ (G*//sind (kPa) } \\
\cline { 2 - 6 } & AC-20 & PG64-28 & PG58-28 & PG70-28 & PG64-16 \\
\hline \hline $\mathbf{5 2}$ & & & 2.86 & & \\
\hline $\mathbf{5 8}$ & 3.25 & 3.90 & 1.27 & & 5.36 \\
\hline $\mathbf{6 4}$ & 1.31 & 1.73 & 0.53 & 2.77 & 1.99 \\
\hline $\mathbf{7 0}$ & 0.41 & 0.84 & & 1.39 & 0.91 \\
\hline $\mathbf{7 6}$ & & & & 0.69 & \\
\hline
\end{tabular}

Table 3.12 -- DSR test results of RFTO-aged binders

\begin{tabular}{|c|c|c|c|c|c|}
\hline \multirow{2}{*}{$\begin{array}{c}\text { Test } \\
\text { Temperature } \\
{ }^{\circ} \mathbf{C}\end{array}$} & \multicolumn{5}{|c|}{ (G $^{*} \mid / \mathbf{s i n}$ (kPa) } \\
\cline { 2 - 6 } & AC-20 & PG64-28 & PG58-28 & PG70-28 & PG64-16 \\
\hline $\mathbf{5 2}$ & & & 5.70 & & \\
\hline $\mathbf{5 8}$ & 6.34 & 4.88 & 2.40 & & 5.76 \\
\hline $\mathbf{6 4}$ & 2.78 & 2.34 & 1.07 & 5.11 & 2.18 \\
\hline $\mathbf{7 0}$ & 1.11 & 1.09 & & 2.84 & 1.26 \\
\hline $\mathbf{7 6}$ & & & & 0.56 & \\
\hline
\end{tabular}

Table 3.13 -- DSR test results of RFTO-PAV aged binders

\begin{tabular}{|c|c|c|c|c|c|}
\hline \multirow{2}{*}{$\begin{array}{c}\text { Test } \\
\text { Temperature } \\
{ }^{\circ} \mathrm{C}\end{array}$} & \multicolumn{5}{|c|}{$\begin{array}{c}\left|\mathrm{G}^{*}\right| \sin \delta(\mathrm{kPa}) \\
\text { (AASHTO PP6 limit }=5000 \mathrm{kPa} \text { max.) }\end{array}$} \\
\hline & AC-20 & PG64-28 & PG58-28 & PG70-28 & PG64-16 \\
\hline 31 & & & & & 4802 \\
\hline 28 & 2656 & & & $x$ & 6716 \\
\hline 25 & 4010 & 2227 & & $x$ & 9367 \\
\hline 22 & 5902 & 3327 & 3565 & $x$ & \\
\hline 19 & & 5061 & 4961 & & \\
\hline 16 & & & 7339 & & \\
\hline
\end{tabular}


Table 3.14 -- BBR test results of RFTO-PAV aged binders

\begin{tabular}{|c|c|c|c|c|c|c|c|c|c|c|}
\hline \multirow{2}{*}{$\begin{array}{c}\text { Test } \\
\text { Temperature } \\
{ }^{\circ} \mathrm{C}\end{array}$} & \multicolumn{2}{|c|}{ AC-20 } & \multicolumn{2}{|c|}{ PG64-28 } & \multicolumn{2}{|c|}{ PG58-28 } & \multicolumn{2}{|c|}{ PG70-28 } & \multicolumn{2}{|c|}{ PG64-16 } \\
\hline & $\begin{array}{c}\mathrm{S}, \\
\mathrm{MPa}\end{array}$ & $\mathbf{m}$ & $\begin{array}{c}\mathrm{S}, \\
\mathrm{MPa}\end{array}$ & $\mathbf{m}$ & $\begin{array}{c}\mathrm{S}, \\
\mathrm{MPa}\end{array}$ & m & $\begin{array}{c}\mathrm{S}, \\
\mathrm{MPa}\end{array}$ & $\mathbf{m}$ & $\begin{array}{c}\mathrm{S}, \\
\mathrm{MPa}\end{array}$ & $\mathbf{m}$ \\
\hline-6 & & & & & & & & & 112 & 0.318 \\
\hline-12 & 186 & 0.314 & & & & & & & 357 & 0.252 \\
\hline-18 & 415 & 0.267 & 200 & 0.314 & 196 & 0.302 & 70 & 0.307 & & \\
\hline-24 & & & 329 & 0.276 & 441 & 0.246 & 132 & 0.294 & & \\
\hline
\end{tabular}

Table 3.15 -- DT test results of RFTO-PAV aged binders

\begin{tabular}{|c|c|c|c|c|c|c|c|c|c|c|}
\hline \multirow{2}{*}{$\begin{array}{c}\text { Test } \\
\text { Temperature } \\
{ }^{\circ} \mathrm{C}\end{array}$} & \multicolumn{2}{|c|}{$A C-20$} & \multicolumn{2}{|c|}{ PG64-28 } & \multicolumn{2}{|c|}{ PG58-28 } & \multicolumn{2}{|c|}{ PG70-28 } & \multicolumn{2}{|c|}{ PG64-16 } \\
\hline & $\begin{array}{c}\sigma_{\mathrm{f}} \\
\mathrm{MPa}\end{array}$ & $\begin{array}{l}\varepsilon_{\mathrm{f}}, \\
\%\end{array}$ & $\begin{array}{c}\sigma_{\mathrm{f}} \\
\mathrm{MPa}\end{array}$ & $\begin{array}{l}\varepsilon_{\mathrm{f}}, \\
\%\end{array}$ & $\begin{array}{c}\sigma_{\mathrm{f}}, \\
\mathrm{MPa}\end{array}$ & $\begin{array}{l}\varepsilon_{f}, \\
\%\end{array}$ & $\begin{array}{c}\sigma_{\mathrm{f}} \\
\mathrm{MPa}\end{array}$ & $\begin{array}{l}\varepsilon_{f}, \\
\%\end{array}$ & $\begin{array}{c}\sigma_{\mathrm{f}} \\
\mathrm{MPa}\end{array}$ & $\begin{array}{l}\varepsilon_{\mathrm{f}}, \\
\%\end{array}$ \\
\hline-6 & & & & & & & & & 2.45 & 0.78 \\
\hline-12 & 3.52 & & & & & & & & 2.18 & 0.37 \\
\hline-18 & 2.91 & & 4.45 & 2.06 & 4.05 & 1.14 & 2.12 & $>10.0$ & & \\
\hline-24 & & & 3.92 & 0.80 & 2.54 & 0.34 & 3.90 & $>10.0$ & & \\
\hline
\end{tabular}

\subsection{Subgrade Properties}

In addition to the above-mentioned quality control tests, soil testing was also conducted to determine the properties of the underlying subgrade and subbase soil. Auger holes were drilled at various points along the shoulder to obtain soil samples for testing. Tests conducted on these soils samples included the Atterberg limits, sieve analysis, moisture content, etc. Based on these data, the subbase soil at all the test section was classified as "A-1-a" and "sandy silt with gravel", according to AASHTO M145 (105) and ASTM D2488 (106), respectively. Soils classified as "A-1-a" have plasticity index $(\mathrm{PI}) \leq 6$ and the cumulative percent passing the no. 10 , no. 40 and no. 200 sieves are $\leq 50, \leq 30$ and $\leq 15$, respectively. Soils classified as "sandy silt with gravel" according to ASTM D2488 meet the following criteria: $\mathrm{PI}<4$, cumulative percent passing sieve no. $200<30$ and the percentage of gravel $\geq 15$.

The subgrade soil classification is given in Table 3.16. The AASHTO and ASTM criteria for these soil classifications are given in Table 3.17. 
Table 3.16 -- Subgrade soil classification

\begin{tabular}{|c||c||c||c||}
\hline Section ID & Location $^{*}$ & $\begin{array}{c}\text { AASHTO } \\
\text { Designation }\end{array}$ & ASTM Designation \\
\hline \multirow{2}{*}{ M-AC-20 } & A & A-2-6 & sandy lean clay \\
& B & A-1-b & sandy silty clay \\
\hline \multirow{2}{*}{ S-64-28 } & A & A-6 & sandy lean clay \\
& B & A-6 & sandy lean clay \\
\hline \multirow{2}{*}{ S-58-28 } & A & A-6 & sandy lean clay \\
& B & A-6 & sandy lean clay w/ gravel \\
\hline \multirow{2}{*}{ R-15\% } & A & A-6 & sandy lean clay \\
& B & A-6 & sandy lean clay \\
\hline S-70-28 & A & A-6 & sandy lean clay \\
S-64-16 & B & A-4 & sandy silty clay \\
\hline \hline
\end{tabular}

${ }^{*} \mathrm{~A}=$ before the monitoring region; $\mathrm{B}=$ after the monitoring region

Table 3.17 -- AASHTO and ASTM criteria for the soil classifications shown in Table 3.16

\begin{tabular}{|c|c|c|}
\hline Classification & & Criteria \\
\hline$A-1-b$ & $\mathrm{PI} \leq 6$ & $\begin{array}{c}\text { percent passing } \\
\text { no. } 10 \leq 50 \\
\text { no. } 40 \leq 30 \\
\text { no. } 200 \leq 15 \\
\end{array}$ \\
\hline A-2-6 & $\begin{array}{l}\mathrm{LL} \leq 40 \\
\mathrm{PI} \geq 11\end{array}$ & percent passing no. $200 \leq 35$ \\
\hline A-4 & $\begin{array}{l}\mathrm{LL} \leq 40 \\
\mathrm{PI} \leq 10\end{array}$ & percent passing no. $200 \geq 36$ \\
\hline A-6 & $\begin{array}{l}\mathrm{LL} \leq 40 \\
\mathrm{PI} \geq 11\end{array}$ & percent passing no. $200 \geq 36$ \\
\hline sandy lean clay & $\begin{aligned} \mathrm{LL} & <50 \\
\mathrm{PI} & >7\end{aligned}$ & $\begin{array}{c}\text { percent passing no. } 200 \geq 30 \\
\text { percent gravel }<15\end{array}$ \\
\hline $\begin{array}{c}\text { sandy lean clay } \\
\text { w/ gravel }\end{array}$ & $\begin{array}{c}\mathrm{LL}<50 \\
\mathrm{PI}>7\end{array}$ & $\begin{array}{c}\text { percent passing no. } 200 \geq 30 \\
\text { percent gravel } \geq 15\end{array}$ \\
\hline sandy silty clay & $\begin{array}{c}\mathrm{LL}<50 \\
4 \leq \mathrm{PI} \leq 7\end{array}$ & $\begin{array}{c}\text { percent passing no. } 200 \geq 30 \\
\text { percent gravel }<15\end{array}$ \\
\hline
\end{tabular}




\section{CHAPTER 4 -- FIELD EVALUATION OF TEST SECTIONS}

\subsection{Background}

Field evaluation of the study site was conducted at regular intervals to provide data for assessment of the long-term performance of the test sections. Data from field surveys could be used to provide validation for the SUPERPAVE Binder Selection program. Field evaluations were conducted by the Long-Term Pavement Performance (LTPP) North Central Regional Coordinator's office of ERES Consultants, who were monitoring this SPS9-A site on behalf of the Federal Highway Administration (FHWA). Field evaluations included (i) manual distress surveys (pavement condition surveys) conducted every 2.5 years (ii) transverse profile measurements (Dipstick ${ }^{\circledR}$ ) taken every 2.5 years and (iii) longitudinal profile measurements $(\mathrm{K} . \mathrm{J}$. Law Profilometer ${ }^{\circledR}$ ) taken every year.

In addition to field evaluations, the weather and traffic conditions at the test site were also monitored during the study period. Weather data was downloaded from the test site remotely via a phone link from Purdue University. As mentioned earlier in Chapter 3 , one of the test sections (S-58-28) was instrumented with temperature sensors that were connected to a weather station that was installed at the test site. In addition of pavement temperature, other data such as air temperature, relative humidity, solar radiation, wind speed and wind direction were also recorded at 15-minute intervals. The instruments used for measuring and recording these data were obtained from Campbell Scientific, Inc.

Traffic count and vehicle classification data from the mainline was obtained from the weigh-in-motion (WIM) station located a few miles east of the test site. These data were obtained from Indiana Department of Transportation (INDOT), Division of Program Development, located at Indianapolis. To get a better estimate of vehicular traffic at the test site, axle and loop 
sensors were installed on the exit and entry ramps located between the test site and the WIM station. Automatic data recorders (ADR 3000), supplied by Peak Traffic Inc., were used to collect the vehicle count and classification data at the entry and exit ramps. Data from the mainline WIM was adjusted by taking into consideration the volume of traffic exiting off and entering the highway (mainline) between the test section and the WIM station.

\section{$\underline{4.2}$ Data Collection}

\subsubsection{Manual Condition Surveys}

Data collected during manual condition surveys were used to create crack maps of the driving lane for all the test sections. These crack maps show the location, length and severity of the longitudinal and transverse cracks present in each $150 \mathrm{~m}$ of the test section. Figure 4.1 shows a typical example of a crack map. Longitudinal cracks typically run parallel to the centerline of the pavement, and are associated with load-related distress and poor construction. Transverse cracks run perpendicular to the centerline and are caused due to excessive thermal stress build up and thermal fatigue, i.e., non-load related.

The guidelines for defining the severity of the cracks are described in the SHRPP-338 report, titled "Distress Identification Manual for Long-Term Pavement Performance Project" (107). The longitudinal and transverse cracks identified in each test section were categorized into three levels of intensity (low, medium and high) based on the crack width. Cracks are defined as "low" if "an unsealed crack has a mean width $\leq 6 \mathrm{~mm}$; or a sealed crack with sealant material in good condition and has a width that cannot be determined"; as "moderate" if "mean width $>6 \mathrm{~mm}$ and $\leq 19 \mathrm{~mm}$; or any crack with a mean width $\leq 19 \mathrm{~mm}$ and adjacent low severity random cracking"; and, "high" if "mean width $>19 \mathrm{~mm}$; or any crack with a mean width $\leq 19 \mathrm{~mm}$ and adjacent moderate to high severity random cracking". These cracks were identified as "L", "M" and " $\mathrm{H}$ " on crack maps, as shown in Figure 4.1. The number of transverse cracks in each category was noted. Cracks less than $0.3 \mathrm{~mm}$ in length were not noted. In the case of longitudinal cracks, the position of the crack with respect to the wheel path was also noted, i. e., 
wheel path (WP) versus non-wheel path (NWP). Table 4.1 shows the magnitude of distress magnitude used by LTPP in assessing the relative performance of LTPP test sites.

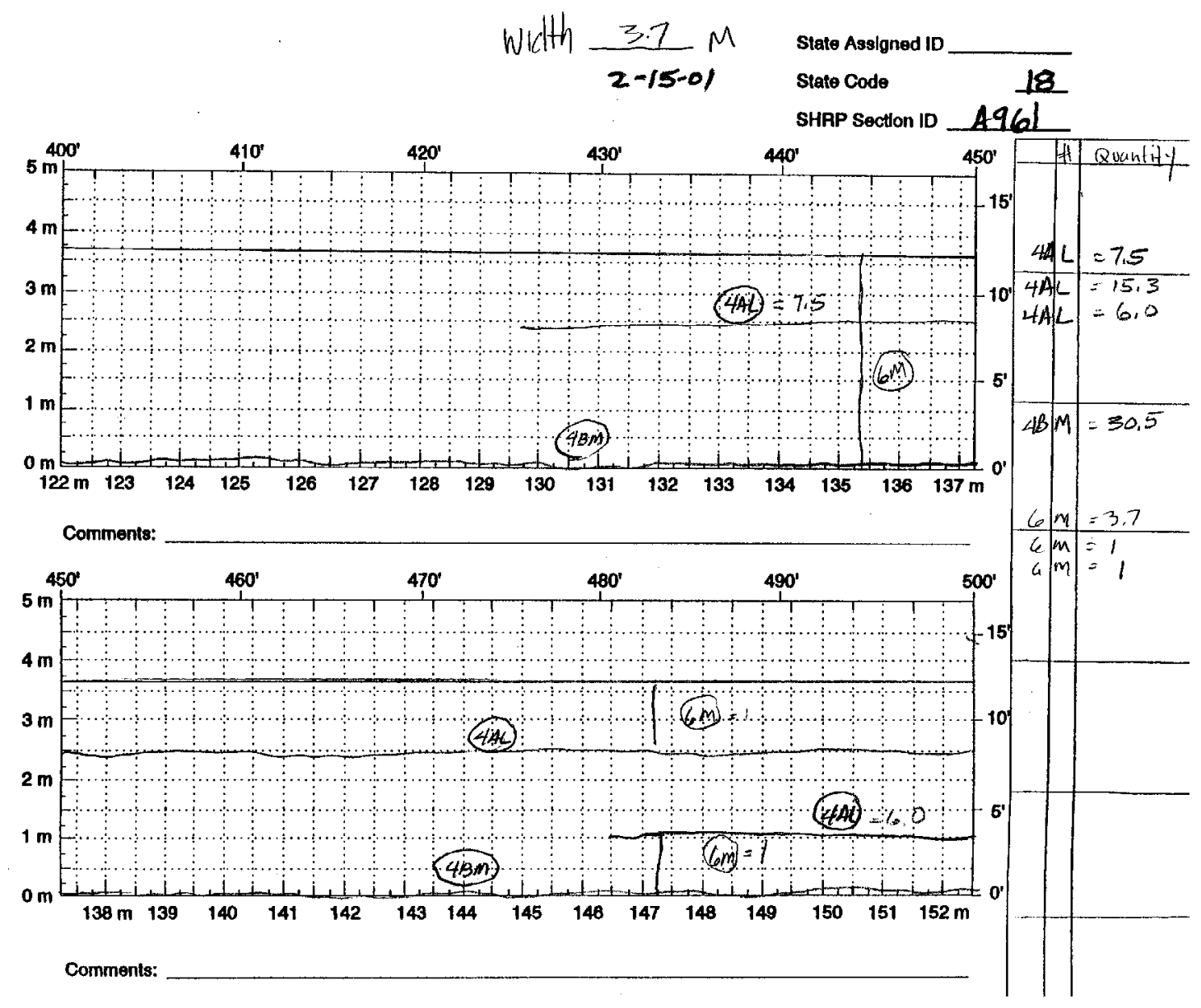

Figure 4.1 -- Example of a crack map

Table 4.1 -- Magnitude of distress for each category (LTTP Tech Brief, November 2000)

\begin{tabular}{|l|c|c|c||}
\hline \multicolumn{1}{|c|}{ Distress Type } & Nominal & Moderate & Excessive \\
\hline Transverse cracking, number & $1-10$ & $11-60$ & $>60$ \\
\hline Longitudinal cracking in the wheel path, $\mathrm{m}$ & $1-50$ & $51-160$ & $>160$ \\
\hline Longitudinal cracking not in the wheel path, $\mathrm{m}$ & $1-50$ & $51-160$ & $>160$ \\
\hline Rutting, $\mathrm{mm}$ & $<7$ & $7-20$ & $>20$ \\
\hline
\end{tabular}




\subsubsection{Transverse Profiling}

Dipstick $^{\circledR}$ manufactured by Face ${ }^{\circledR}$ companies was used to obtain transverse profiles of the test sections concurrently with the pavement condition surveys. The Dipstick consists of an inclinometer and an LCD display unit attached to a footpad (305-mm long). Figure 4.2 shows an example of a Dipstick ${ }^{\circledR}$ used to measure the transverse profile of pavements. The LCD display shows the difference in elevation between the two contact points of the footpad as the width of the lane is traversed. Profile readings are taken at every $15-\mathrm{m}$ interval along the test section, at approximately $300 \mathrm{~mm}$ intervals across the traverse line. Two runs per profile are conducted (up and down the same transverse line) to form a closed loop survey. Other details may be obtained from the SHRP-P-338 report (107) mentioned earlier.

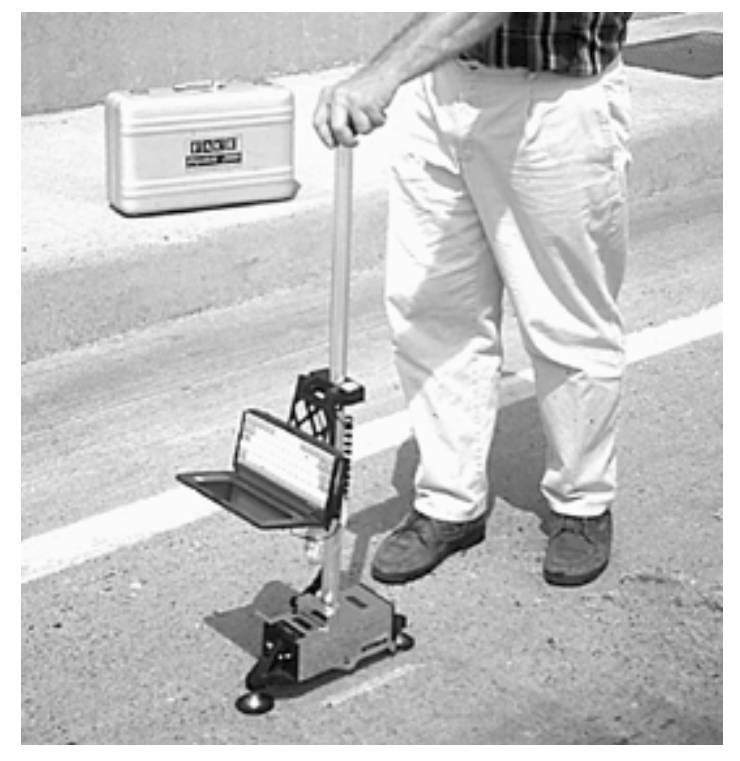

Figure 4.2 -- Example of Face ${ }^{\circledR}$ Companies Dipstick $^{\circledR}$

Transverse profile data is used to calculate rut depth at 15-m intervals along the length of the test section. This data is collected in form of $x$ and $y$ coordinates. The $x$-coordinate represents the distance from the starting point of the traverse line, typically the edge of the pavement. The y-coordinate represents the difference in elevation between successive points 
(typically $305 \mathrm{~mm}$ apart) on the traverse line. In addition to rut depth and rut width, these data may be used to calculate other indices recommended by the Distress and Data Analysis Expert Task Groups (ETGs), such as fill area, positive and negative areas, radius of curvature, etc.

\subsubsection{Longitudinal Profiling}

The K. J. Law Profilometer ${ }^{\circledR}$ T6600 was used to collect longitudinal road profile data of the wheel paths in the driving lane. These non-contact inertial profilometers are capable of collecting data while travelling at speeds between $16-112 \mathrm{~km} / \mathrm{h}(10-70 \mathrm{mph})$. Figure 4.3 shows an example of a typical K. J. Law Profilometer used to collect pavement profile and roughness data. Measurements are taken by three infrared displacement sensor assemblies mounted at the front bumper of the van. Two of the sensors are located in the two wheel paths and the third sensor, located in the center of the vehicle, is used to compute the rut depth using the three-point method. The two outer sensors could be adjusted laterally up to $\pm 50 \mathrm{~mm}$ each (2") to accommodate different center-to-center distances of different vehicle types. In addition to displacement transducers, accelerometers and distance measurement sensors are also mounted on the van to record the vertical acceleration, the longitudinal distance travelled and the speed of the van. Further operational details for this profilometer may be obtained from the report titled, "Manual for Profile Measurement: Operational Field Guidelines", SHRP-P-378 (108) and the "T6600 Profilometer Operation Manual", available at the K. J. Law Profilometer web-site last accessed in October 2003 (http://www.kjlaw.com/tte_systems.htm).

The profile data points were collected every inch, averaged over a 12-inch interval (running average) and stored in an on-board computer at every $150 \mathrm{~mm}$ (6") of distance travelled. The average speed of the profilometer was $80 \mathrm{~km} / \mathrm{h}(49.5 \mathrm{mph})$. The automated rut data measurement was output in form of root mean square vertical acceleration (RMSVA). In addition to longitudinal profile data, pavement smoothness indices such as International Roughness Index (IRI) and the Mays Ride Meter readings were also measured. 


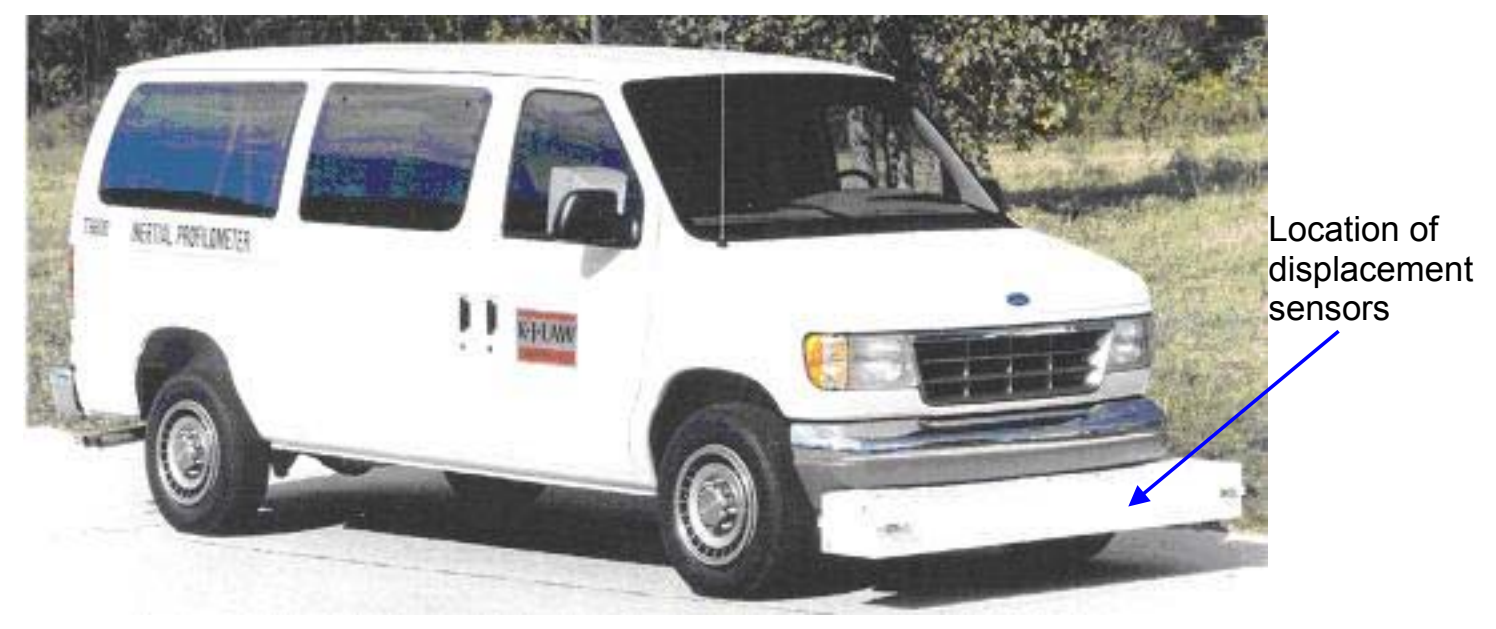

Figure 4.3 -- Example of K.J. Law Profilometer ${ }^{\circledR}$

To obtain digital transverse profiles, PASCO RoadRecon ${ }^{\circledR}$ system was used. This system consists of a 35-mm camera mounted on boom at the top of a van. Photographs are taken approximately every $15 \mathrm{~m}(50 \mathrm{ft})$ of test section at night. The camera is synchronized with a strobe, which has a hairline etched on a glass plate. When the camera is triggered, the strobe projects a shadow of the hairline on the pavement that is captured on film and later digitized along with the coordinates of the hairline image. The film is then used to obtain the digital transverse profile of the pavement. For SPS projects with different test sections, as in this study, the entire project is filmed many times to obtain at least two best complete passes. Further details regarding data collection and data analysis may be obtained from the report titled, "Photographic Pavement Distress Record Collection and Transverse Profile Analysis", SHRP-P660 (109).

\subsubsection{Air and Pavement Temperatures}

To monitor temperature at the pavement surface and at different depths in the pavement, thermocouples were installed in the pavement and in the subbase. Two thermocouples aligned east and west, respectively, were installed at each depth and their readings were averaged to provide temperature at the given depth. In addition, thermistors were 
also installed at the same depth for redundancy in case of failure of thermocouples. Locations of the sensors in the pavement were shown in Chapter 3. Temperature data was used to calculate the monthly and hence the design minimum and maximum air and pavement temperatures, as per SUPERPAVE definitions. In SUPERPAVE design methodology, the design minimum air and pavement temperatures are defined as the lowest minimum air and pavement surface temperatures occurring at a given location, respectively. The design maximum air temperature is defined as the highest 7-day mean high air temperature occurring at any given location. Similarly, the design maximum pavement temperature is defined at the highest 7-day mean high pavement temperature, and is calculated at $20 \mathrm{~mm}$ depth.

\subsubsection{Traffic Volume and Vehicle Classification}

The traffic sensors installed in the exit and entry ramps consisted of two axle sensors and two loop sensors arranged in series, as shown in Figure 4.4. Of these four sensors, only the combination of axle-loop-axle array was used to monitor the traffic; the second loop sensor was installed as a backup in the event that one of the other sensors failed. Data was recorded on to a PC card in the ADR unit, and downloaded to a laptop computer once a month. Data from this station was used to adjust the vehicle count obtained from the WIM station located further down the test site. 


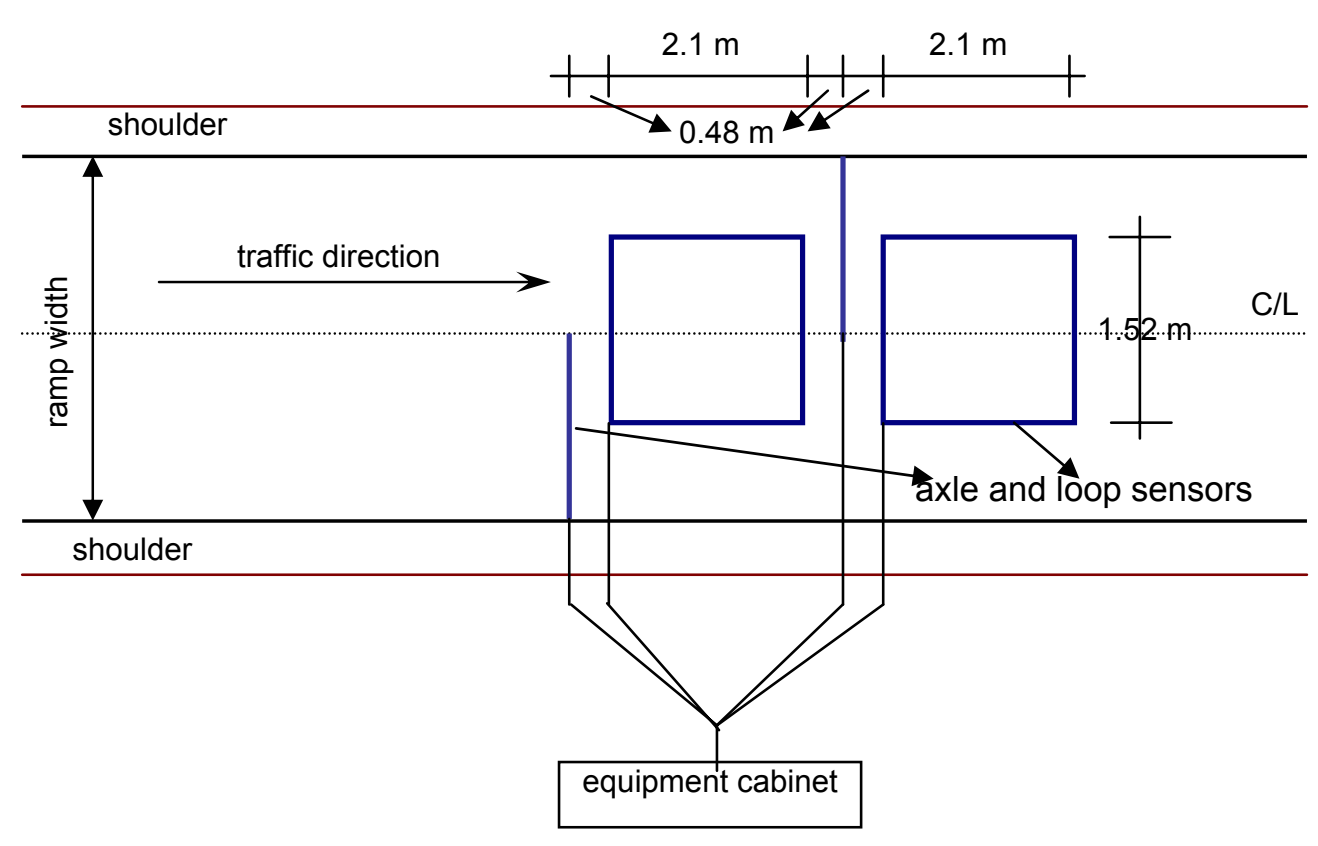

Figure 4.4-- Layout of traffic sensors on the exit and entry ramps

\section{$\underline{4.3 \text { Analysis of Field Survey Data }}$}

\subsubsection{Condition Surveys}

Table 4.2 shows the summary of the transverse cracks observed in each of the six $150-m$ test sections. S-70-28 showed the maximum total length of transverse cracking at the end of 3.5 years, followed by S-64-16. In S-70-28, the percentage of low and medium intensity cracks was approximately equal and accounted for majority of the transverse cracking in this section. S-64-16 did not exhibit any high-intensity cracks, but exhibited a higher percentage of medium-intensity cracks. S-58-28 did not exhibit any transverse cracking at the end of 3.5 years, while M-AC-20, S-64-28 and R-15\% exhibited minimal amount of transverse cracking.

The total number of cracks in each section was determined by summing the number of cracks in the low, medium and high categories. Conclusions regarding the relative performance of the test sections were drawn using the criteria shown in Table 4.1. S-70-28 showed the highest amount of transverse cracking, but only of "moderate" magnitude. M-AC-20, 
S-64-28, R-15\% and S-64-16 showed nominal levels of cracking, while S-58-28 showed no traverse cracking at the end of 3.5 years.

Table 4.2 -- Number and lengths of transverse cracks observed

\begin{tabular}{|c|c|c|c|c|c|c|c|c|}
\hline \multirow{2}{*}{$\begin{array}{l}\text { Section } \\
\text { ID }\end{array}$} & \multirow{2}{*}{$\begin{array}{c}\text { Age } \\
\text { (years) }\end{array}$} & \multicolumn{3}{|c|}{ Number of Cracks/Level } & \multicolumn{3}{|c|}{ Crack Length $(\mathrm{m}) /$ Level } & \multirow{2}{*}{$\begin{array}{l}\text { Total Crack } \\
\text { Length }(\mathrm{m})\end{array}$} \\
\hline & & Low & Med & High & Low & Med & High & \\
\hline \multirow{2}{*}{ M-AC-20 } & 1.0 & 0.0 & 0.0 & 0.0 & 0.0 & 0.0 & 0.0 & 0.0 \\
\hline & 3.5 & 1.0 & 3.0 & 0.0 & 3.7 & 10.4 & 0.0 & 14.1 \\
\hline \multirow{2}{*}{ S-64-28 } & 1.0 & 0.0 & 0.0 & 0.0 & 0.0 & 0.0 & 0.0 & 0.0 \\
\hline & 3.5 & 1.0 & 0.0 & 0.0 & 3.7 & 0.0 & 0.0 & 3.7 \\
\hline \multirow{2}{*}{ S-58-28 } & 1.0 & 0.0 & 0.0 & 0.0 & 0.0 & 0.0 & 0.0 & 0.0 \\
\hline & 3.5 & 0.0 & 0.0 & 0.0 & 0.0 & 0.0 & 0.0 & 0.0 \\
\hline \multirow{2}{*}{ R-15\% } & 1.0 & 0.0 & 0.0 & 0.0 & 0.0 & 0.0 & 0.0 & 0.0 \\
\hline & 3.5 & 1.0 & 0.0 & 0.0 & 3.2 & 0.0 & 0.0 & 3.2 \\
\hline \multirow{2}{*}{ S-70-28 } & 1.0 & 0.0 & 0.0 & 0.0 & 0.0 & 0.0 & 0.0 & 0.0 \\
\hline & 3.5 & 14.0 & 13.0 & 2.0 & 39.4 & 45.8 & 7.4 & 92.6 \\
\hline \multirow{2}{*}{ S-64-16 } & 1.0 & 0.0 & 0.0 & 0.0 & 0.0 & 0.0 & 0.0 & 0.0 \\
\hline & 3.5 & 2.0 & 8.0 & 0.0 & 3.0 & 24.2 & 0.0 & 27.2 \\
\hline
\end{tabular}

Table 4.3 shows the lengths of longitudinal cracks observed in the wheel path (WP) and outside the wheel path (NWP) at the end of 1 and 3.5 years. The total crack length for longitudinal cracks was determined by summing the lengths of cracks in the low, medium and high category. M-AC-20 did not exhibit any longitudinal cracking at the time of the last survey, whereas S-64-16 showed the highest total length of longitudinal cracking. Overall, the incidence of longitudinal cracking in the wheel path was lower than that observed outside the wheel path. Excessive loads (high tire pressures) are known to cause WP cracks at the edges of the wheel path of rutted pavements. Longitudinal cracks present between adjacent lanes and along the shoulders are caused due to the low density of the HMA along these areas. This results in low tensile strength of the HMA, which makes these areas more prone to low-temperature cracking. No longitudinal cracks were observed in the wheel paths of most of the test sections, except in S-70-28 and S-64-16, which exhibited low intensity cracks in the wheel path. This indicates that most of the test sections were adequately designed to support the traffic loads experienced by the pavement thus far. No high-intensity cracks were observed outside the wheel path in all the 
test sections. Although, both S-58-28 and R-15\% exhibited approximately the same amount of total crack length outside the wheel path, S-58-28 had significantly higher medium intensity cracks than R-15\%. The total length of the low and medium intensity cracks in R-15\% was approximately equal.

Using the LTPP criteria shown in Table 4.1, it can be seen that S-70-28 and S-64-16 showed moderate amount of longitudinal cracking in the wheel path. While M-AC-20 did not exhibit any longitudinal cracking, all the SUPERPAVE test sections showed moderate longitudinal cracking outside the wheel path. Among the SUPERPAVE test sections, S-58-28 and $\mathrm{R}-15 \%$ showed comparable crack lengths $(\sim 150 \mathrm{~m})$. S-64-28 showed the least amount (89 m) of cracking outside the wheel path.

Table 4.3 -- Lengths of longitudinal cracks observed

\begin{tabular}{|c|c|c|c|c|c|c|c|c|}
\hline \multirow{2}{*}{$\begin{array}{l}\text { Section } \\
\text { ID }\end{array}$} & \multirow{2}{*}{$\begin{array}{c}\text { Age } \\
\text { (years) }\end{array}$} & \multicolumn{3}{|c|}{ Length of Cracks in WP } & \multicolumn{3}{|c|}{ Length of Cracks NWP } & \multirow{2}{*}{$\begin{array}{l}\text { Total Crack } \\
\text { Length }(\mathrm{m})\end{array}$} \\
\hline & & Low & Med & High & Low & Med & High & \\
\hline \multirow{2}{*}{$M-A C-20$} & 1.0 & 0.0 & 0.0 & 0.0 & 0.0 & 0.0 & 0.0 & 0.0 \\
\hline & 3.5 & 0.0 & 0.0 & 0.0 & 0.0 & 0.0 & 0.0 & 0.0 \\
\hline \multirow{2}{*}{ S-64-28 } & 1.0 & 0.0 & 0.0 & 0.0 & 0.0 & 0.0 & 0.0 & 0.0 \\
\hline & 3.5 & 0.0 & 0.0 & 0.0 & 27.5 & 61.0 & 0.0 & 88.5 \\
\hline \multirow{2}{*}{ S-58-28 } & 1.0 & 0.0 & 0.0 & 0.0 & 0.0 & 0.0 & 0.0 & 0.0 \\
\hline & 3.5 & 0.0 & 0.0 & 0.0 & 14.0 & 138.5 & 0.0 & 152.5 \\
\hline \multirow{2}{*}{ R-15\% } & 1.0 & 0.0 & 0.0 & 0.0 & 0.0 & 0.0 & 0.0 & 0.0 \\
\hline & 3.5 & 0.0 & 0.0 & 0.0 & 73.0 & 70.0 & 0.0 & 143.0 \\
\hline \multirow{2}{*}{ S-70-28 } & 1.0 & 0.0 & 0.0 & 0.0 & 0.0 & 0.0 & 0.0 & 0.0 \\
\hline & 3.5 & 63.0 & 0.0 & 0.0 & 26.5 & 113.8 & 0.0 & 203.3 \\
\hline \multirow{2}{*}{ S-64-16 } & 1.0 & 0.0 & 0.0 & 0.0 & 0.0 & 0.0 & 0.0 & 0.0 \\
\hline & 3.5 & 112.9 & 0.0 & 0.0 & 0.0 & 152.5 & 0.0 & 265.4 \\
\hline
\end{tabular}

\subsubsection{Profile Surveys}

Transverse and longitudinal profile data were used to plot 3-D graphs showing elevation, driving lane width and length of test section on the three axes, respectively. These graphs are shown in Figures 4.5 through 4.10. The vertical scale is exaggerated for effect in these Figures. 
Examination of these Figures clearly indicates the presence of rutting in the wheel paths. The rut depth was typically more pronounced in the right wheel path of the driving lane of all the test sections. R-15\%, S-70-28 and S-64-16 showed heave (positive elevation) in the left wheel path at the end of 1 and 3.5 years. Recall that Dipstick ${ }^{\circledR}$ profiles were measured every $15 \mathrm{~m}$ along the length of the section. The highest maximum rut depth (as defined by the difference between highest point between the wheel paths and lowest point in the wheel path) occurring in each section was used to draw conclusions. At the end of 1.5 years, the highest maximum rut depth was observed in M-AC-20, S-64-28 and S-64-16 was $4 \mathrm{~mm}$. R-15\% and S$70-28$ exhibited $5 \mathrm{~mm}$ rut, while S-58-28 exhibited the highest amount of rutting, $6 \mathrm{~mm}$. At the end of 3.5 years, no change in maximum rut depth was observed in M-AC-20, S-58-28 and S-70$28(4 \mathrm{~mm}, 6 \mathrm{~mm}$ and $5 \mathrm{~mm}$, respectively). However, an increase in the area of "heave" was observed in S-70-28. S-64-28, R-15\% and S-64-16 showed a 2-mm increase in the maximum rut depth at the end of 3.5 years $(6 \mathrm{~mm}, 7 \mathrm{~mm}$ and $6 \mathrm{~mm}$, respectively). These Figures also show a slight shift in the rut to the right, i. e., towards the shoulder. This shift may be accounted for by the tendency of the vehicular traffic to avoid the numerous, patched core holes present along the wheel path. As mentioned earlier in previous chapter, core samples were collected from the test sections at different intervals for laboratory study.

The average value of the elevation at each $305-\mathrm{mm}$ interval was calculated to determine the average rut depth along the transverse cross-section of the pavement at the end of 1 and 3.5 years. These data are plotted in Figures 4.11 through 4.16. M-AC-20 showed the smallest average value of rutting $(3 \mathrm{~mm})$ of rutting at the end of 3.5 years compared with the other sections. When data from 1 year and 3.5 years were compared, R-15\% and S-70-28 showed approximately $1 \mathrm{~mm}$ to $1.5 \mathrm{~mm}$ increase in "heave" in the right wheel path of the driving lane. S-64-16 showed the highest increase $(\sim 1.5 \mathrm{~mm})$ in the rut depth of the left wheel path at the end of 3.5 years. S-58-28 remained fairly stable, in terms of rutting, between the two survey periods. 


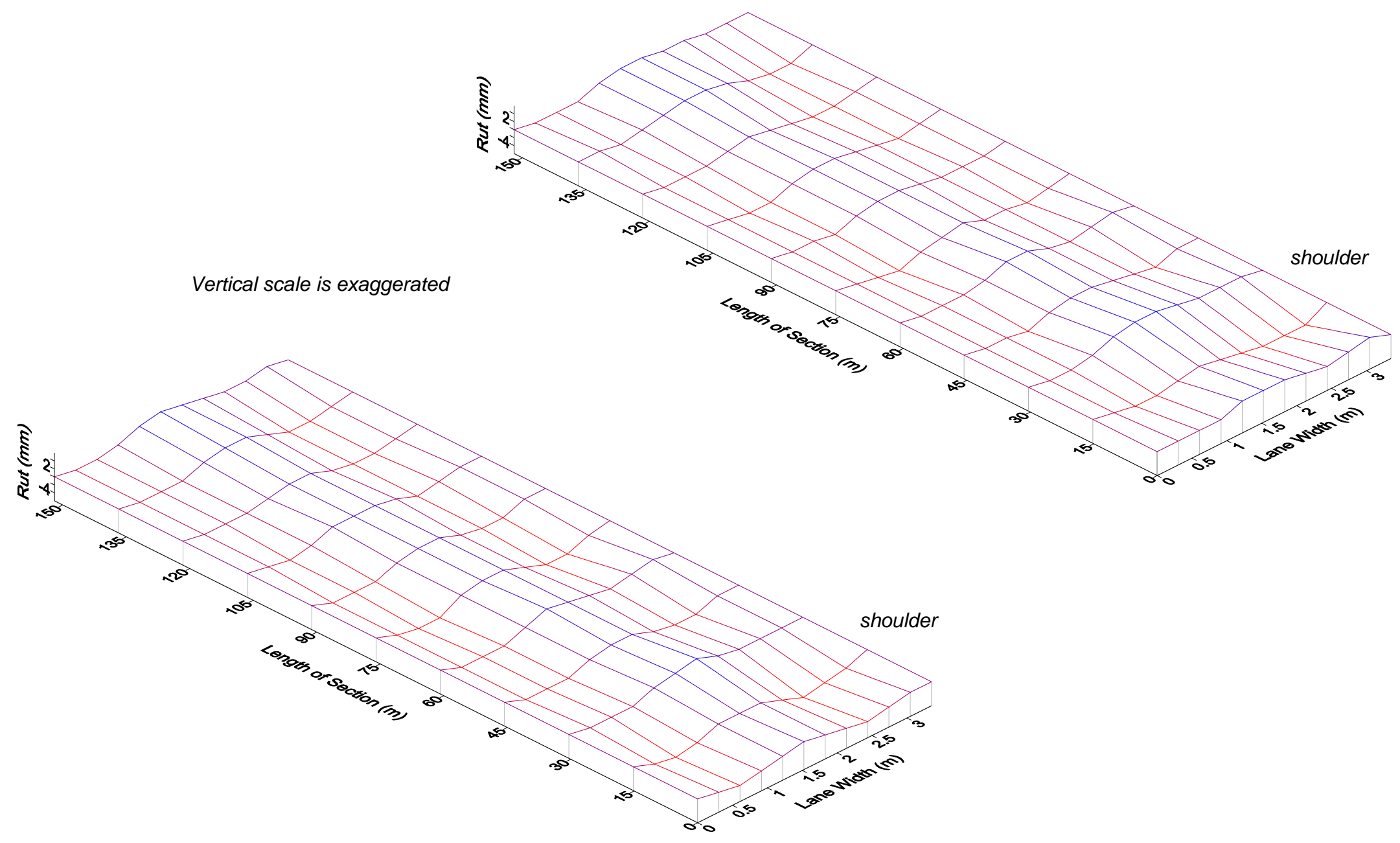

Figure 4.5 -- Road profile of M-AC-20 at the end of 1.5 years (top) and 3.5 years (bottom) 


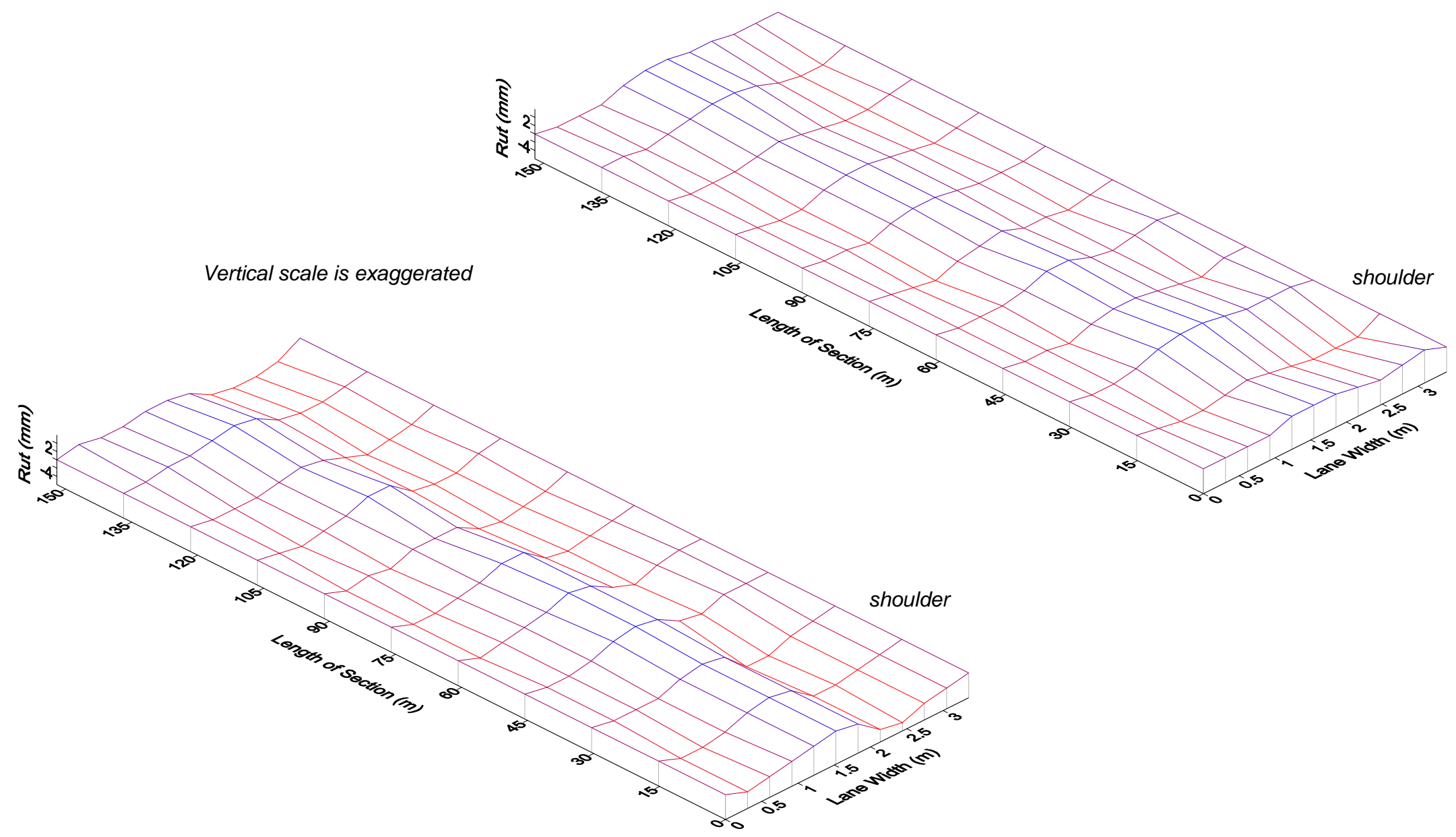

Figure 4.6 -- Road profile of S-64-28 at the end of 1.5 years (top) and 3.5 years (bottom) 


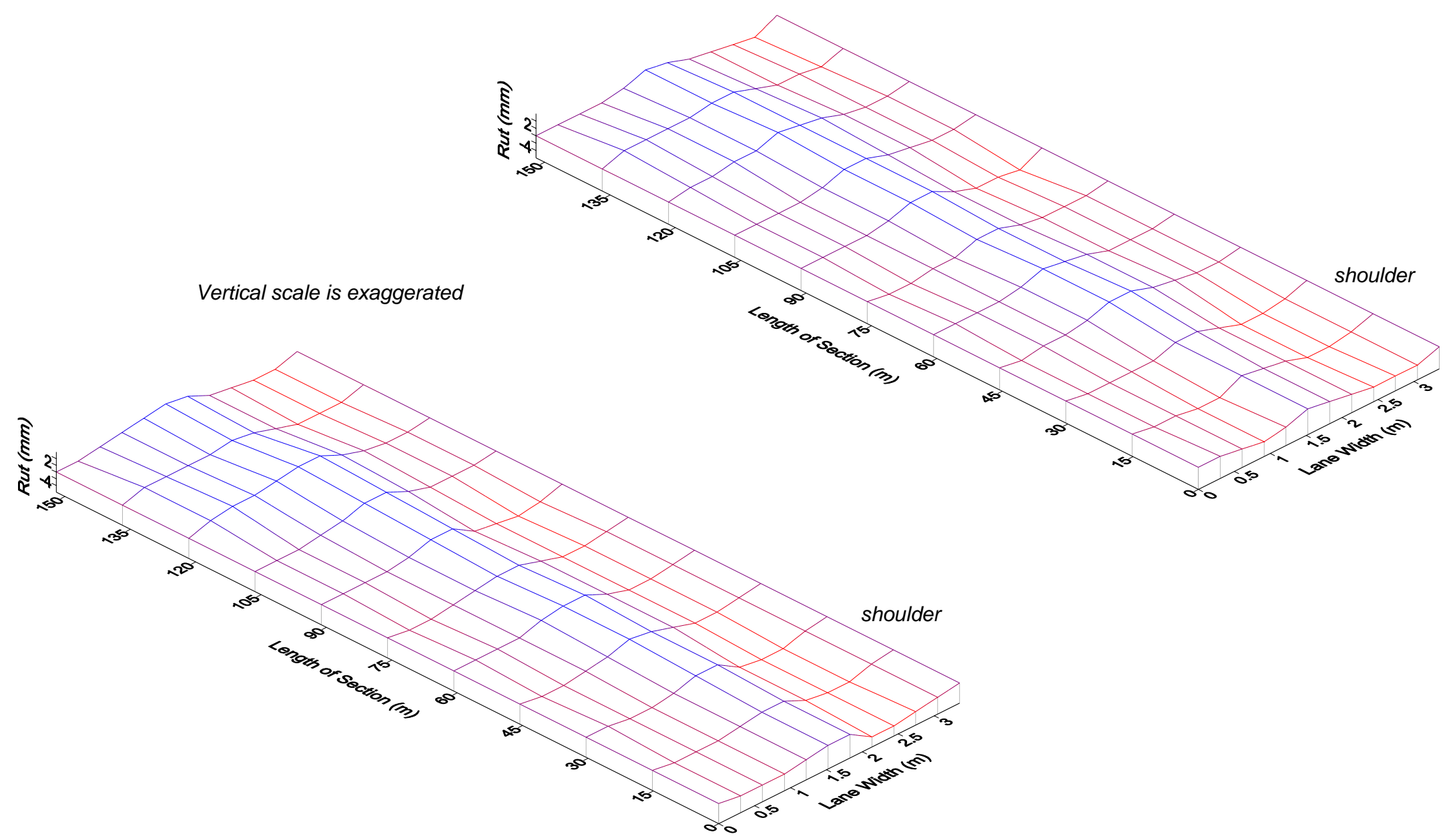

Figure 4.7 -- Road profile of S-58-28 at the end of 1.5 years (top) and 3.5 years (bottom) 


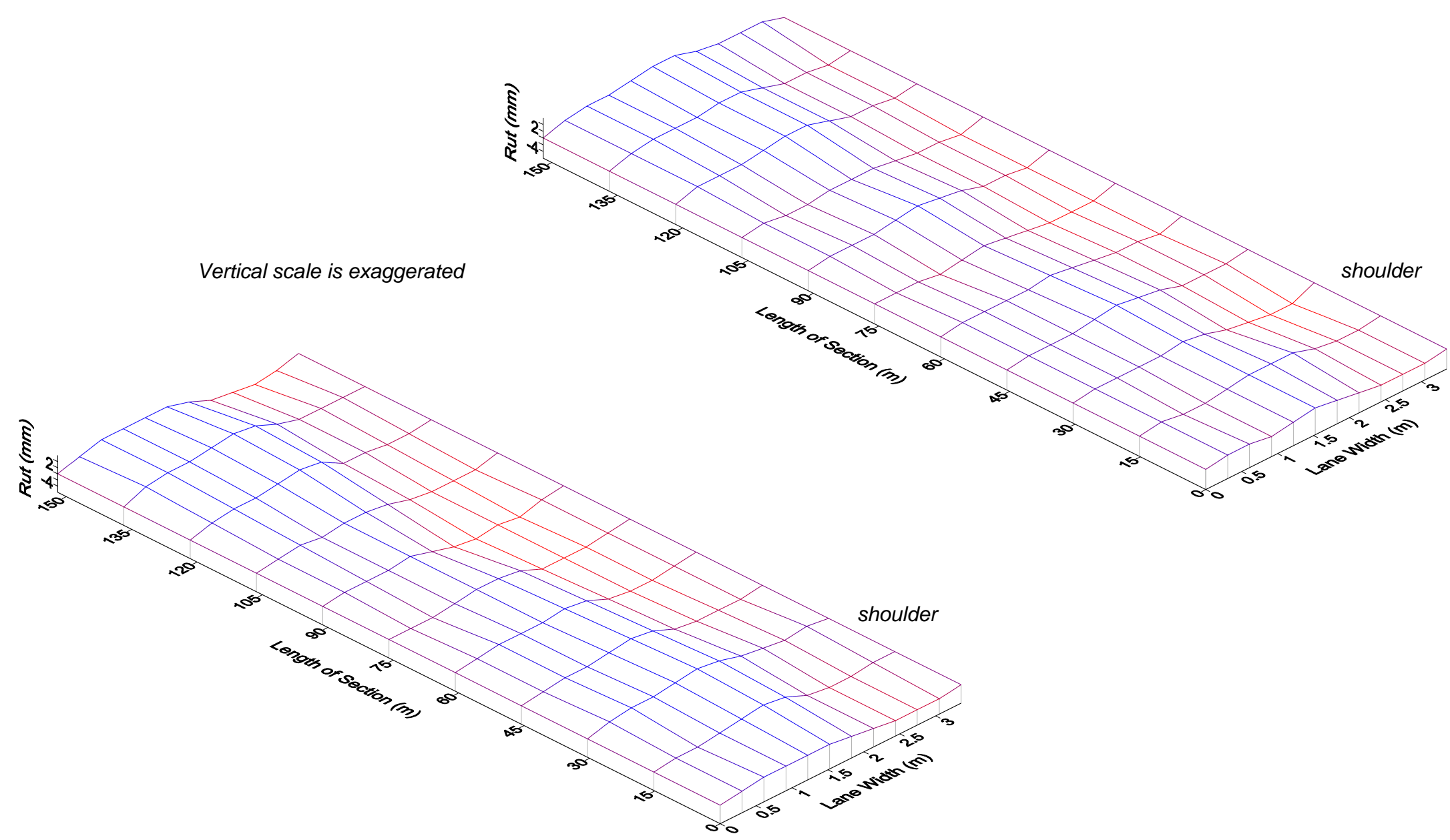

Figure 4.8 -- Road profile of R-15\% at the end of 1.5 years (top) and 3.5 years (bottom) 


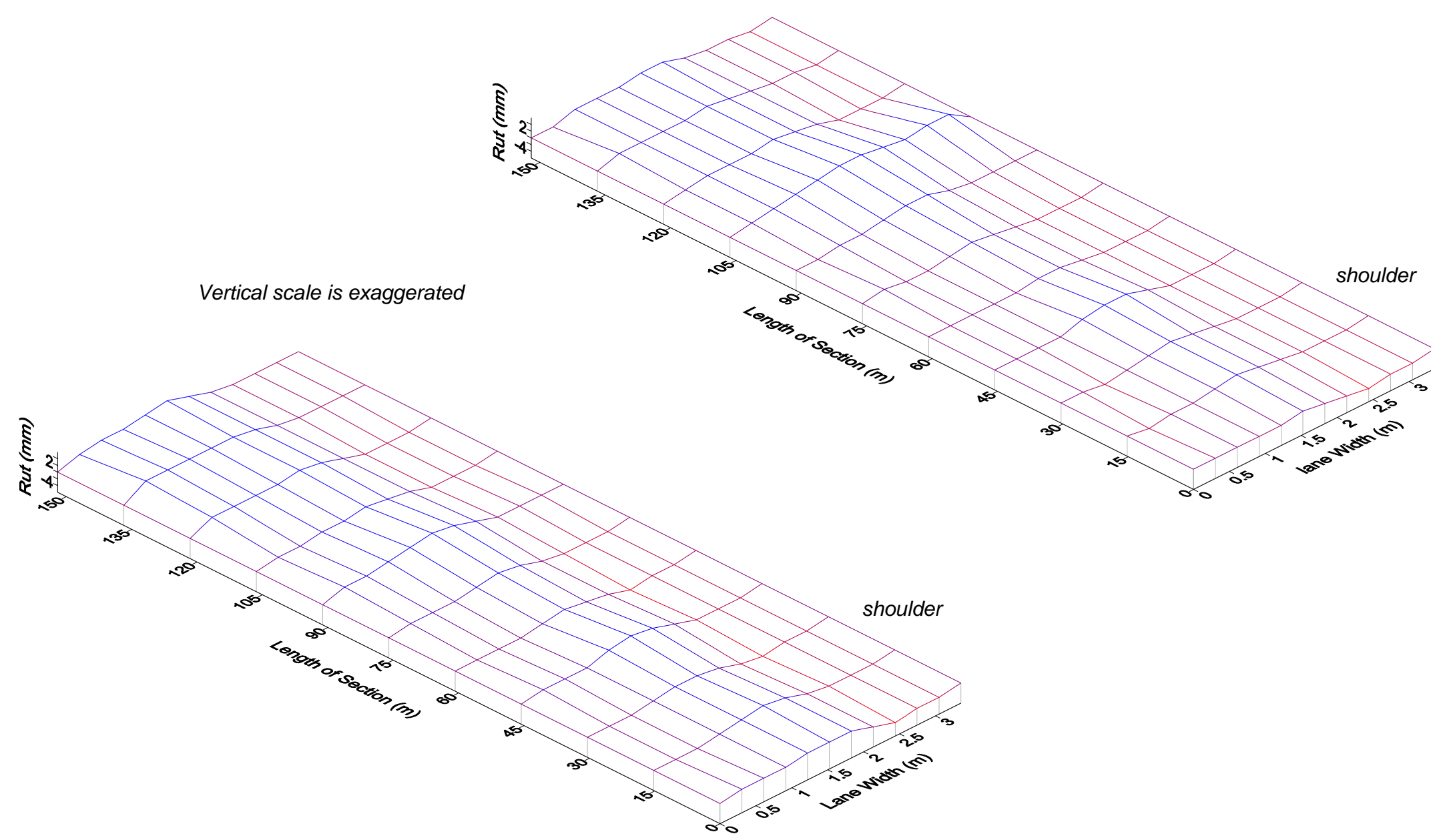

Figure 4.9 -- Road profile of S-70-28 at the end of 1.5 years (top) and 3.5 years (bottom) 


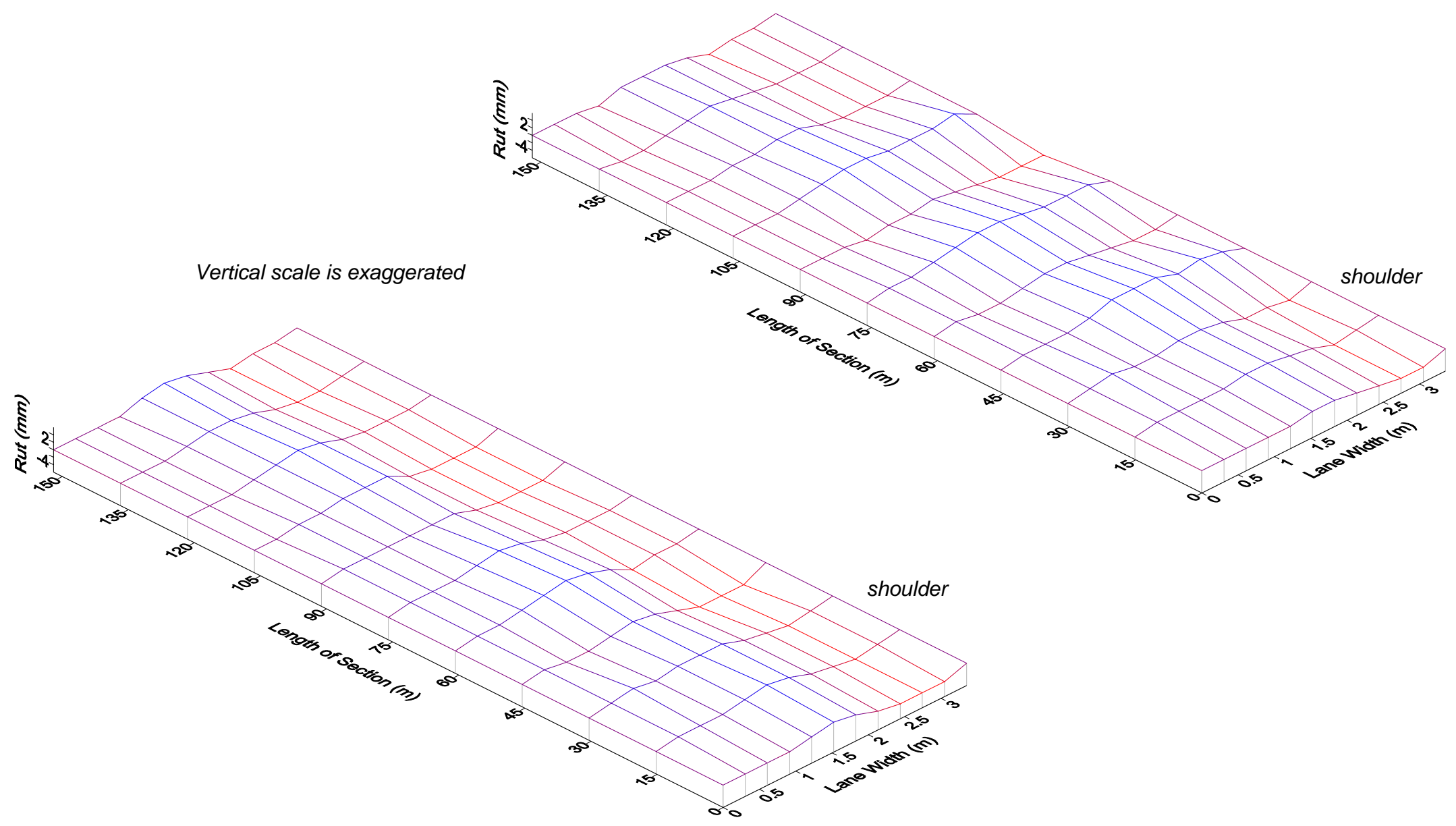

Figure 4.10 -- Road profile of S-64-16 at the end of 1.5 years (top) and 3.5 years (bottom) 


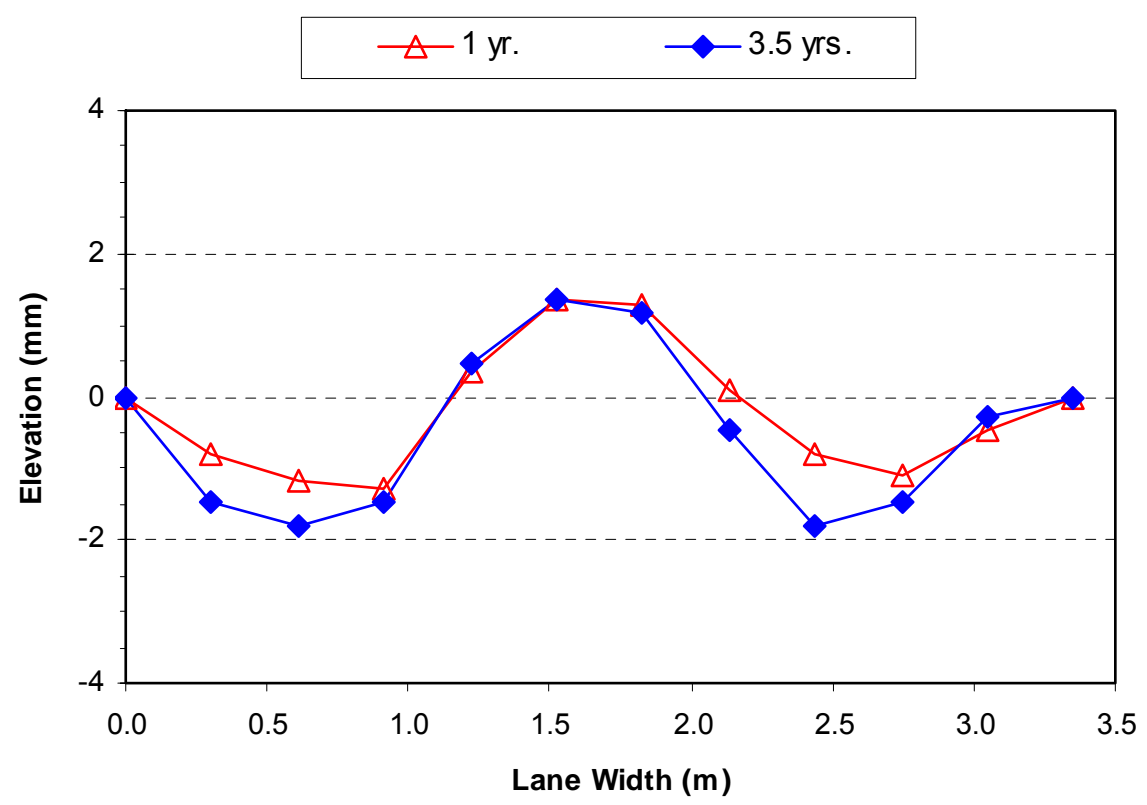

Figure 4.11 -- Average rut depth in M-AC-20

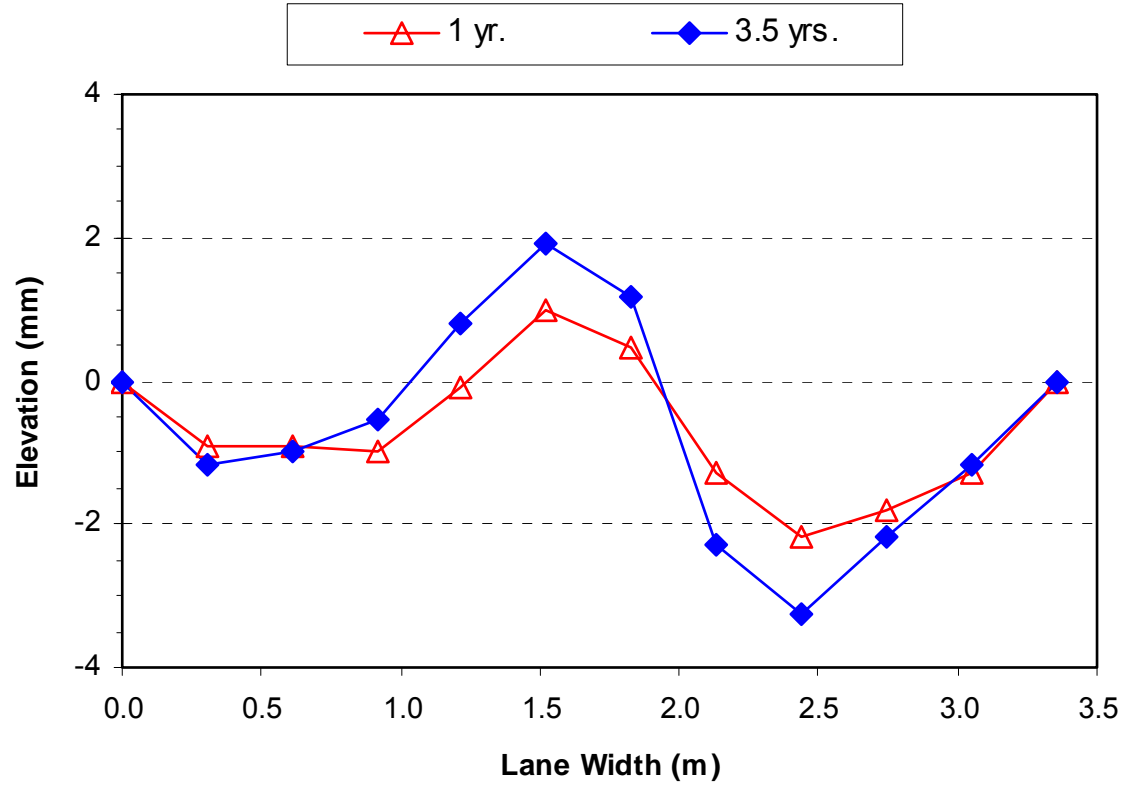

Figure 4.12 -- Average rut depth in S-64-28 


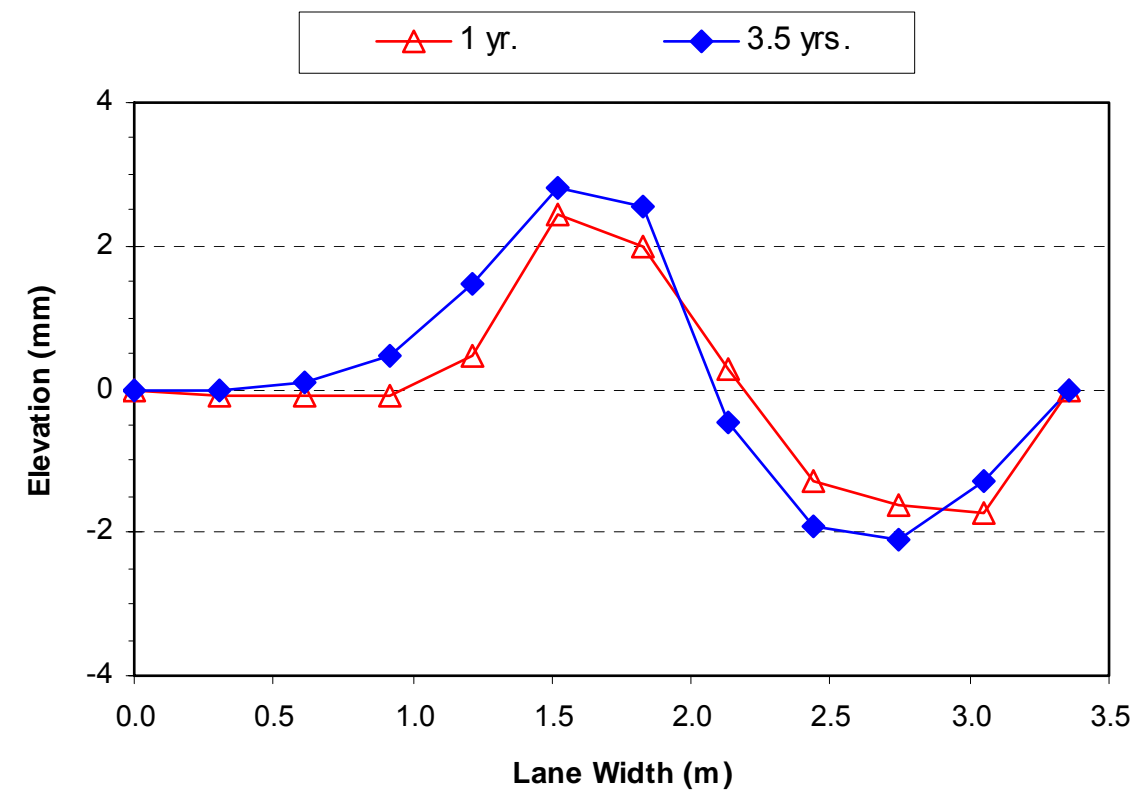

Figure 4.13 -- Average rut depth in S-58-28

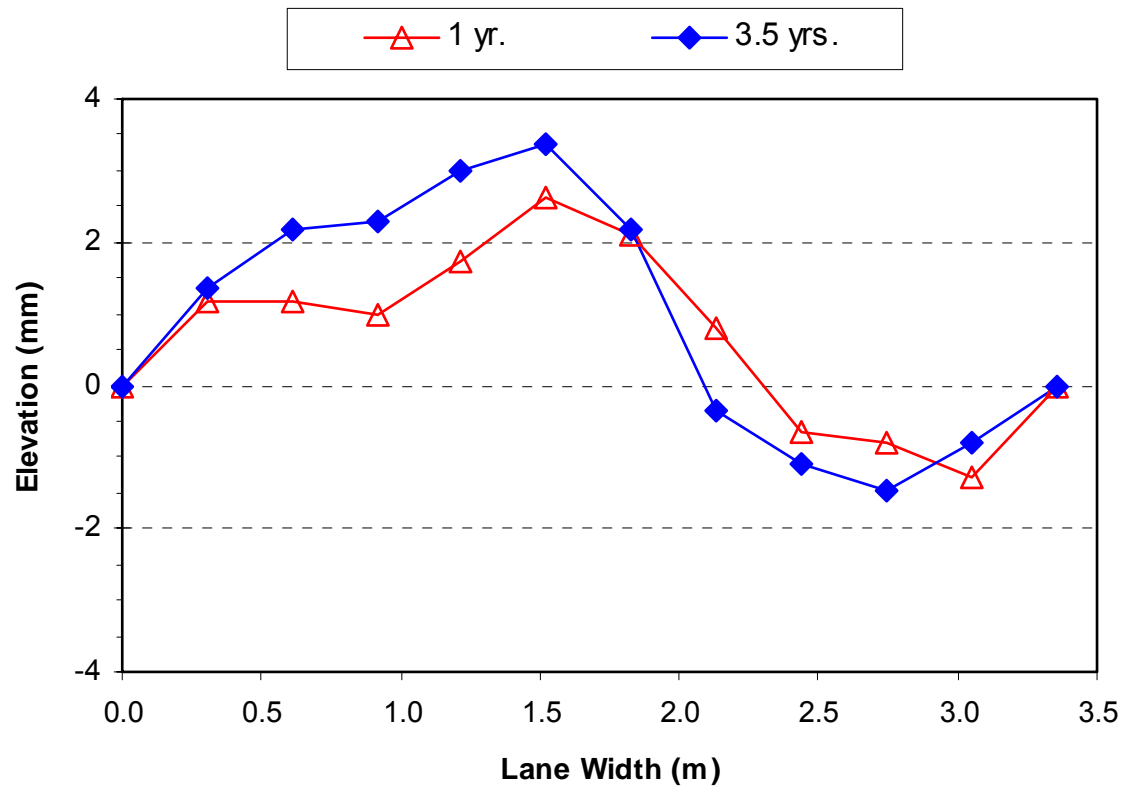

Figure 4.14 -- Average rut depth in R-15\% 


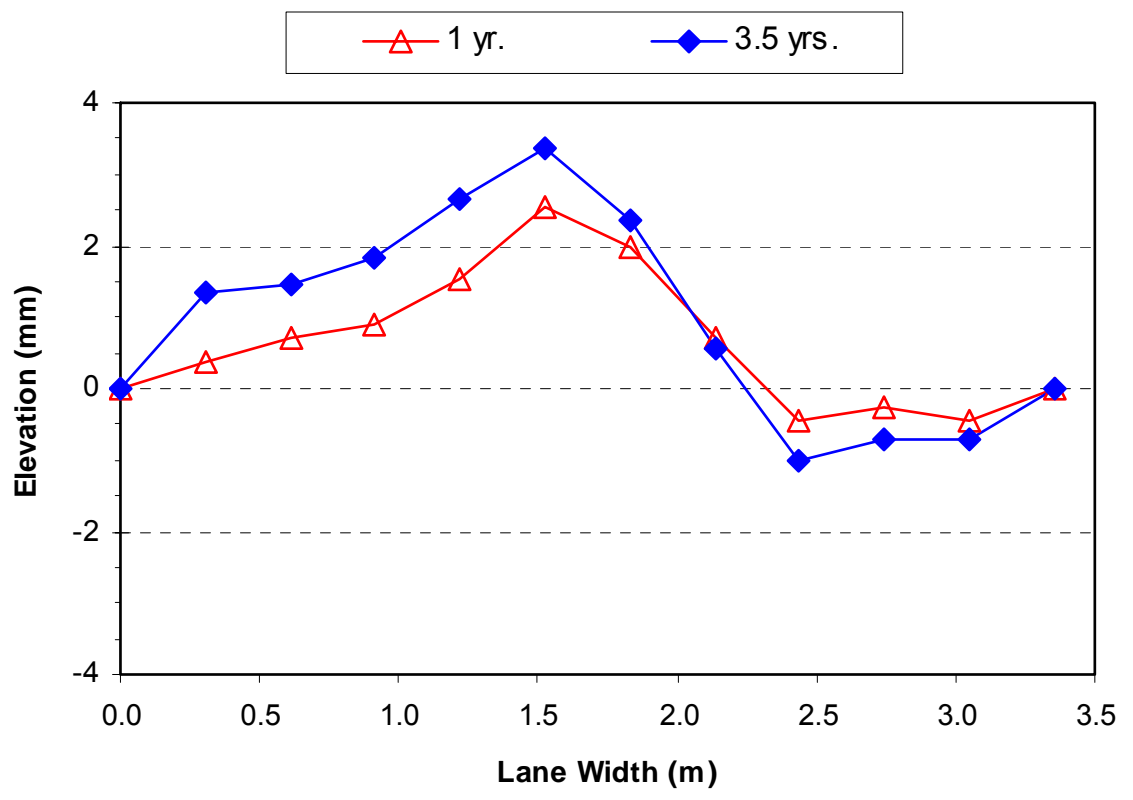

Figure 4.15 -- Average rut depth in S-70-28

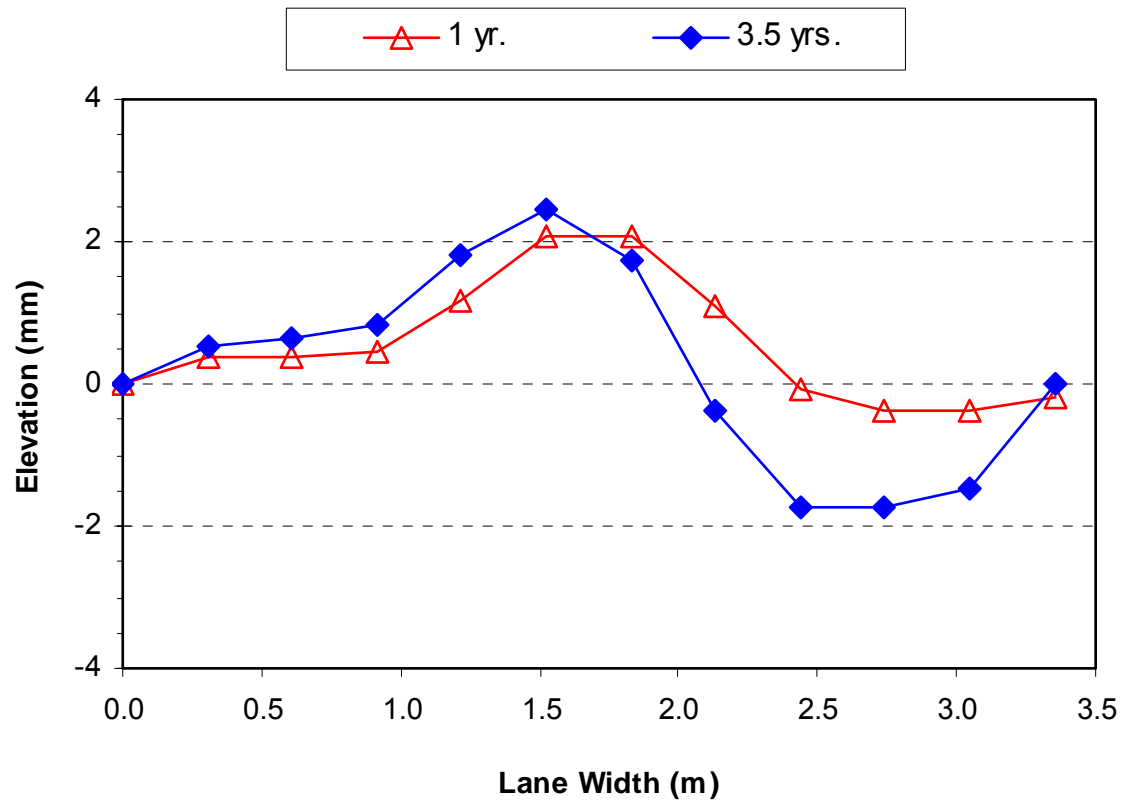

Figure 4.16 -- Average rut depth in S-64-16 
The most commonly used distress index used by practitioners to evaluate the pavement condition is the rut depth. Since this index provides only a one-dimensional measure of rutting, the Distress ETG recommended additional distress indices, such as rut width, fill areas, positive and negative areas, etc $(108,109)$. Due to the lack of wide usage of fill area indices by pavement engineers, no correlations between severity of rutting and fill area index have been established. Therefore, only the rut depth was used to as an indicator of pavement distress in this study.

\subsubsection{Pavement Smoothness}

The smoothness of the pavement was assessed by International Roughness Index (IRI) and the Pavement Serviceability Rating (PSR). These two indices are widely used and required in most states by the FHWA (110). An IRI value of $0 \mathrm{~mm} / \mathrm{m}$ indicates perfectly smooth pavements typically seen in newer pavements. An IRI of $16 \mathrm{~mm} / \mathrm{m}$ indicates erosion gullies and deep depressions. On the other hand, PSR ratings range from 0 to 5 , with " 0 " indicating the worst case or an impassable pavement and " 5 " indicating a perfect pavement.

For this test site, the IRI values for the left and right wheel paths of the driving lane were directly obtained from ERES Consultants. PSR values may be computed using two equations (4.1 and 4.2) shown below, applicable for flexible pavements:

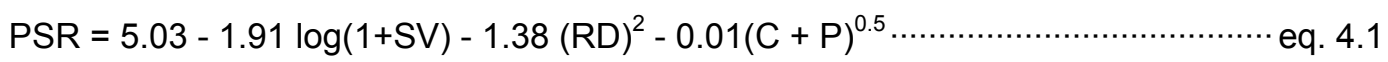

where, $\mathrm{SV}=$ Mean slope variance over the section from CHLOE profilometer (in./mi)

$\mathrm{RD}=$ Mean rut depth (in.)

$C=$ Cracking $\left(\mathrm{m}^{2} / 1000 \mathrm{~m}^{2}\right)$

$P=$ Patching $\left(\mathrm{m}^{2} / 1000 \mathrm{~m}^{2}\right)$

This equation was developed by Carey and Irick in 1960 (Highway Research Board Bulletin No. 250). The $\mathrm{R}^{2}$ and standard error $\left(\mathrm{S}_{\mathrm{e}}\right)$ for this equation were $84 \%$ and 0.38 , respectively, based on a sample size of 74 . Slope variance was the most significant factor influencing PSR and deleting the distress terms $(\mathrm{C}$ and $\mathrm{P})$ did not alter the accuracy of the rating significantly. However, due to lack of SV data from CHLOE profilometer in the present study, this 
equation was not used. Instead, equation 4.2 developed by Al-Omari and Darter (110) was used in the determination of PSR. The $R^{2}$ and $S_{e}$ for the second equation are $81 \%$ and 0.35 , respectively.

$\mathrm{PSR}=5 \exp (-0.24 \mathrm{IRI})$ eq. 4.2

where, IRI is in $\mathrm{mm} / \mathrm{m}$

Figures 4.17 and 4.18 show the IRI values for the left and right wheel paths at the end of 6 months and 4 years after opening to traffic, respectively. Figure 4.19 shows the percentage change between the two time periods. LTPP defines IRI values $<1.4 \mathrm{~m} / \mathrm{km}$ as nominal. The IRI data indicated that the pavement was still in very good condition at the end of 4 years in terms of smoothness, as evidenced by the IRI readings that ranged from 0.5 to 0.7 $\mathrm{mm} / \mathrm{km}$. The IRI of the right wheel path was typically higher than that of the left wheel path. This is a previously observed and expected trend in the driving lanes, which occurs due the cross slope of the pavement and heavy truck traffic occurring on the interstate routes.

On an average, the percent difference in IRI between the left and the right wheel path was the highest in S-70-28 (40\%), followed by S-64-16 (32\%). M-AC-20, S-64-28 and S-58-28 showed a difference of about 16 to $20 \%$, and $\mathrm{R}-15 \%$ showed about $25 \%$. A complete list of IRI obtained each year for all the test sections are shown in Appendix B. M-AC-20 and S-64-28 showed the smallest increase in IRI at the end of 4 years (from about $3 \%$ to about 6 or $7 \%$, for LWP and RWP, respectively). It should be noted that although S-58-28 showed a significant percentage increase in IRI, the actual values of IRI are quite low and representative of a good pavement.

Figure 4.20 shows the change in average IRI with time for all the sections. An unusually high percentage increase in the left wheel path of S-58-28 was observed at the end of the second year, the cause for which is not known. Examination of crack maps and rut depths did not show any unusual activity that could account for this anomaly. S-58-28 shows the greatest change due to a significant increase in the IRI of the left wheel path, as mentioned earlier. Neglecting this anomaly, S-64-16 showed the highest increase in the IRI of the left and the right wheel paths. S-64-28 and R-15\% followed a similar trend, as did M-AC-20 and S-70-28. 


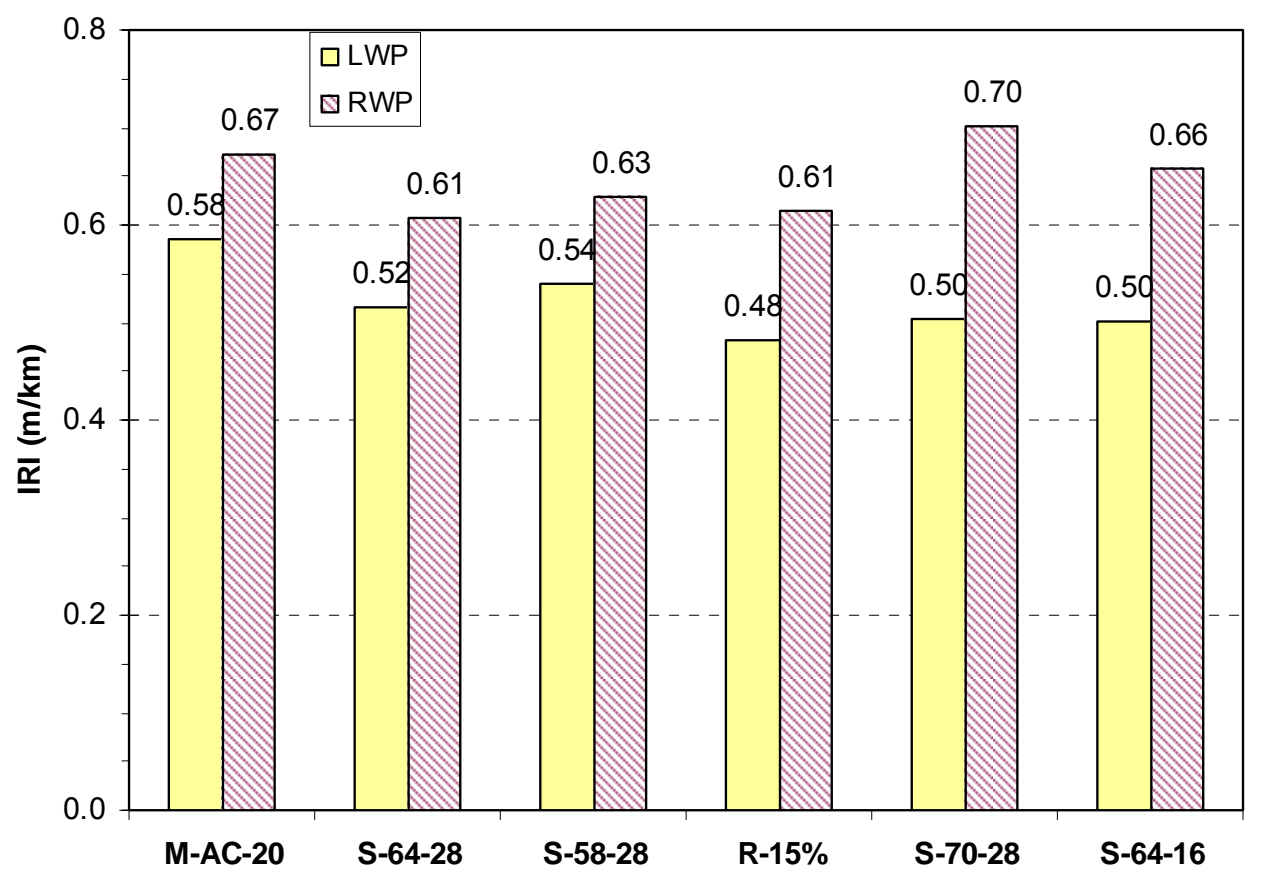

Figure 4.17 -- IRI of the left and right wheel path at the end of 6 months

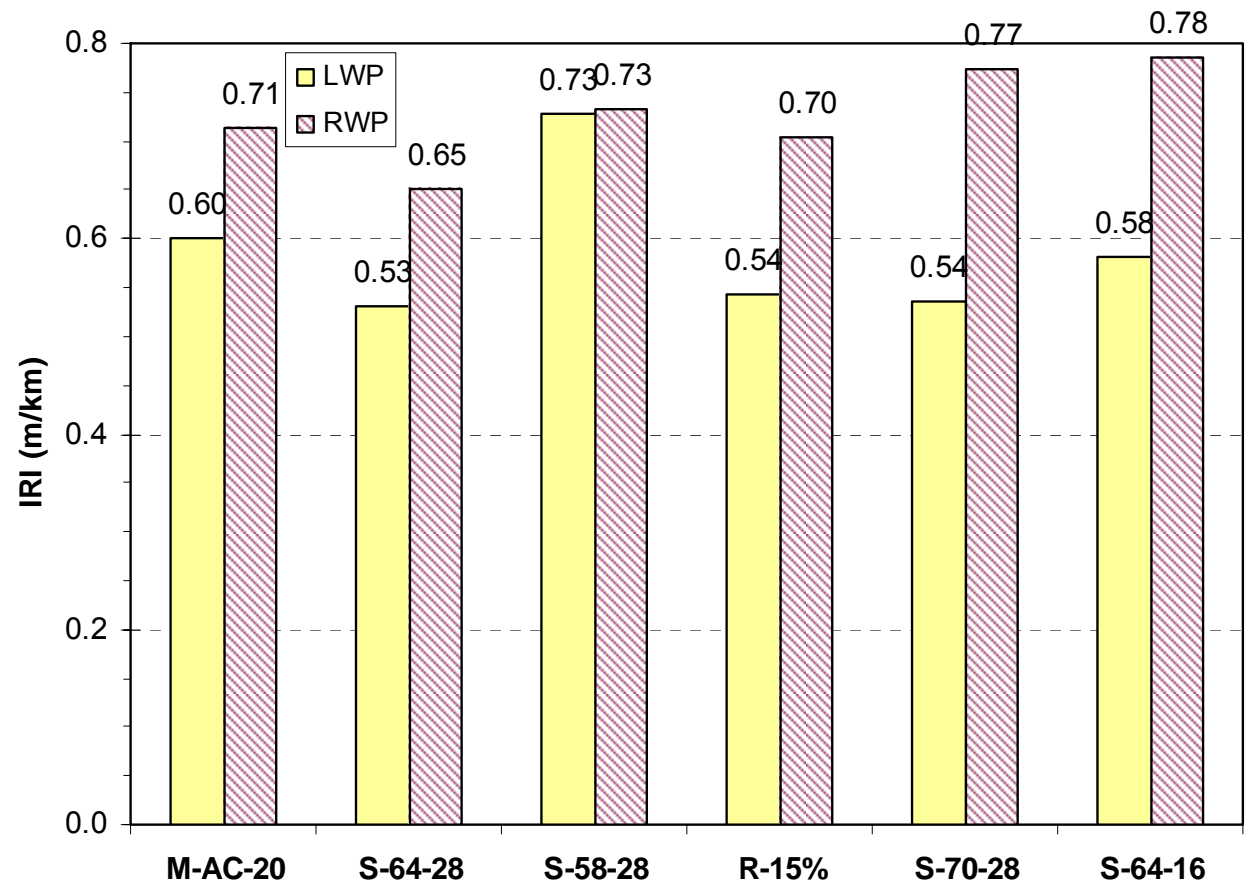

Figure 4.18 -- IRI of the left and right wheel path at the end of 4 years 


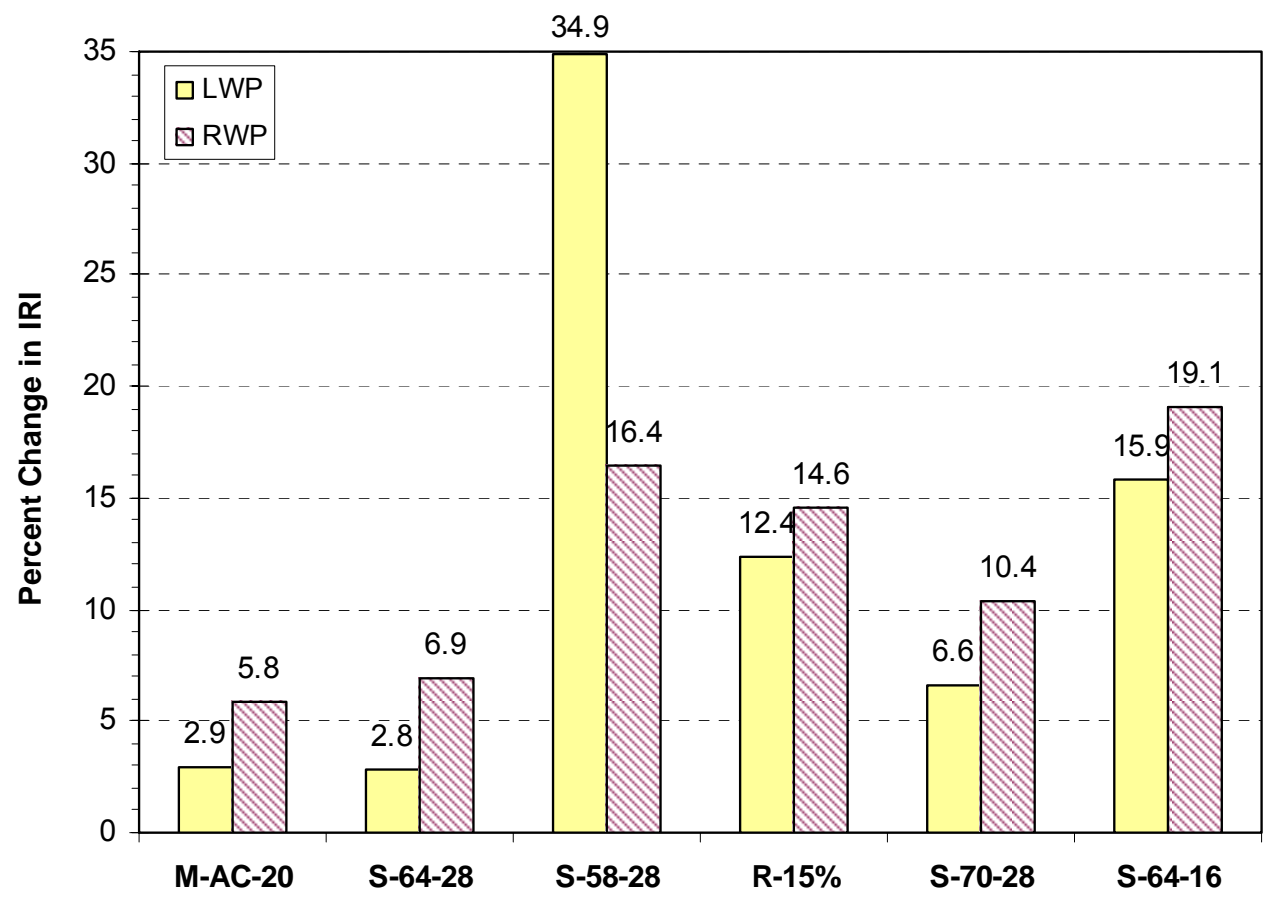

Figure 4.19 -- Percent increase in IRI of the left and right wheel path at the end of 4 years

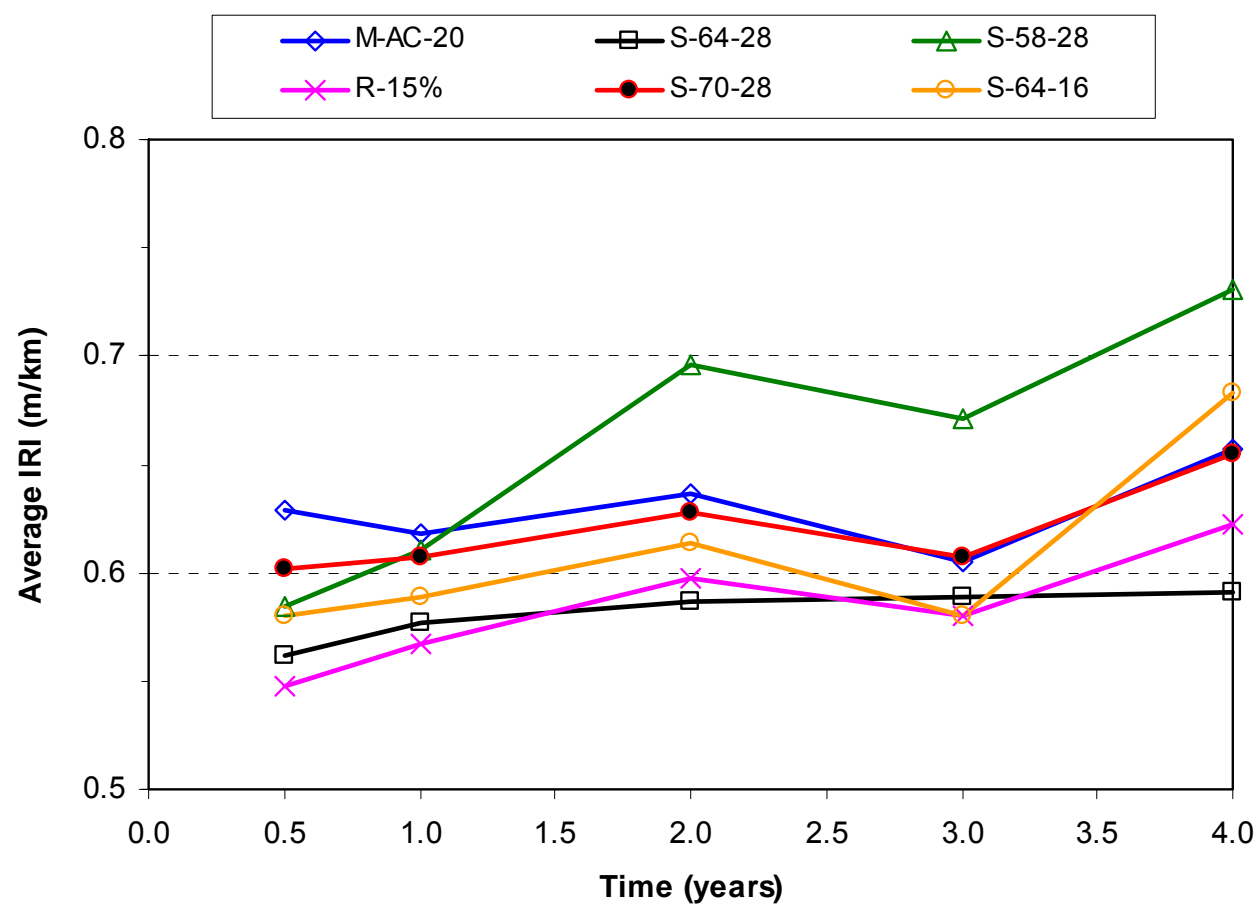

Figure 4.20 -- Change in average IRI with time 
The PSR values calculated from IRI are given in the Appendix B (Table B1). Figure 4.21 shows the change in PSR with time. Since these values were calculated from the IRI value, this plot is a mirror image of Figure 4.20.

As indicated by the low IRI values, the high PSR values also indicate good pavement condition. The largest change was observed in the case of S-58-28, due to the sudden change in the left wheel path IRI after 2 years mentioned earlier.

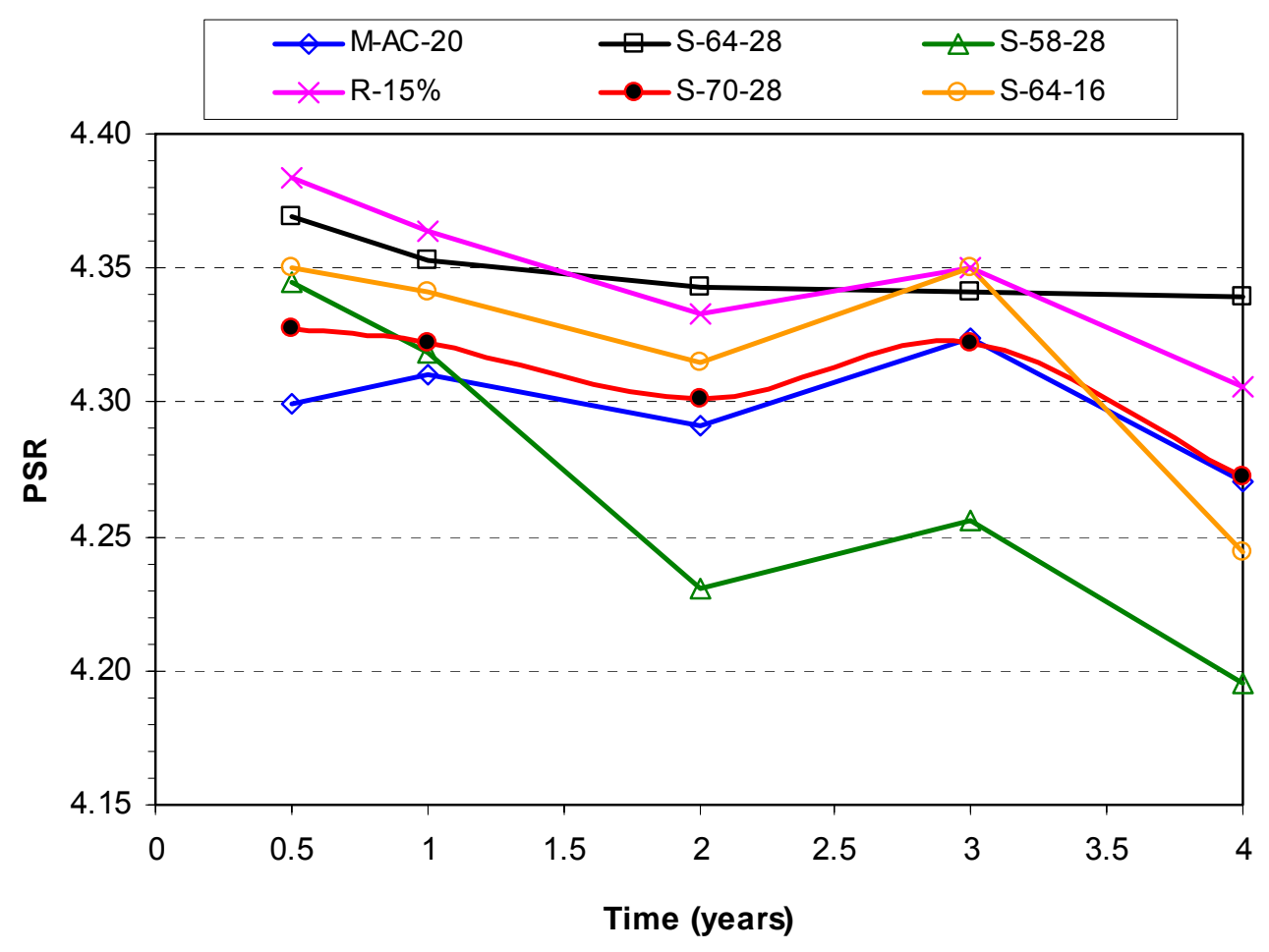

Figure 4.21 -- Change in PSR with time

\subsection{Analysis of Weather Data}

Figure 4.22 shows the trends in air and pavement temperature during the study period (August 1997 to January 2001). Analysis of these data indicates that the minimum air and pavement temperatures typically occurred during the month of January at this study site. The mean 7-day maximum air and pavement temperatures occurred between the months of June and 
August. The typical difference between observed air and pavement temperature was about $10^{\circ} \mathrm{C}$. The ranges of maximum air and pavement temperatures recorded were $38.0^{\circ} \mathrm{C}-43.0^{\circ} \mathrm{C}$ and $31.5^{\circ} \mathrm{C}-36.5^{\circ} \mathrm{C}$, respectively.

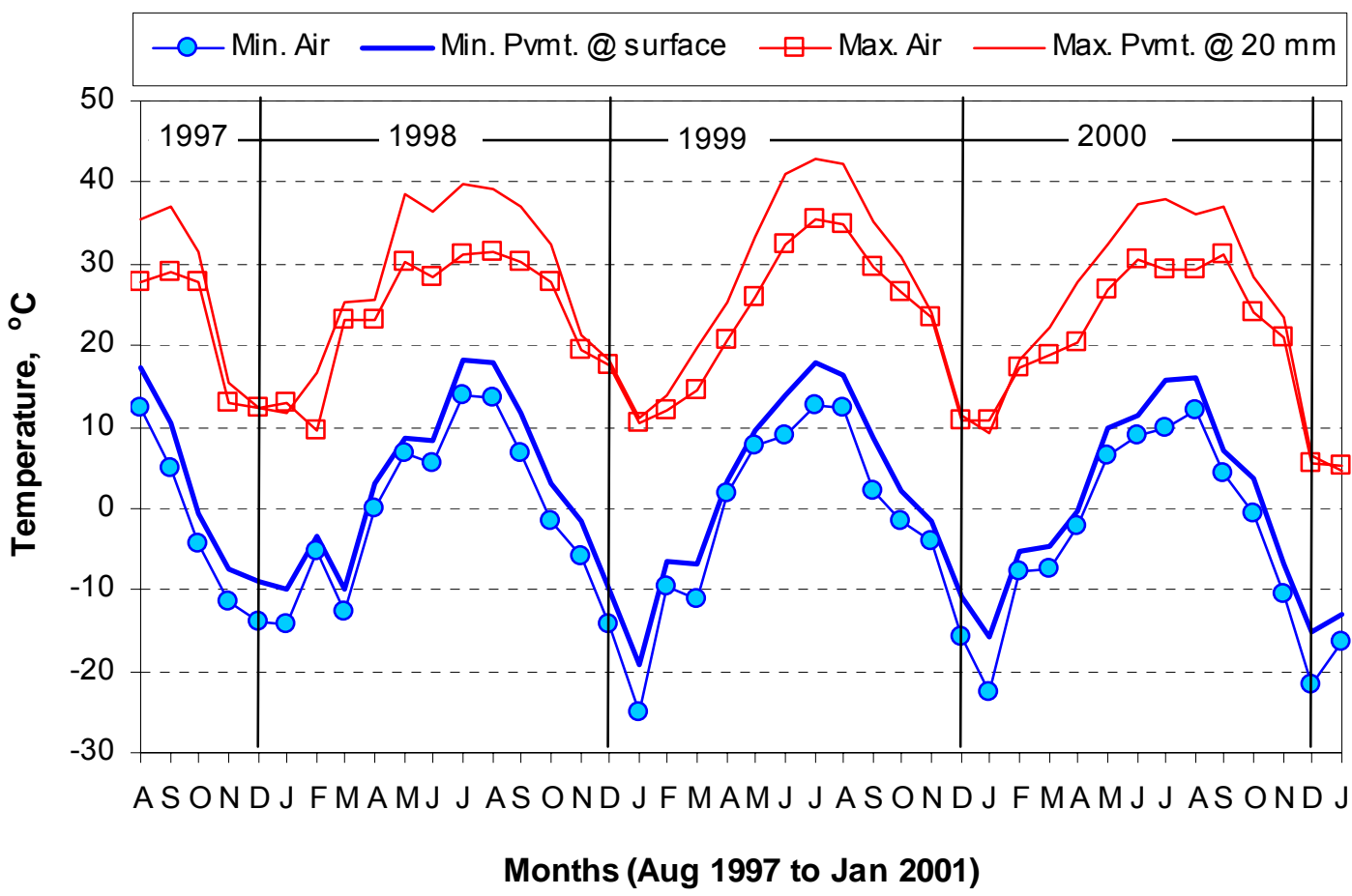

Figure 4.22 -- Trends in air and pavement temperature at the test site

The observed minimum air and pavement temperature ranged between $-19.3^{\circ} \mathrm{C}$ to $-9^{\circ} \mathrm{C}$ and $-25^{\circ} \mathrm{C}$ to $-14^{\circ} \mathrm{C}$, respectively. The observed difference between the minimum air and pavement surface temperature was about $6^{\circ} \mathrm{C}$.

The pavement temperature data from November through March were analyzed to determine the typical pavement cooling rate occurring at the test site. This value was later used in Chapter 6 for the determination of thermal stresses in the pavement. The cooling rate per hour was determined by calculating the change in pavement temperature per every 60 -minute time increment for the entire month of interest. The steepest downward (negative) slope was taken as the maximum cooling rate observed at the test site during the month of interest. These values are shown in Table 4.4. 
The highest cooling rate was typically observed in the month of March with the exception of November 1997, which showed a much higher rate $\left(8^{\circ} \mathrm{C} / \mathrm{h}\right)$. The cooling rate of $6.5^{\circ} \mathrm{C} / \mathrm{h}$ was used in determination of thermal stresses as this was closer to the typically observed cooling rate of $5^{\circ} \mathrm{C} / \mathrm{h}$ at this latitude.

Table 4.4 -- Observed cooling rates in the test pavement

\begin{tabular}{|c||c|c|c|c|c|c||}
\hline \multicolumn{1}{|c||}{ Month } & \multicolumn{7}{|c|}{ Cooling rate ( $\left.^{\circ} \mathbf{C} / \mathbf{h}\right)$} \\
\cline { 2 - 7 } & $\mathbf{1 9 9 7}$ & $\mathbf{1 9 9 8}$ & $\mathbf{1 9 9 9}$ & $\mathbf{2 0 0 0}$ & $\mathbf{2 0 0 1}$ & $\mathbf{2 0 0 2}$ \\
\hline \hline Nov & 8.0 & 3.8 & 4.1 & 4.9 & 4.3 & -3.8 \\
\hline Dec & 3.4 & 4.4 & 3.7 & 3.9 & 2.7 & \\
\hline Jan & & 4.0 & 4.2 & 3.3 & 3.7 & 3.7 \\
\hline Feb & & 4.3 & 4.9 & 4.7 & & 3.3 \\
\hline Mar & & 6.3 & 6.3 & 5.1 & & 5.6 \\
\hline
\end{tabular}

\subsection{Results from Traffic Data}

The estimated Average Annual Daily Traffic (AADT) data obtained from the mainline WIM station was determined by conducting a 48-hour traffic count and averaging it to yield the 24-hour daily traffic count. An axle adjustment factor was applied to the 24-hour daily traffic count to obtain vehicle count, which was then multiplied by a monthly seasonal variation factor to obtain the annual vehicle count in terms of AADT. The Program Development office of INDOT reported the following AADT values during the study period: in $1996 \rightarrow 43,020$, in 1998 $\rightarrow 45,850$, in $2000 \rightarrow 37,460$ and in $2002 \rightarrow 41,690$. The percentage of trucks operating along this interstate was about $38 \%$, typically.

\section{$\underline{4.6 \text { Summary of Findings }}$}

Data from the crack maps indicates that S-70-28 showed the worst performance in terms on transverse cracking, while S-64-28, S-58-28 and R-15\% showed little to no cracking. M-AC-20 and S-64-16 showed moderate amount of transverse cracks. S-58-28 did not exhibit any transverse cracks and M-AC-20 did not exhibit any longitudinal cracks. S-70-28 and S-64-16 showed high amounts of transverse and longitudinal cracks. While a high percentage of 
transverse cracks are to be expected in S-64-16 due to its low low-temperature grade (PGxx-16), the high percentage of transverse cracks in S-70-28 (SBS-modified binder PG70-28) is puzzling. It is hoped that test data from binders recovered from the field cores might provide insight into this issue, especially since the minimum pavement temperature at the test site did not exceed the low-temperature grade of the binder as indicated by the weather data.

The rut depth and IRI of the right wheel path in the driving lane was typically greater than that observed in the left wheel path. This was expected due to the downward crossslope of pavement (towards the shoulder) and the heavy truck volume on the interstate highways. Shoving (heave) was observed in the left wheel path of R-15\%, S-70-28 and S-64-16, possibly due to migration of pavement material away from the right wheel path. In spite of moderate amount of cracking observed in some sections, the low IRI and high PSR values indicate good pavement condition in terms of ridability. 


\section{CHAPTER 5 -- EVALUATION OF RECOVERED BINDERS}

\section{$\underline{5.1 \text { Introduction and Sample Collection }}$}

As a part of the validation of the SUPERPAVE binder selection software (SHRPBIND), binder was recovered from the surface layer of the field cores at specific times during the course of the study. Eight cores were collected from each test section at each time period. For the first 2 years after construction, cores were obtained at the following ages (15 days, 8 months, 1 year, 1.5 years and 2 years). A final set of cores was obtained at the end of 4 years. The surface layers were separated from the intermediate course prior to extraction and recovery process. Binder was recovered from the surface layer cores using the centrifuge extraction method (ASTM D2172, 111), followed by the rotary evaporator method (ASTM D5404, 112). The solvent used in extraction process was a blend of $85 \%$ toluene and $15 \%$ ethanol. Binder recovered from each set of eight cores was combined and mixed thoroughly before testing to ensure homogeneity.

\subsection{Specific Gravity}

The specific gravity $\left(G_{b}\right)$ of binders (hence, density of the binder) was determined at $16^{\circ} \mathrm{C}$ in accordance with AASHTO T228 (113). Typically, two to three replicate samples were tested until the single-operator precision was satisfied (difference between two results $\leq 0.003$ ). The average results are reproduced in Table 5.1, along with test data from tank asphalt for comparison purposes. The percentage increase in the specific gravity of the binder with respect to tank binder data is shown in the last column. Figure 5.1 shows the relative difference in $G_{b}$ of binders between tank binder and recovered binder at the end of 4 years. 
Table 5.1 -- Specific gravity of the binders from all sections at different ages

\begin{tabular}{|l|c|c|c|c|c|c|c|c||}
\hline \multirow{2}{*}{ Binder } & \multicolumn{7}{|c|}{ Time (in months) } & Percent \\
\cline { 2 - 8 } & Tank $^{*}$ & $\mathbf{0 . 5}$ & $\mathbf{8}$ & $\mathbf{1 2}$ & $\mathbf{1 8}$ & $\mathbf{2 4}$ & $\mathbf{4 8}$ & Increase \\
\hline AC-20 & 1.026 & 1.034 & 1.036 & 1.046 & 1.047 & 1.050 & 1.051 & 2.4 \\
\hline PG64-28 & 1.023 & 1.031 & 1.032 & 1.034 & 1.041 & 1.055 & 1.057 & 3.3 \\
\hline PG58-28 & 1.017 & 1.024 & 1.031 & 1.030 & 1.033 & 1.033 & 1.035 & 1.8 \\
\hline PG64-28 w/ RAP & 1.023 & 1.031 & 1.033 & 1.037 & 1.039 & 1.040 & 1.043 & 1.9 \\
\hline PG70-28 & 0.962 & 0.994 & 1.006 & 1.007 & 1.013 & 1.015 & 1.028 & 6.8 \\
\hline PG64-16 & 1.032 & 1.038 & 1.040 & 1.041 & 1.041 & 1.042 & 1.047 & 1.5 \\
\hline
\end{tabular}

* Tested as a part of Quality Control (QC) program

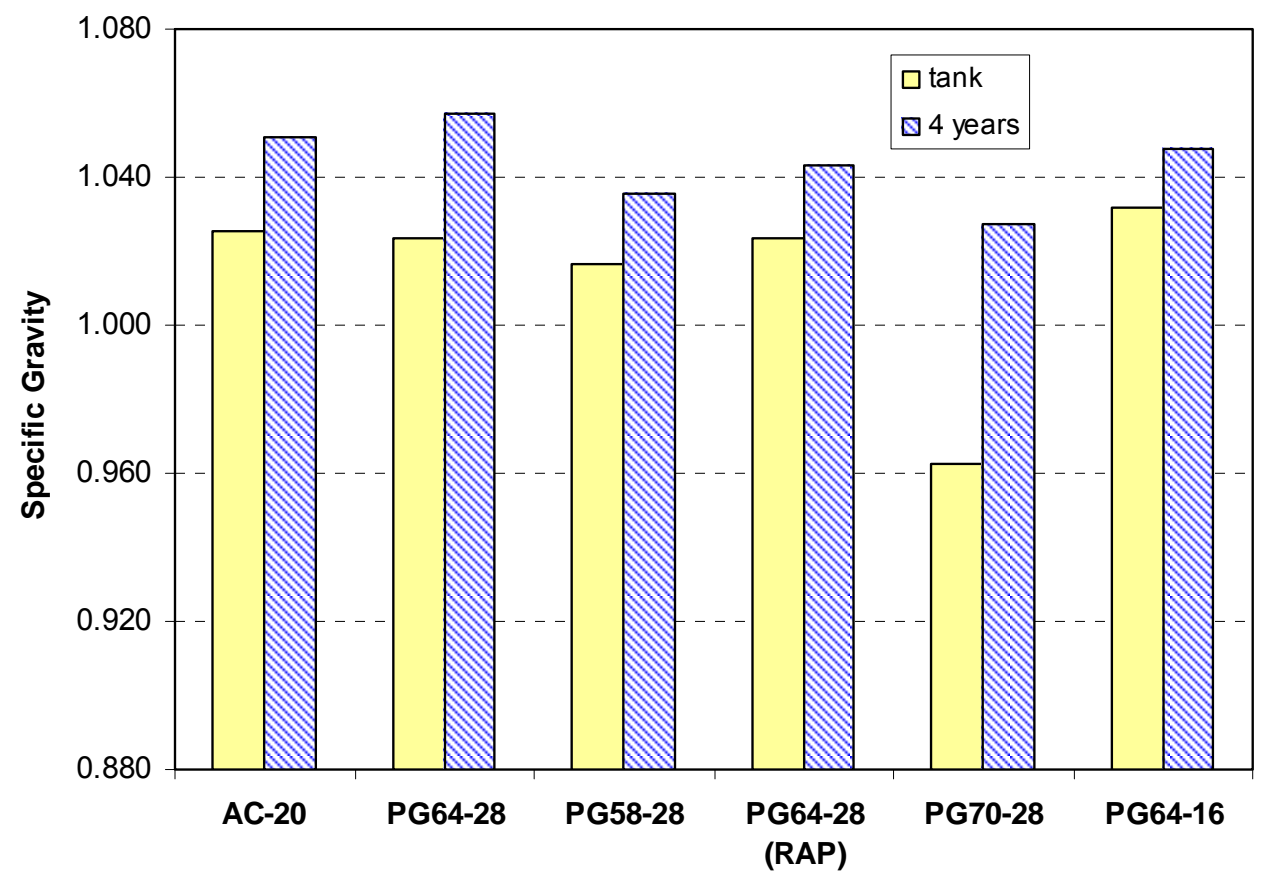

Figure 5.1 -- Specific gravity of the tank binders and recovered binders at the end of 4 years

As is evident from the table and the graph, PG70-28 exhibited the highest increase in specific gravity. It may be noted that the $G_{b}$ for PG64-28 tank binder was also used for $\mathrm{R}-15 \%$, as the same binder was used in both sections. No tests were conducted on binder recovered from the RAP used in $\mathrm{R}-15 \%$. Although the percent increase $G_{b}$ was greatest for PG70-28, PG64-28 had the highest density at the end of 4 years and PG70-28 had the least density. Figure 5.2 shows the change in $G_{b}$ with time. It can be seen that in the case of the 
conventional binders, an increase in density was observed until the end of 2 years after which the $G_{b}$ stayed fairly constant. For the modified binder, the increase in $G_{b}$ continued through the end of 4 years.

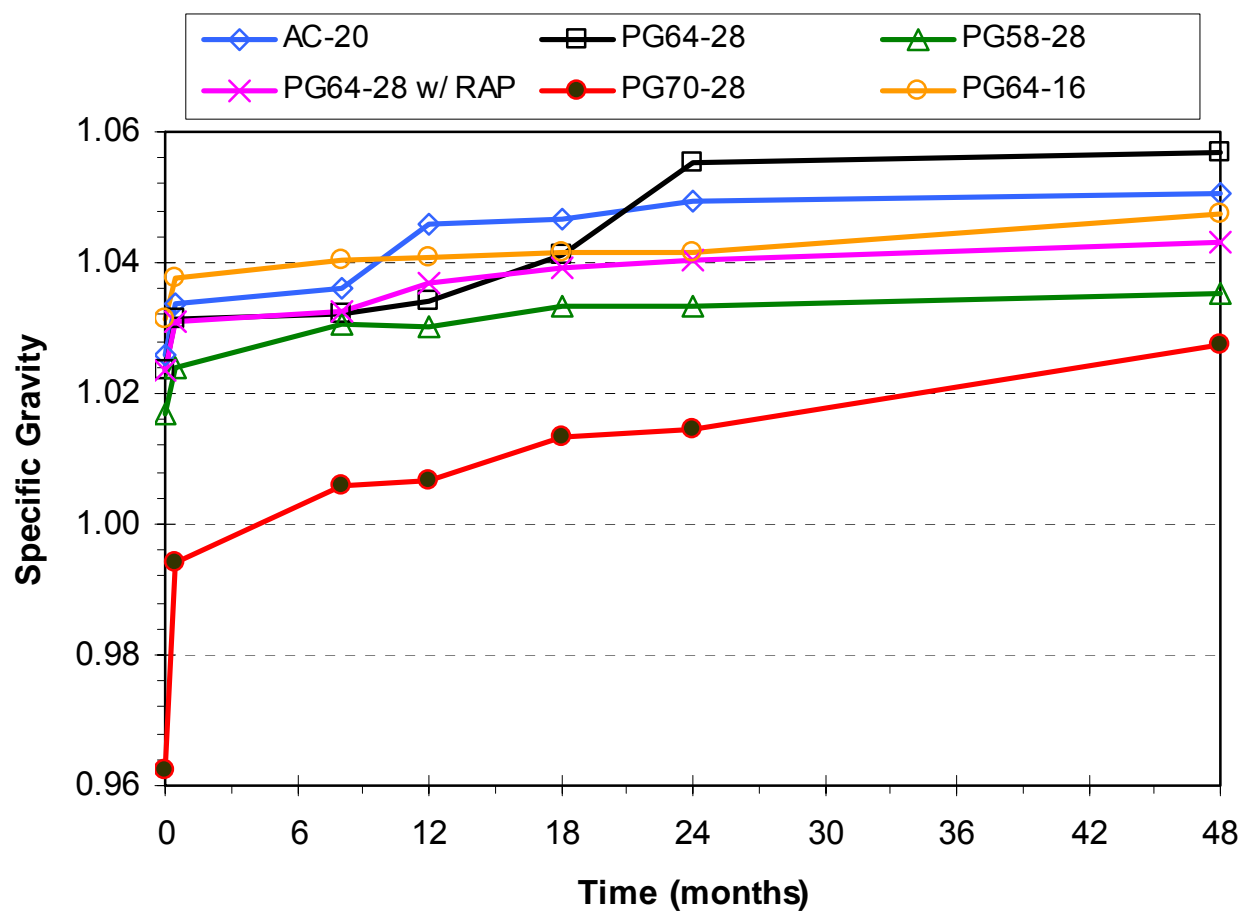

Figure 5.2 -- Change in specific gravity of recovered binders with time

Although the $G_{b}$ of the different binders appears to be within a small range, analysis of variance (ANOVA) tests conducted on data from tank binders indicated that the binders were significantly different $(\alpha=0.05)$. Since the null hypothesis was rejected, multiple comparisons were conducted to ascertain which of the binders used were different. Three methods that are most commonly used by statisticians were used here; Tukey, Bonferroni and Scheffé. All methods indicated that PG64-28 and AC-20 were similar, and that the remaining binders were different.

ANOVA tests indicated that the two variables, binder grade and age, had significant influence on specific gravity of the binder. Further statistical analysis was done using the above-mentioned multiple comparison methods to determine whether all binder grades and 
age groups were different. Results indicated that tank binders were significantly different from recovered binders; with no clear distinction among binders of different ages. This suggests that there was a significant change in the specific gravity of the recovered binders when compared with the corresponding tank binders. On the other hand, the observed change in specific gravity occurring with age of the binder was not statistically significant. When the variable "binder grade" was examined, PG58-28 and PG70-28 were significantly different from the other binders at all ages.

\section{$\underline{5.3}$ Penetration}

Penetration tests were conducted on the recovered binders at $5^{\circ} \mathrm{C}\left(40^{\circ} \mathrm{F}\right)$ and $25^{\circ} \mathrm{C}\left(77^{\circ} \mathrm{F}\right)$ in accordance with AASHTO T49 (115). Penetration at $25^{\circ} \mathrm{C}$ gives a measure of consistency of the binder at the average yearly service temperature in the U. S. This empirical test is not typically conducted as a part of SUPERPAVE binder test program, but is still of interest to some bituminous materials practitioners. In addition, there is a renewed interest among researchers working with time-temperature superposition and shift factors in the determination of Viscosity-Temperature-Susceptibility (VTS) parameter, which requires the determination of penetration and viscosity data at different temperatures. Some researchers have found that low viscosity binders tend to exhibit high susceptibility to permanent deformation. There is also a renewed interest in the determination of Viscosity-Temperature-Susceptibility (VTS), defined as the slope of log log viscosity versus log Kelvin temperature curve, by researchers working with time temperature superposition and calculation of shift factors. VTS factor is determined using an empirical equation that requires determination of penetration, absolute viscosity, rotational viscosity and softening point. To this end, it is worthwhile to examine the changes observed in viscosity of the binders.

Table 5.2 shows the percentage decrease in penetration values with age (time) as compared with the tank binders. Figures 5.3 and 5.4 show the changes in penetration values with age. Tables B2 and B3 in Appendix B shows the data points used to generate these graphs. 
The decrease in penetration is expected due to binder stiffening observed as a result of aging when exposed to environmental, in-service conditions. A higher degree of stiffening indicates higher temperature susceptibility. At lower temperature, the modified binder, PG70-28, showed the largest (82\%) relative decrease in penetration with time and PG64-16 showed the lowest percentage decrease $(51 \%)$ in penetration. At warmer temperature, AC-20 showed the highest (88\%) percentage decrease and PG64-28 showed the lowest decrease (49\%). The data at the end of 4 years for binders recovered from S-64-28 may be erroneous due to problems during the binder recovery process. It is speculated that the solvent was not completely removed from this binder, which resulted in a very soft binder. This is reflected in the other binder tests conducted (penetration, viscosity, DSR, BBR and DTT) on these binders. Therefore, the percent decrease for PG6-28 binder shown in Table 5.2 was calculated at the end of 2 years.

Table 5.2 -- Percent decrease in penetration value of recovered binders with time

\begin{tabular}{|l|c|c|}
\hline \multirow{2}{*}{ Binder } & \multicolumn{2}{|c|}{$\begin{array}{c}\text { Percent Decrease in Penetration } \\
\text { (compared with tank binders) }\end{array}$} \\
\cline { 2 - 3 } & $\mathbf{5}^{\circ} \mathbf{C}$ & $\mathbf{2 5}^{\circ} \mathbf{C}$ \\
\hline AC-20 & 75.3 & 88.1 \\
\hline PG64-28 & 56.9 & 48.7 \\
\hline PG58-28 & 61.3 & 75.2 \\
\hline PG64-28 w/ RAP) & 67.0 & 78.4 \\
\hline PG70-28 & 82.2 & 77.8 \\
\hline PG64-16 & 51.1 & 81.9 \\
\hline
\end{tabular}

While binder stiffening at warmer temperature is desirable for improved rut resistance, binder stiffening at lower temperatures is not desirable for thermal cracking resistance. Due to the significant stiffening shown by most of the binders with age, they may be expected to show improved rut resistance. On the other hand, based on the vast database of penetration data, it was observed by researchers $(116-118)$ that severe cracking may be expected in pavements when the penetration at $25^{\circ} \mathrm{C}$ falls below 20 , and some cracking may be observed when penetration value is between 20 and 30 . Based on these criteria, severe low temperature cracks may be expected in M-AC-20, R-15\%, S-70-28 and S-64-16 and some moderate cracking 


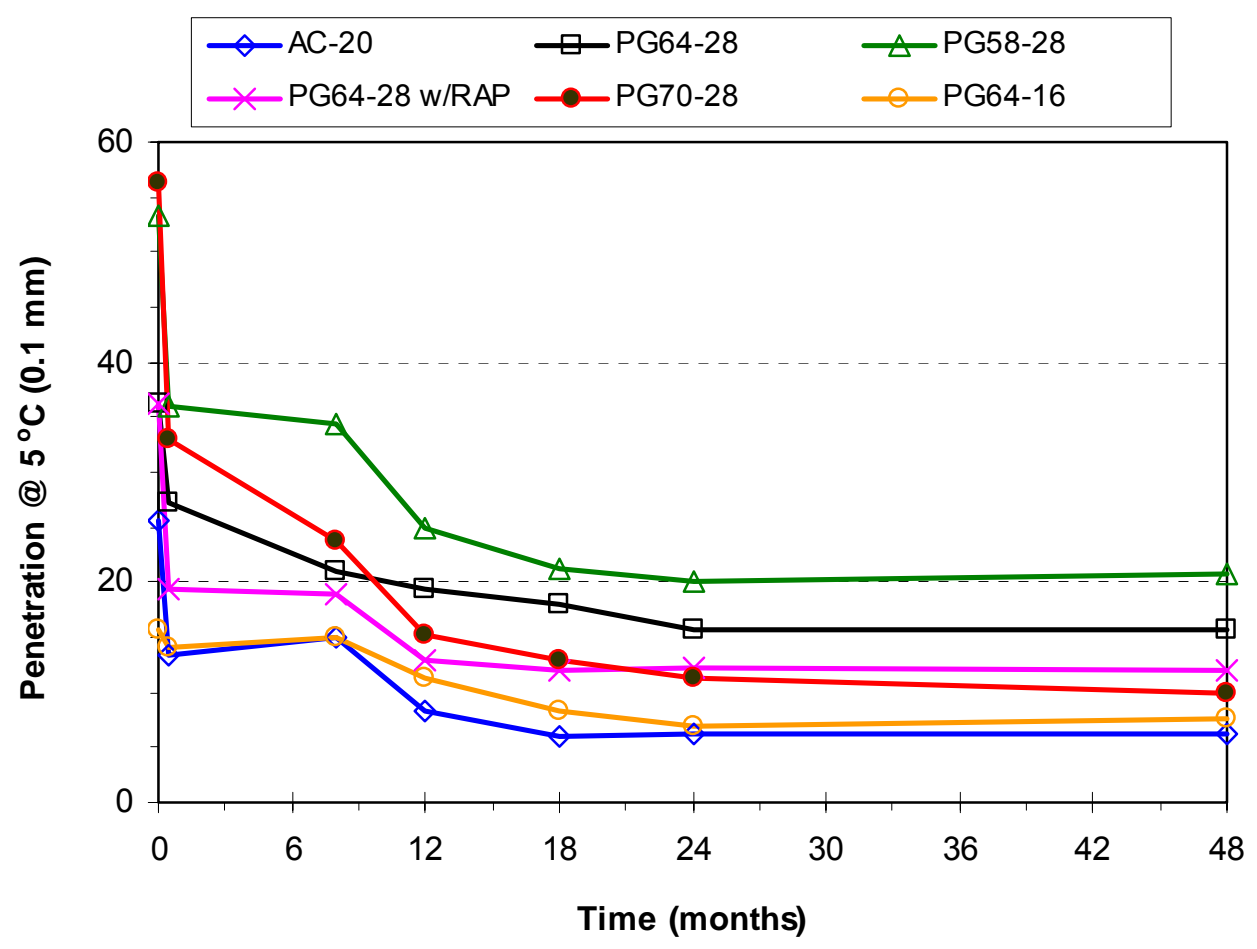

Figure 5.3 -- Change in penetration values of recovered binders at $5^{\circ} \mathrm{C}$

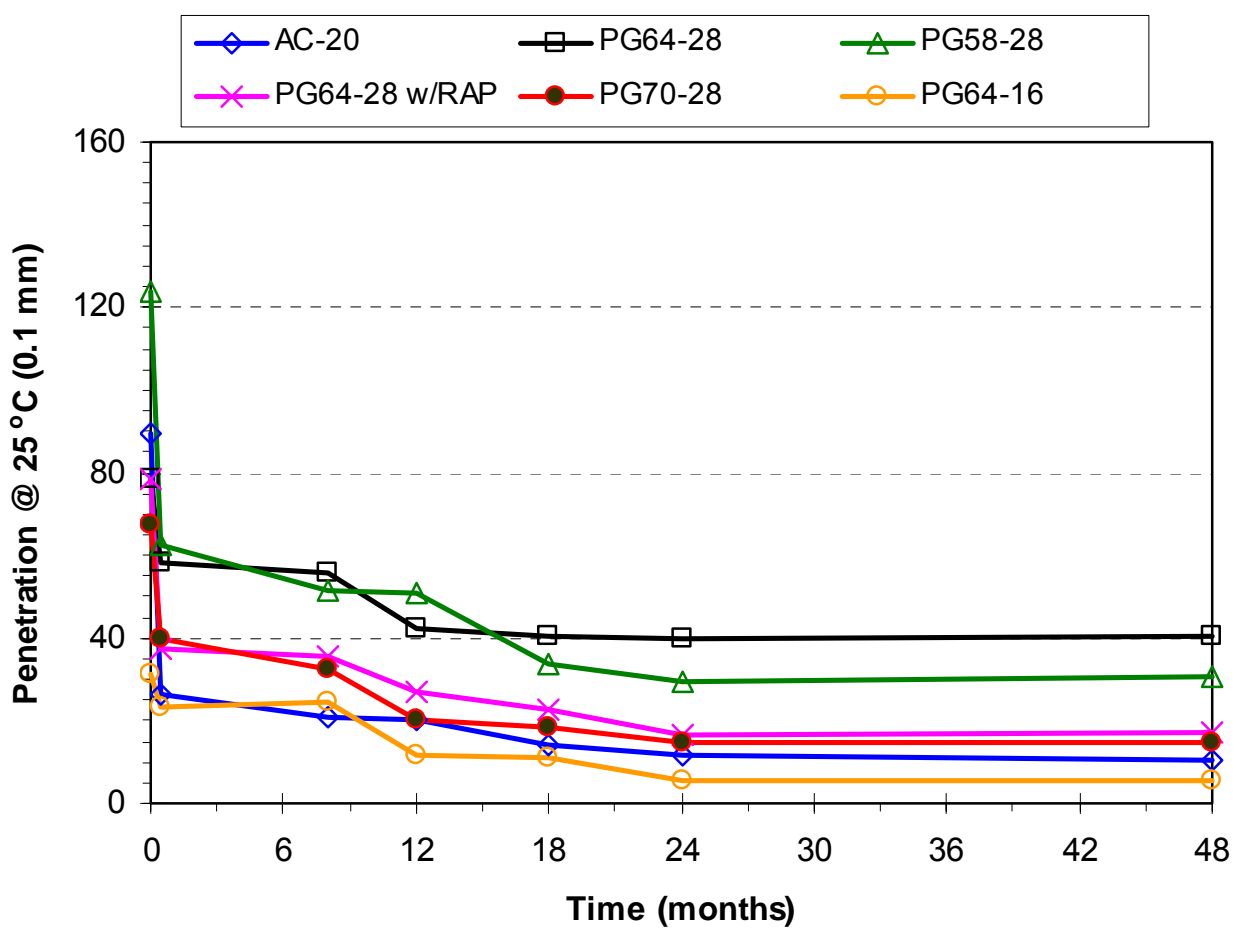

Figure 5.4 -- Change in penetration values of recovered binders at $25^{\circ} \mathrm{C}$ 
may be expected in S-58-28. S-64-28 (control section), which showed a pen-value of 40 at the end of 4 years, at the end of 4 years, may exhibit minimal cracking. As in the case of specific gravity, penetration values also stabilized at the end of two years. Maximum relative decrease in penetration was observed to occur between the data collected from tank binders and the corresponding binders obtained from first set of cores (15 days), which may be assumed to be equivalent to RTFO-aged condition.

Single factor ANOVA test was conducted on tank binders to determine whether their penetration values were significantly different at $\alpha=0.05$ level. Results of the ANOVA tests indicated that the penetration of the binders used were dissimilar, both at $5^{\circ} \mathrm{C}$ and $25^{\circ} \mathrm{C}$. Multiple comparisons indicated that PG58-28 and PG70-28 were different from the remaining binders, similar to the specific gravity data. Two-factor ANOVA test was conducted to verify the influence of binder grade and age on the penetration value. Both factors were found to have significant influence on penetration. Comparison of means with "age" as the variable showed 3 groupings; (i) tank, (ii) 15 days and 8 months and (iii) 1, 1.5, 2 and 4 years. This suggests that binder hardening appeared to occur at three intervals of time. Initial hardening was observed between tank and recovered binders. Then, no further hardening was observed in binders recovered from 15-day and 8-month cores. After 8 months, the binders were observed to further harden with age.

\section{$\underline{5.4 \text { Viscosity }}$}

Two types of viscosities were determined for all the recovered binders; absolute viscosity at $60^{\circ} \mathrm{C}$ and rotational viscosity at $135^{\circ} \mathrm{C}$. These tests were conducted in accordance with AASHTO T202 (119) and AASHTO TP48 (120), respectively. Traditionally, absolute viscosity was used to determine the viscosity grade of the binder. With the nearly nationwide implementation of SUPERPAVE system, absolute viscosity and kinematic viscosity tests are not routinely conducted. Instead, rotational viscosity of tank binders is typically performed on tank binders to determine the mixing and compaction temperatures of HMA and to verify that the binder satisfies the SUPERPAVE requirement of $\leq 3.0 \mathrm{~Pa}$-s. 
Figures 5.5 and 5.6 show, respectively, the trends observed in absolute and rotational viscosity of the recovered binders with time. The data points used to generate these plots may be obtained from Tables B4 and B5 of Appendix B, respectively. All binders showed an increase in both the viscosities with time. The modified binder, PG70-28, showed the highest increase among all the binders used in this study and PG58-28 showed the least increase due to aging. As reported earlier, errors in binder recovery process for S-64-28 at the end of 4 years resulted in a soft binder and hence, a decrease with respect to the original binder.

It is noteworthy that parallel trends were observed in the absolute and rotational viscosity data from PG64-28 and PG58-28 binders; and similar trends were observed between AC-20 and PG64-16 as well. The behavior of binder extracted from the RAP section fell between the two. These overall trends were also noticed in the binder penetration data discussed in the previous section. Based on these trends it may be expected that S-64-28 and S-58-28 and M-AC-20 and S-64-16 show similar behavior in terms of pavement performance. Additionally, since binders with higher viscosity are expected to perform better in terms of rutting performance, it is expected that S-64-28, S-58-28 and S-70-28 would exhibit lower rut depths than M-AC-20 and S-64-16.

Single-factor ANOVA tests on viscosity data from the tank binders used in this study indicated that they were not similar. Comparison of means of tank binders indicated that the rotational viscosity and absolute viscosity of PG70-28 and PG58-28 were different from those of the remaining binders. Two-factor ANOVA indicated, as expected, that both binder grade and age influence the viscosity of the binder. Multiple comparison of means indicated overlapping of age groupings, implying gradual changes in viscosity. The viscosity of PG70-28 was observed to be statistically different from that of the remaining binders. These conclusions apply to both, rotational and absolute viscosities. 


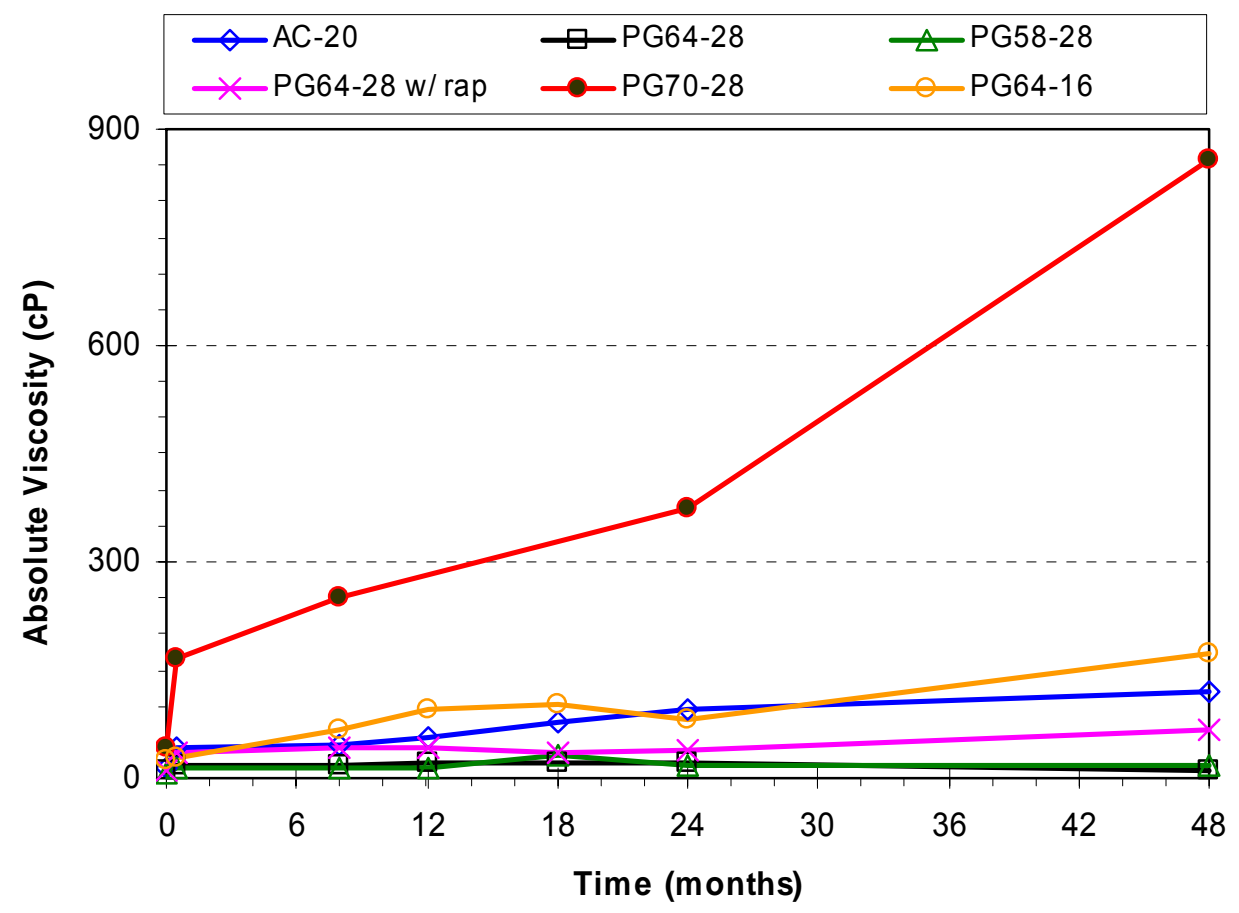

Figure 5.5 -- Trends in absolute viscosity of recovered binders with time

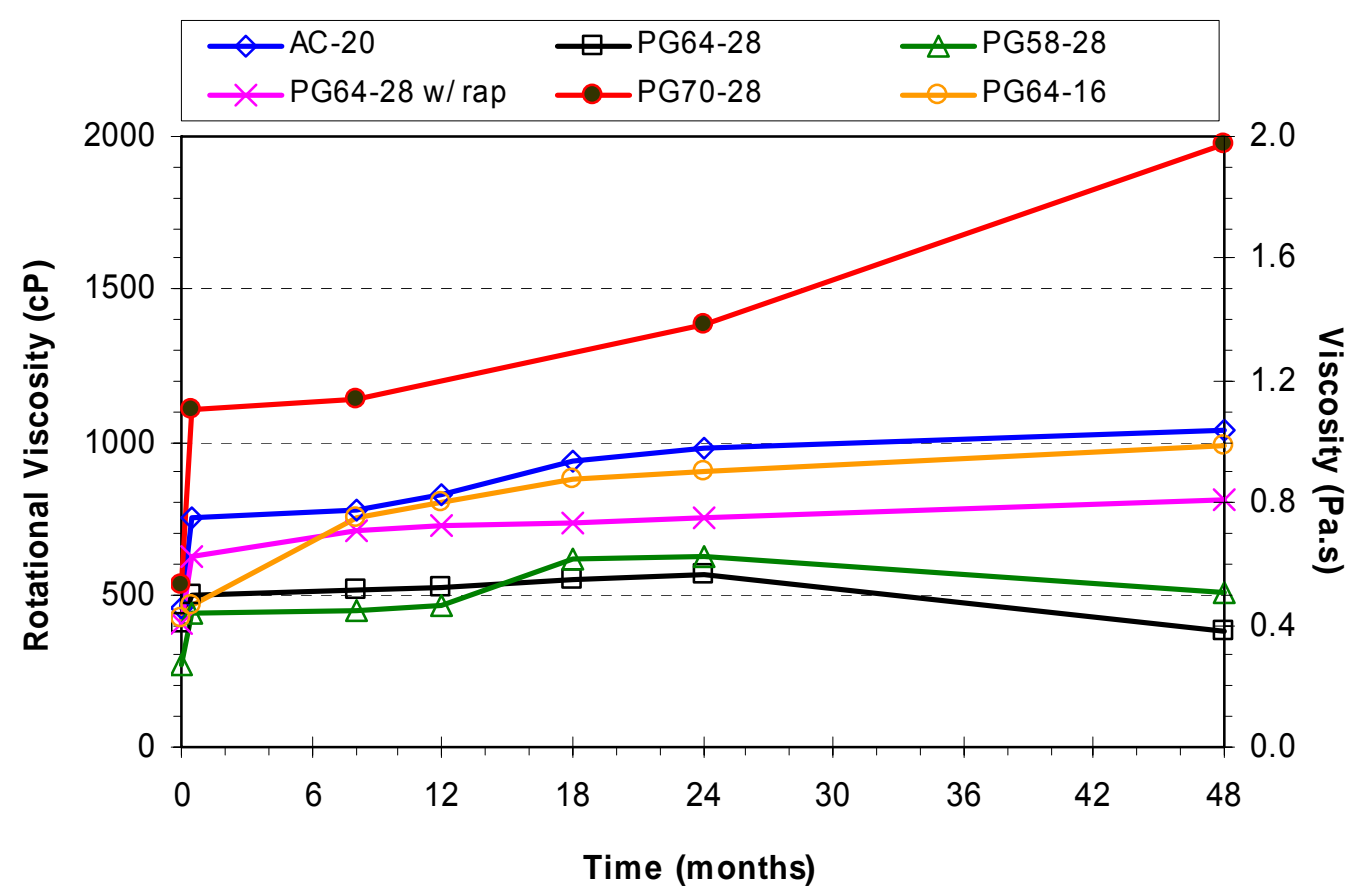

Figure 5.6 -- Trends in rotational viscosity of recovered binders with time 


\section{$\underline{5.5 \text { Complex Modulus and Phase Angle }}$}

Complex modulus $\left(\left|G^{*}\right|\right)$ and phase angle $(\delta)$ of the recovered binders were determined at high and intermediate temperatures using the Dynamic Shear Rheometer (DSR), in accordance with AASHTO TP5 (86). The change in the maximum passing temperature and hence the passing grade of the binder was determined for all the recovered binders. When tested at high temperatures $\left(>52^{\circ} \mathrm{C}\right)$, the AASHTO TP5 specification limit of $2.2 \mathrm{kPa}$ for RTFOaged binders was used as the criterion in determining the maximum passing temperature for all binders, for comparison purposes. It may be noted, however, that only the binders recovered from the first set of field cores (approximately 15 days after construction) may be considered equivalent to RTFO-aged material. Results from tests conducted on RTFO-aged tank binders were compared with results from this set of binders to verify/validate the SUPERPAVE binder aging process.

Table 5.3 shows the maximum passing temperature $\left(T_{D S R}\right)$ of the RTFO-aged tank binders and the recovered binders from the 15 days old pavement. The largest difference in $T_{\mathrm{DSR}}$ was $4^{\circ} \mathrm{C}$ and was observed in AC-20 and PG64-28 w/ RAP; which was less than one temperature grade. Since the R-15\% and S-64-28 had the same binder grade, the $T_{D S R}$ for RTFO-aged binder of these two sections was the same. Upon binder extraction and recovery from this section, some of the RAP binder may be expected to blend with the virgin binder used in this section. Overall, it may be said that RTFO-aging process adequately simulates the aging process that occurs during the initial mixing and compaction processes.

Table $5.3-T_{D S R}$ of RFTO-aged and the first set of recovered binders

\begin{tabular}{|l|c|c|}
\hline \multirow{2}{*}{ Binder (Section) } & \multicolumn{2}{|c|}{ T $_{\text {DSR }}\left({ }^{\circ} \mathrm{C}\right)$} \\
\cline { 2 - 3 } & RFTO-aged & 15 days old \\
\hline AC-20 (M-AC-20) & 66.0 & 69.6 \\
\hline PG64-28 (S-64-28) & 64.7 & 63.0 \\
\hline PG58-28 (S-58-28) & 58.9 & 62.5 \\
\hline PG64-28 w/ RAP (R-15\%) & 64.7 & 68.6 \\
\hline PG70-28 (S-70-28) & 72.8 & \\
\hline PG64-16 (S-64-16) & 69.3 & \\
\hline
\end{tabular}


Figure 5.7 shows the change in maximum passing temperature, $T_{D S R}$, with time. As expected, some binder stiffening has occurred with time as evidenced by the increase in the maximum passing temperature. ANOVA tests indicated that $T_{D S R}$ of the recovered binders was not constant with time.

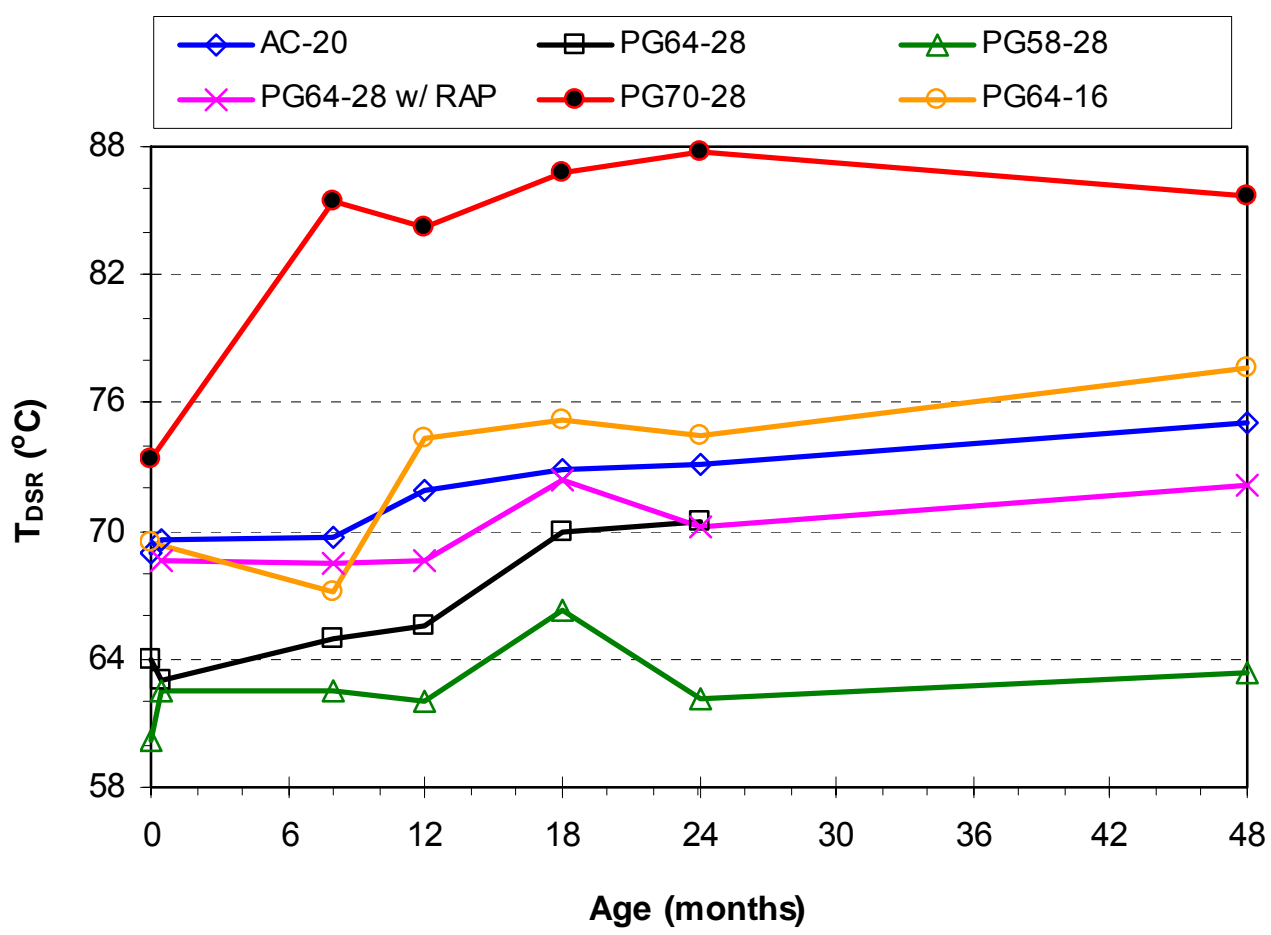

Figure 5.7 -- Change in maximum $\mathrm{T}_{\mathrm{DSR}}$ of the recovered binders with time

\section{$\underline{5.6 \text { Creep Stiffness and Slope }}$}

The low temperature behavior of asphalt is characterized by creep stiffness (S) and slope of the deflection versus time plot (m-value). These tests were conducted on the recovered binders and the RTFO-PAV aged (tank) binders using the Bending Beam Rheometer (BBR) in accordance with AASHTO TP1 (36). Asphalts are known to exhibit elastic behavior at lower temperatures above the glass transition temperature $\left(T_{g}\right)$, which varies with the binder. A typical value of $T_{g}$ is around $-24^{\circ} \mathrm{C}$. At temperatures below $T_{g}$, asphalts exhibit brittle behavior. Brittle behavior is also observed in binders with high stiffness values that accompany cold 
temperatures encountered in pavements during winter months. To limit the excess binder stiffness and brittle behavior, AASHTO PP6 specifies a maximum limit of $S \leq 300 \mathrm{MPa}$ and minimum slope $\geq 0.300$. A high slope values ensures better stress relaxation ability of the binder. These two limits were used to determine the minimum passing temperatures $\left(T_{B B R}\right)$ of the recovered and the RTFO-PAV aged binders. The higher (warmer) of the two estimates was used in making comparisons. It was observed that the limiting stiffness value was the controlling factor in all binders, except PG70-28 where limiting m-value was the controlling factor.

Figure 5.8 shows the increase in the $T_{B B R}$ of the recovered binders during the study period. The increase in the passing temperature of AC-20, PG64-28, PG58-28 and PG64-28 with RAP does not appear to be substantial and was gradual during the study period. PG70-28 and PG64-16, however, showed significant stiffening with time as evidenced by the increase in the passing values. While the stiffening observed in PG64-16 was occurred during the early age of the pavement, the stiffening in PG70-28 occurred at the end of 4 years. A similar trend was also reflected in rotational viscosity and DSR data.

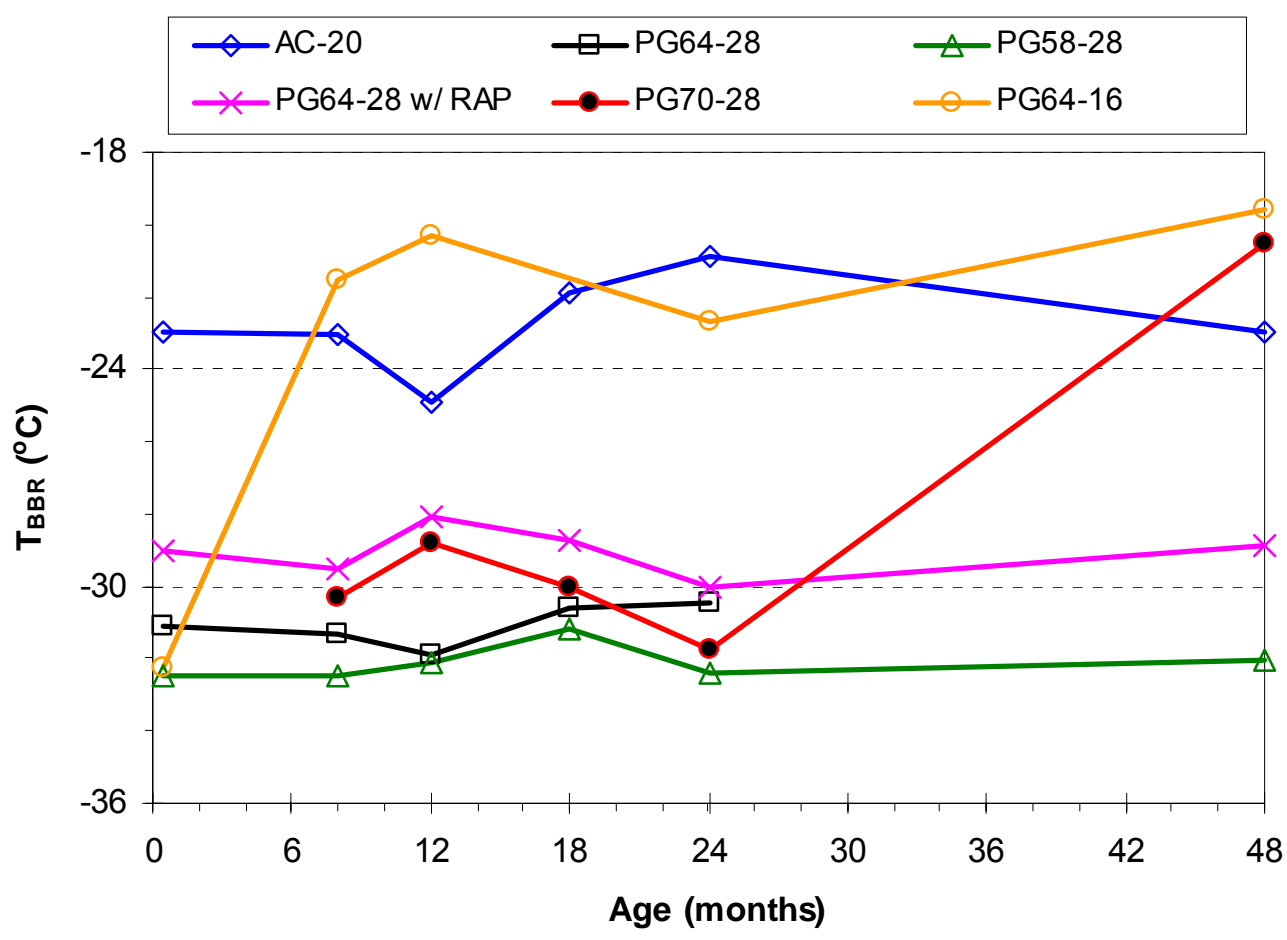

Figure 5.8 -- Change in minimum $T_{\mathrm{BBR}}$ of the recovered binders with time 
The $\mathrm{T}_{\mathrm{BBR}}$ of PG70-28 and PG64-16 were $-20.5^{\circ} \mathrm{C}$ and $-19.9^{\circ} \mathrm{C}$ at the end of 4 years, respectively. These values are almost equal to the $T_{\min (\text { pvmt) }}$ observed at the site $\left(-19.5^{\circ} \mathrm{C}\right)$. Therefore, based on BBR testing it may be expected that S-70-28 and S-64-16 would exhibit thermal cracking. The minimum passing temperatures for the binders recovered from S-64-28,

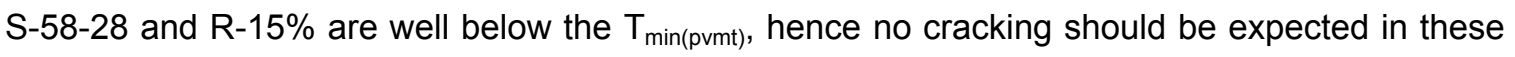
sections. The warmest $T_{B B R}$ observed in M-AC-20 recovered binders was close to $T_{\min (p v m t)}$, hence, the extent of thermal cracking in this section, if present, should be less than that observed in S-70-28 and S-64-16.

The $T_{B B R}$ of the RTFO-PAV aged binders was controlled by the limiting m-value.

It was found that the $T_{B B R}$ of these RTFO-PAV aged binders was higher than or similar to the $T_{B B R}$ of the corresponding recovered binders at the end of 4 years of all binders, except the modified binder. This indicates that RTFO-PAV aging simulates field aging that occurs in 4 years or less, for the unmodified binders used in this study.

\section{$\underline{5.7 \text { Failure Stress and Strain }}$}

The Direct Tension (DT) test was used to determine the ductility of the binders in terms of failure stress and failure strain at low temperatures, in accordance with AASHTO TP3 (37). A minimum failure strain of $1 \%$ is recommended by this specification to ensure that the binder has sufficient flexibility to withstand the thermal stresses that are generated in the pavement at low temperatures. Data from this test were used to determine the minimum passing temperature using the $1 \%$ strain limit. A loss in ductility is indicated by a warming trend in the minimum passing temperature with age.

Figure 5.9 shows the change in minimum passing temperature $\left(T_{D T}\right)$ with age of the binder obtained from DT testing. Overall, no significant warming was observed in the recovered binders with age of the pavement. The largest increase was about $3^{\circ} \mathrm{C}$ and was observed in the case of AC-20, PG70-28 and PG64-16. It can be seen from this figure that 
M-AC-20 and S-64-16 are prone to thermal cracking, since the $T_{D T}$ of these binders at the end of 4 years is close to the $T_{\min (p v m t)}$ encountered at the test site.

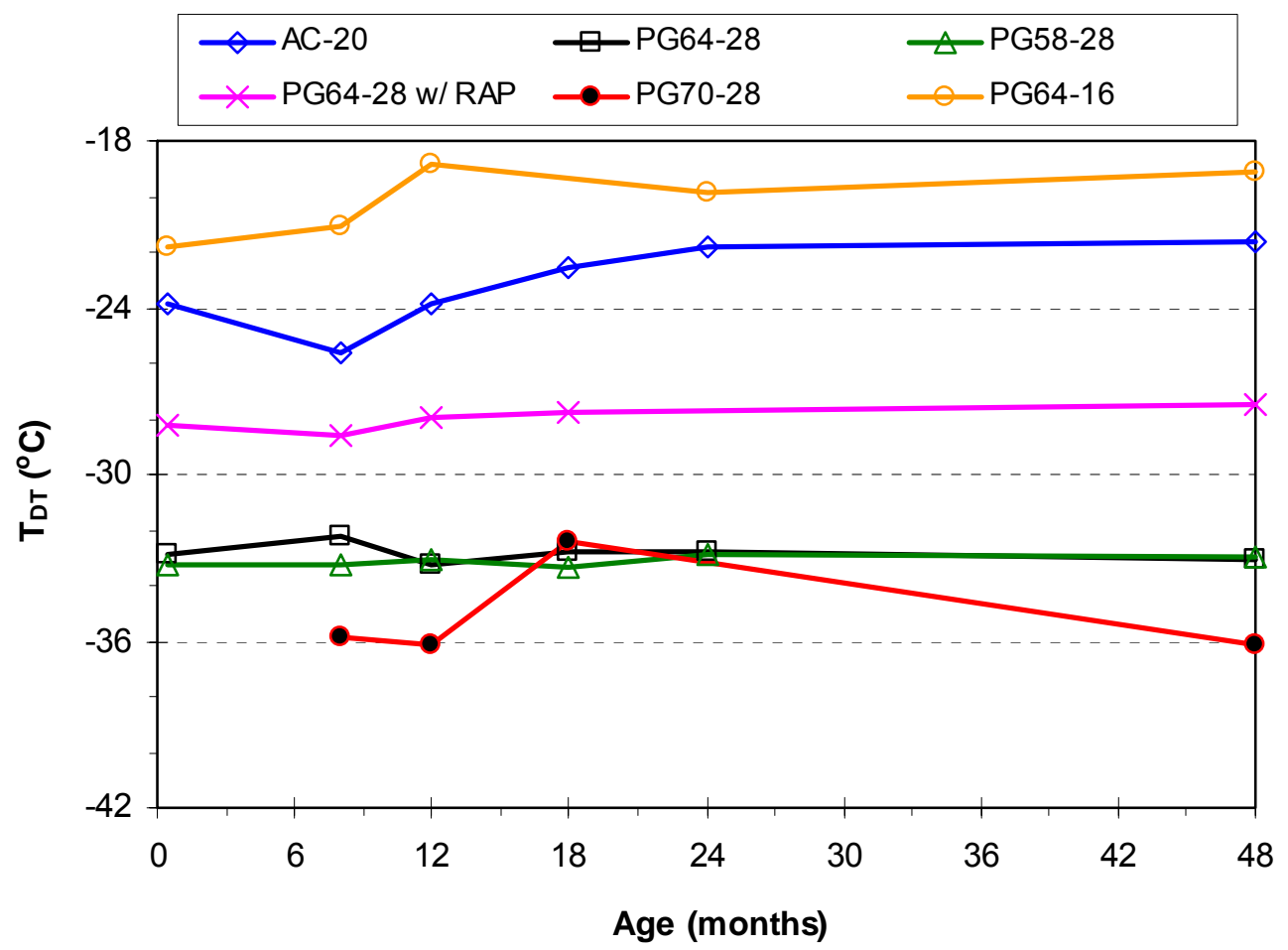

Figure 5.9 -- Change in minimum $\mathrm{T}_{\mathrm{DT}}\left(\min . \varepsilon_{\mathrm{f}}=1 \%\right)$ with time

Thermal Stress Analysis Routine $\left(\operatorname{TSAR}^{\circledR}\right)$ (23) was used to determine the critical cracking temperatures of the binders using DT and BBR data in accordance with AASHTO PP42 (38) and MP1a (121) protocols. Although these protocols are not used in the state of Indiana, it is of interest to study the critical temperature estimates ( $\left.T_{\mathrm{PP} 42}\right)$ obtained from this analysis and how they compare with $\mathrm{T}_{\mathrm{BBR}}$ estimates. $\mathrm{T}_{\mathrm{PP} 42}$ is determined by the intersection of thermal stress curve, generated by the TSAR software using BBR data, and the fracture (tensile) strength curve, obtained from DT testing at the corresponding test temperatures. $T_{\mathrm{PP} 42}$ is the minimum temperature that a pavement can withstand without developing cracks. When the thermal stresses developed in the pavement exceed the tensile strength of the binder, cracking is assumed to occur. A typical TSAR ${ }^{\circledR}$ generated plot is shown in Figure 5.10. Figure 5.11 shows the change in $\mathrm{T}_{\mathrm{PP} 42}$ plotted versus time or age of the pavement (binder). 
S-64-16 (2 years old)

Critical Temperature -19.7 C

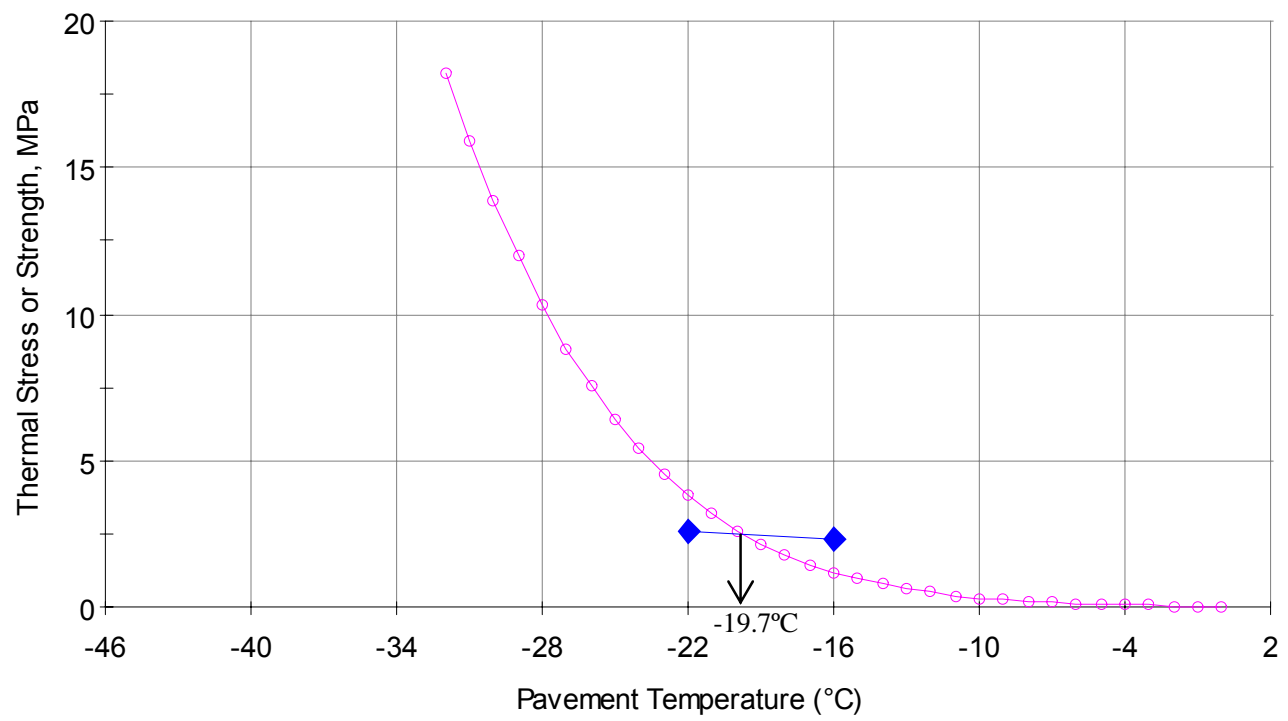

Figure 5.10 -- Typical plot obtained from $\operatorname{TSAR}^{(\circledast)}$ software

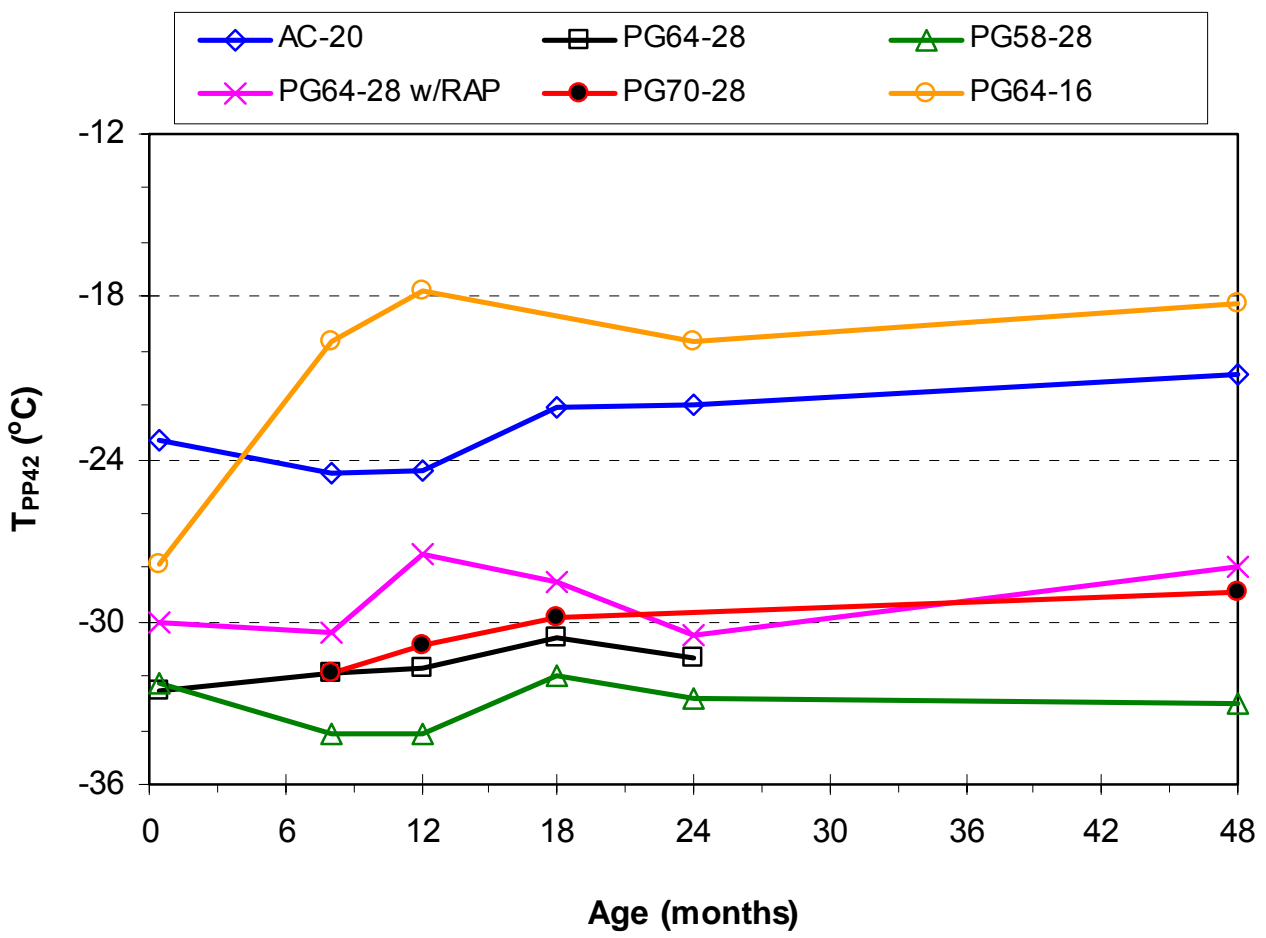

Figure 5.11 -- Change in critical cracking temperature $\left(\mathrm{T}_{\mathrm{PP} 42}\right)$ with time 
As seen from Figure 5.11, PG64-16 showed the largest warming in critical temperature with time. M-AC-20 and S-64-16 may be expected to show poor resistance to thermal cracking due to their high critical temperatures at the end of 4 years. The critical temperature of the modified binder (S-70-28) and the RAP binder (R-15\%) at the end of 4 years was close to the recommended limit of $-28^{\circ} \mathrm{C}$. Since the binders recovered from the RAP section also marginally satisfied the ductility limit at $-28^{\circ} \mathrm{C}$ (see Figure 5.9 ), some degree of cracking may be observed in this test section. S-58-28, which showed good performance in both the ductility requirement and TSAR analysis, is expected to show good thermal cracking resistance.

Finally a comparison of BBR and DT results was done by plotting the $T_{B B R}$ versus $T_{\mathrm{PP} 42}$, and is shown in Figure 5.12. As indicated by the high $\mathrm{R}^{2}(89.9 \%)$ shown on the graph, there is a high degree of correlation between the two test results. The observed difference between $T_{P P 42}$ and $T_{B B R}$ was between $\pm 3^{\circ} \mathrm{C}$ in all sections, with two exceptions. These exceptions were observed in PG70-28 (modified binder) and PG64-16. In the case of the modified binder from S-70-28 recovered at the end of 4 years, BBR tests results gave a minimum passing temperature (m-controlled) of $-20.5^{\circ} \mathrm{C}$. Whereas, critical temperature estimate obtained using the AASHTO MP1a (TSAR estimates) was around $-29^{\circ} \mathrm{C}$. Therefore, while BBR tests results predict cracking in S-70-28 (modified binder); MP1a does not predict cracking in S-70-28. This outlier ( $\approx$ $9^{\circ} \mathrm{C}$ difference) was dropped in calculating the $\mathrm{R}^{2}$ value. In the case of S-64-16, the difference was around $4.5^{\circ} \mathrm{C}$, which was observed in results from the first set of binders (15 days). Deleting this outlier increased the $\mathrm{R}^{2}$ value to $92.5 \%$. 


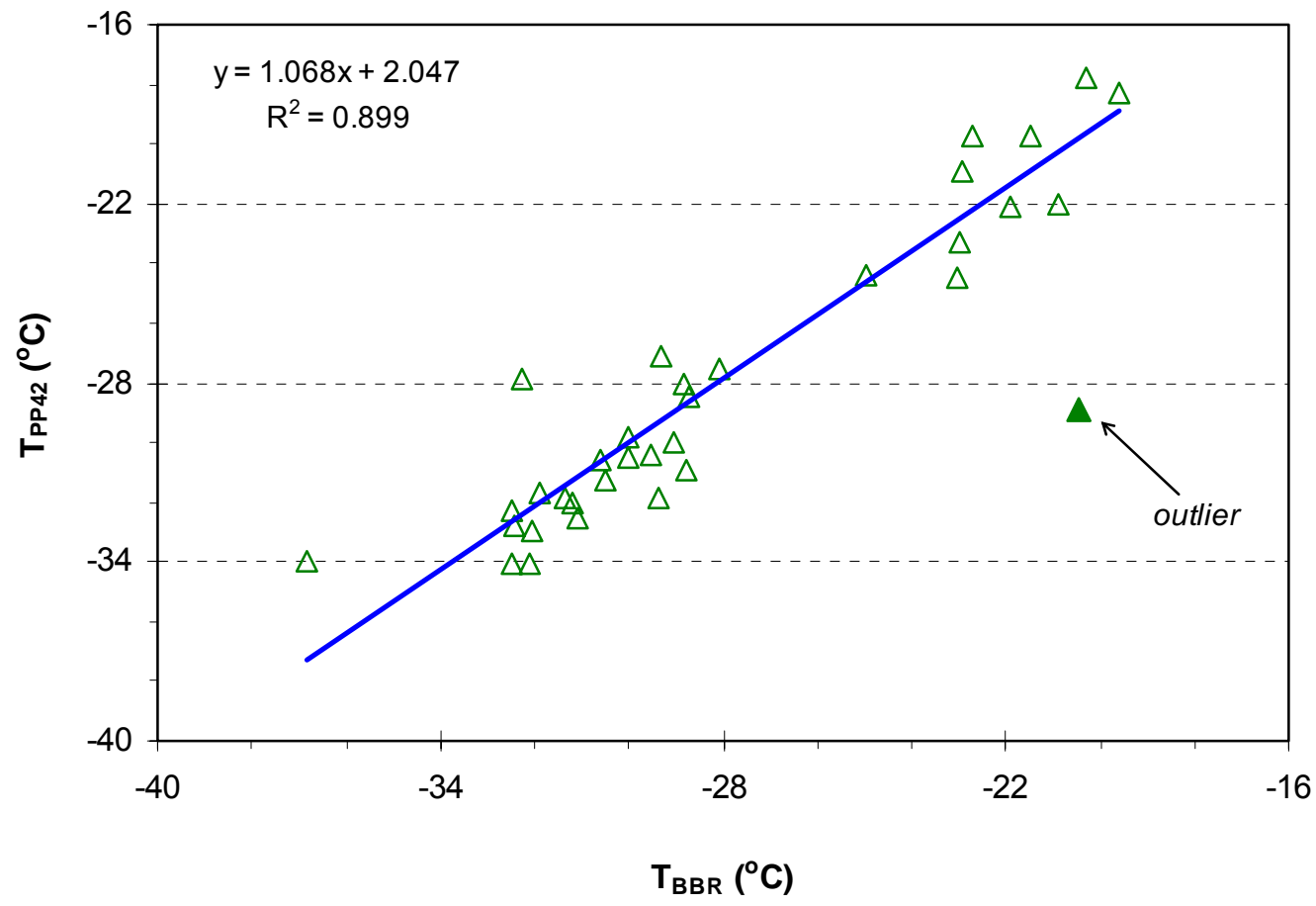

Figure 5.12 -- Comparison of $\mathrm{T}_{\mathrm{BBR}}$ versus $\mathrm{T}_{\mathrm{PP} 42}$

\section{$\underline{5.8 \text { Summary of Binder Tests Results }}$}

This section summarizes the conclusions drawn from the binder test data. All binders showed an increase in specific gravity and hence, the density of the binders. The highest increase was seen in the case of the modified binder. Increased density may be indicative of an increase in binder stiffness which in turn adds to the rut resistance of the corresponding HMA. The increase in $G_{b}$ stabilized at the end of 2 years for the conventional binders, but continued until the end of 4 years for the modified binder. A decrease in observed penetration values also stabilized at the end of 2 years. A major part of the observed decrease in penetration occurred between the tank binders and binders recovered from the field cores at the end of 15 days. Although stiffer binders offer good rut resistance at higher temperatures, excessive stiffening at low temperatures offers poor resistance to thermal cracking. It was observed by other researchers that when the penetration at $25^{\circ} \mathrm{C}$ falls below 20 , severe cracking may be expected 
in the pavement. Penetration values between 20 and 30 indicate moderate cracking and pen value above 30 indicates good thermal crack resistance. Based on these criteria, severe cracking is predicted in M-AC-20, R-15\%, S-70-28 and S-64-16, while moderated cracking may be expected in S-58-28. S-64-28 which had a pen value of 40 , may be expected to show minimal to no low-temperature cracking.

Binders with higher viscosity offer better resistance to rutting at high temperatures. Accordingly, S-64-28 (control section) and S-58-28 are likely to exhibit a higher degree of rutting compared with the other sections. The binder used in S-70-28, PG70-28, had the highest viscosity (absolute and rotational) and is likely to offer better resistance to rutting compared with the other test sections.

Based on SHRPBIND software, the recommended binder for this study site was PG64-28. Based on the performance grades of the binders used in this study, PG58-28 is expected to show a higher degree of rutting in comparison with the other binders. Similarly, PG70-28 is expected to provide superior performance in terms of rut resistance. S-64-16 and M-AC-20 (= PG64-22) are expected to show poor low-temperature crack resistance, due to the warmer low-temperature grade compared with the PGxx-28 binders used in this study.

Due to binder stiffening with age, the DSR parameter $\left|G^{*}\right| / \sin \delta$ indicated an increase in the maximum passing temperature with age (time) of the pavement (binder). Binder recovered from S-58-28 did not meet the specification at $64^{\circ} \mathrm{C}$ and may exhibit rutting at pavement temperatures equal to or higher than $64^{\circ} \mathrm{C}$ for prolonged periods of time. Rutting phenomenon in HMA pavements occurs early during the life of the pavement. The high $T_{D S R}$ values of binders recovered from M-AC-20, R-15\%, S-70-28 and S-64-16 at the early ages indicate that these sections will show higher rut resistance.

If the minimum pavement temperature falls below $-20^{\circ} \mathrm{C}$, approximately, $\mathrm{BBR}$ test data indicate that severe cracking will occur on S-70-28 and S-64-16, and to some extent in M-AC-20. S-64-28 and $\mathrm{R}-15 \%$ are expected to show better resistance to thermal cracking than M-AC-20, S-70-28 and S-64-16, while no cracking is expected in S-58-28. 
On the other hand, the minimum passing temperature estimates obtained using the maximum strain limit in DT tests indicate that only M-AC-20 and S-64-16 will exhibit thermal cracking. The modifier used in PG70-28 improved the ductility of the binder at low temperatures, allowing sufficient binder flexibility at lower temperatures; and this was reflected in this binder's good performance in Direct Tension tests. Little to no cracking is indicated in S-64-28, S-58-28 and S-70-28 by DT test data. The performance of R-15\% is expected to be in between that of M-AC-20 and S-64-16 and that of S-64-28, S-58-28 and S-70-28. Critical temperature estimates using AASHTO PP42 (TSAR ${ }^{\circledR}$ ) also predicted severe cracking in M-AC-20 and S-64-16 and no cracking is predicted in S-58-28. Little to moderate cracking may be expected in S-64-28, R-15\% and S-70-28. The main difference between BBR and AASHTO PP42 predictions occur in the case of S-70-28. While the BBR predicts severe cracking in S-70-28, PP42 predicts little to moderate cracking in this section.

An overview of the distress predicted by the binder tests conducted in this chapter is presented in Table 5.4. Since BBR and DT are low temperature tests, rutting predictions cannot be made from these tests. Similarly, since DSR cannot make thermal cracking (low temperature) predictions since it is a high temperature test. Thermal cracking is predicted in M-AC-20 and S-64-16 by all the low temperature tests. Penetration and BBR tests predicted cracking in S-70-28, while only penetration test predicts cracking in R-15\%. Rutting is predicted on in S-58-28, based on pavement temperature data. The other binder tests do not predict cracking in any of the remaining sections.

Table 5.4 -- Distress predictions from binder tests and pavement temperature

\begin{tabular}{||l|c|c|c|c|c||}
\hline \multirow{2}{*}{ Distress } & \multicolumn{4}{|c|}{ Binder Tests } & Pavement \\
\cline { 2 - 5 } & Penetration & DSR & BBR & DT & Temp. data \\
\hline Rutting \\
(high temperature) & None & None & -- & -- & S-58-28 \\
\hline & M-AC-20 & & M-AC-20 & M-AC-20 & M-AC-20 \\
Thermal Cracking & S-70-28 & - & S-70-28 & S-64-16 & S-64-16 \\
(low temperature) & S-64-16 & - & S-64-16 & & \\
& R-15\% & & & \\
\hline
\end{tabular}




\section{CHAPTER 6 -- EVALUATION OF MIXTURES}

This chapter deals with the tests that were conducted on material collected from the field at the time of construction, i. e., plant mixtures, and the test pavements, i. e., field cores. Plant mixtures were collected from HMA trucks at the time of pavement construction and placed in 5-gallon metal buckets, and sent to Purdue University Bituminous Laboratory for further testing of mixture properties and performance tests. Eight 150-mm (6-in.) field core samples were obtained from each test section at predetermined ages and were also sent to the Purdue Laboratory for determination of mixture properties in the field.

\section{$\underline{6.1 \text { Field Core Samples }}$}

Forty-eight core samples (6 sections $x 8$ cores each) were obtained from the test site at the end of 15 days, 8 months, 12 months, 18 months, 24 months and 48 months. These sets of cores will, hereafter, be referred to as A, B, C, D, E and F, respectively. Of the 8 cores obtained at each age, four were taken from the left wheel path of the driving lane and the other four were taken from the right wheel path.

\subsubsection{Layer Thickness}

Core samples obtained from the field consisted of the surface and intermediate layers. The surface layers of the cores were separated from the intermediate layer by sawing prior to further testing. Any extraneous material from the underlying RCC base course attached to the bottom of the intermediate course was also removed. The average thicknesses of the surface and intermediate layers of each test section were determined at all ages. 
Figures 6.1 and 6.2 show the change in surface and intermediate layer thicknesses with time, respectively. Tables B6 and B7 in Appendix B show the mean, standard deviation and coefficient of variation of the layer thickness data obtained for the six test sections at different ages. ANOVA test was conducted to compare the mean layer thickness of the six test sections, at each age. These results are presented in Table 6.1. A p-value $\geq 0.05$ indicates that the mean thicknesses of the test sections were not significantly different. To determine whether the observed change in the mean layer thickness with age of each test was statistically significant, ANOVA test was conducted on the mean layer thickness data within each test section. These results are presented in Table 6.2.

The surface layers thickness ranged between $40.6 \mathrm{~mm}$ (1.6") and $48.3 \mathrm{~mm}(1.9 ")$, and the observed variation was smaller in comparison with the intermediate layer thickness. In the case of surface layers, the high p-values (> 0.05) shown in Table 6.1 indicate that the mean surface layer thickness of the different test sections were similar at all ages. Similarly, it may be concluded from the high p-values shown in Table 6.2 that the changes observed in the mean surface layer thickness of each section with time are not statistically significant.

The thickness of the intermediate layers showed higher variability than the surface layers and ranged from $109.2 \mathrm{~mm}(4.3 ")$ to $124.5 \mathrm{~mm}$ (4.9"). Results of ANOVA tests shown in Table 6.1 indicate that there were significant differences in the mean intermediate layer thickness between the different test sections in the A, B, E and F cores. Multiple comparisons tests were conducted, but no distinct groupings were found (overlapping groups). When a comparison was made between different ages (Table 6.2), no significant differences with time (age) were observed except in S-70-28. In other words, only S-70-28 appeared to show significant change (decrease) in thickness with time. No data points were dropped in data analyses presented in this section. 


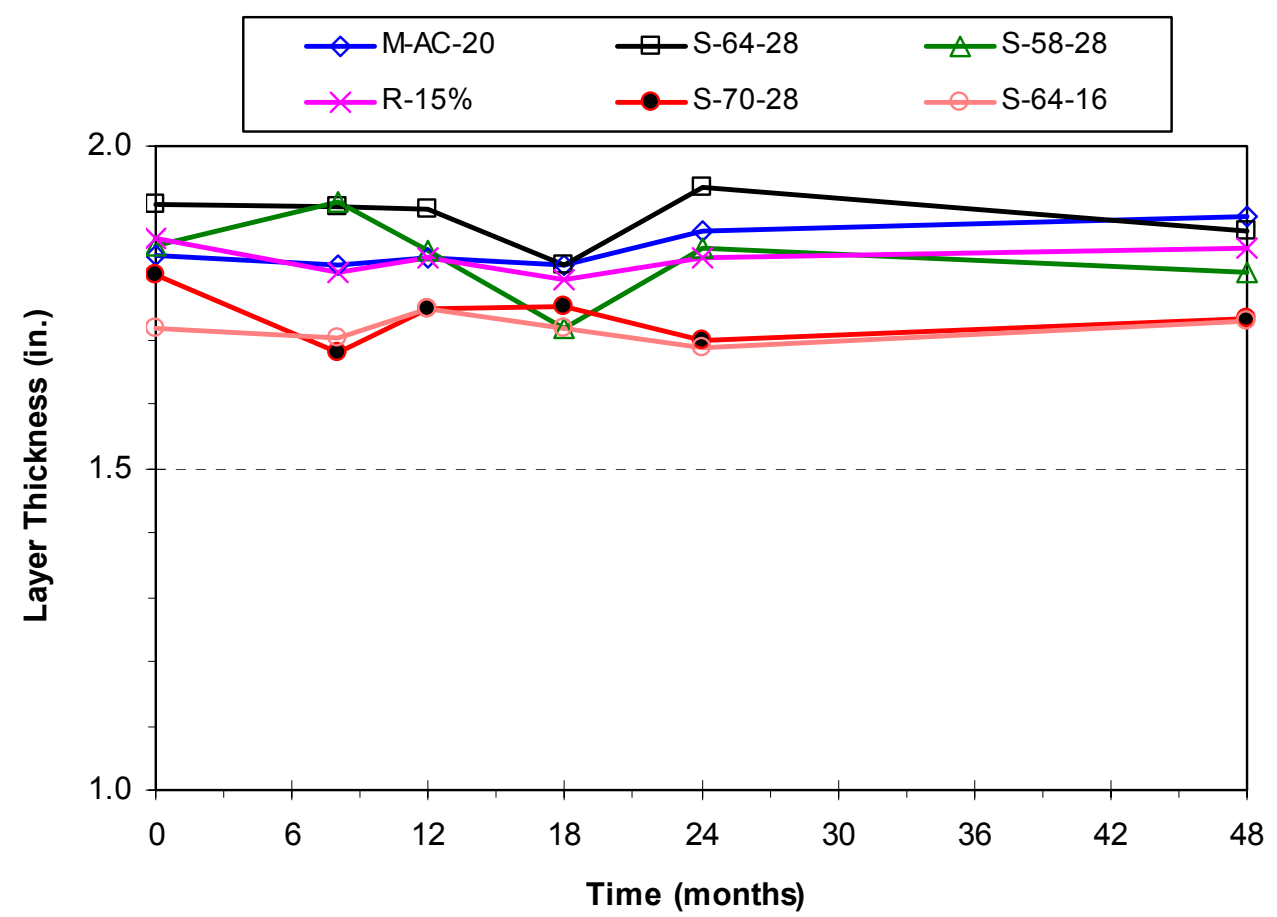

Figure 6.1 -- Trends in surface layer thickness with time

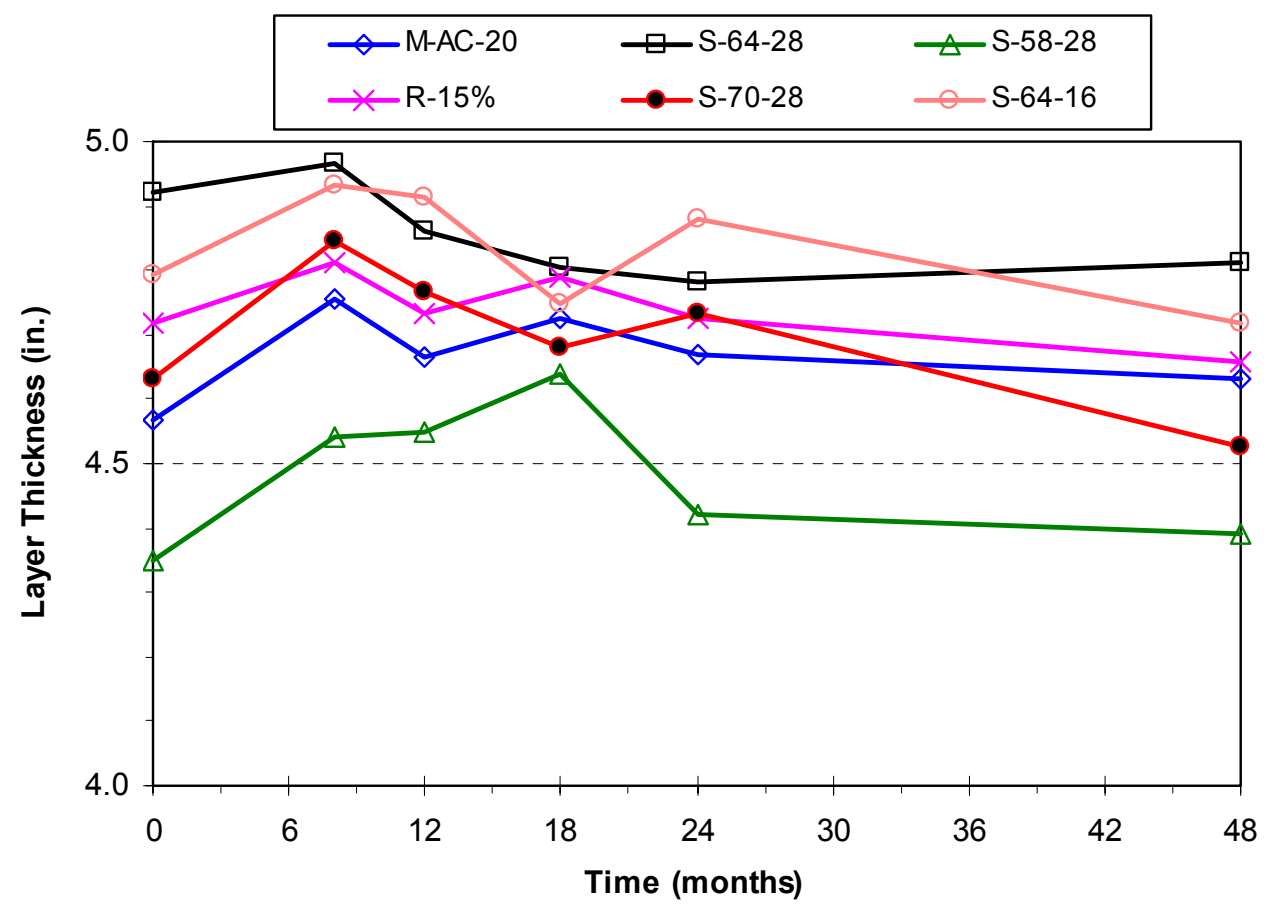

Figure 6.2 -- Trends in intermediate layer thickness with time 
Table 6.1 -- ANOVA results for differences in thickness between the test sections

\begin{tabular}{|c|c|c|c|c|}
\hline \multirow[t]{2}{*}{ Core Set (Age) } & \multicolumn{4}{|c|}{$\begin{array}{l}\text { p-value obtained from ANOVA tests } \\
\text { Null Hypothesis: } \mu_{1}=\mu_{2}=\mu_{3}=\mu_{4}=\mu_{5}=\mu_{6}\end{array}$} \\
\hline & Surface & Conclusion & Intermediate & Conclusion \\
\hline A (0.5 mo.) & 0.343 & \multirow{6}{*}{$\begin{array}{c}\text { Do not reject } \\
\text { null }\end{array}$} & 0.000 & \multirow{2}{*}{ Reject null } \\
\hline B (8 mo.) & 0.131 & & 0.005 & \\
\hline C (12 mo.) & 0.494 & & 0.699 & \multirow{2}{*}{ Do not reject null } \\
\hline D (18 mo.) & 0.771 & & 0.681 & \\
\hline E (24 mo.) & 0.093 & & 0.005 & \multirow{2}{*}{ Reject null } \\
\hline F (48 mo.) & 0.300 & & 0.016 & \\
\hline
\end{tabular}

Table 6.2 -- ANOVA results for differences in thickness with time (age)

\begin{tabular}{|c|c|c|c|c|}
\hline \multirow[t]{2}{*}{ Section ID } & \multicolumn{4}{|c|}{$\begin{array}{l}\text { p-value obtained from ANOVA tests } \\
\text { Null Hypothesis: } \mu_{A}=\mu_{B}=\mu_{C}=\mu_{D}=\mu_{E}=\mu_{F}\end{array}$} \\
\hline & Surface & Conclusion & Intermediate & Conclusion \\
\hline M-AC-20 & 0.990 & \multirow{6}{*}{$\begin{array}{l}\text { Do not reject } \\
\text { null }\end{array}$} & 0.816 & \multirow{4}{*}{ Do not reject null } \\
\hline S-64-28 & 0.603 & & 0.258 & \\
\hline S-58-28 & 0.166 & & 0.320 & \\
\hline R-15\% & 0.988 & & 0.468 & \\
\hline S-70-28 & 0.698 & & 0.013 & Reject null \\
\hline S-64-16 & 0.987 & & 0.670 & Do not reject null \\
\hline
\end{tabular}

\subsubsection{Air Voids}

Following the determination of layer thickness, the bulk specific gravity $\left(G_{m b}\right)$ of the cores was determined in accordance with AASHTO T166. These data were then used to determine the percentage of air voids $\left(\mathrm{P}_{\mathrm{a}}\right)$ of the samples. Some decrease in $\mathrm{P}_{\mathrm{a}}$ is expected with time due to compaction of the pavement layers after the pavement is opened to traffic. Most of the decrease in $\mathrm{P}_{\mathrm{a}}$ due to compaction typically occurs during the early life of the pavement. This is seen in Figures 6.3 and 6.4, respectively, which show the change in $P_{a}$ of the surface and intermediate layers with time. Figure 6.5 shows the relative percentage drop in the air voids between the initial set of cores $(A)$ and the final set of cores $(F)$, for the surface and intermediate layers. The mean, standard deviation and coefficient of variation of the air voids data collected during the study period are shown in Tables B8 and B9 in Appendix B. 


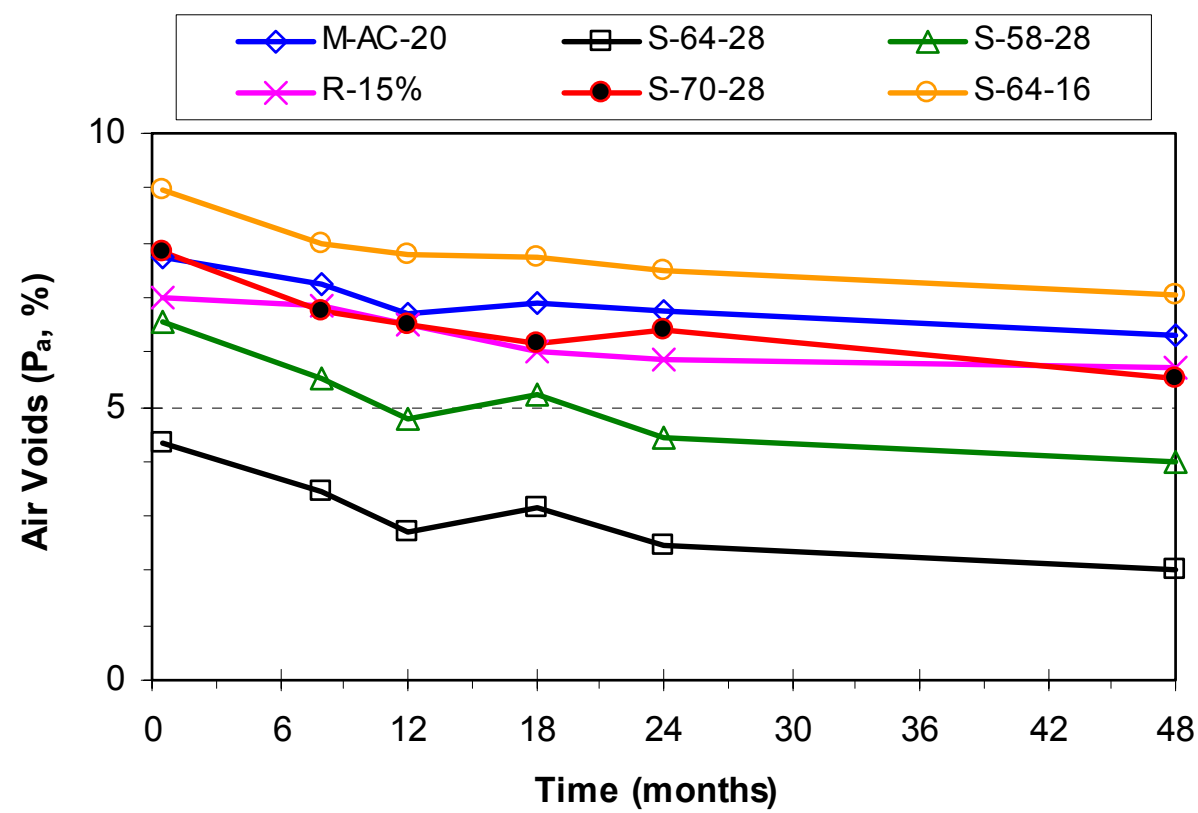

Figure 6.3 -- Change in percentage of air voids in the surface layers with time

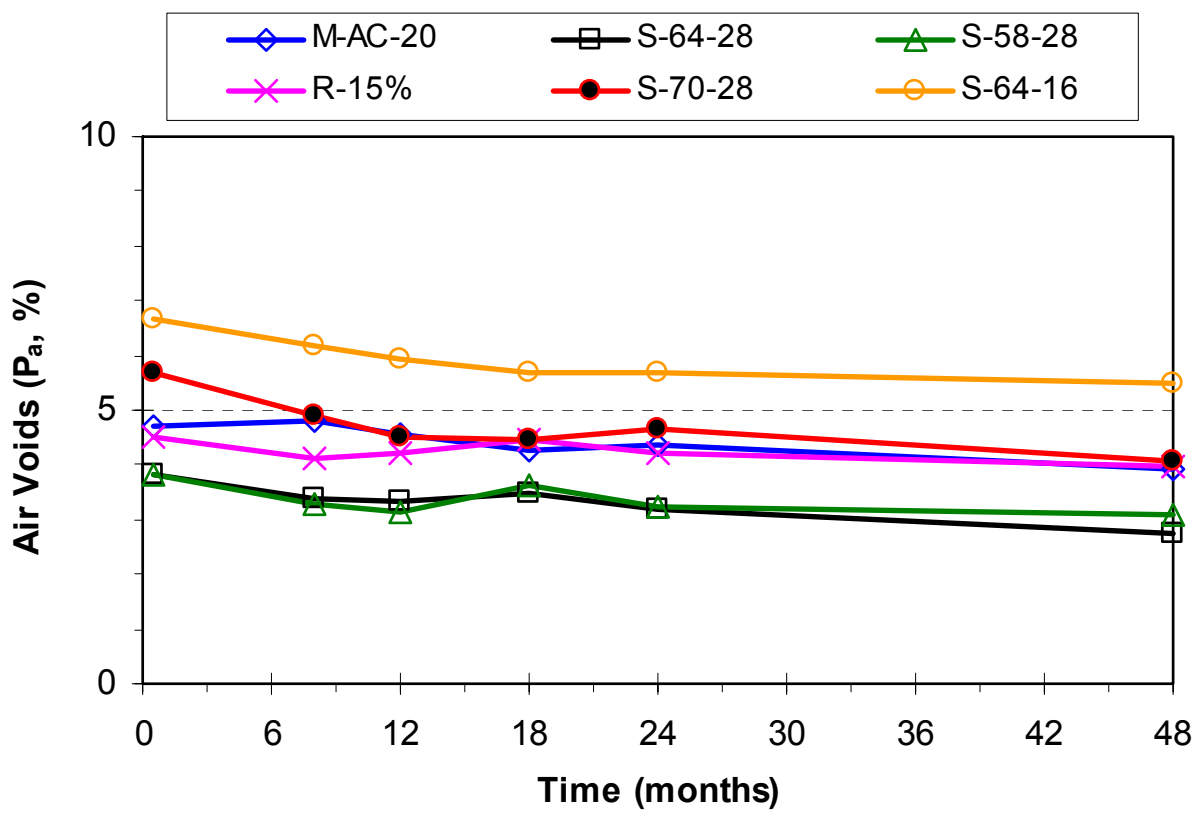

Figure 6.4 -- Change in percentage of air voids in the intermediate layers with time 


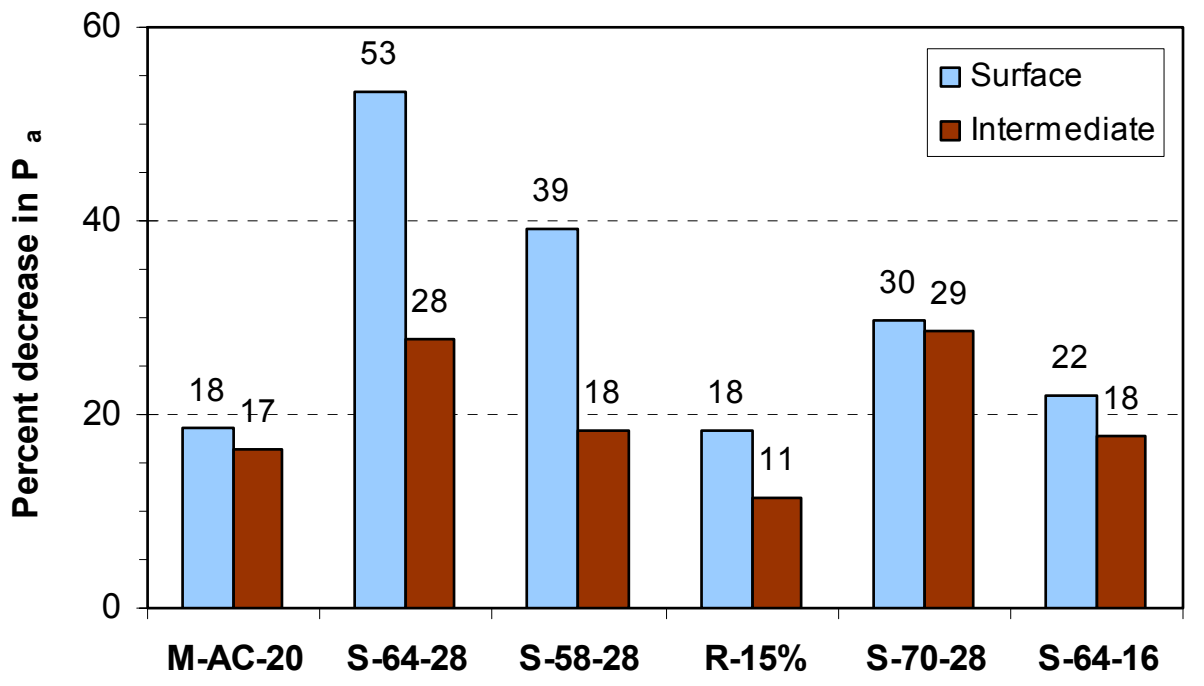

Figure 6.5 -- Percentage decrease in air voids at the end of 4 years

The observed change in $\mathrm{P}_{\mathrm{a}}$ of the intermediate layers was more gradual and lower than that observed in the surface layers. S-64-16 had the highest $\mathrm{P}_{\mathrm{a}}$ in both the surface and the intermediate layers. In the surface layers, S-64-28 had the lowest $P_{a}$ while, S-64-28 and S-58-28 had the lowest $\mathrm{P}_{a}$ in the intermediate layers. The $\mathrm{P}_{a}$ of the S-64-28 surface layer dropped below $3 \%$ at the end of one year. This could indicate that S-64-28 may be prone to rutting. As seen in Figure 6.5, the percentage drop in $\mathrm{P}_{\mathrm{a}}$ was higher in the surface layer of S-64-28 (53\%) and S-58-28 (39\%), compared with the observed drop in the other sections. While the other sections (M-AC-20, R-15\%, S-70-28 and S-64-16) showed comparable percentage drop in $\mathrm{P}_{\mathrm{a}}$ in two pavement layers, a significant difference can be seen between the surface and intermediate layers of S-64-28 and S-58-28. Recall that the binders used in S-64-28 and S-58-28 had the lowest viscosity, which indicates easier compaction ability of these mixtures.

ANOVA tests performed on $\mathrm{P}_{\mathrm{a}}$ data obtained from each set of cores are shown in Tables 6.3 and 6.4. The low p-values $(\leq 0.05)$ shown in Table 6.3 indicate that the differences in $P_{a}$ between the test sections were significant at all ages, in both the layers. Multiple comparisons using the surface layers data indicated that M-AC-20, R-15\% and S-70-28 had similar mean $P_{a}$, while S-64-28, S-58-28 and S-64-16 were all different from the other sections. The same was 
result was observed for the intermediate layer data as well. Table 6.4 shows p-values obtained when comparisons were made between the different set of cores (i. e., considering the age factor) within each test section. In the surface layers, the differences in mean $\mathrm{P}_{\mathrm{a}}$ were also found to be significant in all the test sections. In the intermediate layer only S-70-28 and S-64-16 showed significant differences in the $\mathrm{P}_{\mathrm{a}}$ with time.

Table 6.3 -- ANOVA results for differences in air voids between the test sections

\begin{tabular}{|c|c|c|c|c|}
\hline \multirow[t]{2}{*}{ Core Set (Age) } & \multicolumn{4}{|c|}{$\begin{array}{l}\text { p-value obtained from ANOVA tests } \\
\text { Null Hypothesis: } \mu_{1}=\mu_{2}=\mu_{3}=\mu_{4}=\mu_{5}=\mu_{6}\end{array}$} \\
\hline & Surface & Conclusion & Intermediate & Conclusion \\
\hline A (0.5 mo.) & $2.18 \times 10^{-17}$ & \multirow{6}{*}{ Reject null } & $3.39 \times 10^{-8}$ & \multirow{6}{*}{ Reject null } \\
\hline B (8 mo.) & $1.08 \times 10^{-17}$ & & $2.77 \times 10^{-12}$ & \\
\hline C (12 mo.) & $5.70 \times 10^{-20}$ & & $5.15 \times 10^{-9}$ & \\
\hline D (18 mo.) & $1.46 \times 10^{-16}$ & & 0.0001 & \\
\hline E (24 mo.) & $4.33 \times 10^{-24}$ & & $1.19 \times 10^{-10}$ & \\
\hline F (48 mo.) & $1.98 \times 10^{-23}$ & & $4.46 \times 10^{-13}$ & \\
\hline
\end{tabular}

Table 6.4 -- ANOVA results for differences in air voids with time (age)

\begin{tabular}{|c|c|c|c|c|}
\hline \multirow[t]{2}{*}{ Section ID } & \multicolumn{4}{|c|}{$\begin{array}{l}\text { p-value obtained from ANOVA tests } \\
\text { Null Hypothesis: } \mu_{A}=\mu_{B}=\mu_{C}=\mu_{D}=\mu_{E}=\mu_{F}\end{array}$} \\
\hline & Surface & Conclusion & Intermediate & Conclusion \\
\hline M-AC-20 & $8.31 \times 10^{-13}$ & \multirow{6}{*}{ Reject null } & 0.124 & \multirow{4}{*}{ Do not reject null } \\
\hline S-64-28 & $7.62 \times 10^{-7}$ & & 0.069 & \\
\hline S-58-28 & $4.31 \times 10^{-10}$ & & 0.526 & \\
\hline R-15\% & 0.0002 & & 0.711 & \\
\hline S-70-28 & $7.22 \times 10^{-7}$ & & 0.001 & \multirow{2}{*}{ Reject null } \\
\hline S-64-16 & $3.97 \times 10^{-9}$ & & 0.000 & \\
\hline
\end{tabular}

\subsubsection{Binder Content}

After the bulk specific gravity of the core samples was determined, the core samples were softened in an oven set at $130^{\circ} \mathrm{C}$ for 45 minutes ( 60 minutes for intermediate layer samples). The mixtures were then broken down, cooled to room temperature, and their binder content $\left(P_{b}\right)$ was determined in accordance with ASTM D2172 Method A. This test was conducted to verify the uniformity in the asphalt content of the HMA used in construction of the 
test sections. Excessive binder content could lead to premature rutting and bleeding in AC pavements. Some decrease in binder content may be expected with time in the surface layer due to wearing action (abrasion) by the wheels of passing traffic and stripping.

Figures 6.6 and 6.7 show the change in binder content of the surface and intermediate layers with time, respectively. Tables B10 and B11 in Appendix B show the average, standard deviation and coefficient of variation of the binder content data for the six test sections. The asphalt content of SUPERPAVE mixtures was higher than that of the Marshall mixture in both the layers. In the surface layers, the $\mathrm{P}_{\mathrm{b}}$ ranged between $6.2 \%-6.8 \%$ for the SUPERPAVE mixtures and around $5.5 \%-6.1 \%$ for the Marshall mixture. The design effective $P_{b}$ specified in the JMF for the SUPERPAVE, RAP and Marshall mixtures are 6.5, 6.4 and 6.2, respectively. In the intermediate layers, the $\mathrm{P}_{\mathrm{b}}$ ranged between $4.5 \%$ and $5.4 \%$ for the SUPERPAVE mixtures and between $4.3 \%-4.5 \%$ for the Marshall mixture. The design effective $\mathrm{P}_{\mathrm{b}}$ specified in the JMF was 5.0, 4.7 and 4.3 for the SUPERPAVE, RAP and Marshall mixtures, respectively.

Statistical analysis was conducted to look for differences in the mean $P_{b}$ between the test sections and whether the changes observed in $\mathrm{P}_{\mathrm{b}}$ of each section with age were statistically significant at $\alpha=0.05$ level. These results are presented on Tables 6.5 and 6.6, respectively. Although the variations in binder content between the test sections appear to be minor as seen in the figures, these differences are statistically significant in both the layers at all ages. Multiple comparison of means tests were then conducted to determine which test sections were different from the others. As expected, the mean binder content of the Marshall mixture (MAC-20) was grouped separately for the remaining five sections, in the surface layers. In the intermediate layer, the grouping was as follows: (M-AC-20), (S-64-28 and S-58-28), (S-70-28 and S-64-16) and (R-15\%). 


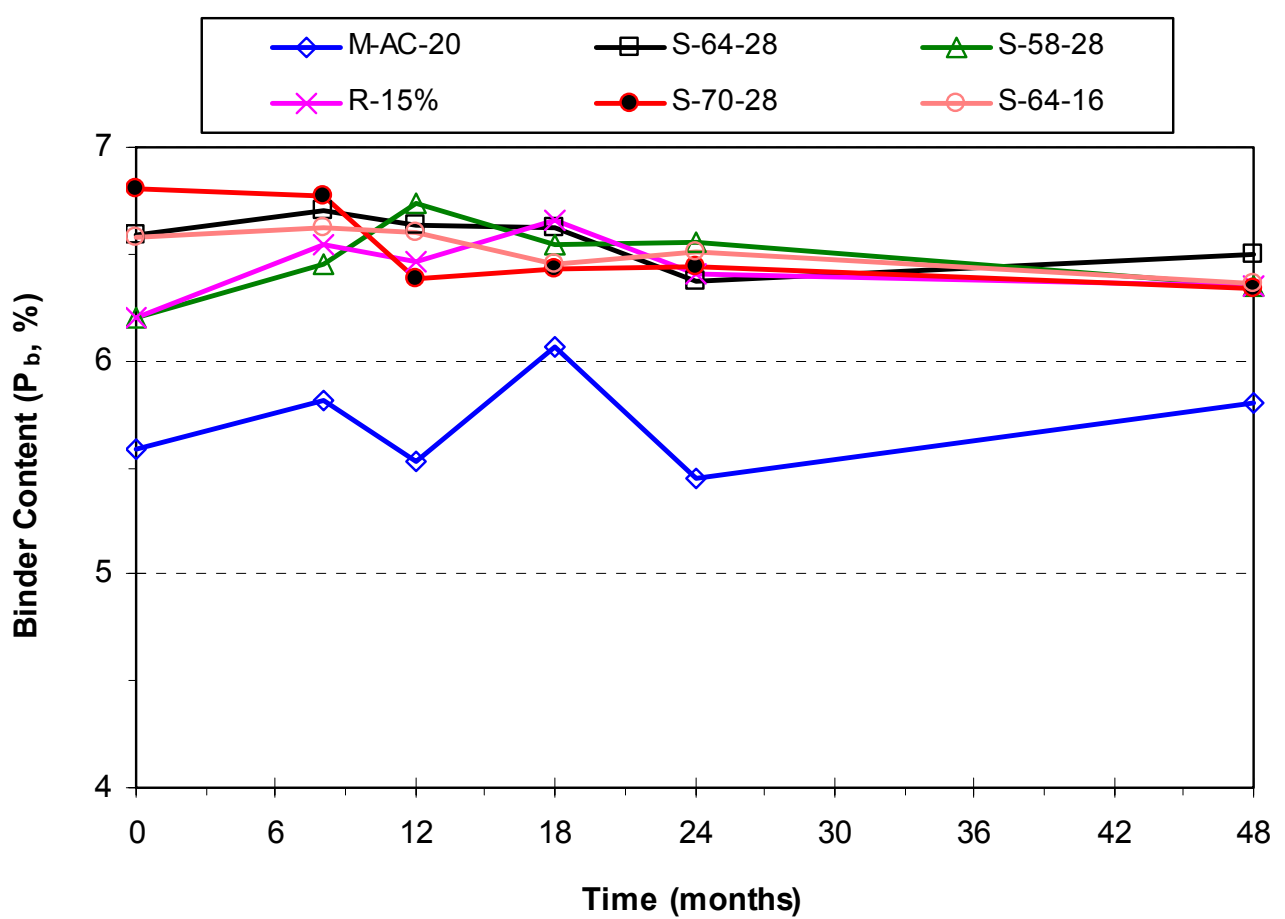

Figure 6.6 -- Change in binder content of the surface layer with time

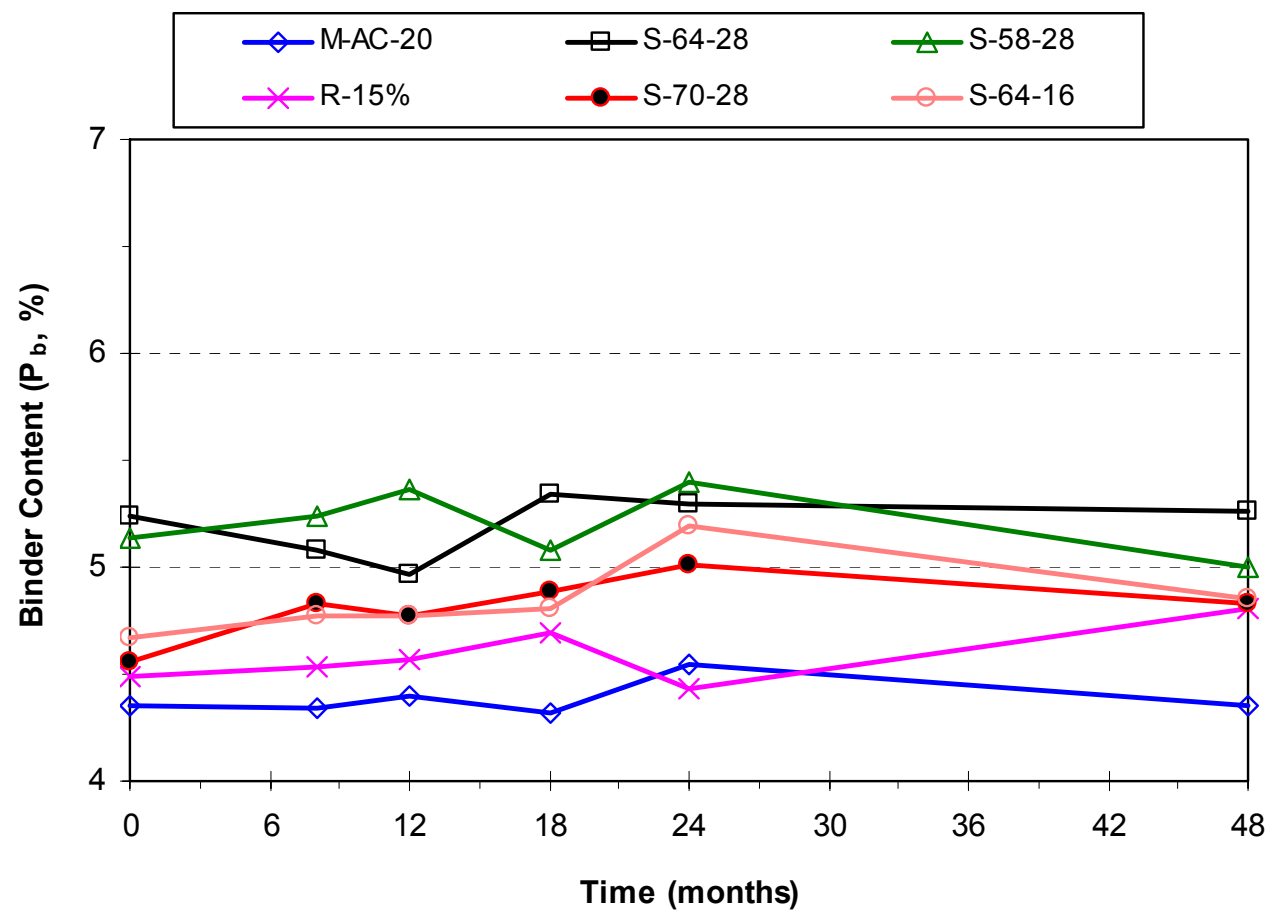

Figure 6.7 -- Change in binder content of the intermediate layer with time 
Table 6.5 -- ANOVA results for differences in binder content between the test sections

\begin{tabular}{|c|c|c|c|c|}
\hline \multirow[t]{2}{*}{ Core Set (Age) } & \multicolumn{4}{|c|}{$\begin{array}{l}\text { p-value obtained from ANOVA tests } \\
\text { Null Hypothesis: } \mu_{1}=\mu_{2}=\mu_{3}=\mu_{4}=\mu_{5}=\mu_{6}\end{array}$} \\
\hline & Surface & Conclusion & Intermediate & Conclusion \\
\hline A (0.5 mo.) & $5.42 \times 10^{-15}$ & \multirow{6}{*}{ Reject null } & $1.08 \times 10^{-9}$ & \multirow{6}{*}{ Reject null } \\
\hline B (8 mo.) & $3.60 \times 10^{-9}$ & & $1.62 \times 10^{-9}$ & \\
\hline C (12 mo.) & $1.32 \times 10^{-14}$ & & $3.69 \times 10^{-8}$ & \\
\hline D (18 mo.) & $1.11 \times 10^{-5}$ & & $3.12 \times 10^{-10}$ & \\
\hline E (24 mo.) & $4.07 \times 10^{-13}$ & & $4.47 \times 10^{-15}$ & \\
\hline F (48 mo.) & $2.91 \times 10^{-11}$ & & $1.93 \times 10^{-10}$ & \\
\hline
\end{tabular}

Table 6.6 -- ANOVA results for differences in binder content with time (age)

\begin{tabular}{|c|c|c|c|c|}
\hline \multirow[t]{2}{*}{ Section ID } & \multicolumn{4}{|c|}{$\begin{array}{l}\text { p-value obtained from ANOVA tests } \\
\text { Null Hypothesis: } \mu_{A}=\mu_{B}=\mu_{C}=\mu_{D}=\mu_{E}=\mu_{F}\end{array}$} \\
\hline & Surface & Conclusion & Intermediate & Conclusion \\
\hline M-AC-20 & $1.77 \times 10^{-8}$ & \multirow{5}{*}{ Reject null } & 0.277 & Do not reject null \\
\hline S-64-28 & 0.019 & & 0.011 & \multirow{5}{*}{ Reject null } \\
\hline S-58-28 & $3.61 \times 10^{-5}$ & & 0.001 & \\
\hline R-15\% & $9.39 \times 10^{-5}$ & & 0.034 & \\
\hline S-70-28 & 0.000 & & 0.002 & \\
\hline S-64-16 & 0.209 & Do not reject null & 0.001 & \\
\hline
\end{tabular}

\subsubsection{Summary of Field Cores Data}

To verify uniformity in construction of the test sections and to assess the change in mixture properties with time, tests were conducted on field core samples collected from the test sections at pre-determined time intervals. The properties determined were layer thickness, binder content and percentage of air voids.

A decrease in the layer thickness indicated some degree of densification in the pavement layers with time, as expected. In general, no significant differences were observed in the mean thickness of surface and intermediate layers between the different test sections, thus indicating uniformity of the pavement mat throughout the whole length of the test site at all ages.

Analysis of $P_{a}$ data indicated that there were statistically significant variations in the percent air voids between the test sections, in both the surface and the intermediate layers. 
Further analyses using multiple comparisons procedure indicated that the $P_{a}$ of $M-A C-20, R-15 \%$ and S-70-28 were similar, while the $P_{a}$ of S-64-28, S-70-28 and S-64-16 were different from all other sections, in both the surface and intermediate layers. S-64-28 and S-58-28 had lower air voids compared with the other sections while S-64-16 had the highest air voids. The $P_{a}$ of S-64-28 fell below $3 \%$, indicating that this section may be prone to rutting.

Analysis of $\mathrm{P}_{\mathrm{b}}$ data also indicated variations in $\mathrm{P}_{\mathrm{b}}$ between test sections. This was expected, since the Marshall mixture and the RAP mixture had different effective $P_{b}$ (JMF) compared with the SUPERPAVE sections. A slight decrease in $\mathrm{P}_{\mathrm{b}}$ was observed with time in the surface sections. None of the sections exhibited excessive asphalt content or bleeding

\subsection{Laboratory Compacted Specimens}

Plant mixtures samples were collected in 5-gallon buckets at the time of pavement construction and stored at room temperature at Purdue University, until further testing. The mixtures were softened in an oven set at $135^{\circ} \mathrm{C}\left(275^{\circ} \mathrm{C}\right)$ for 2 hours and split for further testing in the laboratory as needed. Superpave gyratory samples (150 mm diameter) were compacted and cut to produce 50-mm samples for conducting SUPERPAVE performance tests, such as Creep Compliance, Indirect Tensile Strength, Frequency Sweep at Constant Height (FSCH) and Simple Shear at Constant Height (SSCH). In addition, the optional SUPERPAVE test, Repeated Shear at Constant Height (RSCH) was also conducted.

\subsubsection{Creep Compliance and Indirect Tensile Strength}

\subsubsection{Creep Compliance}

Creep compliance and strength tests were conducted on surface and intermediate layer samples in accordance with AASHTO TP9, using the Instron ${ }^{\circledR}$ Testing Machine. Three replicates were tested for each section and layer. Prior to testing these samples were subjected to long-term aging (120 hours) in an oven set at $85 \pm 3^{\circ} \mathrm{C}$ in accordance with AASHTO 
PP2. The test samples were compacted to $3 \pm 0.5 \%$ and $7 \pm 0.5 \%$ air voids $\left(P_{a}\right)$, to study the influence on air voids on compliance, strength and mixture critical temperature estimates.

Creep compliance testing was conducted for a period of $100 \mathrm{~s}$ at $-20^{\circ} \mathrm{C},-10^{\circ} \mathrm{C}$ and $0^{\circ} \mathrm{C}$, during which the samples were subjected to vertical compressive load at the rate of 12.5 $\mathrm{mm} / \mathrm{min}$ until the horizontal strain reached $50 \mu \mathrm{m}$. When the horizontal strain reached $50 \mu \mathrm{m}$, the vertical load was held constant until the completion of the test period. Load and displacement are recorded throughout the duration of the test. The load and displacement readings are converted into stress and strain and used to calculate creep compliance. Creep compliance $\left(D_{t}\right)$ is defined as the ratio of time dependent strain $\left(\varepsilon_{t}\right)$ to constant applied stress $\left(\sigma_{\circ}\right)$ in a uniaxial loading condition. The creep compliance data obtained from the three test temperatures are used to produce a master creep compliance curve as a function of time. Thermal stresses developed in the pavement at low temperatures can be predicted using relaxation modulus $\left(E_{t}\right)$, which can be obtained from creep compliance by applying Laplace transformation. The intersection of the thermal stress curve and the tensile strength (or fracture strength) curve gives the critical pavement temperature $\left(T_{I D T}\right)$ of the mixtures. It is assumed that cracking of pavements occurs when the minimum pavement temperature exceeds the estimated critical temperature. A higher compliance (or lower stiffness) indicates that the mixture has better ability to relax the thermal stresses in the pavement as the temperature drops, and vice versa. Denser mixtures are generally less compliant (or stiffer) in comparison with open-graded mixtures.

Comparison between creep stiffness of the mixtures (also called stiffness modulus) is typically made at $60 \mathrm{~s}$. These data for the surface and intermediate mixtures are presented in Tables 6.7 and 6.8 , respectively. The relative ranking $(1=$ highest stiffness, $6=$ lowest stiffness) of mixtures is also shown in these tables. 
Table 6.7 -- Creep stiffness at $60 \mathrm{~s}$ of the surface mixtures with $7 \%$ and $3 \%$ air voids

\begin{tabular}{||l|c|c|c|c||}
\hline \multirow{2}{*}{ Section ID } & \multicolumn{2}{|c|}{$\mathbf{7 \%}$ air voids } & \multicolumn{2}{c|}{ 3\% air voids } \\
\cline { 2 - 5 } & Stiffness, GPa (psi) & Rank & Stiffness, GPa (psi) & Rank \\
\hline M-AC-20 & $13.0\left(1.89 \times 10^{6}\right)$ & 4 & $28.2\left(4.08 \times 10^{6}\right)$ & 1 \\
\hline S-64-28 & $17.7\left(2.56 \times 10^{6}\right)$ & 1 & $16.9\left(2.45 \times 10^{6}\right)$ & 4 \\
\hline S-58-28 & $8.7\left(1.27 \times 10^{6}\right)$ & 6 & $9.7\left(1.40 \times 10^{6}\right)$ & 6 \\
\hline R-15\% & $16.4\left(2.38 \times 10^{6}\right)$ & 3 & $17.4\left(2.52 \times 10^{6}\right)$ & 3 \\
\hline S-70-28 & $12.3\left(1.79 \times 10^{6}\right)$ & 5 & $12.3\left(1.78 \times 10^{6}\right)$ & 5 \\
\hline S-64-16 & $17.4\left(2.52 \times 10^{6}\right)$ & 2 & $26.2\left(3.79 \times 10^{6}\right)$ & 2 \\
\hline
\end{tabular}

Table 6.8 -- Creep stiffness at $60 \mathrm{~s}$ of the intermediate mixtures with $7 \%$ and $3 \%$ air voids

\begin{tabular}{||l|c|c|c|c||}
\hline \multirow{2}{*}{ Section ID } & \multicolumn{2}{|c|}{$\mathbf{7 \%}$ air voids } & \multicolumn{2}{c||}{ 3\% air voids } \\
\cline { 2 - 5 } & Stiffness, GPa (psi) & Rank & Stiffness, GPa (psi) & Rank \\
\hline M-AC-20 & $16.0\left(2.32 \times 10^{6}\right)$ & 3 & $22.0\left(3.19 \times 10^{6}\right)$ & 2 \\
\hline S-64-28 & $14.8\left(2.15 \times 10^{6}\right)$ & 4 & $14.5\left(2.11 \times 10^{6}\right)$ & 4 \\
\hline S-58-28 & $9.9\left(1.44 \times 10^{6}\right)$ & 5 & $11.2\left(1.62 \times 10^{6}\right)$ & 5 \\
\hline R-15\% & $17.1\left(2.48 \times 10^{6}\right)$ & 1 & $20.0\left(2.90 \times 10^{6}\right)$ & 3 \\
\hline S-70-28 & $9.7\left(1.41 \times 10^{6}\right)$ & 6 & $11.1\left(1.62 \times 10^{6}\right)$ & 6 \\
\hline S-64-16 & $16.8\left(2.43 \times 10^{6}\right)$ & 2 & $23.8\left(3.46 \times 10^{6}\right)$ & 1 \\
\hline
\end{tabular}

In the case of surface mixtures, the creep stiffness of $7 \%$ air voids samples was comparable with the creep stiffness of the $3 \%$ air void samples, except in the case of M-AC-20 and S-64-16. The mixture rankings at $7 \%$ and $3 \%$ air void level were the same, except for M-AC-20 and S-64-28. Section 3 with the lowest creep stiffness may be expected to perform better than the other sections, in terms of thermal cracking resistance. Similarly, S-70-28 which ranked fifth is also expected to perform better than the remaining sections. Sections with high creep stiffness values, such as S-64-28 and S-64-16 at 7\% and M-AC-20 and S-64-16 at 3\%, are more prone to thermal cracking. M-AC-20 samples (Marshall mixture) were compacted to $4 \%$ air voids since they could not be compacted to $3 \%$ in spite of increasing the number of gyrations to about 300 . This could be due to the high percentage of natural sand $(52 \%)$ present in this mixture.

In the intermediate mixtures, the decrease in air voids increased the stiffness of all the mixtures, except S-64-28. S-58-28 and S-70-28 of the intermediate mixtures also had 
lower stiffness than the other sections at both air voids level and therefore are expected to be thermal cracking resistant. Of these, S-58-28 had lower stiffness than S-70-28 and may be expected to show the highest resistance to thermal cracking compared to the other sections. M-AC-20 and S-64-16 at 3\% air voids and R-15\% and S-64-16 at 7\% showed higher stiffness values, as in the case of surface mixtures, and accordingly are prone to thermal stress build up and higher cracking potential.

For a mixture to provide good resistance to thermal cracking, a combination of low stiffness and high strength are desirable. While the low stiffness enables the mixture to relax stresses easily, the high strength is necessary to withstand the thermal stresses that develop in the pavement. Therefore, the tensile strength of mixtures was also examined and presented in the next section

\subsubsection{Indirect Tensile Strength}

After the creep compliance testing was completed, the same specimens were used to test the indirect tensile strengths of the mixtures at $-10^{\circ} \mathrm{C}$. Three replicates per mixture were tested at $7 \%$ and $3 \%$ air voids. The relative ranking of the surface and intermediate mixtures are given in Tables 6.9 and 6.10, respectively, along with the percentage change in strength between the $7 \%$ and $3 \%$ air voids samples. Unlike stiffness, noticeable gains in strength were observed with decrease in $\mathrm{P}_{\mathrm{a}}$. The gains ranged between $23-40 \%$ and $23-87 \%$ for the surface and intermediate mixtures, respectively. Figures 6.8 and 6.9 show the mean strengths of the surface and intermediate mixtures at $7 \%$ and $3 \%$ air voids, respectively.

Table 6.9 -- Ranking of the surface mixtures based on indirect tensile strength

\begin{tabular}{||l|c|c|c||}
\hline \multirow{2}{*}{ Section ID } & \multicolumn{2}{|c|}{ Rank } & Percent gain in strength \\
\cline { 2 - 3 } & $\mathbf{7 \%}$ air voids & $\mathbf{3 \%}$ air voids & (compared with $\mathbf{7 \%} \mathbf{P}_{\mathbf{a}}$ ) \\
\hline M-AC-20 & 3 & 5 & 26.9 \\
\hline S-64-28 & 4 & 3 & 40.2 \\
\hline S-58-28 & 5 & 4 & 41.0 \\
\hline R-15\% & 2 & 2 & 28.1 \\
\hline S-70-28 & 6 & 6 & 39.6 \\
\hline S-64-16 & 1 & 1 & 22.9 \\
\hline
\end{tabular}


Table 6.10 -- Ranking of the intermediate mixtures based on indirect tensile strength

\begin{tabular}{||l|c|c|c||}
\hline \multirow{2}{*}{ Section ID } & \multicolumn{2}{|c|}{ Rank } & Percent gain in strength \\
\cline { 2 - 3 } & $\mathbf{7 \%}$ air voids & $\mathbf{3 \%}$ air voids & (compared with 7\% $\mathbf{P}_{\mathbf{a}}$ ) \\
\hline M-AC-20 & 4 & 4 & 44.1 \\
\hline S-64-28 & 1 & 3 & 31.7 \\
\hline S-58-28 & 3 & 5 & 23.2 \\
\hline R-15\% & 5 & 1 & 86.5 \\
\hline S-70-28 & 6 & 6 & 34.5 \\
\hline S-64-16 & 2 & 2 & 38.0 \\
\hline
\end{tabular}

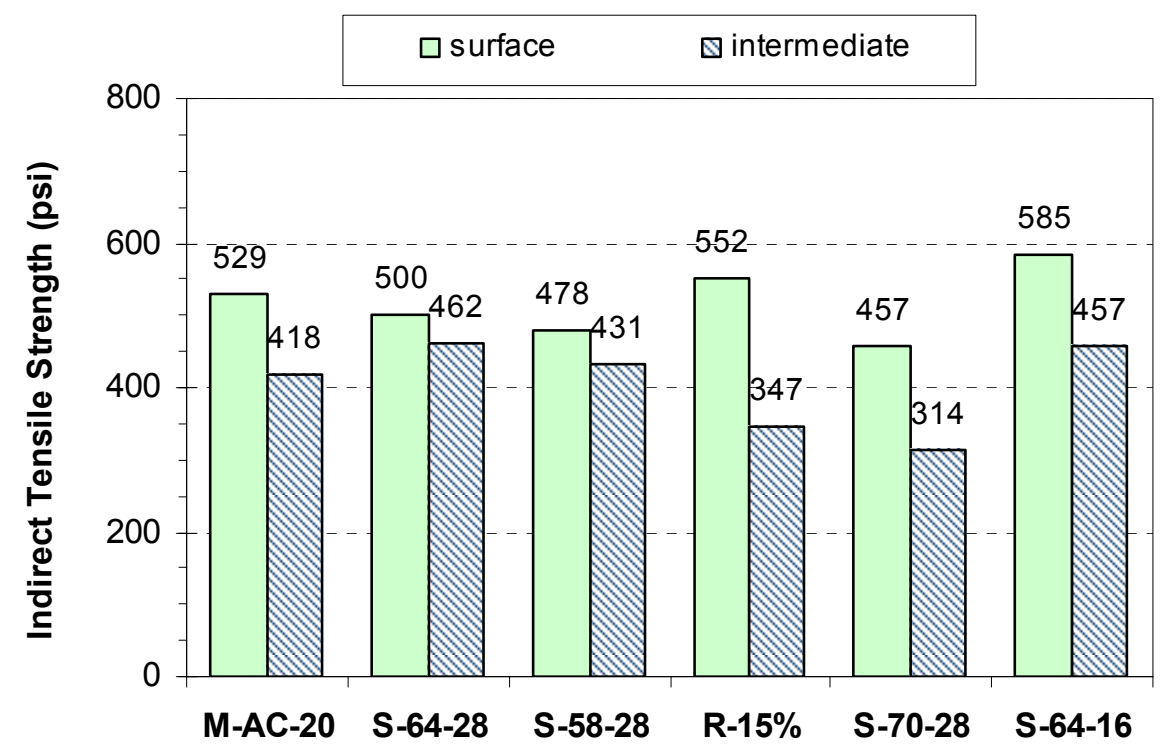

Figure 6.8 -- Mean strength of the surface and intermediate mixtures at $7 \%$ air voids 


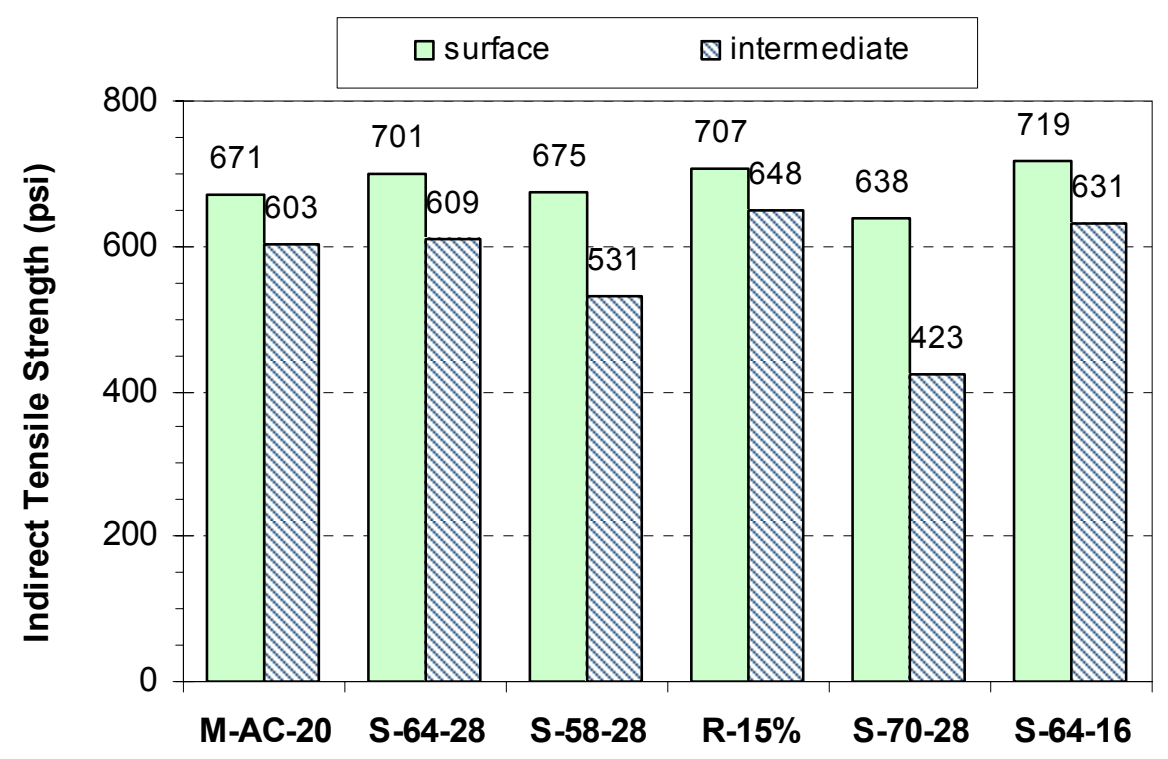

Figure 6.9 -- Mean strength of the surface and intermediate mixtures at $3 \%$ air voids

Among the surface mixtures, S-70-28 had the least strength. Although this mixture had low stiffness values, the low strength of the mixture is detrimental to its low temperature performance and some cracking may be expected in this section. In the surface mixtures, S-58-28 at 7\% $\mathrm{P}_{\mathrm{a}}$ had slightly higher strength than S-70-28 but slightly lower stiffness than S-70-28. Accordingly, this section is expected to show better resistance to thermal cracking than S-70-28. At 3\% $\mathrm{P}_{\mathrm{a}}, \mathrm{M}-\mathrm{AC}-20$ had the highest stiffness and low strength (ranked fifth). But since the strengths of the mixtures at $3 \% \mathrm{P}_{\mathrm{a}}$ are much higher than $600 \mathrm{psi}$, in most cases, minimal amount of cracking is expected in this section. S-64-16 had the highest strength, in addition to high stiffness (ranked second), which might indicate that some cracking may be expected in this section as well. R-15\% ranked between the extremes in both strength and stiffness and may be expected to perform well in the field (zero to minimal cracking) in comparison with the other test sections.

In the intermediate mixtures, R-15\% and S-70-28 had lower strengths compared with the other sections at $7 \%$ air voids. But, R-15\% had the highest stiffness and S-70-28 had the lowest stiffness. Since a combination of low stiffness and high strength is considered optimal for 
good thermal cracking resistance, these two sections may be expected to exhibit some cracking. S-64-28 had the highest strength and average stiffness (ranked $4^{\text {th }}$ ) and hence may be expected to perform adequately. At $7 \%$ air voids level, the differences between the strengths of the surface and the intermediate mixtures were much lower than those observed at the $3 \%$ air voids level. Note that since thermal cracking is generally thought to start in the surface layers and propagate down into the pavement layers (top-down cracking), the mixture properties of the surface layers may be considered more critical than that of the intermediate layers.

Statistical analyses (ANOVA) were conducted to test various null hypotheses. Mean strength of mixtures with the same high temperature binder grade (PG64-xx) and JMF were compared to determine whether a change in high temperature grade influenced the strength of the mixtures. This would be an indicator of the sensitivity of the indirect tensile strength test to changes in binder grade. Similarly, mixtures with the same low temperature grade (PGxx-28) and same JMF were also compared to evaluate the influence of changing the low temperature grade on strength. To determine whether the addition of RAP influenced the tensile strength of mixtures, mean strength of R-15\% mixtures was compared with S-64-29 mixtures. Finally, the mean strength of Marshall section was compared with that of the control section (S-64-28) to determine whether SUPERPAVE mixtures were stronger than a comparable Marshall mixture. The p-values obtained for these tests are summarized in Tables 6.11 and 6.12 for the surface and intermediate mixtures, respectively.

Table 6.11 -- Results of ANOVA tests on surface mixtures strength data

\begin{tabular}{|c|c|c|c|c|}
\hline \multirow{2}{*}{ Null Hypothesis } & \multicolumn{2}{|c|}{$7 \%$ air voids } & \multicolumn{2}{|c|}{$3 \%$ air voids } \\
\hline & p-value & conclusion & p-value & conclusion \\
\hline $\begin{array}{l}\boldsymbol{\mu}_{\mathrm{S}-64-28}=\mu_{\mathrm{S}-64-16} \\
\text { (PG64-xx binders and same JMF) }\end{array}$ & 0.0534 & $\begin{array}{l}\text { Do not } \\
\text { reject null }\end{array}$ & 0.5019 & $\begin{array}{l}\text { Do not } \\
\text { reject null }\end{array}$ \\
\hline $\begin{array}{l}\mu_{\mathrm{S}-64-28}=\mu_{\mathrm{S}-58-28}=\mu_{\mathrm{S}-70-28} \\
\text { (PGXX-28 binders and same JMF) }\end{array}$ & 0.1709 & $\begin{array}{l}\text { Do not } \\
\text { reject null }\end{array}$ & 0.0426 & Reject null \\
\hline $\begin{array}{l}\mu_{\mathrm{M}-\mathrm{AC}-20}=\mu_{\mathrm{S}-64-28} \\
\text { (Marshall versus control) }\end{array}$ & 0.3705 & $\begin{array}{l}\text { Do not } \\
\text { reject null }\end{array}$ & 0.3573 & $\begin{array}{l}\text { Do not } \\
\text { reject null }\end{array}$ \\
\hline $\begin{array}{l}\mu_{\mathrm{S}-64-28}=\mu_{\mathrm{R}-15 \%} \\
(\mathrm{PG} 64-28 \text { versus RAP) }\end{array}$ & 0.0907 & $\begin{array}{l}\text { Do not } \\
\text { reject null }\end{array}$ & 0.8053 & $\begin{array}{l}\text { Do not } \\
\text { reject null }\end{array}$ \\
\hline
\end{tabular}


Table 6.12 -- Results of ANOVA tests on intermediate mixtures strength data

\begin{tabular}{|c|c|c|c|c|}
\hline \multirow{2}{*}{ Null Hypothesis } & \multicolumn{2}{|c|}{$7 \%$ air voids } & \multicolumn{2}{|c|}{$3 \%$ air voids } \\
\hline & p-value & conclusion & p-value & conclusion \\
\hline $\begin{array}{l}\mu_{\mathrm{S}-70-28}=\mu_{\mathrm{S}-64-16} \\
\text { (PG64-xx binders and same JMF) }\end{array}$ & 0.8793 & $\begin{array}{c}\text { Do not } \\
\text { reject null }\end{array}$ & 0.0029 & Reject null \\
\hline $\begin{array}{l}\mu_{\mathrm{S}-64-28}=\mu_{\mathrm{S}-58-28}=\mu_{\mathrm{S}-70-28} \\
(\mathrm{PGXX-28} \text { binders and same JMF) }\end{array}$ & 0.0020 & Reject null & 0.0069 & Reject null \\
\hline $\begin{array}{l}\mu_{\mathrm{M}-\mathrm{AC}-20}=\mu_{\mathrm{S}-64-28} \\
\text { (Marshall versus Control) }\end{array}$ & 0.1560 & $\begin{array}{l}\text { Do not } \\
\text { reject null }\end{array}$ & 0.2727 & $\begin{array}{l}\text { Do not } \\
\text { reject null }\end{array}$ \\
\hline $\begin{array}{l}\boldsymbol{\mu}_{\mathrm{S}-64-28}=\boldsymbol{\mu}_{\mathrm{R}-15 \%} \\
\text { (PG64-28 versus RAP) }\end{array}$ & 0.0206 & Reject null & 0.0014 & Reject null \\
\hline
\end{tabular}

If the p-values obtained from ANOVA tests were greater than 0.05 , it indicated that the null hypotheses tested were not rejected, i.e., were true. In other words, at the $7 \% \mathrm{~Pa}_{\mathrm{a}}$ level, changing the low temperature grade of the binders (PG64-28 versus PG64-16) or the high temperature grade (PG58-28, PG64-28, PG70-28) did not change the mean strength of the mixtures. No differences were found between the strengths of the control mixture and the strength of the Marshall mixture at $3 \%$ and at $7 \%$ air voids. Addition of RAP did not significantly alter the strength of the mixtures at $3 \%$ and at $7 \%$ air voids. At the $3 \%$ air void level, changing the high temperature grade appeared to be statistically significant, as indicated by $p$-value $<0.05$.

In the intermediate mixtures, changing the high temperature grade appeared to change the mean strength of the mixtures at both air void levels. Addition of RAP also altered the strength of the intermediate mixture in comparison with the control section. No difference in strength was observed between M-AC-20 (Marshall) and S-64-28 (control) intermediate mixtures at the $7 \%$ and $3 \%$ air void levels. Change in low temperature binder grade had no influence on the strength of intermediate mixtures at $7 \%$ level, but did influence the strength at $3 \%$ air voids.

\subsubsection{Pavement Critical Temperature Estimates}

The creep compliance data and strength data were used to determine the critical pavement temperature $\left(T_{I D T}\right)$ of the mixtures. It is generally assumed that thermal cracking of pavements occurs when the minimum pavement temperature exceeds the critical temperature. 
As mentioned earlier in Section 6.2.1.1 and in Chapter 2, the estimated pavement temperature is given by the intersection of the thermal stress curve and the strength of the mixture.

The thermal stresses generated in the pavement were determined using the thermal stress analysis model developed by Christensen. The algorithm used in this model involved the following steps. Three compliance curves were obtained at the three test temperatures and combined to a single master creep compliance curve by shifting two of the compliance curves horizontally (along the time axis) while keeping the reference temperature curve fixed. The shift factors were characterized using a power law. The shifted creep compliance data was then defined using an exponential series function. Although creep compliance is widely used to characterize creep response, asphalt researchers use the term "creep stiffness". Uniaxial creep stiffness or stiffness modulus, $S_{t}$, is a time dependent property and is given by the ratio of applied constant uniaxial stress $\left(\sigma_{0}\right)$ to the resulting time dependent uniaxial strain $\left(\varepsilon_{t}\right)$. A creep stiffness curve is obtained by taking the inverse of (uniaxial) creep compliance. The creep stiffness function is then converted into relaxation modulus through the inverse Laplace transformation. In Christensen's thermal stress analysis method, an approximate solution to the Laplace transformation was determined by the "direct method". Further details of this procedure may be found in a paper by Christensen (43).

For this study, the assumed (default) model input value for initial temperature was $10^{\circ} \mathrm{C}\left(50^{\circ} \mathrm{F}\right)$. The cooling rate used in determination of the thermal stresses was $6.5^{\circ} \mathrm{C} / \mathrm{h}$ (from observed temperature trends at the test site). Actual IDT strength test data were used to represent the tensile strength of the mixtures. The coefficient of thermal contraction $\left(\alpha_{\text {mix }}\right)$ was calculated using an empirical equation involving the relative volume percentages of aggregate and binder present in the mixture (as shown below), following procedure recommended by Christensen (43). In a personal communication, Christensen stated that the estimate of $\alpha_{\text {mix }}$ given by this equation is within $30 \%$ of the measured value $95 \%$ of the time.

$\alpha_{\text {mix }}=\frac{\left(\alpha_{\text {mix }} V_{A C}+\alpha_{a g g} V_{a g g}\right)}{\left(V_{A C}+V_{a g g}\right)}$

where, $a_{\text {mix }}=$ coefficient of thermal contraction of the mixture, ${ }^{\circ} \mathrm{C} / \mathrm{h}$ 
$\alpha_{A C}=$ coefficient of thermal contraction of the asphalt cement, $115 \times 10^{-6}{ }^{\circ} \mathrm{C} / \mathrm{h}$

$\alpha_{\mathrm{agg}}=$ coefficient of thermal contraction of the aggregate, $6.75 \times 10^{-6}{ }^{\circ} \mathrm{C} / \mathrm{h}$

$\mathrm{V}_{\mathrm{AC}}=$ Volume percent of asphalt cement

$\mathrm{V}_{\text {agg }}=$ Volume percent of aggregate

The critical temperature estimates $\left(T_{I D T}\right)$ for the surface and intermediate mixtures are shown in Table 6.13. At $7 \% \mathrm{P}_{\mathrm{a}}$ level, the $\mathrm{T}_{\mathrm{IDT}}$ estimates ranged between $-28^{\circ} \mathrm{C}$ and $-41.4^{\circ} \mathrm{C}$ for the surface mixtures and between $-20.2^{\circ} \mathrm{C}$ and $-39.3^{\circ} \mathrm{C}$ for the intermediate mixtures. At $3 \% \mathrm{P}_{\mathrm{a}}$ level, the $\mathrm{T}_{\mathrm{IDT}}$ range for surface and intermediate mixtures was $-14^{\circ} \mathrm{C}$ and $-37.2^{\circ} \mathrm{C}$ and $-14.2^{\circ} \mathrm{C}$ and $-37.7^{\circ} \mathrm{C}$, respectively. Based on the pavement temperature data obtained from the test site, the lowest minimum pavement temperature observed at the surface was $-19.5^{\circ} \mathrm{C}\left(-3.0^{\circ} \mathrm{F}\right)$. Although all the $\mathrm{T}_{\mathrm{IDT}}$ estimates for the surface mixtures were colder than $-19.5^{\circ} \mathrm{C}$ at $7 \%$ air voids level, M-AC-20 and S-64-16 had warmer $\mathrm{T}_{\text {IDT }}$ at the $3 \%$ air voids level. This indicates that thermal cracks are expected in these two sections based on weather data and mixture test data. The minimum pavement temperature observed at the top of the intermediate layer in the duration of the study was $-13.5^{\circ} \mathrm{C}$. All the intermediate mixtures except S-64-16 had lower $T_{\text {IDT }}$ than $-13.5^{\circ} \mathrm{C}$ at both $P_{a}$ levels. While the $T_{\text {IDT }}$ of S-64-16 at $7 \%$ level was lower than this limit, the $T_{I D T}$ at $3 \%$ level was very close to this value. This may result in some cracking in the intermediate layer of this section, which in turn would lead to cracking the in upper (surface) layer as well.

Table 6.13 -- Pavement critical temperature estimates for surface and intermediate mixtures

\begin{tabular}{|l|c|c|c|c||}
\hline \multirow{2}{*}{ Section ID } & \multicolumn{4}{|c||}{ Pavement Critical Temperature ${ }^{\circ} \mathbf{C}$ ) } \\
\cline { 2 - 5 } & \multicolumn{2}{|c|}{ Surface Mixtures } & \multicolumn{2}{c||}{ Intermediate Mixtures } \\
\cline { 2 - 5 } & $@ \mathbf{3 \%} \mathbf{P}_{\mathbf{a}}$ & $@ \mathbf{7 \%} \mathbf{P}_{\mathbf{a}}$ & @ 3\% $\mathbf{P}_{\mathbf{a}}$ & @ 7\% $\mathbf{P}_{\mathbf{a}}$ \\
\hline M-AC-20 & -14.0 & -35.3 & -24.9 & -30.3 \\
\hline S-64-28 & -29.5 & -30.8 & -31.0 & -32.5 \\
\hline S-58-28 & -36.5 & -41.4 & -37.7 & -39.3 \\
\hline R-15\% & -33.1 & -28.0 & -23.0 & -23.6 \\
\hline S-70-28 & -37.2 & -33.4 & -31.0 & -22.2 \\
\hline S-64-16 & -15.1 & -32.9 & -14.2 & -20.2 \\
\hline
\end{tabular}




\subsubsection{Frequency Sweep at Constant Height}

This performance test is typically performed on laboratory-compacted samples or cored samples obtained from the pavement at three test temperatures $\left(10^{\circ} \mathrm{C}, 20^{\circ} \mathrm{C}\right.$ and $\left.40^{\circ} \mathrm{C}\right)$ or at the effective temperature for permanent deformation, $T_{\text {eff(PD) }}$, and at effective temperature for

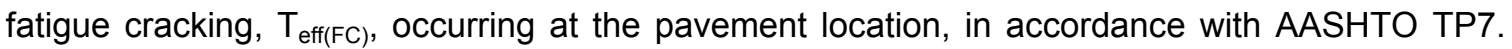
The purpose of this test is to determine the complex shear modulus of the mixtures when subjected to shear loads at various frequencies that simulate traffic loads. The results of this test are indicative of the rut resistance of the HMA used in the pavement. In the frequency sweep at constant height test, the test sample is held between two platens and subjected to sinusoidal shear strain cycles of $0.0001 \mathrm{~mm} / \mathrm{mm}$ amplitude at different frequencies. As the sample tends to deform under the applied shear strain, the axial load is controlled through a feedback loop to maintain constant height of the specimen. The shear load required to apply the desired strain level is recorded, along with the phase lag between applied shear strain and shear load. At the end of the test cycle, the complex shear modulus, $\left|G^{*}\right|$, and the phase angle, $\delta$, are saved as the output file.

In this study, frequency sweep testing was conducted using the Interlaken ${ }^{\circledR}$ shear tester at $\mathrm{T}_{\mathrm{eff}(\mathrm{PD})}$ and $\mathrm{T}_{\mathrm{eff}(\mathrm{FC})}$ on samples compacted to $7 \pm 0.5 \%$. Five replicates per sample were tested at each test temperature. The effective temperature for permanent deformation, $T_{\text {eff(}(P D) \text {, }}$ and effective temperature for fatigue cracking, $T_{\text {eff( }(F C)}$, were determined using the following SHRP equations:

$\mathrm{T}_{\text {eff(PD) }}=30.8-0.12 \mathrm{Z}_{\mathrm{cr}}+0.92 \mathrm{MAAT}_{\text {design }}$

$\mathrm{T}_{\text {eff(FC) }}=0.8$ (MAPT) -2.7

where, $T_{\text {eff }(\mathrm{PD})}=$ effective temperature for permanent deformation, ${ }^{\circ} \mathrm{C}$

$\mathrm{T}_{\mathrm{eff}(\mathrm{FC})}=$ effective temperature for fatigue cracking, ${ }^{\circ} \mathrm{C}$

MAPT = mean annual pavement temperature at one-third depth of pavement layer, ${ }^{\circ} \mathrm{C}$

MAAT $_{\text {design }}=$ design mean annual air temperature $=M A A T_{\text {average }}+\mathrm{K}_{\alpha} \sigma_{\text {MAT }}$

$\mathrm{MAAT}_{\text {average }}=$ average mean annual air temperature from historical data

$\mathrm{K}_{\alpha}=2.327$ for $98 \%$ reliability level

$\sigma_{\text {MAAT }}=$ standard deviation for the distribution of MAAT at the site location 
The $\mathrm{T}_{\text {eff(PD) }}$ and $\mathrm{T}_{\text {eff( }(\mathrm{FC})}$ for the Indiana SPS9-A site were $29.5^{\circ} \mathrm{C}\left(85^{\circ} \mathrm{F}\right)$ and $40.5^{\circ} \mathrm{C}$ $\left(105^{\circ} \mathrm{F}\right)$, respectively. Figures 6.10 through 6.13 show the average $\log \left|\mathrm{G}^{*}\right|$ as a function of $\log$ frequency for the surface and intermediate mixtures at the two test temperatures. The average $\left|\mathrm{G}^{*}\right|$ at $10 \mathrm{~Hz}$ was used to make relative comparisons of the performance of the mixtures, as this frequency simulates the commonly occurring traffic speed on an interstate. The higher the $\left|G^{*}\right|$ value the higher will be the resistance of the mixture to rutting. The slope of the log $\left|G^{*}\right|$ versus log frequency line is also considered to be a strong indicator of the rut resistance of the mixture. A higher slope indicates higher rut susceptibility of the mixture. Tables 6.14 and 6.15 show the average $\left|G^{*}\right|$ and slope values for the mixtures at the two test temperatures.

As seen from the Figures and the Tables, the surface mixture of R-15\% had the highest rut resistance as indicated by the highest $\left|G^{*}\right|$ value, while S-58-28 showed the least resistance (lowest $\left|\mathrm{G}^{*}\right|$ value), at both test temperatures. This is to be expected since the binder used in S-58-28 was PG58-28. Among the intermediate mixtures, S-64-16 had the highest $\left|G^{*}\right|$ at both test temperatures, while S-64-28 and S-58-28 had the lowest $\left|G^{*}\right|$ at $T_{\text {eff(FC) }}$ and $T_{\text {eff(}(P D)}$, respectively. Tables B12 through B15 in Appendix B show the $\left|G^{*}\right|$ data for all the replicate samples tested and their average, standard deviation and coefficient of variation.

Asphalt Institute categorizes asphalt mixtures based on the $\left|\mathrm{G}^{*}\right|$ values at $10 \mathrm{~Hz}$ (122) at $40^{\circ} \mathrm{C}$ as "good" (35000 - 50000 psi), "moderate" (22000 - 35000 psi) and "poor" (<22000 psi). Based on these criteria, all the mixtures may be considered "good" and hence may be expected to show minimal rutting, if any, in the field. 


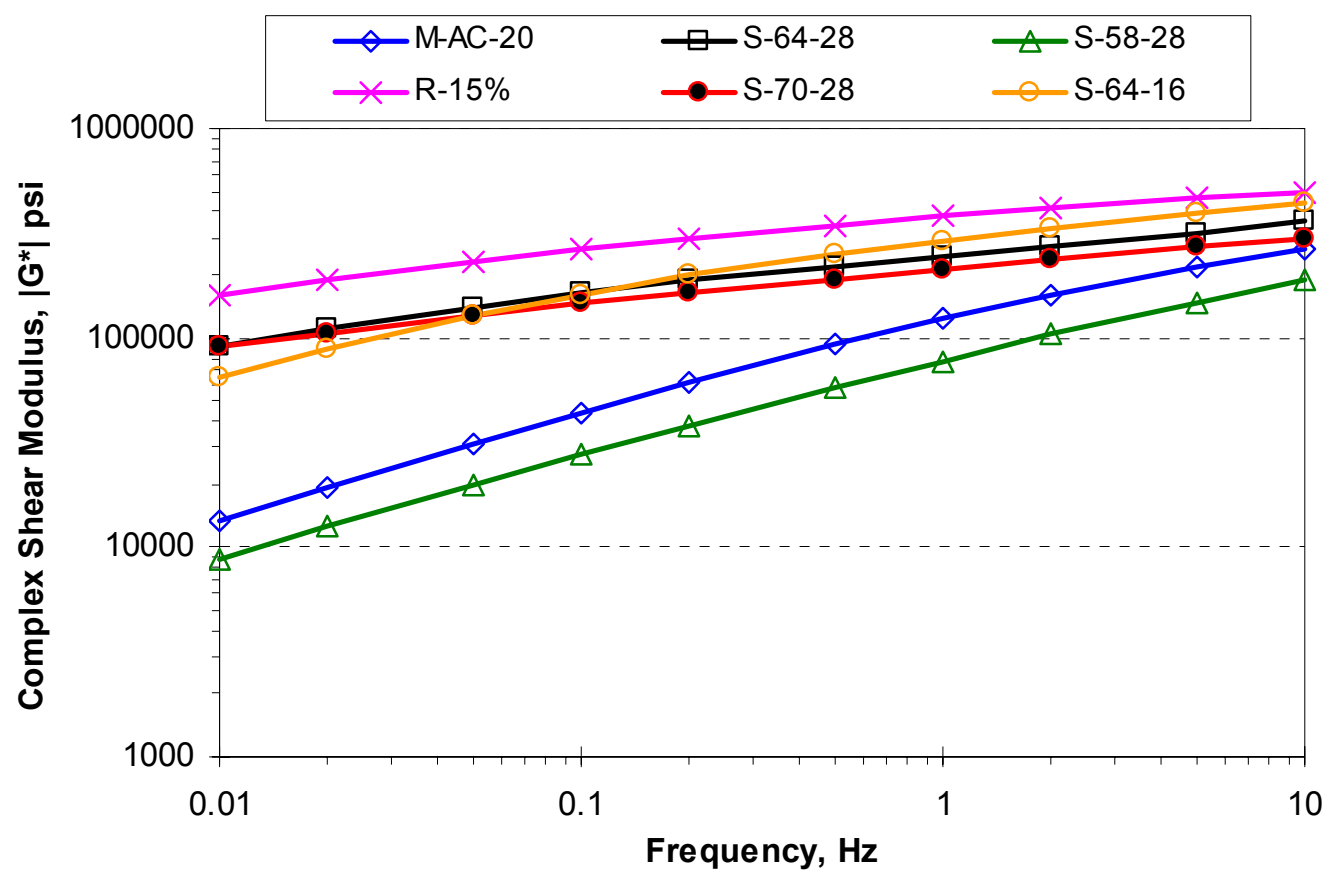

Figure 6.10 -- $\log \left|\mathrm{G}^{*}\right|$ versus log frequency for surface mixtures at $T_{\text {eff(FC) }}$

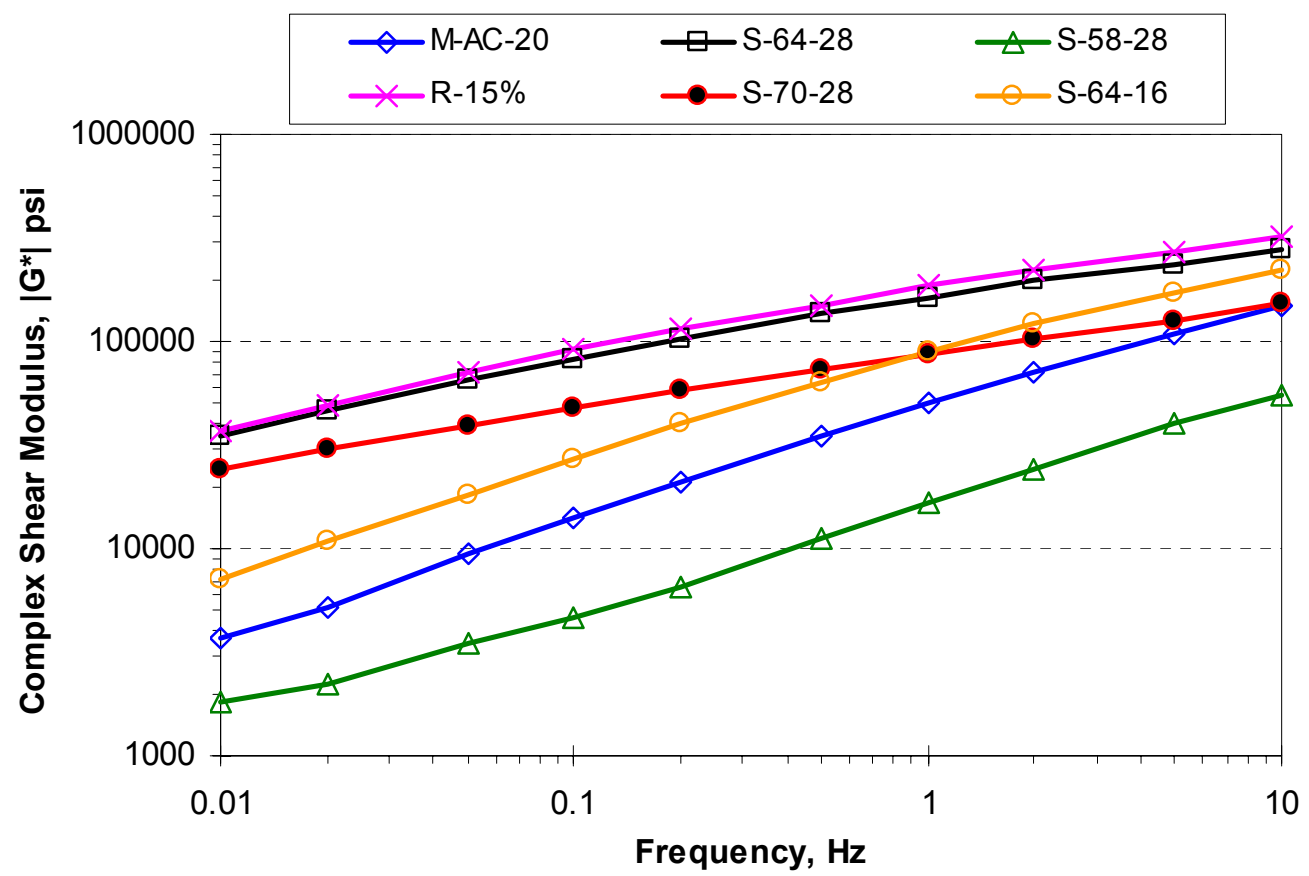

Figure 6.11 -- $\log \left|G^{*}\right|$ versus log frequency for surface mixtures at $T_{\text {eff(PD) }}$ 


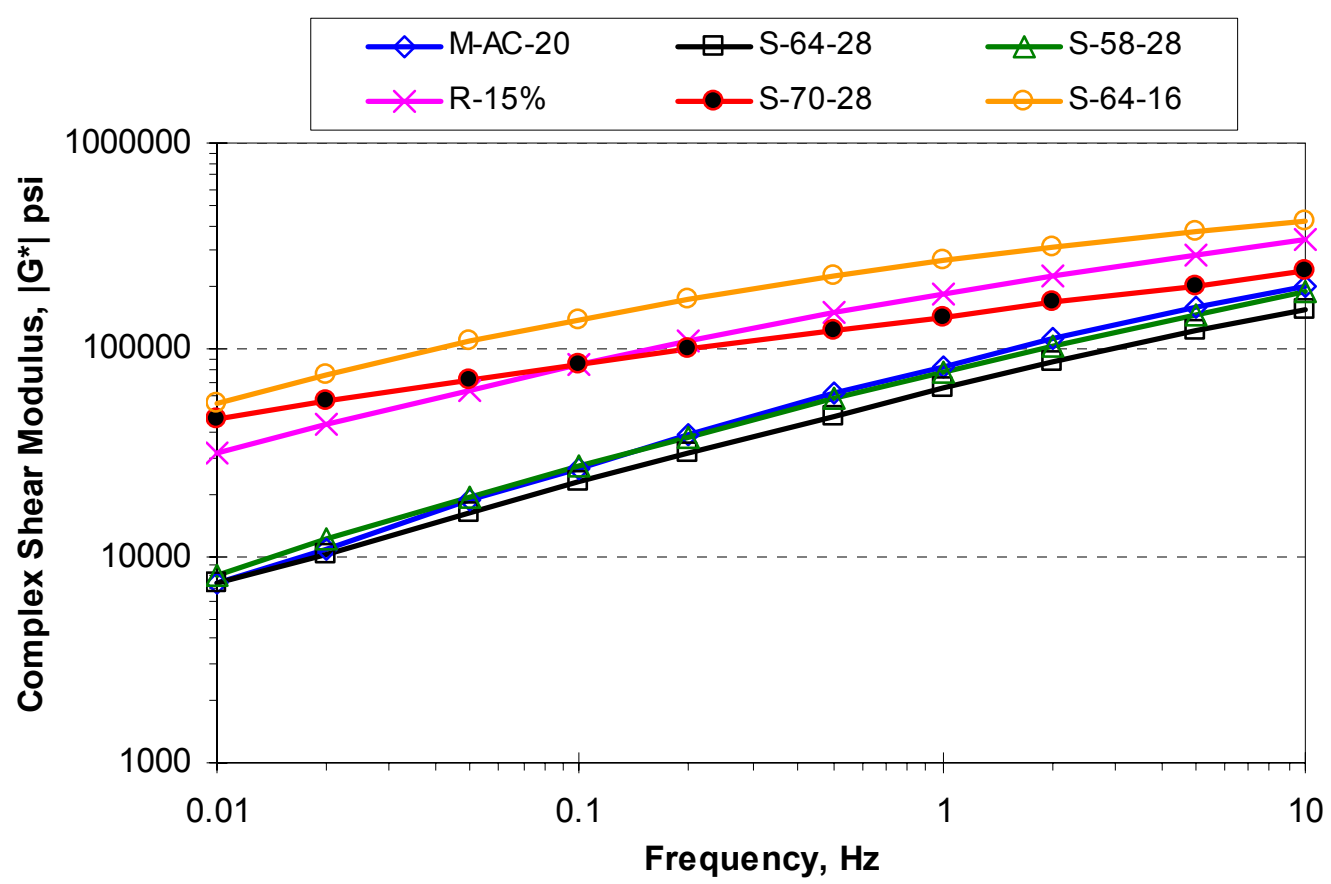

Figure 6.12 -- $\log \left|G^{*}\right|$ versus log frequency for intermediate mixtures at $T_{\text {eff( }(F C)}$

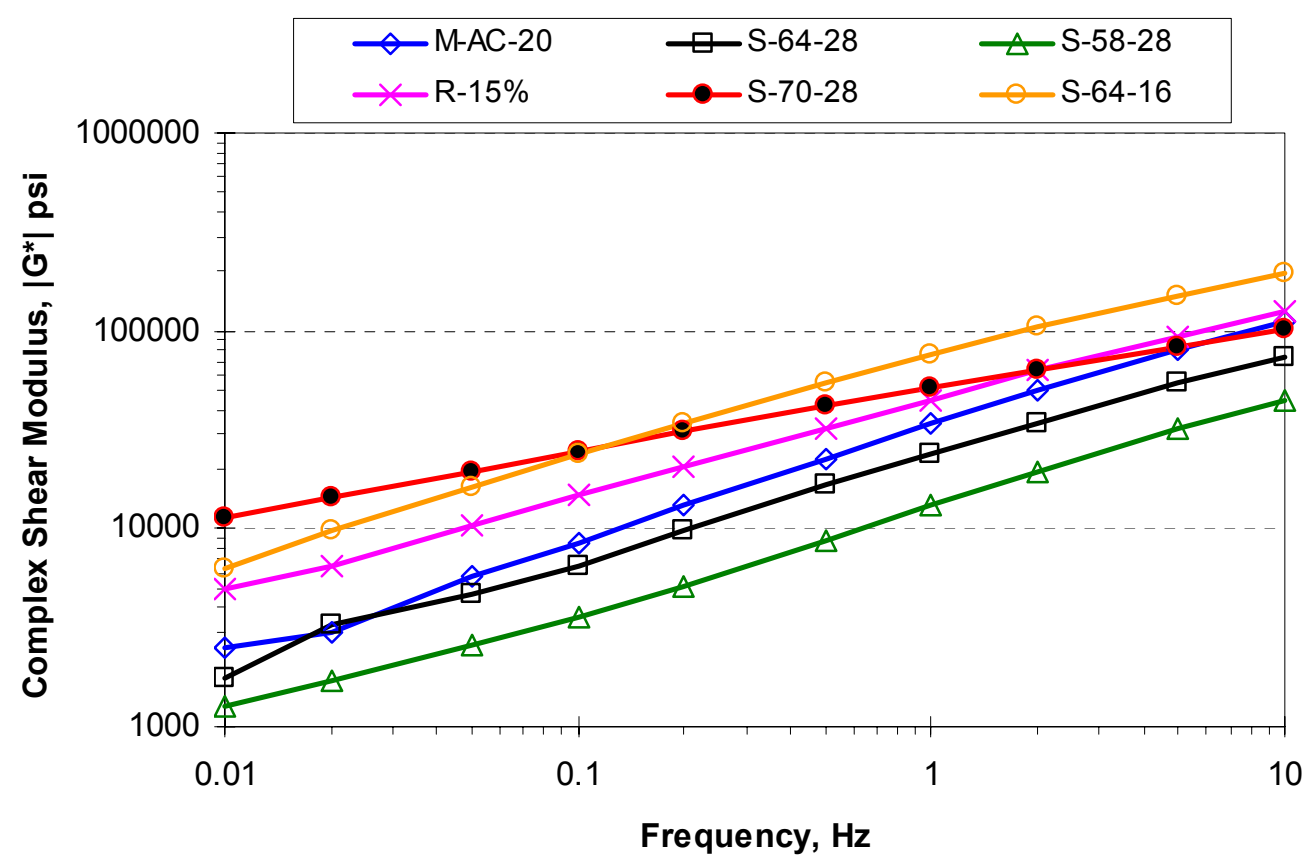

Figure 6.13 -- $\log \left|G^{*}\right|$ versus log frequency for intermediate mixtures at $T_{\text {eff(PD) }}$ 
Table 6.14 -- $\left|G^{*}\right|$ and slope values for surface mixtures

\begin{tabular}{|l|c|c|c|c||}
\hline \multirow{2}{*}{ Section ID } & \multicolumn{2}{|c|}{$T_{\text {eff(FC) }}$} & \multicolumn{2}{c||}{$T_{\text {eff(PD) }}$} \\
\cline { 2 - 5 } & $\left|G^{*}\right|$, GPa (psi) & slope & $\left.\right|^{*} \mid$, GPa (psi) & slope \\
\hline M-AC-20 & $1.85(268473)$ & 0.44 & $1.02(147912)$ & 0.54 \\
\hline S-64-28 & $2.50(362253)$ & 0.19 & $1.90(275193)$ & 0.30 \\
\hline S-58-28 & $1.31(190818)$ & 0.45 & $0.38(55037)$ & 0.51 \\
\hline R-15\% & $3.38(490120)$ & 0.16 & $2.20(319296)$ & 0.31 \\
\hline S-70-28 & $2.07(300002)$ & 0.17 & $1.06(153244)$ & 0.26 \\
\hline S-64-16 & $3.06(460720)$ & 0.27 & $1.51(219790)$ & 0.50 \\
\hline
\end{tabular}

Table 6.15 -- $\left|G^{*}\right|$ and slope values for intermediate mixtures

\begin{tabular}{|c|c|c|c|c|}
\hline \multirow{2}{*}{ Section ID } & \multicolumn{2}{|l|}{$\mathrm{T}_{\text {eff(FC) }}$} & \multicolumn{2}{|c|}{$\mathrm{T}_{\text {eff(PD) }}$} \\
\hline & $\left|G^{*}\right|, G P a(p s i)$ & slope & |G*|, GPa (psi) & slope \\
\hline M-AC-20 & $1.38(200019)$ & 0.48 & $0.77(111714)$ & 0.57 \\
\hline S-64-28 & $1.07(154724)$ & 0.45 & $0.50(72776)$ & 0.53 \\
\hline S-58-28 & $1.30(188489)$ & 0.45 & $0.30(44153)$ & 0.53 \\
\hline R-15\% & $2.34(340121)$ & 0.35 & $0.87(125762)$ & 0.48 \\
\hline S-70-28 & $1.66(241123)$ & 0.24 & $0.71(103166)$ & 0.32 \\
\hline S-64-16 & 2.85 (412953) & 0.29 & $1.33(193128)$ & 0.50 \\
\hline
\end{tabular}

In terms of slope value, the surface and intermediate mixtures of S-70-28 showed the least susceptibility (lowest slope value) at both temperatures, although the $\left|G^{*}\right|$ value was not as high as that of the other sections. The low slope value is intuitive and expected since the binder used in S-70-28 mixtures was PG70-28, a modified binder designed to withstand high temperature range. In the surface mixtures, M-AC-20, S-58-28 and S-64-16 had higher (and similar) slopes compared with the other test sections at $\mathrm{T}_{\text {eff(}(\mathrm{PD})}$ and may be expected to show higher permanent deformation in comparison with the other sections. S-64-28 and R-15\% had similar slope values that were slightly higher than that of S-70-28 and accordingly may show better performance than M-AC-20, S-58-28 and S-64-16, but worse than S-70-28, in terms of rutting.

ANOVA tests $(\alpha=0.05)$ were conducted to look for differences in the mean $\left|G^{*}\right|$ of mixtures with the same JMF and (a) the same high temperature grade, and (b) the same low temperature grade. The influence of RAP on the complex shear modulus was assessed by 
comparing the $\left|G^{*}\right|$ of the RAP mixture with that of the control section (S-64-28). Finally, the $\left|G^{*}\right|$ of the control section was compared with that of M-AC-20. The p-values shown in Table 6.16 indicate that there are significant differences in the mean complex modulus for all the hypotheses tested in all the mixtures.

Table 6.16 -- ANOVA results on complex shear modulus data from surface mixtures

\begin{tabular}{|c|c|c|c|c|}
\hline \multirow{2}{*}{ Null Hypothesis } & \multicolumn{2}{|c|}{ At $29.5^{\circ} \mathrm{C}$} & \multicolumn{2}{|c|}{ At $40.5^{\circ} \mathrm{C}$} \\
\hline & p-value & conclusion & p-value & conclusion \\
\hline $\begin{array}{l}\mu_{\mathrm{s}-64-28}=\mu_{\mathrm{s}-64-16} \\
(\mathrm{PG} 4-\mathrm{xx} \text { binders and same JMF) }\end{array}$ & 0.0227 & Reject null & 0.0045 & Reject null \\
\hline $\begin{array}{l}\mu_{\mathrm{S}-64-28}=\mu_{\mathrm{S}-58-28}=\mu_{\mathrm{S}-70-28} \\
(\mathrm{PGXx-28} \text { binders and same JMF) }\end{array}$ & $6.47 \times 10^{-7}$ & Reject null & $1.12 \times 10^{-9}$ & Reject null \\
\hline $\begin{array}{l}\mu_{\mathrm{M}-\mathrm{AC}-20}=\mu_{\mathrm{S}-64-28} \\
\text { (Marshall versus Control) }\end{array}$ & 0.0087 & Reject null & $2.55 \times 10^{-6}$ & Reject null \\
\hline $\begin{array}{l}\mu_{\mathrm{S}-64-28}=\mu_{\mathrm{R}-15 \%} \\
(\mathrm{PG} 64-28 \text { versus RAP) }\end{array}$ & 0.0006 & Reject null & 0.0229 & Reject null \\
\hline
\end{tabular}

Table 6.17 -- ANOVA results on complex shear modulus data from intermediate mixtures

\begin{tabular}{|c|c|c|c|c|}
\hline \multirow{2}{*}{ Null Hypothesis } & \multicolumn{2}{|c|}{ At $29.5^{\circ} \mathrm{C}$} & \multicolumn{2}{|c|}{ At $40.5^{\circ} \mathrm{C}$} \\
\hline & p-value & conclusion & p-value & conclusion \\
\hline $\begin{array}{l}\mu_{\mathrm{S}-64-28}=\mu_{\mathrm{s}-64-16} \\
(\mathrm{PG} 64-\mathrm{xx} \text { binders and same JMF) }\end{array}$ & $1.31 \times 10^{-8}$ & Reject null & $1.08 \times 10^{-7}$ & Reject null \\
\hline $\begin{array}{l}\mu_{\mathrm{S}-64-28}=\mu_{\mathrm{S}-58-28}=\mu_{\mathrm{S}-70-28} \\
(\text { PGxx-28 binders and same JMF) }\end{array}$ & $1.76 \times 10^{-7}$ & Reject null & $2.82 \times 10^{-7}$ & Reject null \\
\hline $\begin{array}{l}\mu_{\mathrm{M}-\mathrm{AC}-20}=\mu_{\mathrm{S}-64-28} \\
\text { (Marshall versus Control) }\end{array}$ & 0.0013 & Reject null & 0.0008 & Reject null \\
\hline $\begin{array}{l}\mu_{\mathrm{S}-64-28}=\mu_{\mathrm{R}-15 \%} \\
(\text { PG64-28 versus RAP) }\end{array}$ & $4.02 \times 10^{-7}$ & Reject null & $9.93 \times 10^{-5}$ & Reject null \\
\hline
\end{tabular}

\subsubsection{Simple Shear at Constant Height}

The simple shear at constant height test is a static shear test that is conducted on 150-mm diameter HMA samples (laboratory compacted or field core samples) at the same test temperatures as frequency sweep tests. The results from this test are used to determine the resilience of HMA, in terms of percent recovered strain with respect to the maximum strain.

In this test, a static shear stress is applied at a rate of $70 \mathrm{kPa} / \mathrm{s}$ until a maximum shear stress is reached and then held constant for $10 \mathrm{~s}$. The maximum shear stress applied varies with test temperature: $345 \mathrm{kPa}, 105 \mathrm{kPa}$ and $35 \mathrm{kPa}$ at $4{ }^{\circ} \mathrm{C}, 20^{\circ} \mathrm{C}$ and $40^{\circ} \mathrm{C}$, respectively. 
At other test temperatures, the maximum shear stress is linearly interpolated. After $10 \mathrm{~s}$, the shear stress is decreased at a rate of $25 \mathrm{kPa} / \mathrm{s}$ and held at $0 \mathrm{kPa}$ for a further $10 \mathrm{~s}$. The applied axial stress is varied during the test to maintain constant specimen height. The shear deformation $(\bar{\delta})$ experienced by the sample is recorded throughout the duration of the test.

In this study, simple shear testing was conducted after the completion of $\mathrm{FSCH}$ testing on the same samples. Five replicates per mixture were tested at two temperatures $\left(29.5^{\circ} \mathrm{C}\right.$ and $\left.40.5^{\circ} \mathrm{C}\right)$. Figures 6.14 through 6.17 show the plots of shear deformation versus time for the different surface and intermediate samples tested at two test temperatures. The raw data used to obtain the average values shown in these graphs are presented in Tables B16 through B19 of Appendix B. In the surface mixtures, S-58-28 showed the highest maximum shear deformation $\left(\delta_{\max }\right)$ at both test temperatures, followed by M-AC-20. All the remaining sections showed significantly lower $\delta_{\max }$ in comparison. Although S-64-16 showed minimal shear deformation at $\mathrm{T}_{\text {eff(FC) }}$ along with S-64-28, R-15\% and S-70-28, it showed higher deformations at

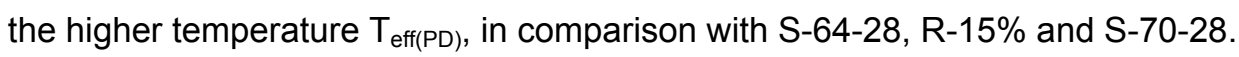

In the intermediate mixtures, M-AC-20, S-64-28 and S-58-28 showed comparable $\delta_{\max }$ at $29.5^{\circ} \mathrm{C}$. However, at $40.5^{\circ} \mathrm{C}$ the $\delta_{\max }$ experienced by S-58-28 samples was significantly higher than that $\mathrm{M}-\mathrm{AC}-20$ and $\mathrm{S}-64-28$. The $\delta_{\max }$ of the intermediate mixtures was higher than that of the surface mixtures.

Tables 6.18 and 6.19 show the maximum shear deformation, $\delta_{\max }$, rank and the percent resilience of the mixtures at the two test temperatures. The overall ranking of the six mixtures in terms of $\delta_{\max }$ remained the same at the two temperatures in both the mixture types (surface and intermediate). The surface mixtures of M-AC-20 and S-64-16 showed poor resilience at both test temperatures, in comparison with the other sections. A high degree of resilience indicates that a given mixture is less prone to rutting due to the ability of the mixture to recover most of the strain caused by passing vehicular traffic. Contrary to expectations, S-58-28 showed lower resilience at lower temperature than at higher temperature. S-70-28 showed the highest percent resilience at the two test temperatures, in the surface and intermediate mixtures. 


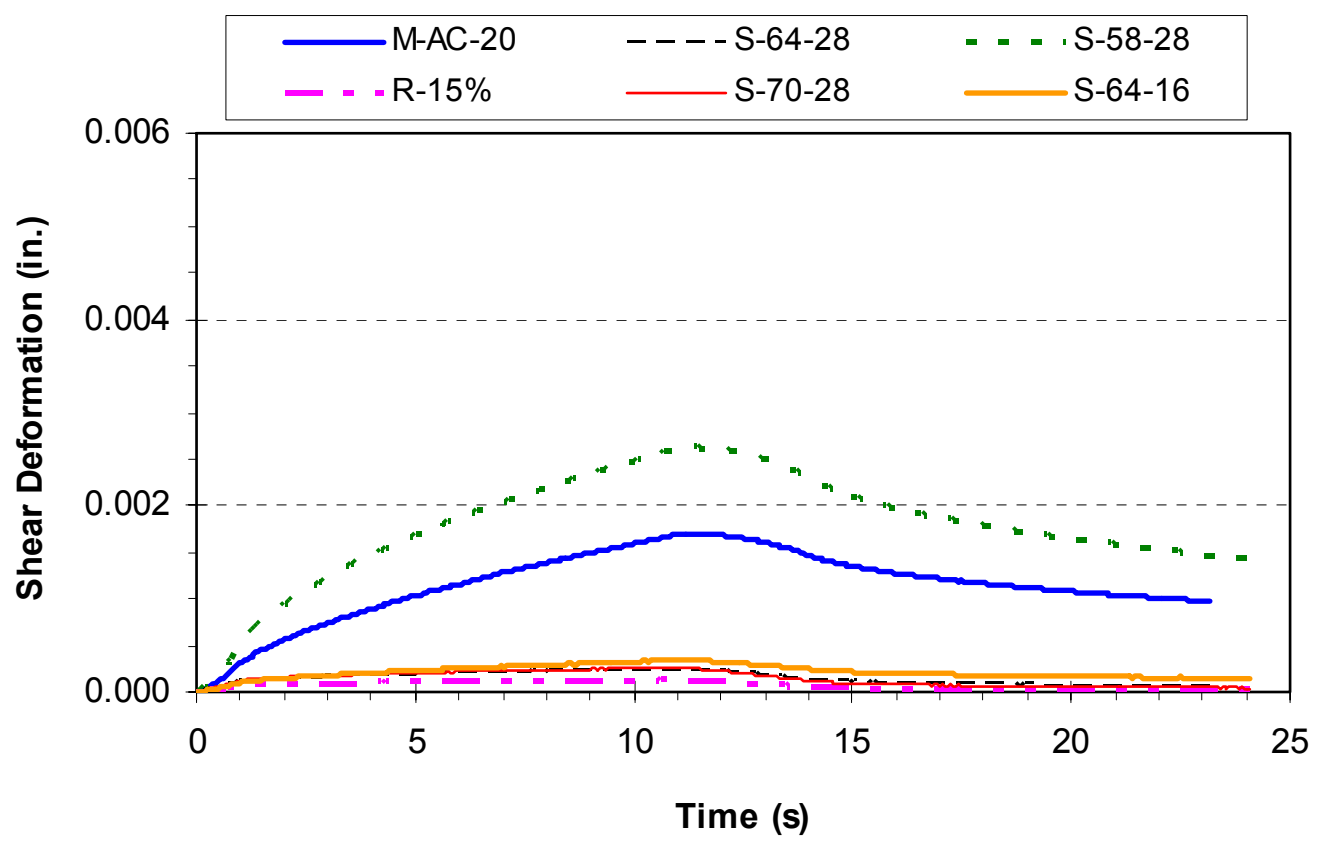

Figure 6.14 -- Shear deformation versus time for surface mixtures at $29.5^{\circ} \mathrm{C}$

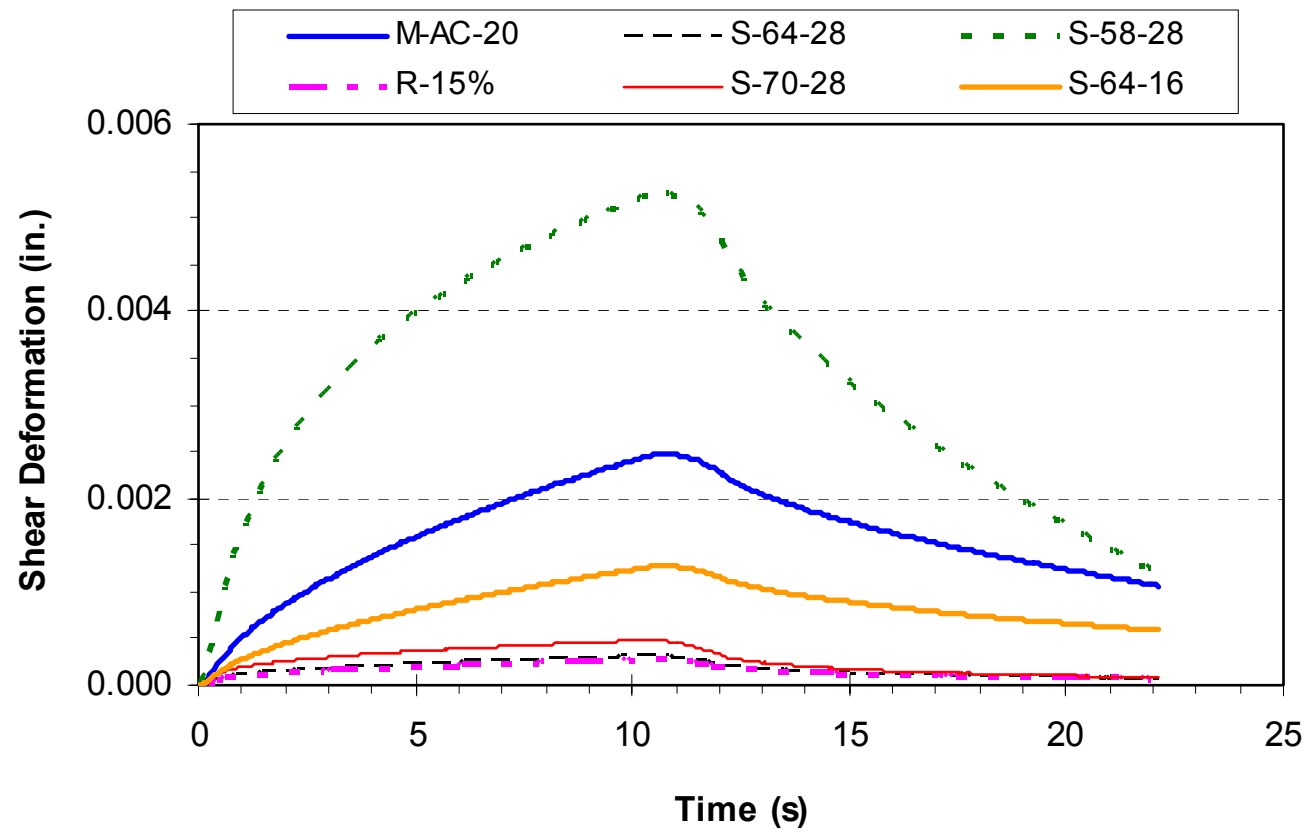

Figure 6.15 -- Shear deformation versus time for surface mixtures at $40.5^{\circ} \mathrm{C}$ 


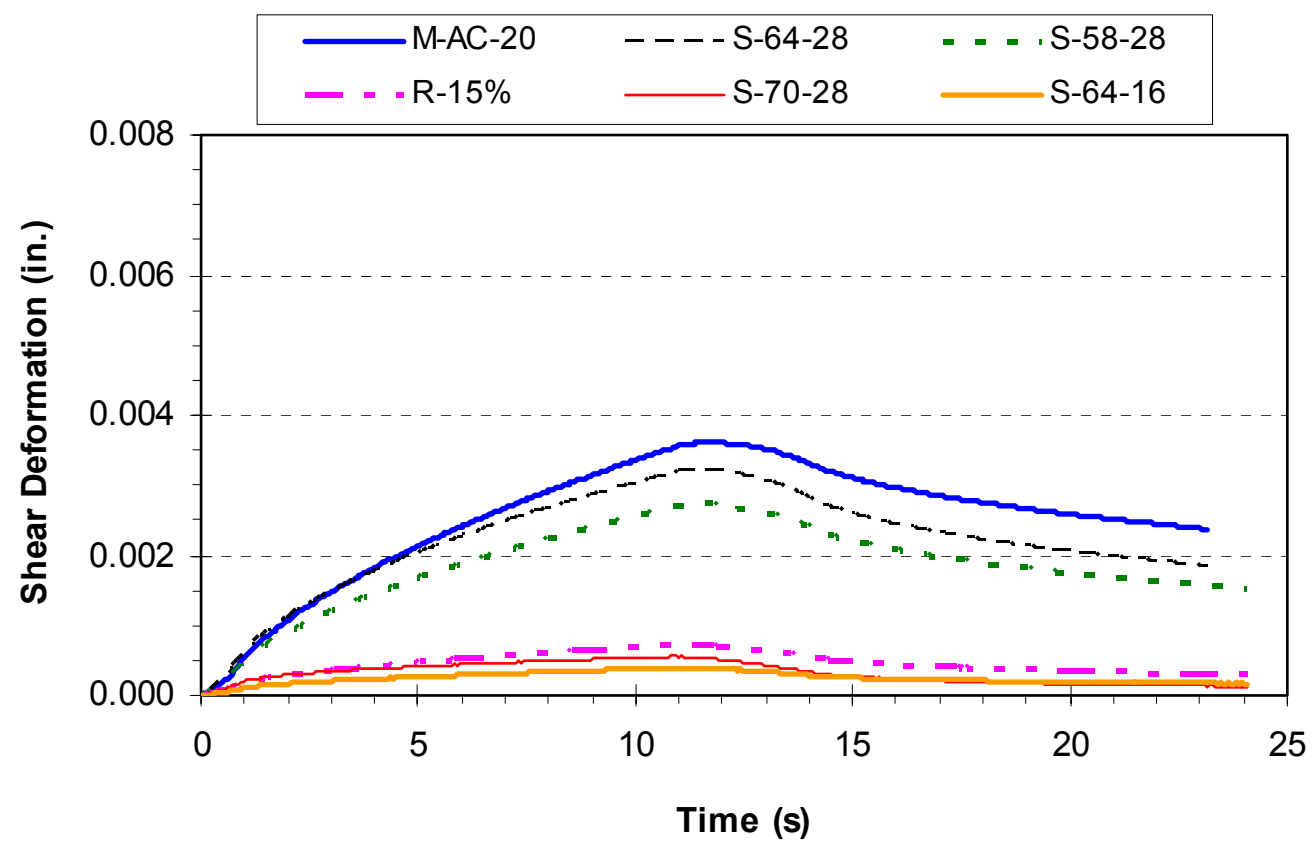

Figure 6.16 -- Shear deformation versus time for intermediate mixtures at $29.5^{\circ} \mathrm{C}$

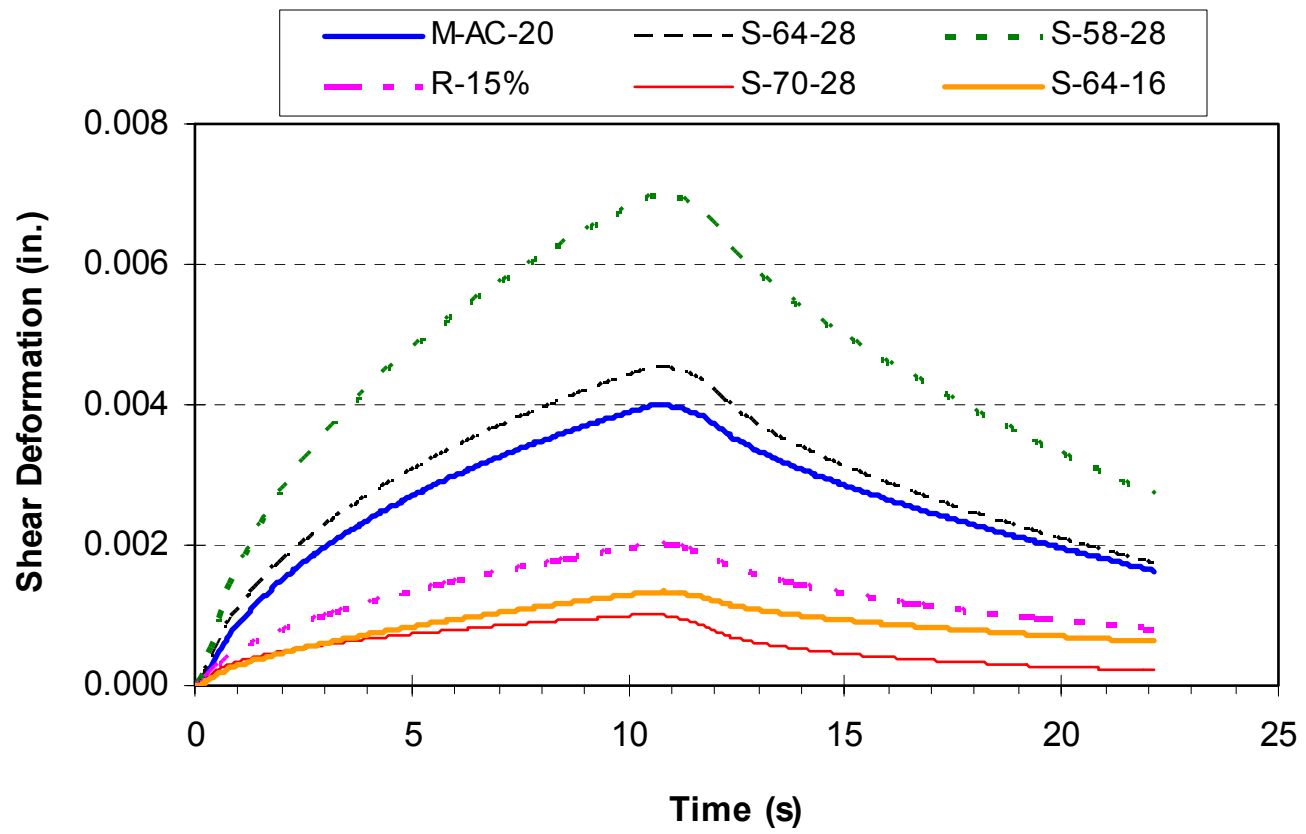

Figure 6.17 -- Shear deformation versus time for intermediate mixtures at $40.5^{\circ} \mathrm{C}$ 
Table 6.18 -- Maximum shear deformation, rank and percent resilience of surface mixtures

\begin{tabular}{|l|c|c|c|c||}
\hline \multirow{2}{*}{ Section (Binder) } & \multicolumn{2}{|c|}{ At 29.5 ${ }^{\circ} \mathbf{C}$} & \multicolumn{2}{c|}{ At 40.5 ${ }^{\circ} \mathbf{C}$} \\
\cline { 2 - 5 } & $\delta_{\max }$ (rank) & Resilience (\%) & $\boldsymbol{\delta}_{\max }$ (rank) & Resilience (\%) \\
\hline M-AC-20 & $0.00170(2)$ & 42.7 & $0.00248(2)$ & 57.1 \\
\hline S-64-28 & $0.00024(5)$ & 77.2 & $0.00031(5)$ & 80.9 \\
\hline S-58-28 & $0.00263(1)$ & 45.8 & $0.00528(1)$ & 77.4 \\
\hline R-15\% & $0.00013(6)$ & 83.8 & $0.00028(6)$ & 75.0 \\
\hline S-70-28 & $0.00026(4)$ & 83.6 & $0.00049(4)$ & 83.5 \\
\hline S-64-16 & $0.00034(3)$ & 56.7 & $0.00128(3)$ & 54.1 \\
\hline \hline
\end{tabular}

Table 6.19 -- Maximum shear deformation, rank and percent resilience of intermediate mixtures

\begin{tabular}{||l|c|c|c|c||}
\hline \multirow{2}{*}{ Section ID } & \multicolumn{2}{|c|}{ At $29.5^{\circ} \mathbf{C}$} & \multicolumn{2}{c|}{ At 40.5 ${ }^{\circ} \mathbf{C}$} \\
\cline { 2 - 5 } & $\boldsymbol{\delta}_{\max }$ (rank) & Resilience (\%) & $\boldsymbol{\delta}_{\max }$ (rank) & Resilience (\%) \\
\hline M-AC-20 & $0.00361(1)$ & 34.2 & $0.00419(3)$ & 59.0 \\
\hline S-64-28 & $0.00321(2)$ & 42.8 & $0.00476(2)$ & 61.9 \\
\hline S-58-28 & $0.00273(3)$ & 44.4 & $0.00734(1)$ & 61.0 \\
\hline R-15\% & $0.00072(4)$ & 59.8 & $0.00212(4)$ & 60.3 \\
\hline S-70-28 & $0.00056(5)$ & 77.5 & $0.00107(6)$ & 79.2 \\
\hline S-64-16 & $0.00040(6)$ & 56.8 & $0.00141(5)$ & 53.1 \\
\hline
\end{tabular}

In general, the intermediate mixtures showed poorer resilience in comparison with the surface mixtures. This could be due to the higher binder content present in the surface mixtures. The influence of the modified binder in S-70-28 was more evident in the intermediate mixtures than in the surface mixtures, as indicated by the higher percent resilience in comparison with the other intermediate mixtures. M-AC-20 samples, which showed low resilience in the surface mixtures, also showed poor resilience in the intermediate mixture samples as well.

\subsubsection{Repeated Shear at Constant Height}

This optional SUPERPAVE test (AASHTO TP7) was conducted to identify mixtures that are likely to exhibit tertiary flow (plastic flow) due to mixture instability. In the repeated shear at constant height test, the HMA sample is held between two platens and subjected to repeated shear stress of $69 \pm 5 \mathrm{kPa}$ for a period of $0.1 \mathrm{~s}$ followed by a rest period of $0.6 \mathrm{~s}$ to allow the sample to recover between the applied load pulses. Constant specimen height 
is maintained (within $\pm 0.013 \mathrm{~mm}$ ) by adjusting the vertical load through a feedback loop. The test is run until 5000 cycles are completed or $5 \%$ permanent strain is reached, whichever occurs earlier. The permanent strain as a function of load cycles is recorded throughout the test duration.

The test was conducted on plant mix samples compacted to $3 \pm 0.5 \%$ air voids. Five replicates per each mixture were tested and averaged (presented in Tables B20 and B21 of Appendix B). This test is typically conducted at the 7-day maximum pavement temperature in the pavement layer of interest. The test temperature for the surface and intermediate layer mixtures was $58^{\circ} \mathrm{C}$ and $54^{\circ} \mathrm{C}$, respectively. Figures 6.18 and 6.19 show the log of cumulative plastic (or permanent) strain $\left(\varepsilon_{p}\right)$ to log of load cycles $(N)$ for the surface and intermediate mixtures tested, respectively.

In the surface and intermediate mixtures, S-58-28 showed the highest amount of strain, while S-70-28 showed the least. This result is expected since the binder used in S-58-28 was a soft binder (PG58-28) and the binder used in S-70-28 was a modified binder (PG70-28). However, none of the samples tested reached the $5 \%$ strain limit before the end of 5000 cycles. Overall, this indicates that the mixtures may be expected to perform relatively well in terms of rut resistance. Table 6.20 shows the slope values for the $\log \varepsilon_{p}$ versus $\log N$ plots shown in Figures 6.18 and 6.19 and the maximum $\varepsilon_{p}$ attained by the mixtures. As mentioned earlier, the surface course mixtures of $\mathrm{M}-\mathrm{AC}-20$ could not be compacted to $3 \%$ air voids. The samples were compacted to $4 \%$, but the test could not be conducted on these samples due to problems with the Shear Tester. Data from the initial part of S-64-28 surface mixtures were not shown due to errors in data collection. 


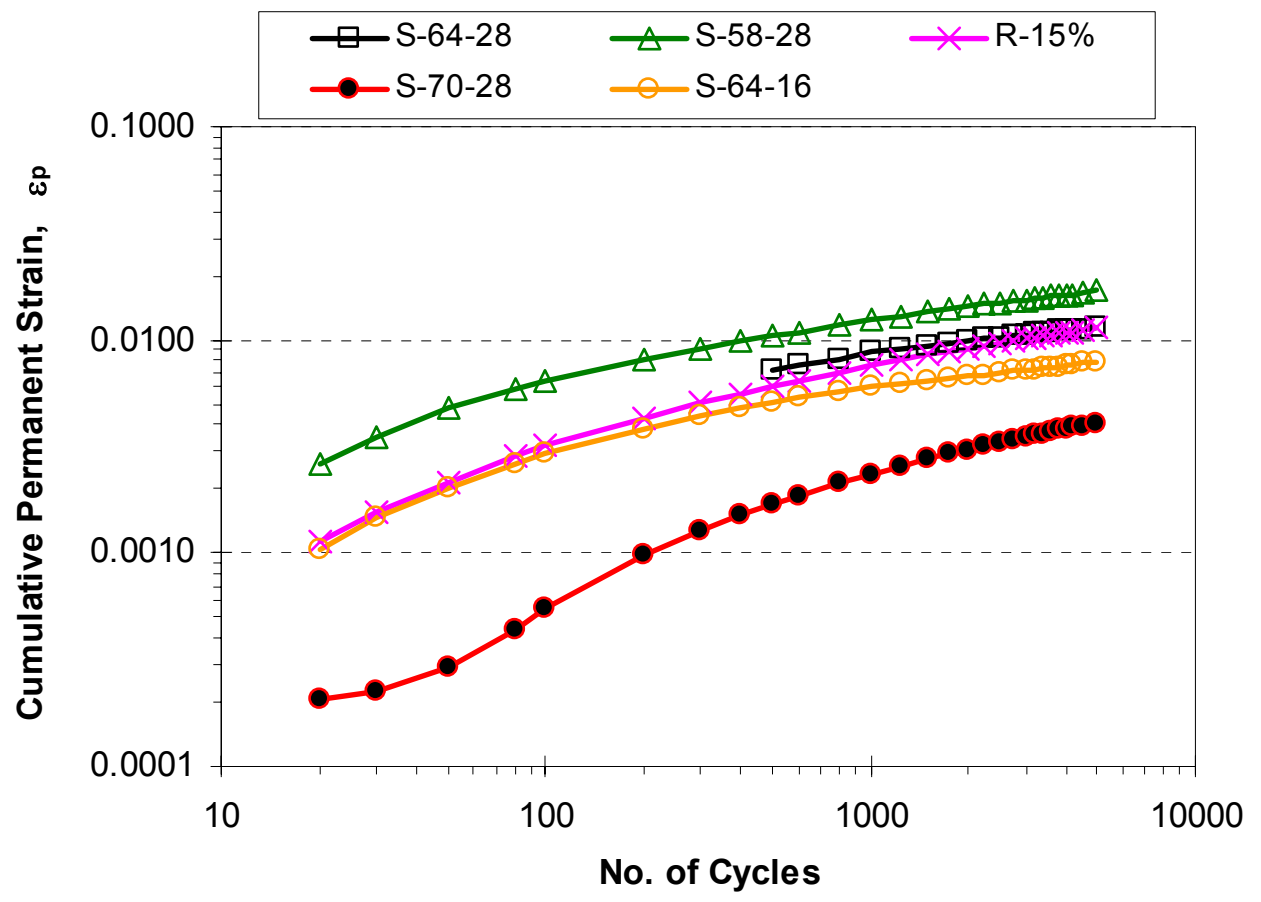

Figure 6.18 -- Cumulative permanent strain at $58^{\circ} \mathrm{C}$ for surface mixtures

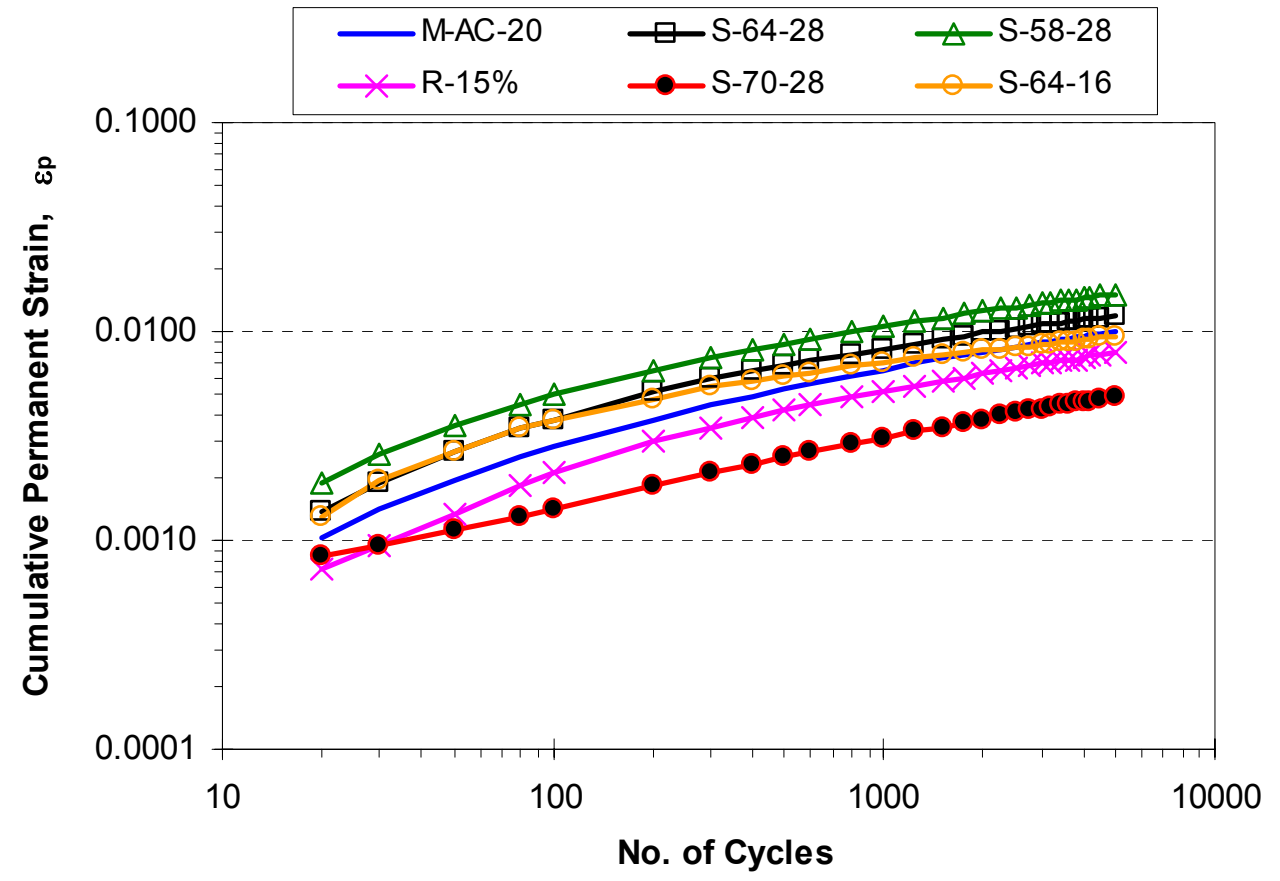

Figure 6.19 -- Cumulative permanent strain at $54^{\circ} \mathrm{C}$ for intermediate mixtures 
Table 6.20 -- Maximum cumulative strain and slope values from $\mathrm{RSCH}$ testing

\begin{tabular}{|l|c|c|c|c||}
\hline \multirow{2}{*}{ Section ID } & \multicolumn{2}{|c|}{ Surface } & \multicolumn{2}{c||}{ Intermediate } \\
\cline { 2 - 5 } & Max. $\varepsilon_{\mathbf{p}}$ (rank) & Slope & Max. $\varepsilon_{\mathbf{p}}$ (rank) & Slope \\
\hline M-AC-20 & -- & -- & $0.0100(3)$ & 0.28 \\
\hline S-64-28 & $0.0114(2)$ & 0.19 & $0.0119(2)$ & 0.24 \\
\hline S-58-28 & $0.0169(1)$ & 0.21 & $0.0152(1)$ & 0.24 \\
\hline R-15\% & $0.0113(3)$ & 0.27 & $0.0079(5)$ & 0.28 \\
\hline S-70-28 & $0.0041(5)$ & 0.37 & $0.0049(6)$ & 0.29 \\
\hline S-64-16 & $0.0079(4)$ & 0.18 & $0.0095(4)$ & 0.19 \\
\hline
\end{tabular}

The surface samples from S-64-28 and R-15\% showed similar maximum $\varepsilon_{p}$ but different slopes and hence may be expected to show similar total rut depth in the field, but the rate of strain accumulation would be different. $\mathrm{R}-15 \%$ is likely to reach a given rut depth earlier than S-64-28 due to its higher slope value compared with that of S-64-28. The surface samples from S-64-16 is expected to show lower rut depth than S-64-28, S-58-28 and R-15\%, but higher than S-70-28.

The rate of strain accumulation in the intermediate mixtures was more or less similar in all the sections, except S-64-16, which had the lowest rate as indicated by the low slope value. S-58-28 would be expected to show the highest rutting, followed S-64-28, M-AC-20, S-64-16, R-15\% and S-70-28. S-70-28 had the lowest $\varepsilon_{\mathrm{p}}$ values, but the highest slope values indicating that this section is likely to reach a given strain level earlier than all the other sections. The overall ranking of mixtures based on maximum plastic strain appears to be similar in the surface and intermediate mixtures.

Asphalt Institute uses the maximum permanent strain, $\varepsilon_{\mathrm{p}}$, parameter to categorize the rut resistance of HMA (122). Mixtures with $\varepsilon_{p}>1 \%$ are considered "excellent" and hence, not prone to rutting. Mixtures with $\varepsilon_{\mathrm{p}}$ between $2 \%$ and $3 \%$ are considered "fair" and are therefore, likely to exhibit some degree of rutting in the field. Mixtures with $\varepsilon_{\mathrm{p}}$ between $1 \%$ and $2 \%$ are categorized as "good" and are accordingly, expected to show intermediate performance. Based on these criteria, S-70-28 and S-64-16 surface mixtures may be expected to show minimal 
to no rutting, while S-64-28, S-58-28 and R-15\% may be expected to show nominal amount of rutting.

\subsubsection{Summary of Performance Test Results}

Creep compliance and strength testing at low temperatures was conducted on HMA samples compacted to $3 \%$ and $7 \%$ air voids $\left(P_{a}\right)$. Compliance data was used to determine mixture stiffness and estimate pavement critical temperature using Christensen's model. Stiffness of the surface mixtures was not significantly influenced by change in $\mathrm{P}_{\mathrm{a}}$ from $7 \%$ to $3 \%$, except in the case of S-58-28 and S-64-16. However, the stiffness of the intermediate mixtures increased with decrease in $\mathrm{P}_{\mathrm{a}}$. S-58-28 and S-70-28 had the lowest stiffness at both $\mathrm{P}_{\mathrm{a}}$ levels among the surface and the intermediate mixtures. M-AC-20 and S-64-16 had the highest stiffness at $3 \% \mathrm{P}_{\mathrm{a}}$, in the surface and intermediate mixtures. Among the mixtures at $7 \% \mathrm{P}_{\mathrm{a}}$, surface mixtures of S-64-28 and S-64-16, and intermediate mixtures of R-15\% and S-64-16 had the highest stiffness. Therefore, based on stiffness values alone S-58-28 and S-70-28 appear to be thermal cracking resistant, while S-64-16 appears to be the most susceptible to thermal cracking.

Indirect tensile strength of the mixtures showed a significant increase with the lowering of $\mathrm{P}_{\mathrm{a}}$ from $7 \%$ to $3 \%$. S-70-28 had the lowest strength at both $\mathrm{P}_{\mathrm{a}}$ levels. Although low mixture stiffness is required to resist thermal cracking, the low strength of this mixture used in S-70-28 tends to lower its cracking resistance. Similarly, although S-64-16 mixtures had high strength in comparison with the other mixtures, the high stiffness of this mixture will also lead to thermal cracking in this section. Surface mixture of R-15\%, which showed average stiffness and strength, is expected to show minimal cracking in the field.

ANOVA tests were conducted to verify the influence of high temperature grade and low temperature grade on the strength of the mixture. Change in low temperature grade (from PG64-28 to PG64-16) did not influence the strength of the surface mixtures at both $P_{a}$ levels, but did influence the strength of the intermediate mixtures at $3 \% \mathrm{P}_{\mathrm{a}}$. Changing the high 
temperature grade influenced the strength of the intermediate mixtures at both $\mathrm{P}_{\mathrm{a}}$ levels, but did not influence the strength of the surface mixtures at $7 \% \mathrm{P}_{\mathrm{a}}$. Tests also indicated that there were no significant differences in the mean strength of the control mixtures and the Marshall mixtures at both $\mathrm{P}_{\mathrm{a}}$ levels tested. Significant differences were found between the intermediate mixtures of the control section and the RAP section, but not between the surface mixtures.

Critical pavement temperature estimates obtained from mixture testing of samples compacted to $7 \%$ air voids were lower than the minimum pavement temperature $\left(-19.5^{\circ} \mathrm{C}\right)$ experienced at the test site, during the duration of the study. However, the estimates obtained for the $3 \%$ air voids samples from $\mathrm{M}-\mathrm{AC}-20$ and S-64-16 were warmer than this temperature. This indicates that thermal cracking may be expected in these two sections when the percent air voids drops to approximately $3 \%$.

Frequency sweep testing was conducted at $\mathrm{T}_{\text {eff }(\mathrm{FC})}$ and $\mathrm{T}_{\text {eff(}(\mathrm{PD})}$ to determine the complex shear modulus of the mixtures. Complex shear modulus is used as a measure of mixture stiffness when subjected to moving loads of different frequencies that simulate different traffic speeds and axle weights. S-58-28 showed the lowest mixture stiffness at both test temperatures in the surface and intermediate mixtures, followed by M-AC-20 among the surface mixtures and S-64-28 among the intermediate mixtures. R-15\% was the stiffest surface mixture, while S-64-16 was the stiffest intermediate mixture. Accordingly, higher degree of rutting is expected in S-58-28 in comparison with the other sections, while R-15\% and S-64-16 are expected to shown relatively low rut depths. The slope parameter, $\log \left|G^{*}\right|$ versus log frequency, which is used an indicator of temperature susceptibility indicated that S-70-28 mixtures were the least temperature susceptible in comparison with the other sections.

ANOVA tests indicated that there were significant differences in stiffness (a) between the control mixture and the Marshall mixture, and (b) between the control mixture and the RAP mixture. Further, change in high temperature grade of the binder appeared to significantly change the $\left|G^{*}\right|$ of the mixtures tested. Similar results were obtained when the low temperature grade of the binder was changed. 
Simple shear at constant height tests indicate that S-58-28 is most prone to rutting due to the higher $\delta_{\max }$ value observed in these mixtures in comparison with other sections. Marshall mixtures also appeared to be prone to rutting, but not to the same extent as S-58-28. Samples from the remaining sections experienced minimal amount of $\delta_{\max }$ compared with M-AC-20 and S-58-20. The highest degree of resilience was observed in S-70-28 with PG70-28. This could be attributed to the influence of the SBS-modifier used in this binder. In general, surface mixtures had lower $\delta_{\max }$ and higher resilience in comparison with intermediate mixtures. Contrary to expectations, S-58-28 samples showed lower resilience at lower temperature, than at higher temperature (as would be intuitively expected).

S-58-28 samples also showed the maximum amount of plastic strain $\left(\varepsilon_{p}\right)$ when subjected to repeated shear at constant height testing. The low values of percent resilience for S-58-28 samples shown in the SSCH test was indicative of poor strain recovery during the rest period. S-64-28 samples also showed higher amount of accumulated strain compared with the other sections, but less than that of S-58-28. This could be attributed to the high degree of resilience shown in $\mathrm{SSCH}$ testing compared with S-58-28. It must be noted that the $\varepsilon_{\mathrm{p}}$ experienced by all the sections was significantly lower than the $5 \%$ strain limit proposed by the test protocol. The section with the modified binder, S-70-28, had the least amount of $\varepsilon_{\mathrm{p}}$ and highest slope value. This indicates that this test section is likely to undergo the least amount of rutting in comparison with the other sections. R-15\% showed overall good performance in this test as indicated by the high resilience values and the relatively low maximum shear strains at both test temperatures. 


\section{CHAPTER 7 -- EFFECT OF BINDER GRADE ON OBSERVED PAVEMENT DISTRESS}

This chapter deals with the correlations between the observed pavement distress and the different binder grades used in the test sections. As mentioned earlier, the binder grade recommended for the test site (based on weather data) alone was PG58-28 (98\% and 79\% reliability, respectively). To account for the expected increase in the traffic volume during the service life of the pavement, the high temperature grade was raised one grade to PG64-28. To compare the performance of mixture constructed with the existing state agency's design methodology, one section was built with a Marshall mixture (M-AC-20). In addition, four supplemental sections were also constructed, one of which incorporated 15\% RAP (R-15\%) and the remaining three sections had alternate binder grades. PG64-16 (S-64-16) was used as one of the alternate binders, to study the influence of lowering the low temperature grade on thermal cracking performance. PG58-28 was used in one of the test sections (S-58-28), to study the influence of lowering the high temperature grade on rutting resistance of SUPERPAVE mixtures. Finally, a SBS-modified binder (PG70-28) was also used as an alternate binder to study the performance of modifier binder in a SUPERPAVE mixture.

As indicated in Chapter 4, field distress surveys were conducted by the North Central Regional Coordinators, ERES Consultants, during the study period. Distress data in terms of crack length, crack frequency, longitudinal and transverse profile were obtained from ERES Consultants and are analyzed in this section. 


\subsection{Thermal (Transverse) Cracking}

Transverse crack data from distress maps that was summarized in Chapter 4 is reproduced here in Table 7.1. No transverse cracking was observed at the time of the first survey (1.5 years after construction). At the end of 3.5 years, Section 3 with the lowest viscosity binder showed no thermal cracking, while Section 5 with the highest viscosity binder showed the maximum amount of thermal cracking. Excluding the section with the modified binder (S-70-28), the binders with warmer low temperature grades showed higher amounts of cracking than section with colder high temperature grades. That is, S-64-16 with PGxx-16 exhibited the maximum amount of crack and S-64-28, S-58-28 and R-15\% with PGxx-28 showed little to no cracking. Recall that the binder used in M-AC-20, AC-20, was performance graded as PG64-22.

Table 7.1 -- Transverse cracking observed at the end of 3.5 years

\begin{tabular}{|l||c|c|c||c|c|c||c||}
\hline \multirow{2}{*}{\multicolumn{1}{|c||}{ Section ID }} & \multicolumn{3}{|c||}{ Number of Cracks/Level } & \multicolumn{3}{c||}{$\begin{array}{c}\text { Length of Crack } \\
\text { (m)/Level }\end{array}$} & $\begin{array}{c}\text { Total Crack } \\
\text { Length } \\
\text { (m/150 m) }\end{array}$ \\
\cline { 2 - 9 } & Low & Med & High & Low & Med & High & \\
\hline M-AC-20 & 1.0 & 3.0 & 0.0 & 3.7 & 10.4 & 0.0 & 14.1 \\
\hline S-64-28 & 1.0 & 0.0 & 0.0 & 3.7 & 0.0 & 0.0 & 3.7 \\
\hline S-58-28 & 0.0 & 0.0 & 0.0 & 0.0 & 0.0 & 0.0 & 0.0 \\
\hline R-15\% & 1.0 & 0.0 & 0.0 & 3.2 & 0.0 & 0.0 & 3.2 \\
\hline S-70-28 & 14.0 & 13.0 & 2.0 & 39.4 & 45.8 & 7.4 & 92.6 \\
\hline S-64-16 & 2.0 & 8.0 & 0.0 & 3.0 & 24.2 & 0.0 & 27.2 \\
\hline
\end{tabular}

Figure 7.1 shows the total crack length versus the critical cracking temperature of the recovered binders obtained at the end of 4 years. S-64-28 and R-15\% showed similar crack lengths. The addition of $15 \%$ RAP to R-15\% did not appear to alter the thermal cracking resistance of the mixture. With the exception of S-70-28, the sections with PGxx-28 binders showed good cracking resistance. Although the influence of SBS binder modification is typically known to improve the rutting resistance of the mixture, in this study, it proved to have a negative impact on the thermal cracking resistance of the mixture in that, this section (S-70-28) with the modified binder showed a higher degree of transverse cracking in comparison with the other test sections. A 9-degree C difference was observed between the critical temperature estimates obtained from BBR and PP42 procedures for this test section. 


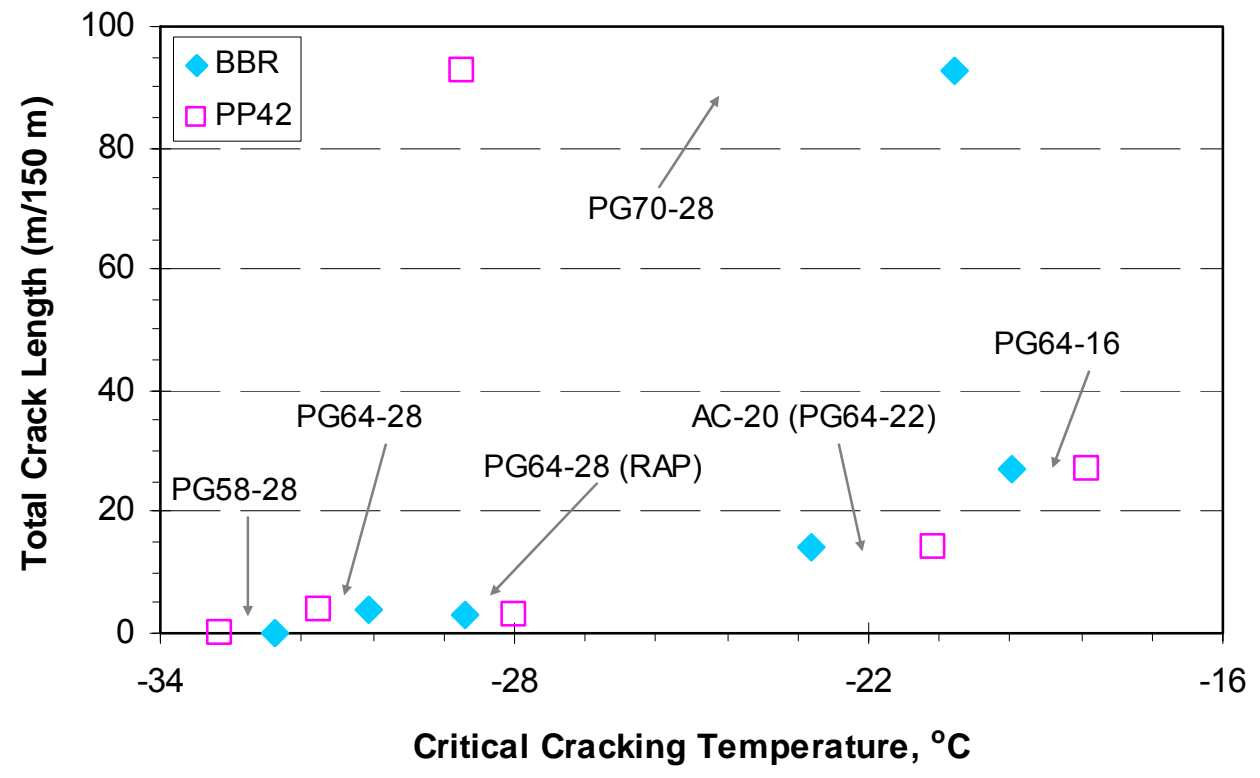

Figure 7.1 -- Total transverse crack length versus critical cracking temperature

Pavement critical temperature estimates obtained for IDT testing also indicated that thermal cracking may be expected in M-AC-20 and S-64-16. The high creep stiffness observed in these sections was also indicative of poor thermal cracking performance in these two sections. The low creep stiffness values of S-58-28 and S-70-28 indicated that these two sections would show better resistance to thermal cracking. While this was true in the case of S-58-28, S-70-28 showed the worst performance in terms of thermal cracking. The low temperature mixture properties of the other sections did not give clear cut results as to their thermal cracking resistance. This indicates that other factors, in addition to low temperature mixture properties, are governing the low temperature behavior to these mixtures.

These factors can be found from binder testing at low temperatures. BBR and DT test data from recovered binders indicate some degree of binder stiffening with time in some of the binders, most notably in S-70-28 and S-64-16. Figure 7.1 clearly shows an increase in the degree (severity) of cracking, in terms of total crack length, with increasing critical cracking temperatures of the binders obtained from BBR and PP42. Although S-64-28, S-58-28, R-15\% and S-70-28 had the same low temperature grade, the degree of binder stiffening observed in 
S-58-28 was insignificant compared with that observed in S-70-28. In spite of the binder stiffening observed in PG70-28, this binder retained its ductility at low temperatures due to the addition of the modifier in the binder. Hence, the BBR limiting criterion ( $m$-value) gave a warmer critical temperature than the PP42 criterion. BBR tests predicted cracking in S-70-28 and S-6416 and this prediction was confirmed by field observations.

\section{$\underline{7.2 \text { Load-Related (Longitudinal) Cracking }}$}

Longitudinal cracking observed in the field was also shown on the crack maps generated as a result of the distress surveys. This type of cracking is generally associated with load-related fatigue, poor pavement structure and/or mixture design. Since the test sections were laid out consecutively in the same stretch of the test pavement, it is logical to assume that all the sections were subjected to the same temperature and traffic loading conditions.

Table 7.2 shows the frequency of the longitudinal cracks occurring in the wheel path and the total crack length in each section at the end of 3.5 years. The Marshall section (M-AC-20) showed the best performance in terms of load-associated distress, while the SUPERPAVE mixture with PG64-16 (S-64-16) showed the worst performance. It would have been intuitively expected that S-70-28 with the modified binder would show little to no longitudinal cracking. Frequency sweep testing at the $T_{\text {eff(FC) }}$ indicated that $S-64-16$ and $R-15 \%$ had the highest stiffness and would therefore perform well in the field under traffic loads. Contrary to these expectations, S-70-28 and S-64-16 showed the worst performance among all the test sections. At the same time, $M-A C-20$, which had lower stiffness at $T_{\text {eff( }(F C)}$ in comparison with the other sections, showed no longitudinal cracking. Using the LTPP criteria shown in Table 4.1, S-58-28, R-15\%, S-70-28 and S-64-16 showed severe cracking and S-64-28 showed moderate amount of cracking. 
Table 7.2 -- Longitudinal cracking observed at the end of 3.5 years

\begin{tabular}{|c|c|c|c|c|c|c|c|}
\hline \multirow[t]{2}{*}{ Section ID } & \multicolumn{3}{|c|}{$\begin{array}{l}\text { Length of Cracks in the } \\
\text { Wheel Path }(\mathrm{m})\end{array}$} & \multicolumn{3}{|c|}{$\begin{array}{l}\text { Length of Cracks not in } \\
\text { the Wheel Path }(\mathrm{m})\end{array}$} & \multirow{2}{*}{$\begin{array}{l}\text { Total Crack } \\
\text { Length } \\
(\mathrm{m} / 150 \mathrm{~m})\end{array}$} \\
\hline & Low & Med & High & Low & Med & High & \\
\hline M-AC-20 & 0.0 & 0.0 & 0.0 & 0.0 & 0.0 & 0.0 & 0.0 \\
\hline S-64-28 & 0.0 & 0.0 & 0.0 & 27.5 & 61.0 & 0.0 & 88.5 \\
\hline S-58-28 & 0.0 & 0.0 & 0.0 & 14.0 & 138.5 & 0.0 & 152.5 \\
\hline R-15\% & 0.0 & 0.0 & 0.0 & 73.0 & 70.0 & 0.0 & 143.0 \\
\hline S-70-28 & 63.0 & 0.0 & 0.0 & 26.5 & 113.8 & 0.0 & 203.3 \\
\hline S-64-16 & 112.9 & 0.0 & 0.0 & 0.0 & 152.0 & 0.0 & 265.4 \\
\hline
\end{tabular}

\section{$\underline{7.3}$ Permanent Deformation (Rutting)}

The transverse profile of the pavement was measured at every $15 \mathrm{~m}$ along the length of each test section $(150 \mathrm{~m})$, at the end of 1.5 and 3.5 years. The average rut depth at every $305 \mathrm{~mm}$ interval (length of the footpad) along the $3.5 \mathrm{~m}$ of the lane width was calculated. These data are represented graphically in Figures 7.2 and 7.3. The rut depth in the right wheel path (RWP) was typically deeper than that observed in the left wheel path. In addition, some degree of "heaving" or "shoving" was observed in the left wheel paths of S-58-28, R-15\%, S-70-28 and S-64-16. It can also be seen that the point of maximum rut depth in the RWP showed a slight rightward shift (towards the shoulder) in most cases. These features are typically attributed to the cross-slope of the pavement, which causes the vehicles exert a downward and sideways force on the pavement surface. In addition, a slight lateral migration (wander) in the traffic pattern with time might also have occurred due to the increasing frequency of the patched core holes. Only the rut depths in the RWP were used here for making comparisons.

At the end of 1.5 years, S-64-28 and S-58-28 exhibited the maximum amount of rutting in the RWP, while S-70-28 and S-64-16 showed the least amount of rutting. At the end of 3.5 years, S-64-28 showed the highest rut depth, followed by S-58-28 and R-15\%. While a higher degree of rutting was expected in S-58-28 due to the softer binder grade (PG58-28), the higher degree of rutting observed in the control section (S-64-28) and R-154\% was not expected based on the performance grade of the binder. However, the percent air voids data obtained 


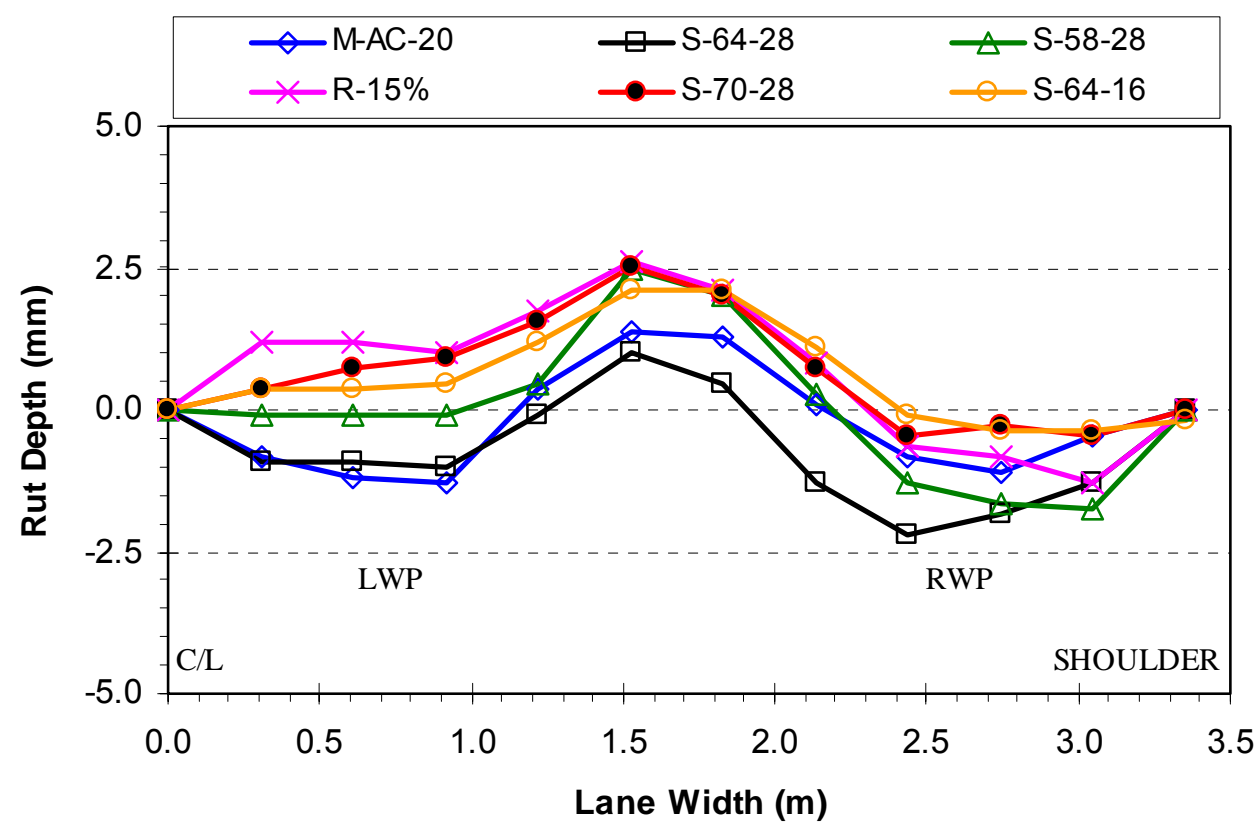

Figure 7.2 -- Average rut depth at the end of 1.5 years

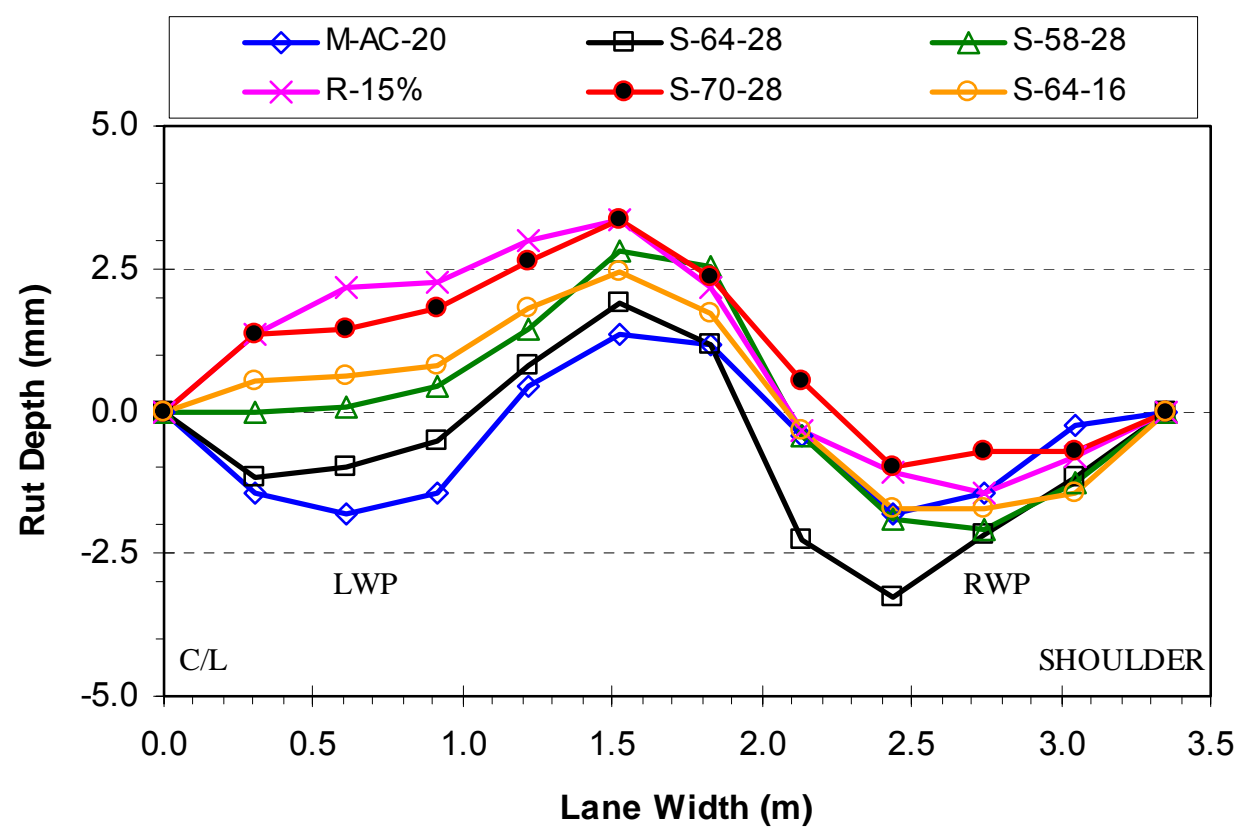

Figure 7.3 -- Average rut depth at the end of 3.5 years 
from field core samples indicated that the $\mathrm{P}_{\mathrm{a}}$ of S-64-28 fell below $3 \%$ at the end of one year ( $37 \%$ decrease in $\mathrm{P}_{\mathrm{a}}$ ). This was indicative of rutting problems in the section early-on during the life of the pavement. M-AC-20, S-70-28 and S-64-16 showed the least amount of rutting at the end of 3.5 years. The use of the SBS-modified binder in this section appears to have improved the rut resistance of this section.

The low modulus value and high slope value of S-58-28 mixtures obtained from frequency sweep testing were also indicative of high rutting and temperature susceptibility of this mixture. R-15\%, S-70-28 and S-64-16 mixtures, which had relatively high $\left|\mathrm{G}^{*}\right|$ showed lower rut depths in comparison with the other sections. All the mixtures were categorized as "good" based on the $\left|\mathrm{G}^{*}\right|$ at $40^{\circ} \mathrm{C}$, according to the Asphalt Institute criteria indicating that all the mixtures tested may be expected to show good rut resistance in the field.

The higher values of maximum shear deformation $\left(\delta_{\max }\right)$ experienced by S-58-28 mixtures also indicated that these mixtures were prone to rutting. Although this section had high percent resilience in the $\mathrm{SSCH}$ test, this parameter does not appear to be a good indicator its rutting behavior in the field, within the confines of this test conditions. This was also true in the case of S-64-28, which had higher percent resilience, but showed poor rutting performance in the field. Intermediate mixtures of M-AC-20 and S-64-28 and surface mixtures of M-AC-20 and S-64-16 also showed higher $\delta_{\max }$ in comparison with the other mixtures at $40.5^{\circ} \mathrm{C}$, but less than that observed in S-58-28.

All the mixtures performed fairly well in the RSCH tests, but S-58-28 showed significantly higher plastic strain $\left(\varepsilon_{\mathrm{p}}\right)$ compared with the other sections. This indicates that S-58-28 would show a higher amount of rutting, if any, in comparison with the other sections. S-64-28 and R-15\% had the same $\varepsilon_{\mathrm{p}}$ and were expected to show similar performance. But this was not found to be true in the field, due to low in-place air void content of S-64-28. S-70-28 had lowest rut depth as indicated by the low $\varepsilon_{\mathrm{p}}$ of these mixtures. Asphalt Institute criteria indicate that S-64-28, S-58-28 and R-15\% are move prone to rutting, compared with M-AC-20, S-70-28 and S-64-16. 


\subsection{Laboratory Distress Indicators versus Observed Field Performance}

Distress predictions obtained from the low and high temperature mixture and binder tests conducted in the laboratory (penetration, DSR, BBR, DT, IDT, FSCH, SSCH and $\mathrm{RSCH}$ ) were summarized and compared with observed field distress. Table 7.3 shows the summary of the predicted and observed distress based on low temperature testing (thermal cracking). Table 7.4 shows the summary of the predicted and observed distress based on high temperature testing (rutting and longitudinal cracking).

Of all the low temperature tests conducted in the laboratory, results obtained from binder tests appear to be good indicators of expected thermal cracking (low temperature) performance of the pavement under field conditions. Results from low temperature mixture testing gave mixed results. Conclusions drawn from creep stiffness and tensile strength results at $3 \% \mathrm{P}_{\mathrm{a}}$ level did not always agree with conclusions drawn from results at $7 \% \mathrm{P}_{\mathrm{a}}$ level. Therefore, trends shown in Table 7.3 apply either at the $3 \%$ or at the $7 \% \mathrm{P}_{\mathrm{a}}$ level. Similarly, the conclusions from the surface and the intermediate mixtures of a given section did not always coincide. Typically, the conclusions shown in Table 7.3 were drawn from surface mixtures since they are more critical than the intermediate mixtures. Thermal cracking was predicted in S-64-16 by most

of the tests and this was confirmed by field observation, which showed a high degree of cracking in comparison with the other test sections. While many tests also predicted cracking in M-AC-20 and S-70-28, the amount of cracking observed in S-70-28 was significantly higher than that observed in M-AC-20. Minimal to no thermal cracking was predicted in S-64-28, S-58-28 and R-15\%; which was validated by field observations.

All the high temperature tests conducted in the laboratory indicated that the overall rut resistance of the mixtures was high. Any rutting, if present, was expected to be only minimal. This was confirmed by field observations. S-58-28 was expected to show a higher degree of rutting by most of the tests conducted in comparison with the other test sections. This was confirmed by field observations as well, which also indicated that S-64-28 and R-15\% developed rut depths comparable to rut depths observed in S-64-28. Of all the high temperature 
Table 7.3 -- Low-temperature related distress predicted and observed

\begin{tabular}{|c|c|c|c|c|c|c|c|c|c|}
\hline Distress & & Test & Layer & $M-A C-20$ & S-64-28 & S-58-28 & R-15\% & S-70-28 & S-64-16 \\
\hline \multirow{10}{*}{$\begin{array}{c}\text { Low } \\
\text { Temperature } \\
\text { (Thermal) } \\
\text { Cracking }\end{array}$} & \multirow{4}{*}{ 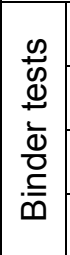 } & Penetration & Surface & + & & - & + & + & + \\
\hline & & BBR & Surface & - & & & & + & + \\
\hline & & DT & Surface & - & & & & & + \\
\hline & & PP42 & Surface & - & & & & & + \\
\hline & \multirow{6}{*}{ 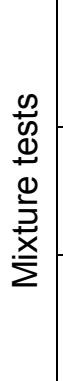 } & \multirow{2}{*}{$\begin{array}{c}\text { Creep } \\
\text { Stiffness }\end{array}$} & Surface & + & + & - & + & - & + \\
\hline & & & Intermediate & + & + & - & + & - & + \\
\hline & & \multirow{2}{*}{\begin{tabular}{|c|} 
Indirect \\
Tensile \\
Strength
\end{tabular}} & Surface & - & - & & - & + & + \\
\hline & & & Intermediate & - & - & + & + & + & - \\
\hline & & \multirow{2}{*}{\begin{tabular}{|c|} 
Pavement \\
Cracking \\
Temperature $^{*}$
\end{tabular}} & Surface & + & & & & & + \\
\hline & & & Intermediate & & & & & & + \\
\hline \multicolumn{4}{|c|}{ Transverse cracking observed in the field } & - & - & & - & + & + \\
\hline
\end{tabular}

* = Conclusions indicated do not apply at both $\mathrm{P}_{\mathrm{a}}$ levels;"+" = higher degree; "-" = lower degree 
Table 7.4 -- High-temperature related and load related distress predicted and observed

\begin{tabular}{|c|c|c|c|c|c|c|c|c|c|}
\hline Distress & & Test & Layer & $M-A C-20$ & S-64-28 & S-58-28 & R-15\% & S-70-28 & S-64-16 \\
\hline \multirow{7}{*}{$\begin{array}{l}\text { Permanent } \\
\text { Deformation } \\
\text { (Rutting) }\end{array}$} & $\infty$ & DSR & Surface & & & & & & \\
\hline & \multirow{6}{*}{ 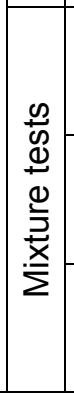 } & \multirow{2}{*}{$\begin{array}{c}\text { Frequency } \\
\text { Sweep } \\
\left(40.5^{\circ} \mathrm{C}\right)\end{array}$} & Surface & - & - & + & - & - & - \\
\hline & & & Intermediate & - & - & + & - & - & - \\
\hline & & \multirow{2}{*}{$\begin{array}{l}\text { Simple } \\
\text { Shear } \\
\left(40.5^{\circ} \mathrm{C}\right)\end{array}$} & Surface & + & - & + & - & - & + \\
\hline & & & Intermediate & + & + & + & - & - & - \\
\hline & & \multirow{2}{*}{$\begin{array}{l}\text { Repeated } \\
\text { Shear }\end{array}$} & Surface & - & + & + & + & - & - \\
\hline & & & Intermediate & + & + & + & - & - & - \\
\hline \multicolumn{4}{|c|}{ Rutting observed in the field } & - & + & + & + & - & - \\
\hline \multirow{4}{*}{$\begin{array}{l}\text { Fatigue } \\
\text { Cracking }\end{array}$} & \multirow{4}{*}{ 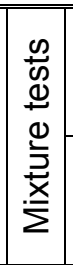 } & \multirow{2}{*}{$\begin{array}{c}\text { Frequency } \\
\text { Sweep } \\
\left(29.5^{\circ} \mathrm{C}\right) \\
\end{array}$} & Surface & + & - & + & - & + & - \\
\hline & & & Intermediate & - & - & + & - & + & - \\
\hline & & \multirow{2}{*}{$\begin{array}{c}\text { Simple } \\
\text { Shear } \\
\left(29.5^{\circ} \mathrm{C}\right) \\
\end{array}$} & Surface & + & & + & & & \\
\hline & & & Intermediate & + & + & + & & & \\
\hline \multicolumn{4}{|c|}{ Longitudinal cracking observed in the field } & & - & - & - & + & + \\
\hline
\end{tabular}

B = binder test; "+" = higher degree; "-" = lesser degree 
tests, repeated shear at constant height test appears to be a better (although not entirely accurate) indicator of rut susceptibility of the mixtures.

The results from frequency sweep and simple shear tests conducted at $\mathrm{T}_{\text {eff(FC) }}$ did not provide accurate predictions about the expected field performance of the mixtures. This was not surprising since the behavior of a pavement under fatigue loads is a complex phenomenon and depends on the pavement thickness, mixture stiffness and binder viscosity (4). Thinner pavements, pavements with low viscosity binders or with low stiffness mixtures are generally tested under constant strain mode. While thicker pavements, pavements with high viscosity binders or with high mixture stiffness are evaluated under constant stress mode. Marshall section did not exhibit any longitudinal cracking, while all the SUPERPAVE sections exhibited longitudinal cracking to varying degrees in the field. 
Table A1 -- Aggregate blend used in surface course of M-AC-20

\begin{tabular}{|c|c|c|c|c|c|c|c|c|c|}
\hline \multirow{3}{*}{$\begin{array}{l}\text { Sieve } \\
\text { No. }\end{array}$} & \multirow{3}{*}{$\begin{array}{l}\text { Size } \\
(\mathrm{mm})\end{array}$} & \multirow{2}{*}{\multicolumn{2}{|c|}{$\begin{array}{c}\text { \#11 Slag (24\%) } \\
\text { \% Passing }\end{array}$}} & \multirow{2}{*}{\multicolumn{2}{|c|}{$\begin{array}{c}\text { \#11 Dolomite (24\%) } \\
\text { \% Passing }\end{array}$}} & \multirow{2}{*}{\multicolumn{2}{|c|}{$\begin{array}{c}\text { \# } 24 \text { Natural Sand (52\%) } \\
\text { \% Passing }\end{array}$}} & \multirow{3}{*}{$\begin{array}{c}\text { \% Passing } \\
\text { in Total } \\
\text { Blend }\end{array}$} & \multirow{3}{*}{$\begin{array}{l}\text { Specification } \\
\text { Limit }\end{array}$} \\
\hline & & & & & & & & & \\
\hline & & In Stockpile & In Mix & In Stockpile & In Mix & In Stockpile & In Mix & & \\
\hline $1 / 2 "$ & 12.50 & 100.0 & 24.0 & 100.0 & 24.0 & 100.0 & 52.0 & 100.0 & 100 \\
\hline $3 / 8$ & 9.50 & 87.0 & 20.9 & 85.8 & 20.6 & 100.0 & 52.0 & 93.5 & $85-98$ \\
\hline 4 & 4.75 & 17.0 & 4.1 & 22.0 & 5.3 & 100.0 & 52.0 & 61.4 & $52-67$ \\
\hline 8 & 2.36 & 5.7 & 1.4 & 5.0 & 1.2 & 93.0 & 48.4 & 50.9 & $31-62$ \\
\hline 16 & 1.16 & 4.9 & 1.2 & 4.5 & 1.1 & 72.0 & 37.4 & 39.7 & $17-50$ \\
\hline 30 & 0.600 & 4.2 & 1.0 & 4.0 & 1.0 & 45.0 & 23.4 & 25.4 & $8-37$ \\
\hline 50 & 0.300 & 3.8 & 0.9 & 3.8 & 0.9 & 24.0 & 12.5 & 14.3 & $3-25$ \\
\hline 100 & 0.150 & 3.4 & 0.8 & 3.3 & 0.8 & 4.0 & 2.1 & 3.7 & $0-14$ \\
\hline 200 & 0.075 & 3.0 & 0.7 & 2.0 & 0.5 & 2.5 & 1.3 & 2.5 & $0-4$ \\
\hline
\end{tabular}

Table A2 -- Aggregate blend used in intermediate course of M-AC-20

\begin{tabular}{|c|c|c|c|c|c|c|c|c|c|}
\hline \multirow{3}{*}{$\begin{array}{l}\text { Sieve } \\
\text { No. }\end{array}$} & \multirow{3}{*}{$\begin{array}{l}\text { Size } \\
(\mathrm{mm})\end{array}$} & \multirow{2}{*}{\multicolumn{2}{|c|}{$\begin{array}{c}\text { \#8 Crushed Stone (60\%) } \\
\% \text { Passing }\end{array}$}} & \multirow{2}{*}{\multicolumn{2}{|c|}{$\begin{array}{c}\text { \#11 Crushed Stone (15\%) } \\
\text { \% Passing }\end{array}$}} & \multirow{2}{*}{\multicolumn{2}{|c|}{$\begin{array}{c}\text { \#24 Natural Sand (25\%) } \\
\text { \% Passing }\end{array}$}} & \multirow{3}{*}{$\begin{array}{c}\% \\
\text { Passing } \\
\text { in Total } \\
\text { Blend }\end{array}$} & \multirow{3}{*}{$\begin{array}{l}\text { Specification } \\
\text { Limit }\end{array}$} \\
\hline & & & & & & & & & \\
\hline & & In Stockpile & In Mix & In Stockpile & In Mix & In Stockpile & In Mix & & \\
\hline 1" & 25.00 & 100.0 & 60.0 & 100.0 & 15.0 & 100.0 & 25.0 & 100.0 & 100 \\
\hline $3 / 4 "$ & 19.00 & 88.0 & 52.8 & 100.0 & 15.0 & 100.0 & 25.0 & 92.8 & $80-98$ \\
\hline $1 / 2 "$ & 12.50 & 50.0 & 30.0 & 100.0 & 15.0 & 100.0 & 25.0 & 70.0 & $56-80$ \\
\hline 3/8" & 9.50 & 30.0 & 18.0 & 90.0 & 13.5 & 100.0 & 25.0 & 56.5 & $43-68$ \\
\hline 4 & 4.75 & 7.0 & 4.2 & 23.0 & 3.5 & 100.0 & 25.0 & 32.7 & $25-40$ \\
\hline 8 & 2.36 & 4.5 & 2.7 & 5.3 & 0.8 & 93.0 & 23.3 & 26.7 & $14-40$ \\
\hline 16 & 1.16 & 4.0 & 2.4 & 4.2 & 0.6 & 72.0 & 18.0 & 21.0 & $8-32$ \\
\hline 30 & 0.600 & 3.5 & 2.1 & 3.8 & 0.6 & 45.0 & 11.3 & 13.9 & $5-24$ \\
\hline 50 & 0.300 & 2.9 & 1.7 & 3.3 & 0.5 & 24.0 & 6.0 & 8.2 & $2-16$ \\
\hline 100 & 0.150 & 2.7 & 1.6 & 3.0 & 0.5 & 4.0 & 1.0 & 3.1 & $0-10$ \\
\hline 200 & 0.075 & 2.5 & 1.5 & 2.5 & 0.4 & 2.5 & 0.6 & 2.5 & $0-4$ \\
\hline
\end{tabular}


Table A3 -- Aggregate blend used in surface course of S-64-28, S-58-28, S-70-28 and S-64-16

\begin{tabular}{|c|c|c|c|c|c|c|c|c|c|c|c|}
\hline \multirow{3}{*}{$\begin{array}{c}\text { Sieve } \\
\text { No. }\end{array}$} & \multirow{3}{*}{$\begin{array}{l}\text { Size } \\
(\mathrm{mm})\end{array}$} & \multirow{2}{*}{\multicolumn{2}{|c|}{$\begin{array}{c}\begin{array}{c}\text { \#11 Slag } \\
(30 \%)\end{array} \\
\text { \% Passing }\end{array}$}} & \multirow{2}{*}{\multicolumn{2}{|c|}{$\begin{array}{c}\text { \#11 Dolomite } \\
(30 \%)\end{array}$}} & \multirow{2}{*}{\multicolumn{2}{|c|}{$\begin{array}{c}\text { \#24 Dolomite Sand } \\
(30 \%)\end{array}$}} & \multirow{2}{*}{\multicolumn{2}{|c|}{$\begin{array}{c}\begin{array}{c}\text { Ag Lime } \\
(10 \%)\end{array} \\
\% \text { Passing }\end{array}$}} & \multirow{3}{*}{$\begin{array}{c}\% \\
\text { Passing } \\
\text { in Total } \\
\text { Blend }\end{array}$} & \multirow{3}{*}{$\begin{array}{c}\text { Specification } \\
\text { Limit }\end{array}$} \\
\hline & & & & & & & & & & & \\
\hline & & $\begin{array}{c}\text { In } \\
\text { Stockpile }\end{array}$ & In Mix & $\begin{array}{c}\text { In } \\
\text { Stockpile }\end{array}$ & In Mix & $\begin{array}{c}\text { In } \\
\text { Stockpile }\end{array}$ & In Mix & $\begin{array}{c}\text { In } \\
\text { Stockpile }\end{array}$ & In Mix & & \\
\hline $1 / 2 "$ & 12.50 & 100.0 & 30.0 & 100.0 & 30.0 & 100.0 & 30.0 & 100.0 & 10.0 & 100.0 & 100.0 \\
\hline $3 / 8 "$ & 9.50 & 83.4 & 25.0 & 85.2 & 25.6 & 100.0 & 30.0 & 100.0 & 10.0 & 90.6 & $90.0-100.0$ \\
\hline 4 & 4.75 & 14.5 & 4.4 & 19.0 & 5.7 & 99.5 & 29.9 & 100.0 & 10.0 & 49.9 & \\
\hline 8 & 2.36 & 6.0 & 1.8 & 5.0 & 1.5 & 93.0 & 27.9 & 95.0 & 9.5 & 40.7 & $32.0-47.2$ \\
\hline 16 & 1.16 & 5.0 & 1.5 & 4.5 & 1.4 & 60.0 & 18.0 & 80.0 & 8.0 & 28.9 & $\leq 31.6$ \\
\hline 30 & 0.600 & 4.0 & 1.2 & 4.3 & 1.3 & 37.0 & 11.1 & 58.0 & 5.8 & 19.4 & $\leq 23.5$ \\
\hline 50 & 0.300 & 3.8 & 1.1 & 3.6 & 1.1 & 21.0 & 6.3 & 32.0 & 3.2 & 11.7 & $\leq 18.7$ \\
\hline 100 & 0.150 & 3.5 & 1.1 & 3.0 & 0.9 & 11.0 & 3.3 & 22.0 & 2.2 & 7.5 & \\
\hline 200 & 0.075 & 3.2 & 1.0 & 2.5 & 0.8 & 5.2 & 1.6 & 17.0 & 1.7 & 5.0 & $2.0-10.0$ \\
\hline
\end{tabular}

Table A4 -- Aggregate blend used in intermediate course of S-64-28, S-58-28, S-70-28 and S-64-16

\begin{tabular}{|c|c|c|c|c|c|c|c|c|c|c|c|}
\hline \multirow{3}{*}{$\begin{array}{c}\text { Sieve } \\
\text { No. }\end{array}$} & \multirow{3}{*}{$\begin{array}{l}\text { Size } \\
(\mathrm{mm})\end{array}$} & \multirow{2}{*}{\multicolumn{2}{|c|}{$\begin{array}{c}\text { \#8 Crushed Stone } \\
(45 \%)\end{array}$}} & \multirow{2}{*}{\multicolumn{2}{|c|}{$\begin{array}{c}\text { \#11 Crushed Stone } \\
(15 \%)\end{array}$}} & \multirow{2}{*}{\multicolumn{2}{|c|}{$\begin{array}{c}\text { \#24 Stone Sand } \\
(30 \%)\end{array}$}} & \multirow{2}{*}{\multicolumn{2}{|c|}{$\begin{array}{c}\text { \#12 Crushed Stone } \\
(10 \%)\end{array}$}} & \multirow{3}{*}{$\begin{array}{c}\% \\
\text { Passing } \\
\text { in Total } \\
\text { Blend }\end{array}$} & \multirow{3}{*}{$\begin{array}{c}\text { Specification } \\
\text { Limit }\end{array}$} \\
\hline & & & & & & & & & & & \\
\hline & & $\begin{array}{c}\text { In } \\
\text { Stockpile }\end{array}$ & In Mix & $\begin{array}{c}\text { In } \\
\text { Stockpile }\end{array}$ & In Mix & $\begin{array}{c}\text { In } \\
\text { Stockpile }\end{array}$ & In Mix & $\begin{array}{c}\text { In } \\
\text { Stockpile }\end{array}$ & In Mix & & \\
\hline $1 "$ & 25.00 & 100.0 & 45.0 & 100.0 & 15.0 & 100.0 & 30.0 & 100.0 & 10.0 & 100.0 & 100.0 \\
\hline $3 / 4 "$ & 19.00 & 88.0 & 39.6 & 100.0 & 15.0 & 100.0 & 30.0 & 100.0 & 10.0 & 94.6 & $90.0-100.0$ \\
\hline $1 / 2 "$ & 12.50 & 50.0 & 22.5 & 100.0 & 15.0 & 100.0 & 30.0 & 100.0 & 10.0 & 77.5 & \\
\hline $3 / 8 "$ & 9.50 & 30.0 & 13.5 & 90.0 & 13.5 & 100.0 & 30.0 & 100.0 & 10.0 & 67.0 & \\
\hline 4 & 4.75 & 7.0 & 3.2 & 23.1 & 3.5 & 99.5 & 29.9 & 70.0 & 7.0 & 43.5 & \\
\hline 8 & 2.36 & 4.5 & 2.0 & 7.0 & 1.1 & 82.0 & 24.6 & 12.0 & 1.2 & 28.9 & $23.0-34.6$ \\
\hline 16 & 1.16 & 4.0 & 1.8 & 4.5 & 0.7 & 44.0 & 13.2 & 8.0 & 0.8 & 16.5 & $\leq 22.3$ \\
\hline 30 & 0.600 & 3.5 & 1.6 & 4.3 & 0.6 & 24.0 & 7.2 & 6.0 & 0.6 & 10.0 & $\leq 16.7$ \\
\hline 50 & 0.300 & 2.9 & 1.3 & 3.6 & 0.5 & 14.0 & 4.2 & 5.0 & 0.5 & 6.5 & $\leq 13.7$ \\
\hline 100 & 0.150 & 2.7 & 1.2 & 3.0 & 0.5 & 9.0 & 2.7 & 3.8 & 0.4 & 4.7 & \\
\hline 200 & 0.075 & 2.5 & 1.1 & 2.5 & 0.4 & 5.0 & 1.5 & 2.6 & 0.3 & 3.3 & $2.0-8.0$ \\
\hline
\end{tabular}


Table A5 -- Aggregate blend used in surface course of R-15\%

\begin{tabular}{|c|c|c|c|c|c|c|c|c|c|c|c|}
\hline \multirow{3}{*}{$\begin{array}{c}\text { Sieve } \\
\text { No. }\end{array}$} & \multirow{3}{*}{$\begin{array}{l}\text { Size } \\
(\mathrm{mm})\end{array}$} & \multirow{2}{*}{\multicolumn{2}{|c|}{$\begin{array}{l}\begin{array}{c}\text { \#11 Slag } \\
(27 \%)\end{array} \\
\% \text { Passing }\end{array}$}} & \multirow{2}{*}{\multicolumn{2}{|c|}{$\begin{array}{c}\text { \#11 Dolomite } \\
\text { (27\%) } \\
\% \text { Passing }\end{array}$}} & \multirow{2}{*}{\multicolumn{2}{|c|}{$\begin{array}{c}\text { \#24 Dolomite Sand } \\
(31 \%)\end{array}$}} & \multirow{2}{*}{\multicolumn{2}{|c|}{$\begin{array}{c}\text { RAP } \\
\text { (15\%) } \\
\text { \% Passing } \\
\end{array}$}} & \multirow{3}{*}{$\begin{array}{c}\% \\
\text { Passing } \\
\text { in Total } \\
\text { Blend }\end{array}$} & \multirow{3}{*}{$\begin{array}{c}\text { Specification } \\
\text { Limit }\end{array}$} \\
\hline & & & & & & & & & & & \\
\hline & & $\begin{array}{c}\text { In } \\
\text { Stockpile }\end{array}$ & In Mix & $\begin{array}{c}\text { In } \\
\text { Stockpile }\end{array}$ & In Mix & $\begin{array}{c}\text { In } \\
\text { Stockpile }\end{array}$ & In Mix & $\begin{array}{c}\text { In } \\
\text { Stockpile }\end{array}$ & In Mix & & \\
\hline $1 / 2 "$ & 12.50 & 100.0 & 27.0 & 100.0 & 27.0 & 100.0 & 31.0 & 100.0 & 15.0 & 100.0 & 100.0 \\
\hline $3 / 8 "$ & 9.50 & 83.4 & 22.5 & 85.2 & 23.0 & 100.0 & 31.0 & 85.0 & 12.8 & 89.3 & $90.0-100.0$ \\
\hline 4 & 4.75 & 14.5 & 3.9 & 19.0 & 5.1 & 99.5 & 30.8 & 66.0 & 9.9 & 49.8 & \\
\hline 8 & 2.36 & 6.0 & 1.6 & 5.0 & 1.4 & 93.0 & 28.8 & 50.0 & 7.5 & 39.3 & $32.0-47.2$ \\
\hline 16 & 1.16 & 5.0 & 1.4 & 4.5 & 1.2 & 60.0 & 18.6 & 40.0 & 6.0 & 27.2 & $\leq 31.6$ \\
\hline 30 & 0.600 & 4.0 & 1.1 & 4.3 & 1.2 & 37.0 & 11.5 & 30.0 & 4.5 & 18.2 & $\leq 23.5$ \\
\hline 50 & 0.300 & 3.8 & 1.0 & 3.6 & 1.0 & 21.0 & 6.5 & 17.0 & 2.6 & 11.1 & $\leq 18.7$ \\
\hline 100 & 0.150 & 3.5 & 0.9 & 3.0 & 0.8 & 11.0 & 3.4 & 10.0 & 1.5 & 6.7 & \\
\hline 200 & 0.075 & 3.2 & 0.9 & 2.5 & 0.7 & 5.2 & 1.6 & 6.5 & 1.0 & 4.1 & $2.0-10.0$ \\
\hline
\end{tabular}

Table A6 -- Aggregate blend used in intermediate course of R-15\%

\begin{tabular}{|c|c|c|c|c|c|c|c|c|c|c|c|}
\hline \multirow{3}{*}{$\begin{array}{l}\text { Sieve } \\
\text { No. }\end{array}$} & \multirow{3}{*}{$\begin{array}{l}\text { Size } \\
(\mathrm{mm})\end{array}$} & \multirow{2}{*}{\multicolumn{2}{|c|}{$\begin{array}{c}\text { \#8 Crushed Stone } \\
(45 \%) \\
\% \text { Passing }\end{array}$}} & \multirow{2}{*}{\multicolumn{2}{|c|}{$\begin{array}{c}\text { \#11 Crushed Stone } \\
\text { (15\%) } \\
\text { \% Passing }\end{array}$}} & \multirow{2}{*}{\multicolumn{2}{|c|}{$\begin{array}{c}\text { \#24 Stone Sand } \\
(25 \%) \\
\text { \% Passing }\end{array}$}} & \multirow{2}{*}{\multicolumn{2}{|c|}{$\begin{array}{c}\text { RAP } \\
\text { (15\%) } \\
\% \text { Passing }\end{array}$}} & \multirow{3}{*}{$\begin{array}{c}\% \\
\text { Passing } \\
\text { in Total } \\
\text { Blend }\end{array}$} & \multirow{3}{*}{$\begin{array}{c}\text { Specification } \\
\text { Limit }\end{array}$} \\
\hline & & & & & & & & & & & \\
\hline & & $\begin{array}{c}\text { In } \\
\text { Stockpile }\end{array}$ & In Mix & $\begin{array}{c}\text { In } \\
\text { Stockpile }\end{array}$ & In Mix & $\begin{array}{c}\text { In } \\
\text { Stockpile }\end{array}$ & In Mix & $\begin{array}{c}\text { In } \\
\text { Stockpile }\end{array}$ & In Mix & & \\
\hline 1" & 25.00 & 100.0 & 45.0 & 100.0 & 15.0 & 100.0 & 25.0 & 100.0 & 15.0 & 100.0 & 100.0 \\
\hline $3 / 4 "$ & 19.00 & 88.0 & 39.6 & 100.0 & 15.0 & 100.0 & 25.0 & 84.0 & 12.6 & 92.2 & $90.0-100.0$ \\
\hline $1 / 2 "$ & 12.50 & 50.0 & 22.5 & 100.0 & 15.0 & 100.0 & 25.0 & 75.0 & 11.3 & 73.8 & \\
\hline $3 / 8 "$ & 9.50 & 30.0 & 13.5 & 90.0 & 13.5 & 100.0 & 25.0 & 69.0 & 10.4 & 62.4 & \\
\hline 4 & 4.75 & 7.0 & 3.2 & 23.1 & 3.5 & 99.5 & 24.9 & 48.0 & 7.2 & 38.7 & \\
\hline 8 & 2.36 & 4.5 & 2.0 & 7.0 & 1.1 & 82.0 & 20.5 & 40.0 & 6.0 & 29.6 & $23.0-34.6$ \\
\hline 16 & 1.16 & 4.0 & 1.8 & 4.5 & 0.7 & 44.0 & 11.0 & 25.0 & 3.8 & 17.2 & $\leq 22.3$ \\
\hline 30 & 0.600 & 3.5 & 1.6 & 4.3 & 0.6 & 24.0 & 6.0 & 15.0 & 2.3 & 10.5 & $\leq 16.7$ \\
\hline 50 & 0.300 & 2.9 & 1.3 & 3.6 & 0.5 & 14.0 & 3.5 & 9.0 & 1.4 & 6.7 & $\leq 13.7$ \\
\hline 100 & 0.150 & 2.7 & 1.2 & 3.0 & 0.5 & 9.0 & 2.3 & 6.5 & 1.0 & 4.9 & \\
\hline 200 & 0.075 & 2.5 & 1.1 & 2.5 & 0.4 & 5.0 & 1.3 & 5.0 & 0.8 & 3.5 & $2.0-8.0$ \\
\hline
\end{tabular}


Table B1 -- IRI data from the left and right wheel paths of all sections

\begin{tabular}{|c|c|c|c|c|c|}
\hline $\begin{array}{c}\text { Time } \\
\text { (years) }\end{array}$ & Left IRI & Right IRI & $\begin{array}{c}\text { Average } \\
\text { IRI }\end{array}$ & $\begin{array}{c}\text { Percent } \\
\text { Difference }\end{array}$ & $\begin{array}{c}\text { PSR } \\
\text { (Carey and Darter) }\end{array}$ \\
\hline \multicolumn{6}{|c|}{ M-AC-20 } \\
\hline 0.5 & 0.585 & 0.673 & 0.629 & 15.2 & 4.30 \\
\hline 1 & 0.581 & 0.655 & 0.618 & 12.9 & 4.31 \\
\hline 2 & 0.580 & 0.694 & 0.637 & 19.7 & 4.29 \\
\hline 3 & 0.564 & 0.645 & 0.605 & 14.4 & 4.32 \\
\hline 4 & 0.602 & 0.713 & 0.657 & 18.5 & 4.27 \\
\hline \multicolumn{6}{|c|}{ S-64-28 } \\
\hline 0.5 & 0.516 & 0.608 & 0.562 & 17.8 & 4.37 \\
\hline 1 & 0.522 & 0.632 & 0.577 & 21.1 & 4.35 \\
\hline 2 & 0.532 & 0.642 & 0.587 & 20.6 & 4.34 \\
\hline 3 & 0.531 & 0.646 & 0.589 & 21.6 & 4.34 \\
\hline 4 & 0.531 & 0.650 & 0.591 & 22.5 & 4.34 \\
\hline \multicolumn{6}{|c|}{ S-58-28 } \\
\hline 0.5 & 0.540 & 0.630 & 0.585 & 16.6 & 4.35 \\
\hline 1 & 0.567 & 0.653 & 0.610 & 15.2 & 4.32 \\
\hline 2 & 0.700 & 0.692 & 0.696 & -1.3 & 4.23 \\
\hline 3 & 0.676 & 0.666 & 0.671 & -1.6 & 4.26 \\
\hline 4 & 0.729 & 0.733 & 0.731 & 0.6 & 4.20 \\
\hline \multicolumn{6}{|c|}{ R-15\% } \\
\hline 0.5 & 0.483 & 0.614 & 0.548 & 27.1 & 4.38 \\
\hline 1 & 0.504 & 0.630 & 0.567 & 25.1 & 4.36 \\
\hline 2 & 0.543 & 0.651 & 0.597 & 19.7 & 4.33 \\
\hline 3 & 0.536 & 0.625 & 0.580 & 16.7 & 4.35 \\
\hline 4 & 0.542 & 0.703 & 0.623 & 29.6 & 4.31 \\
\hline \multicolumn{6}{|c|}{ S-70-28 } \\
\hline 0.5 & 0.503 & 0.702 & 0.602 & 39.5 & 4.33 \\
\hline 1 & 0.513 & 0.701 & 0.607 & 36.6 & 4.32 \\
\hline 2 & 0.523 & 0.732 & 0.627 & 39.9 & 4.30 \\
\hline 3 & 0.504 & 0.711 & 0.607 & 41.2 & 4.32 \\
\hline 4 & 0.536 & 0.775 & 0.655 & 44.5 & 4.27 \\
\hline \multicolumn{6}{|c|}{ S-64-16 } \\
\hline 0.5 & 0.501 & 0.659 & 0.580 & 31.4 & 4.35 \\
\hline 1 & 0.504 & 0.674 & 0.589 & 33.7 & 4.34 \\
\hline 2 & 0.531 & 0.697 & 0.614 & 31.3 & 4.31 \\
\hline 3 & 0.501 & 0.658 & 0.580 & 31.2 & 4.35 \\
\hline 4 & 0.581 & 0.785 & 0.683 & 35.1 & 4.24 \\
\hline
\end{tabular}


Table B2 -- Penetration values of the binders at all ages at $5^{\circ} \mathrm{C}$

\begin{tabular}{|c|c|c|c|c|c|c|c|}
\hline \multirow{2}{*}{ Binder } & \multicolumn{7}{|c|}{ Penetration Values (0.1 $\mathbf{~ m m})$} \\
\cline { 2 - 8 } & Tank & $\mathbf{2}$ wks. & $\mathbf{8}$ mo. & $\mathbf{1 2}$ mo. & $\mathbf{1 8} \mathbf{~ m o .}$ & $\mathbf{2 4}$ mo. & $\mathbf{4 8}$ mo. \\
\hline AC-20 & 26 & 13 & 15 & 8 & 6 & 6 & 6 \\
\hline PG64-28 & 36 & 27 & 21 & 19 & 18 & 16 & 16 \\
\hline PG58-28 & 53 & 36 & 34 & 25 & 21 & 20 & 21 \\
\hline $\begin{array}{c}\text { PG64-28 } \\
\text { wI RAP }\end{array}$ & 36 & 19 & 19 & 13 & 12 & 12 & 12 \\
\hline PG70-28 & 56 & 33 & 24 & 15 & 13 & 11 & 10 \\
\hline PG64-16 & 16 & 14 & 15 & 11 & 8 & 7 & 8 \\
\hline
\end{tabular}

Table B3 -- Penetration values of the binders at all ages at $25^{\circ} \mathrm{C}$

\begin{tabular}{|c|c|c|c|c|c|c|c|}
\hline \multirow{2}{*}{ Binder } & \multicolumn{7}{|c|}{ Penetration Values (0.1 $\mathbf{~ m m}$ ) } \\
\cline { 2 - 8 } & Tank & 2 wks. & $\mathbf{8}$ mo. & $\mathbf{1 2}$ mo. & $\mathbf{1 8}$ mo. & 24 mo. & $\mathbf{4 8}$ mo. \\
\hline AC-20 & 89 & 26 & 21 & 20 & 14 & 12 & 11 \\
\hline PG64-28 & 79 & 58 & 56 & 42 & 41 & 40 & 40 \\
\hline PG58-28 & 124 & 63 & 51 & 51 & 34 & 30 & 31 \\
\hline $\begin{array}{c}\text { PG64-28 } \\
\text { W/ RAP }\end{array}$ & 79 & 37 & 35 & 27 & 23 & 16 & 17 \\
\hline PG70-28 & 68 & 40 & 32 & 20 & 19 & 15 & 15 \\
\hline PG64-16 & 31 & 23 & 24 & 12 & 11 & 5 & 6 \\
\hline
\end{tabular}


Table B4 -- Absolute viscosity of the binders at all ages at $60^{\circ} \mathrm{C}$

\begin{tabular}{|c|c|c|c|c|c|c|c|}
\hline \multirow{2}{*}{ Binder } & \multicolumn{7}{|c|}{ Absolute Viscosity (cP) } \\
\cline { 2 - 8 } & Tank & 2 wks. & $\mathbf{8}$ mo. & $\mathbf{1 2}$ mo. & $\mathbf{1 8 ~ m o . ~}$ & $\mathbf{2 4}$ mo. & $\mathbf{4 8}$ mo. \\
\hline AC-20 & 15.7 & 43.3 & 46.1 & 55.8 & 78.1 & 96.0 & 120.5 \\
\hline PG64-28 & 11.2 & 16.6 & 18.0 & 19.5 & 20.1 & 20.6 & $10.9^{*}$ \\
\hline PG58-28 & 6.6 & 13.1 & 13.5 & 13.7 & $32.6^{\star}$ & 16.4 & 17.4 \\
\hline $\begin{array}{c}\text { PG64-28 } \\
\text { W/ RAP }\end{array}$ & 11.2 & 34.5 & 40.7 & 41.8 & 36.7 & 60.4 & 66.4 \\
\hline PG70-28 & 41.7 & 165.0 & 251.9 & $643.3^{\star}$ & $126.5^{\star}$ & 373.4 & 858.4 \\
\hline PG64-16 & 23.4 & 29.2 & 67.6 & 93.7 & 101.6 & 82.6 & 174.3 \\
\hline
\end{tabular}

Table B5 -- Rotational viscosity of the binders at all ages at $135^{\circ} \mathrm{C}$

\begin{tabular}{|c|c|c|c|c|c|c|c|}
\hline \multirow{2}{*}{ Binder } & \multicolumn{7}{|c|}{ Rotational Viscosity (Pa-s) } \\
\cline { 2 - 8 } & Tank & 2 wks. & $\mathbf{8}$ mo. & 12 mo. & 18 mo. & 24 mo. & 48 mo. \\
\hline AC-20 & 456.3 & 750.0 & 775.0 & 825.0 & 937.5 & 975.0 & 1037.5 \\
\hline PG64-28 & 408.3 & 500.0 & 512.5 & 525.0 & 550.0 & 562.5 & $381.3^{*}$ \\
\hline PG58-28 & 272.9 & 437.5 & 450.0 & 462.5 & 612.5 & 625.0 & 506.3 \\
\hline $\begin{array}{c}\text { PG64-28 } \\
\text { W/ RAP }\end{array}$ & 408.3 & 625.0 & 712.5 & 725.0 & 737.5 & 750.0 & 809.4 \\
\hline PG70-28 & 529.2 & 1104.3 & 1138.0 & $1650.0^{*}$ & $975.0^{*}$ & 1388.0 & 1971.5 \\
\hline PG64-16 & 425.0 & 462.5 & 750.0 & 800.0 & 875.0 & 900.0 & 987.5 \\
\hline
\end{tabular}


Table B6 -- Layer thickness data for M-AC-20, S-64-28 and S-58-28

\begin{tabular}{|c|c|c|c|c|c|c|}
\hline \multirow{2}{*}{$\begin{array}{c}\text { Age } \\
\text { (months) }\end{array}$} & \multicolumn{3}{|c|}{ M-AC-20 -- Surface } & \multicolumn{3}{|c|}{ M-AC-20 -- Intermediate } \\
\hline & Mean (in.) & Std. Dev. & C. V. & Mean (in.) & Std. Dev. & C. $\mathrm{V}$. \\
\hline 0.5 & 1.83 & 0.23 & 12.7 & 4.57 & 0.21 & 4.5 \\
\hline 8 & 1.81 & 0.34 & 18.8 & 4.75 & 0.28 & 5.8 \\
\hline 12 & 1.83 & 0.26 & 14.2 & 4.66 & 0.23 & 5.0 \\
\hline 18 & 1.82 & 0.28 & 15.7 & 4.73 & 0.37 & 7.9 \\
\hline 24 & 1.87 & 0.25 & 13.5 & 4.67 & 0.24 & 5.1 \\
\hline 48 & 1.89 & 0.22 & 11.7 & 4.63 & 0.34 & 7.4 \\
\hline \multirow{2}{*}{$\begin{array}{c}\text { Age } \\
\text { (months) }\end{array}$} & \multicolumn{3}{|c|}{ S-64-28 -- Surface } & \multicolumn{3}{|c|}{ S-64-28 -- Intermediate } \\
\hline & Mean (in.) & Std. Dev. & C. V. & Mean (in.) & Std. Dev. & C. V. \\
\hline 0.5 & 1.91 & 0.12 & 6.5 & 4.92 & 0.24 & 4.8 \\
\hline 8 & 1.91 & 0.19 & 9.9 & 4.97 & 0.10 & 2.0 \\
\hline 12 & 1.90 & 0.10 & 5.2 & 4.86 & 0.15 & 3.0 \\
\hline 18 & 1.81 & 0.11 & 5.8 & 4.80 & 0.24 & 5.1 \\
\hline 24 & 1.94 & 0.17 & 8.8 & 4.78 & 0.16 & 3.3 \\
\hline 48 & 1.87 & 0.13 & 7.2 & 4.81 & 0.13 & 2.8 \\
\hline \multirow{2}{*}{$\begin{array}{c}\text { Age } \\
\text { (months) }\end{array}$} & \multicolumn{3}{|c|}{ S-58-28 -- Surface } & \multicolumn{3}{|c|}{ S-58-58 -- Intermediate } \\
\hline & Mean (in.) & Std. Dev. & C. V. & Mean (in.) & Std. Dev. & C. V. \\
\hline 0.5 & 1.84 & 0.13 & 7.3 & 4.35 & 0.31 & 7.2 \\
\hline 8 & 1.91 & 0.15 & 7.9 & 4.54 & 0.33 & 7.4 \\
\hline 12 & 1.84 & 0.11 & 6.2 & 4.55 & 0.24 & 5.4 \\
\hline 18 & 1.72 & 0.14 & 8.2 & 4.64 & 0.22 & 4.8 \\
\hline 24 & 1.84 & 0.15 & 8.2 & 4.42 & 0.33 & 7.5 \\
\hline 48 & 1.80 & 0.16 & 8.7 & 4.39 & 0.25 & 5.6 \\
\hline
\end{tabular}


Table B7 -- Layer thickness data for R-15\%, S-70-28 and S-64-16

\begin{tabular}{|c|c|c|c|c|c|c|}
\hline \multirow{2}{*}{$\begin{array}{c}\text { Age } \\
\text { (months) }\end{array}$} & \multicolumn{3}{|c|}{ R-15\% -- Surface } & \multicolumn{3}{|c|}{ R-15\% -- Intermediate } \\
\hline & Mean (in.) & Std. Dev. & C. V. & Mean (in.) & Std. Dev. & C. $\mathrm{V}$. \\
\hline 0.5 & 1.86 & 0.22 & 11.8 & 4.72 & 0.17 & 3.7 \\
\hline 8 & 1.80 & 0.16 & 8.8 & 4.81 & 0.18 & 3.6 \\
\hline 12 & 1.83 & 0.18 & 9.8 & 4.73 & 0.12 & 2.6 \\
\hline 18 & 1.79 & 0.19 & 10.6 & 4.79 & 0.18 & 3.8 \\
\hline 24 & 1.83 & 0.25 & 13.7 & 4.72 & 0.14 & 3.0 \\
\hline 48 & 1.84 & 0.20 & 11.0 & 4.66 & 0.19 & 4.0 \\
\hline \multirow{2}{*}{$\begin{array}{c}\text { Age } \\
\text { (months) }\end{array}$} & \multicolumn{3}{|c|}{ S-70-28 -- Surface } & \multicolumn{3}{|c|}{ S-70-28 -- Intermediate } \\
\hline & Mean (in.) & Std. Dev. & C. V. & Mean (in.) & Std. Dev. & C. $\mathrm{V}$. \\
\hline 0.5 & 1.80 & 0.13 & 7.4 & 4.63 & 0.26 & 5.5 \\
\hline 8 & 1.68 & 0.18 & 10.7 & 4.85 & 0.16 & 3.3 \\
\hline 12 & 1.75 & 0.17 & 9.5 & 4.77 & 0.23 & 4.8 \\
\hline 18 & 1.75 & 0.15 & 8.7 & 4.68 & 0.10 & 2.2 \\
\hline 24 & 1.70 & 0.15 & 9.1 & 4.73 & 0.10 & 2.1 \\
\hline 48 & 1.73 & 0.17 & 9.9 & 4.53 & 0.13 & 2.8 \\
\hline \multirow{2}{*}{$\begin{array}{c}\text { Age } \\
\text { (months) }\end{array}$} & \multicolumn{3}{|c|}{ S-64-16 -- Surface } & \multicolumn{3}{|c|}{ S-64-16 -- Intermediate } \\
\hline & Mean (in.) & Std. Dev. & C. V. & Mean (in.) & Std. Dev. & C. $\mathrm{V}$. \\
\hline 0.5 & 1.72 & 0.14 & 8.4 & 4.79 & 0.20 & 4.2 \\
\hline 8 & 1.70 & 0.16 & 9.5 & 4.93 & 0.15 & 3.1 \\
\hline 12 & 1.75 & 0.20 & 11.5 & 4.91 & 0.93 & 19.0 \\
\hline 18 & 1.72 & 0.18 & 10.3 & 4.75 & 0.12 & 2.6 \\
\hline 24 & 1.69 & 0.16 & 9.5 & 4.88 & 0.27 & 5.5 \\
\hline 48 & 1.73 & 0.14 & 8.3 & 4.72 & 0.28 & 6.0 \\
\hline
\end{tabular}


Table B8 -- Air void data for M-AC-20, S-64-28 and S-58-28

\begin{tabular}{|c|c|c|c|c|c|c|}
\hline \multirow{2}{*}{$\begin{array}{c}\text { Age } \\
\text { (months) }\end{array}$} & \multicolumn{3}{|c|}{ M-AC-20 -- Surface } & \multicolumn{3}{|c|}{ M-AC-20 -- Intermediate } \\
\hline & Mean (\%) & Std. Dev. & C. V. & Mean (\%) & Std. Dev. & C. V. \\
\hline 0.5 & 7.7 & 0.3 & 4.4 & 4.7 & 1.1 & 22.6 \\
\hline 8 & 7.2 & 0.2 & 3.1 & 4.8 & 0.3 & 7.3 \\
\hline 12 & 6.7 & 0.2 & 2.3 & 4.6 & 0.7 & 16.3 \\
\hline 18 & 6.9 & 0.3 & 4.9 & 4.3 & 0.4 & 9.9 \\
\hline 24 & 6.8 & 0.2 & 2.3 & 4.4 & 0.3 & 6.1 \\
\hline 48 & 6.3 & 0.2 & 3.9 & 3.9 & 0.5 & 11.9 \\
\hline \multirow{2}{*}{$\begin{array}{c}\text { Age } \\
\text { (months) }\end{array}$} & \multicolumn{3}{|c|}{ S-64-28 -- Surface } & \multicolumn{3}{|c|}{ S-64-28 -- Intermediate } \\
\hline & Mean (\%) & Std. Dev. & C. V. & Mean (\%) & Std. Dev. & C. V. \\
\hline 0.5 & 4.3 & 0.6 & 12.9 & 3.8 & 0.7 & 18.6 \\
\hline 8 & 3.5 & 1.1 & 30.5 & 3.4 & 0.6 & 17.5 \\
\hline 12 & 2.7 & 0.9 & 32.6 & 3.3 & 0.7 & 21.0 \\
\hline 18 & 3.2 & 0.6 & 17.8 & 3.5 & 0.7 & 20.8 \\
\hline 24 & 2.5 & 0.4 & 16.1 & 3.2 & 0.7 & 20.3 \\
\hline 48 & 2.0 & 0.4 & 21.7 & 2.7 & 0.5 & 20.0 \\
\hline \multirow{2}{*}{$\begin{array}{c}\text { Age } \\
\text { (months) }\end{array}$} & \multicolumn{3}{|c|}{ S-58-28 -- Surface } & \multicolumn{3}{|c|}{ S-58-58 -- Intermediate } \\
\hline & Mean (\%) & Std. Dev. & C. V. & Mean (\%) & Std. Dev. & C. V. \\
\hline 0.5 & 6.5 & 0.7 & 10.4 & 3.8 & 0.7 & 18.5 \\
\hline 8 & 5.5 & 0.6 & 10.4 & 3.3 & 0.9 & 26.6 \\
\hline 12 & 4.8 & 0.5 & 10.7 & 3.2 & 1.1 & 34.8 \\
\hline 18 & 5.2 & 0.4 & 8.2 & 3.6 & 0.9 & 23.6 \\
\hline 24 & 4.5 & 0.4 & 8.8 & 3.2 & 1.0 & 30.5 \\
\hline 48 & 4.0 & 0.6 & 15.1 & 3.1 & 0.7 & 21.1 \\
\hline
\end{tabular}


Table B9 -- Air void data for R-15\%, S-70-28 and S-64-16

\begin{tabular}{|c|c|c|c|c|c|c|}
\hline \multirow{2}{*}{$\begin{array}{c}\text { Age } \\
\text { (months) }\end{array}$} & \multicolumn{3}{|c|}{ R-15\% -- Surface } & \multicolumn{3}{|c|}{ R-15\% -- Intermediate } \\
\hline & Mean (\%) & Std. Dev. & C. V. & Mean (\%) & Std. Dev. & C. V. \\
\hline 0.5 & 7.0 & 0.4 & 5.3 & 4.5 & 0.9 & 20.2 \\
\hline 8 & 6.9 & 0.5 & 7.6 & 4.1 & 0.2 & 5.4 \\
\hline 12 & 6.5 & 0.6 & 9.1 & 4.2 & 0.6 & 14.1 \\
\hline 18 & 6.0 & 0.8 & 13.7 & 4.4 & 0.8 & 17.3 \\
\hline 24 & 5.9 & 0.7 & 11.8 & 4.2 & 0.5 & 11.1 \\
\hline 48 & 5.7 & 0.5 & 9.5 & 4.0 & 0.6 & 14.0 \\
\hline \multirow{2}{*}{$\begin{array}{c}\text { Age } \\
\text { (months) }\end{array}$} & \multicolumn{3}{|c|}{ S-70-28 -- Surface } & \multicolumn{3}{|c|}{ S-70-28 -- Intermediate } \\
\hline & Mean (\%) & Std. Dev. & C. V. & Mean (\%) & Std. Dev. & C. V. \\
\hline 0.5 & 7.9 & 1.0 & 12.1 & 5.7 & 1.1 & 18.9 \\
\hline 8 & 6.7 & 0.5 & 7.0 & 4.9 & 0.5 & 9.4 \\
\hline 12 & 6.5 & 0.4 & 6.3 & 4.5 & 0.3 & 6.6 \\
\hline 18 & 6.1 & 0.7 & 11.7 & 4.4 & 1.3 & 29.6 \\
\hline 24 & 6.4 & 0.6 & 9.8 & 4.6 & 0.2 & 4.2 \\
\hline 48 & 5.5 & 0.6 & 10.8 & 4.1 & 0.2 & 6.1 \\
\hline \multirow{2}{*}{$\begin{array}{c}\text { Age } \\
\text { (months) }\end{array}$} & \multicolumn{3}{|c|}{ S-64-16 -- Surface } & \multicolumn{3}{|c|}{ S-64-16 -- Intermediate } \\
\hline & Mean (\%) & Std. Dev. & C. V. & Mean (\%) & Std. Dev. & C. V. \\
\hline 0.5 & 9.0 & 0.5 & 5.8 & 6.7 & 0.4 & 6.2 \\
\hline 8 & 8.0 & 0.4 & 5.1 & 6.2 & 0.5 & 7.4 \\
\hline 12 & 7.8 & 0.7 & 8.8 & 5.9 & 0.5 & 7.8 \\
\hline 18 & 7.7 & 0.4 & 4.9 & 5.7 & 0.8 & 14.1 \\
\hline 24 & 7.5 & 0.3 & 3.6 & 5.7 & 0.4 & 7.8 \\
\hline 48 & 7.0 & 0.3 & 4.7 & 5.5 & 0.3 & 5.0 \\
\hline
\end{tabular}


Table B10 -- Binder content data for M-AC-20, S-64-28 and S-58-28

\begin{tabular}{|c|c|c|c|c|c|c|}
\hline \multirow{2}{*}{$\begin{array}{c}\text { Age } \\
\text { (months) }\end{array}$} & \multicolumn{3}{|c|}{ M-AC-20 -- Surface } & \multicolumn{3}{|c|}{ M-AC-20 -- Intermediate } \\
\hline & Mean (\%) & Std. Dev. & C. V. & Mean (\%) & Std. Dev. & C. $\mathrm{V}$. \\
\hline 0.5 & 5.6 & 0.1 & 2.4 & 4.4 & 0.1 & 2.7 \\
\hline 8 & 5.8 & 0.2 & 3.9 & 4.3 & 0.3 & 5.8 \\
\hline 12 & 5.5 & 0.2 & 3.9 & 4.4 & 0.3 & 6.6 \\
\hline 18 & 6.1 & 0.1 & 1.8 & 4.3 & 0.1 & 3.0 \\
\hline 24 & 5.5 & 0.1 & 2.7 & 4.5 & 0.3 & 5.6 \\
\hline 48 & 5.8 & 0.1 & 1.8 & 4.4 & 0.2 & 3.5 \\
\hline \multirow{2}{*}{$\begin{array}{c}\text { Age } \\
\text { (months) }\end{array}$} & \multicolumn{3}{|c|}{ S-64-28 -- Surface } & \multicolumn{3}{|c|}{ S-64-28 -- Intermediate } \\
\hline & Mean (\%) & Std. Dev. & C. V. & Mean (\%) & Std. Dev. & C. V. \\
\hline 0.5 & 6.6 & 0.2 & 2.9 & 5.2 & 0.3 & 5.3 \\
\hline 8 & 6.7 & 0.1 & 1.7 & 5.1 & 0.2 & 3.9 \\
\hline 12 & 6.6 & 0.1 & 2.1 & 5.0 & 0.2 & 4.9 \\
\hline 18 & 6.6 & 0.2 & 3.5 & 5.3 & 0.2 & 3.9 \\
\hline 24 & 6.4 & 0.3 & 4.5 & 5.3 & 0.2 & 2.9 \\
\hline 48 & 6.5 & 0.1 & 1.6 & 5.3 & 0.2 & 4.2 \\
\hline \multirow{2}{*}{$\begin{array}{c}\text { Age } \\
\text { (months) }\end{array}$} & \multicolumn{3}{|c|}{ S-58-28 -- Surface } & \multicolumn{3}{|c|}{ S-58-58 -- Intermediate } \\
\hline & Mean (\%) & Std. Dev. & C. V. & Mean (\%) & Std. Dev. & C. V. \\
\hline 0.5 & 6.2 & 0.2 & 2.6 & 5.1 & 0.2 & 3.6 \\
\hline 8 & 6.5 & 0.3 & 4.1 & 5.2 & 0.2 & 3.8 \\
\hline 12 & 6.7 & 0.2 & 2.4 & 5.4 & 0.3 & 4.9 \\
\hline 18 & 6.5 & 0.2 & 2.7 & 5.1 & 0.2 & 3.8 \\
\hline 24 & 6.6 & 0.2 & 3.1 & 5.4 & 0.1 & 2.8 \\
\hline 48 & 6.4 & 0.1 & 2.3 & 5.0 & 0.2 & 4.7 \\
\hline
\end{tabular}


Table B11 -- Binder content data for R-15\%, S-70-28 and S-64-16

\begin{tabular}{|c|c|c|c|c|c|c|}
\hline \multirow{2}{*}{$\begin{array}{c}\text { Age } \\
\text { (months) }\end{array}$} & \multicolumn{3}{|c|}{ R-15\% -- Surface } & \multicolumn{3}{|c|}{ R-15\% -- Intermediate } \\
\hline & Mean (\%) & Std. Dev. & C. V. & Mean (\%) & Std. Dev. & C. V. \\
\hline 0.5 & 6.2 & 0.2 & 3.2 & 4.5 & 0.4 & 8.6 \\
\hline 8 & 6.5 & 0.1 & 2.1 & 4.5 & 0.2 & 5.0 \\
\hline 12 & 6.5 & 0.2 & 2.5 & 4.6 & 0.2 & 5.2 \\
\hline 18 & 6.7 & 0.2 & 3.0 & 4.7 & 0.2 & 4.3 \\
\hline 24 & 6.4 & 0.2 & 2.6 & 4.4 & 0.1 & 3.0 \\
\hline 48 & 6.3 & 0.2 & 2.7 & 4.8 & 0.2 & 4.2 \\
\hline \multirow{2}{*}{$\begin{array}{c}\text { Age } \\
\text { (months) }\end{array}$} & \multicolumn{3}{|c|}{ S-70-28 -- Surface } & \multicolumn{3}{|c|}{ S-70-28 -- Intermediate } \\
\hline & Mean (\%) & Std. Dev. & C. V. & Mean (\%) & Std. Dev. & C. V. \\
\hline 0.5 & 6.8 & 0.3 & 4.2 & 4.6 & 0.2 & 4.6 \\
\hline 8 & 6.8 & 0.4 & 5.3 & 4.8 & 0.3 & 5.3 \\
\hline 12 & 6.4 & 0.2 & 3.3 & 4.8 & 0.2 & 5.2 \\
\hline 18 & 6.4 & 0.2 & 3.5 & 4.9 & 0.2 & 4.0 \\
\hline 24 & 6.4 & 0.2 & 3.0 & 5.0 & 0.1 & 2.8 \\
\hline 48 & 6.3 & 0.1 & 2.2 & 4.8 & 0.1 & 2.2 \\
\hline \multirow{2}{*}{$\begin{array}{c}\text { Age } \\
\text { (months) }\end{array}$} & \multicolumn{3}{|c|}{ S-64-16 -- Surface } & \multicolumn{3}{|c|}{ S-64-16 -- Intermediate } \\
\hline & Mean (\%) & Std. Dev. & C. V. & Mean (\%) & Std. Dev. & C. V. \\
\hline 0.5 & 6.6 & 0.1 & 2.2 & 4.7 & 0.2 & 3.4 \\
\hline 8 & 6.6 & 0.2 & 3.7 & 4.8 & 0.2 & 4.1 \\
\hline 12 & 6.6 & 0.3 & 4.2 & 4.8 & 0.2 & 4.9 \\
\hline 18 & 6.5 & 0.3 & 4.0 & 4.8 & 0.3 & 7.0 \\
\hline 24 & 6.5 & 0.2 & 3.7 & 5.2 & 0.2 & 4.0 \\
\hline 48 & 6.4 & 0.2 & 2.6 & 4.8 & 0.2 & 3.3 \\
\hline
\end{tabular}


Table B12 -- Frequency sweep test data for the surface mixtures at $29.5^{\circ} \mathrm{C}$

\begin{tabular}{|c|r|r|r|r|r|r||}
\hline \multirow{2}{*}{ Replicate } & M-AC-20 & S-64-28 & \multicolumn{1}{|c|}{ S-58-28 } & \multicolumn{1}{|c|}{ R-15\% } & S-70-28 & S-64-16 \\
\cline { 2 - 7 } & \multicolumn{6}{|c|}{ Complex Shear Modulus at 10 Hz, |G*| psi } \\
\hline $\mathbf{1}$ & 237594 & 303675 & 193016 & 500831 & 309165 & 433627 \\
\hline $\mathbf{2}$ & 267216 & 385280 & 188618 & 457724 & 301269 & 485066 \\
\hline $\mathbf{3}$ & $190029^{\star}$ & $474475^{\star}$ & 192650 & 499315 & 301125 & 374383 \\
\hline $\mathbf{4}$ & 261114 & 374954 & 206926 & 469311 & 284715 & 471388 \\
\hline $\mathbf{5}$ & 307969 & 385104 & 172878 & 523419 & 303737 & 452799 \\
\hline Mean & $\mathbf{2 6 8 4 7 3}$ & $\mathbf{3 6 2 2 5 3}$ & $\mathbf{1 9 0 8 1 8}$ & $\mathbf{4 9 0 1 2 0}$ & $\mathbf{3 0 0 0 0 2}$ & $\mathbf{4 4 3 4 5 3}$ \\
\hline Std. Dev. & $\mathbf{2 9 2 6 4}$ & $\mathbf{3 9 3 4 9}$ & $\mathbf{1 2 1 9 0}$ & $\mathbf{2 6 4 1 3}$ & $\mathbf{9 1 4 4}$ & $\mathbf{4 3 2 0 5}$ \\
\hline C. of Var. & $\mathbf{1 0 . 9}$ & $\mathbf{1 0 . 9}$ & $\mathbf{6 . 4}$ & $\mathbf{5 . 4}$ & $\mathbf{3 . 0}$ & $\mathbf{9 . 7}$ \\
\hline \hline
\end{tabular}

* indicates outliers

Table B13 -- Frequency sweep test data for the surface mixtures at $40.5^{\circ} \mathrm{C}$

\begin{tabular}{|c|r|r|r|r|r|r|}
\hline \multirow{2}{*}{ Replicate } & \multicolumn{7}{|c|}{ M-AC-20 } & \multicolumn{6}{|c|}{ S-64-28 } & \multicolumn{1}{|c|}{ S-58-28 } & \multicolumn{1}{c|}{ R-15\% } & S-70-28 & S-64-16 \\
\cline { 2 - 7 } & \multicolumn{6}{|c|}{ Complex Shear Modulus at 10 Hz, |G*| psi } \\
\hline $\mathbf{1}$ & 158601 & 236266 & 58658 & 305350 & 156713 & 252548 \\
\hline $\mathbf{2}$ & 126436 & 271812 & 46848 & 346474 & 134933 & 214847 \\
\hline $\mathbf{3}$ & 122945 & 300594 & 63663 & 321345 & 131553 & 207663 \\
\hline $\mathbf{4}$ & 157226 & 289388 & 56045 & 284319 & 171135 & 200602 \\
\hline $\mathbf{5}$ & 174353 & 277905 & 49969 & 338990 & 171885 & 223291 \\
\hline Mean & $\mathbf{1 4 7 9 1 2}$ & $\mathbf{2 7 5 1 9 3}$ & $\mathbf{5 5 0 3 7}$ & $\mathbf{3 1 9 2 9 6}$ & $\mathbf{1 5 3 2 4 4}$ & $\mathbf{2 1 9 7 9 0}$ \\
\hline Std. Dev. & $\mathbf{2 2 2 7 5}$ & $\mathbf{2 4 3 9 7}$ & $\mathbf{6 7 3 2}$ & $\mathbf{2 5 2 4 2}$ & $\mathbf{1 9 2 7 0}$ & $\mathbf{2 0 1 5 6}$ \\
\hline C. of Var. & $\mathbf{1 5 . 1}$ & $\mathbf{8 . 9}$ & $\mathbf{1 2 . 2}$ & $\mathbf{7 . 9}$ & $\mathbf{1 2 . 6}$ & $\mathbf{9 . 2}$ \\
\hline \hline
\end{tabular}


Table B14 -- Frequency sweep test data for the intermediate mixtures at $29.5^{\circ} \mathrm{C}$

\begin{tabular}{|c|r|r|r|r|r|r||}
\hline \multirow{2}{*}{ Replicate } & M-AC-20 & S-64-28 & \multicolumn{1}{|c|}{ S-58-28 } & \multicolumn{1}{|c|}{ R-15\% } & S-70-28 & S-64-16 \\
\cline { 2 - 7 } & \multicolumn{6}{|c|}{ Complex Shear Modulus at 10 Hz, |G*| psi } \\
\hline $\mathbf{1}$ & 199594 & 160497 & 169497 & $538693^{*}$ & 234209 & 415652 \\
\hline $\mathbf{2}$ & 207811 & 161226 & 189782 & 321175 & 240930 & 431603 \\
\hline $\mathbf{3}$ & 185584 & 157898 & 193808 & 367116 & 262392 & 420019 \\
\hline $\mathbf{4}$ & 169945 & 140870 & 185165 & 324969 & 235678 & 425314 \\
\hline $\mathbf{5}$ & \multicolumn{1}{|c|}{207086} & 153129 & 204195 & 347225 & 232405 & 372179 \\
\hline Mean & $\mathbf{1 9 4 0 0 4}$ & $\mathbf{1 5 4 7 2 4}$ & $\mathbf{1 8 8 4 8 9}$ & $\mathbf{3 4 0 1 2 1}$ & $\mathbf{2 4 1 1 2 3}$ & $\mathbf{4 1 2 9 5 3}$ \\
\hline Std. Dev. & $\mathbf{1 6 1 4 6}$ & $\mathbf{8 3 6 9}$ & $\mathbf{1 2 7 3 2}$ & $\mathbf{2 1 3 5 2}$ & $\mathbf{1 2 3 0 7}$ & $\mathbf{2 3 5 6 0}$ \\
\hline C. of Var. & $\mathbf{8 . 3}$ & $\mathbf{5 . 4}$ & $\mathbf{6 . 8}$ & $\mathbf{6 . 3}$ & $\mathbf{5 . 1}$ & $\mathbf{5 . 7}$ \\
\hline \hline
\end{tabular}

* indicates outliers

Table B15 -- Frequency sweep test data for the intermediate mixtures at $40.5^{\circ} \mathrm{C}$

\begin{tabular}{|c|r|r|r|r|r|r|r|}
\hline \multirow{2}{*}{ Replicate } & M-AC-20 & \multicolumn{7}{|c|}{ S-64-28 } & \multicolumn{2}{|c|}{ S-58-28 } & \multicolumn{2}{c|}{ R-15\% } & \multicolumn{1}{c|}{ S-70-28 } & S-64-16 \\
\cline { 2 - 7 } & \multicolumn{6}{|c|}{ Complex Shear Modulus at 10 Hz, |G*| psi } \\
\hline $\mathbf{1}$ & 132727 & 74672 & 34916 & 122044 & 104113 & 207986 \\
\hline $\mathbf{2}$ & 119617 & 69232 & 46042 & 149631 & 109597 & 203996 \\
\hline $\mathbf{3}$ & 107427 & 75469 & 47967 & 105140 & 94126 & 170759 \\
\hline $\mathbf{4}$ & 88884 & 66874 & 49303 & 128698 & 118620 & 192527 \\
\hline $\mathbf{5}$ & 109914 & 77634 & 42537 & 123295 & 89372 & 190372 \\
\hline Mean & $\mathbf{1 1 1 7 1 4}$ & $\mathbf{7 2 7 7 6}$ & $\mathbf{4 4 1 5 3}$ & $\mathbf{1 2 5 7 6 2}$ & $\mathbf{1 0 3 1 6 6}$ & $\mathbf{1 9 3 1 2 8}$ \\
\hline Std. Dev. & $\mathbf{1 6 1 7 7}$ & $\mathbf{4 5 2 3}$ & $\mathbf{5 7 5 7}$ & $\mathbf{1 5 9 9 6}$ & $\mathbf{1 1 7 5 9}$ & $\mathbf{1 4 5 5 3}$ \\
\hline C. of Var. & $\mathbf{1 4 . 5}$ & $\mathbf{6 . 2}$ & $\mathbf{1 3 . 0}$ & $\mathbf{1 2 . 7}$ & $\mathbf{1 1 . 4}$ & $\mathbf{7 . 5}$ \\
\hline \hline
\end{tabular}


Table B16 -- Simple shear test data for the surface mixtures at $29.5^{\circ} \mathrm{C}$

\begin{tabular}{|c|r|r|r|r|r|r||}
\hline \multirow{2}{*}{ Replicate } & M-AC-20 & S-64-28 & \multicolumn{1}{|c|}{ S-58-28 } & \multicolumn{1}{c|}{ R-15\% } & S-70-28 & S-64-16 \\
\cline { 2 - 7 } & \multicolumn{7}{|c|}{ Maximum Shear Deformation (in.) } \\
\hline $\mathbf{1}$ & 0.00190 & 0.00028 & 0.00253 & 0.00013 & 0.00025 & 0.00033 \\
\hline $\mathbf{2}$ & 0.00182 & 0.00028 & 0.00280 & 0.00014 & 0.00028 & 0.00031 \\
\hline $\mathbf{3}$ & $0.00296^{\star}$ & 0.00015 & 0.00237 & 0.00012 & 0.00026 & 0.00039 \\
\hline $\mathbf{4}$ & 0.00152 & 0.00021 & 0.00237 & 0.00014 & 0.00027 & 0.00035 \\
\hline $\mathbf{5}$ & 0.00158 & 0.00020 & 0.00307 & 0.00013 & 0.00024 & 0.00035 \\
\hline Mean & $\mathbf{0 . 0 0 1 7 0}$ & $\mathbf{0 . 0 0 0 2 2}$ & $\mathbf{0 . 0 0 2 6 3}$ & $\mathbf{0 . 0 0 0 1 3}$ & $\mathbf{0 . 0 0 0 2 6}$ & $\mathbf{0 . 0 0 0 3 4}$ \\
\hline Std. Dev. & $\mathbf{0 . 0 0 0 1 9}$ & $\mathbf{0 . 0 0 0 0 5}$ & $\mathbf{0 . 0 0 0 3 0}$ & $\mathbf{0 . 0 0 0 0 1}$ & $\mathbf{0 . 0 0 0 0 2}$ & $\mathbf{0 . 0 0 0 0 3}$ \\
\hline C. of Var. & $\mathbf{1 0 . 9}$ & $\mathbf{2 3 . 9}$ & $\mathbf{1 1 . 4}$ & $\mathbf{7 . 2}$ & $\mathbf{5 . 9}$ & $\mathbf{9 . 3}$ \\
\hline \hline
\end{tabular}

* indicates outliers

Table B17 -- Simple shear test data for the surface mixtures at $40.5^{\circ} \mathrm{C}$

\begin{tabular}{|c|r|r|r|r|r|r||}
\hline \multirow{2}{*}{ Replicate } & \multicolumn{7}{|c|}{ M-AC-20 } & S-64-28 & \multicolumn{1}{c|}{ S-58-28 } & \multicolumn{1}{c|}{ R-15\% } & \multicolumn{1}{c|}{ S-70-28 } & S-64-16 \\
\cline { 2 - 7 } & \multicolumn{7}{|c|}{ Maxim Shear Deformation (in.) } \\
\hline $\mathbf{1}$ & 0.00242 & 0.00040 & $0.00290^{\star}$ & 0.00025 & 0.00041 & 0.00112 \\
\hline $\mathbf{2}$ & 0.00250 & 0.00038 & 0.00558 & 0.00024 & 0.00058 & 0.00114 \\
\hline $\mathbf{3}$ & $0.00381^{\star}$ & 0.00025 & 0.00491 & 0.00034 & 0.00053 & 0.00138 \\
\hline $\mathbf{4}$ & 0.00253 & 0.00026 & 0.00497 & 0.00030 & 0.00044 & 0.00143 \\
\hline $\mathbf{5}$ & 0.00247 & 0.00027 & 0.00566 & 0.00027 & 0.00048 & 0.00133 \\
\hline Mean & $\mathbf{0 . 0 0 2 4 8}$ & $\mathbf{0 . 0 0 0 3 1}$ & $\mathbf{0 . 0 0 5 2 8}$ & $\mathbf{0 . 0 0 0 2 8}$ & $\mathbf{0 . 0 0 0 4 9}$ & $\mathbf{0 . 0 0 1 2 8}$ \\
\hline Std. Dev. & $\mathbf{0 . 0 0 0 0 5}$ & $\mathbf{0 . 0 0 0 0 7}$ & $\mathbf{0 . 0 0 0 3 9}$ & $\mathbf{0 . 0 0 0 0 4}$ & $\mathbf{0 . 0 0 0 0 7}$ & $\mathbf{0 . 0 0 0 1 4}$ \\
\hline C. of Var. & $\mathbf{1 . 8}$ & $\mathbf{2 3 . 7}$ & $\mathbf{7 . 5}$ & $\mathbf{1 4 . 0}$ & $\mathbf{1 3 . 5}$ & $\mathbf{1 1 . 2}$ \\
\hline \hline
\end{tabular}

* indicates outliers 
Table B18 -- Simple shear test data for the intermediate mixtures at $29.5^{\circ} \mathrm{C}$

\begin{tabular}{|c|r|r|r|r|r|r||}
\hline \multirow{2}{*}{ Replicate } & M-AC-20 & S-64-28 & S-58-28 & \multicolumn{1}{c|}{ R-15\% } & S-70-28 & S-64-16 \\
\cline { 2 - 7 } & \multicolumn{7}{|c|}{ Maximum Shear Deformation (in.) } \\
\hline $\mathbf{1}$ & $0.00120^{*}$ & 0.00328 & 0.00360 & 0.00062 & 0.00056 & 0.00040 \\
\hline $\mathbf{2}$ & 0.00333 & 0.00316 & 0.00206 & 0.00074 & 0.00059 & 0.00037 \\
\hline $\mathbf{3}$ & 0.00416 & 0.00342 & 0.00297 & 0.00069 & 0.00053 & 0.00043 \\
\hline $\mathbf{4}$ & 0.00379 & 0.00316 & 0.00246 & 0.00075 & 0.00055 & 0.00039 \\
\hline $\mathbf{5}$ & 0.00317 & 0.00301 & 0.00256 & 0.00082 & 0.00057 & 0.00037 \\
\hline Mean & $\mathbf{0 . 0 0 3 6 1}$ & $\mathbf{0 . 0 0 3 2 1}$ & $\mathbf{0 . 0 0 2 7 3}$ & $\mathbf{0 . 0 0 0 7 2}$ & $\mathbf{0 . 0 0 0 5 6}$ & $\mathbf{0 . 0 0 0 4 0}$ \\
\hline Std. Dev. & $\mathbf{0 . 0 0 0 4 5}$ & $\mathbf{0 . 0 0 0 1 5}$ & $\mathbf{0 . 0 0 0 5 9}$ & $\mathbf{0 . 0 0 0 0 7}$ & $\mathbf{0 . 0 0 0 0 2}$ & $\mathbf{0 . 0 0 0 0 2}$ \\
\hline C. of Var. & $\mathbf{1 2 . 5}$ & $\mathbf{4 . 8}$ & $\mathbf{2 1 . 5}$ & $\mathbf{9 . 9}$ & $\mathbf{3 . 9}$ & $\mathbf{6 . 0}$ \\
\hline \hline
\end{tabular}

* indicates outliers

Table B19 -- Simple shear test data for the intermediate mixtures at $40.5^{\circ} \mathrm{C}$

\begin{tabular}{|c|r|r|r|r|r|r||}
\hline \multirow{2}{*}{ Replicate } & \multicolumn{1}{|c|}{ M-AC-20 } & \multicolumn{7}{|c|}{ S-64-28 } & \multicolumn{1}{c|}{ S-58-28 } & \multicolumn{1}{c|}{ R-15\% } & \multicolumn{1}{c|}{ S-70-28 } & \multicolumn{1}{c|}{ S-64-16 } \\
\cline { 2 - 7 } & \multicolumn{6}{|c|}{ Max Shear Deformation (in.) } \\
\hline $\mathbf{1}$ & 0.00242 & 0.00040 & $0.00290^{*}$ & 0.00025 & 0.00041 & 0.00112 \\
\hline $\mathbf{2}$ & 0.00250 & 0.00038 & 0.00558 & 0.00024 & 0.00058 & 0.00114 \\
\hline $\mathbf{3}$ & $0.00381^{\star}$ & 0.00025 & 0.00491 & 0.00034 & 0.00053 & 0.00138 \\
\hline $\mathbf{4}$ & 0.00253 & 0.00026 & 0.00497 & 0.00030 & 0.00044 & 0.00143 \\
\hline $\mathbf{5}$ & 0.00247 & 0.00027 & 0.00566 & 0.00027 & 0.00048 & 0.00133 \\
\hline Mean & $\mathbf{0 . 0 0 2 4 8}$ & $\mathbf{0 . 0 0 0 3 1}$ & $\mathbf{0 . 0 0 5 2 8}$ & $\mathbf{0 . 0 0 0 2 8}$ & $\mathbf{0 . 0 0 0 4 9}$ & $\mathbf{0 . 0 0 1 2 8}$ \\
\hline Std. Dev. & $\mathbf{0 . 0 0 0 0 5}$ & $\mathbf{0 . 0 0 0 0 7}$ & $\mathbf{0 . 0 0 0 3 9}$ & $\mathbf{0 . 0 0 0 0 4}$ & $\mathbf{0 . 0 0 0 0 7}$ & $\mathbf{0 . 0 0 0 1 4}$ \\
\hline C. of Var. & $\mathbf{1 . 8}$ & $\mathbf{2 3 . 7}$ & $\mathbf{7 . 5}$ & $\mathbf{1 4 . 0}$ & $\mathbf{1 3 . 5}$ & $\mathbf{1 1 . 2}$ \\
\hline \hline
\end{tabular}

* indicates outliers 
Table B20 -- Repeated shear test data for the surface mixtures at $58^{\circ} \mathrm{C}$

\begin{tabular}{|c|c|c|c|c|c|c|}
\hline \multirow{2}{*}{ Replicate } & M-AC-20 & S-64-28 & S-58-28 & R-15\% & S-70-28 & S-64-16 \\
\hline & \multicolumn{6}{|c|}{ Cumulative Permanent Strain } \\
\hline 1 & & 0.0122 & 0.0185 & 0.0112 & $0.0165^{\star}$ & 0.0097 \\
\hline 2 & & 0.0110 & 0.0156 & 0.0083 & 0.0041 & 0.0113 \\
\hline 3 & & $0.0248 *$ & 0.0174 & 0.0131 & 0.0041 & 0.0076 \\
\hline 4 & & 0.0110 & 0.0168 & $0.0190^{*}$ & 0.0041 & 0.0064 \\
\hline 5 & & & 0.0162 & 0.0128 & $0.0097^{*}$ & 0.0096 \\
\hline Mean & & 0.0114 & 0.0169 & 0.0113 & 0.0041 & 0.0089 \\
\hline Std. Dev. & & 0.0007 & 0.0011 & 0.0022 & 0.0000 & 0.0019 \\
\hline C. of Var. & & 6.4 & 6.6 & 19.3 & 0.1 & 21.4 \\
\hline
\end{tabular}

* indicates outliers

Table B21 -- Repeated shear test data for the intermediate mixtures at $54^{\circ} \mathrm{C}$

\begin{tabular}{|c|r|r|r|r|r|r||}
\hline \multirow{2}{*}{ Replicate } & \multicolumn{1}{|c|}{ M-AC-20 } & S-64-28 & \multicolumn{1}{c|}{ S-58-28 } & \multicolumn{1}{c|}{ R-15\% } & \multicolumn{1}{c|}{ S-70-28 } & S-64-16 \\
\cline { 2 - 7 } & \multicolumn{7}{|c|}{ Cumulative Permanent Strain } \\
\hline $\mathbf{1}$ & 0.0093 & 0.0073 & 0.0105 & 0.0070 & \multicolumn{1}{c|}{0.0061} & \multicolumn{1}{c|}{0.0095} \\
\hline $\mathbf{2}$ & 0.0060 & 0.0103 & 0.0155 & 0.0053 & 0.0056 & $0.0120^{*}$ \\
\hline $\mathbf{3}$ & 0.0132 & 0.0136 & 0.0196 & 0.0115 & 0.0052 & 0.0083 \\
\hline $\mathbf{4}$ & 0.0137 & 0.0119 & 0.0154 & 0.0094 & 0.0063 & 0.0104 \\
\hline $\mathbf{5}$ & 0.0080 & 0.0112 & 0.0148 & 0.0065 & 0.0029 & $0.0155^{\star}$ \\
\hline Mean & $\mathbf{0 . 0 1 0 0}$ & $\mathbf{0 . 0 1 0 8}$ & $\mathbf{0 . 0 1 5 2}$ & $\mathbf{0 . 0 0 7 9}$ & $\mathbf{0 . 0 0 5 2}$ & $\mathbf{0 . 0 0 9 4}$ \\
\hline Std. Dev. & $\mathbf{0 . 0 0 3 3}$ & $\mathbf{0 . 0 0 2 3}$ & $\mathbf{0 . 0 0 3 2}$ & $\mathbf{0 . 0 0 2 5}$ & $\mathbf{0 . 0 0 1 4}$ & $\mathbf{0 . 0 0 1 0}$ \\
\hline C. of Var. & $\mathbf{3 3 . 1}$ & $\mathbf{2 1 . 5}$ & $\mathbf{2 1 . 2}$ & $\mathbf{3 1 . 1}$ & $\mathbf{2 6 . 0}$ & $\mathbf{1 1 . 1}$ \\
\hline \hline
\end{tabular}

